\title{
APLICACIÓN DEL LÁSER DE FEMTOSEGUNDO EN ESMALTE: ANÁLISIS MORFOLÓGICO Y MEJORA DE LA EFICACIA ADHESIVA BRACKET-ESMALTE
}

TESIS DOCTORAL

Ma CRUZ LORENZO LUENGO

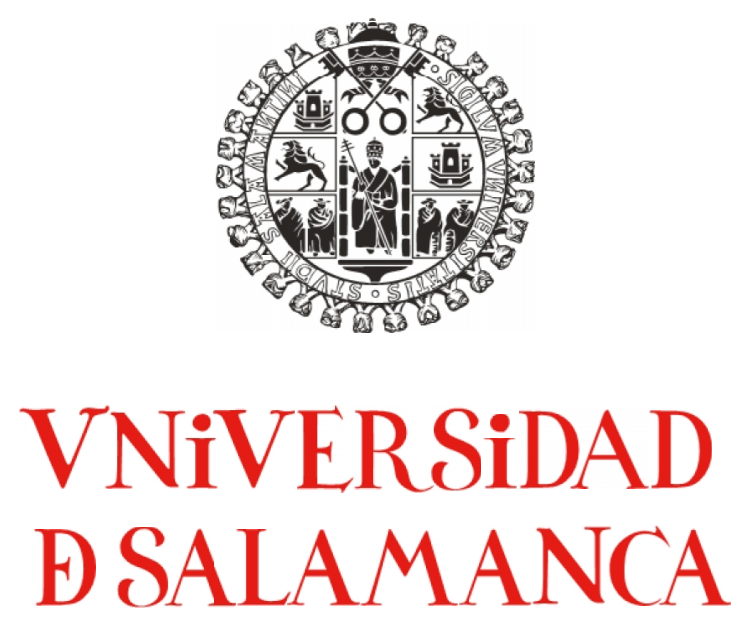

Directores:

Dr. D. Alberto Albaladejo Martínez

Dr. D. Pablo Moreno Pedraz

Dr. D. José Miguel Sánchez LLorente

FACULTAD DE MEDICINA

DEPARTAMENTO DE CIRUGÍA 



\section{DECLARACIÓN}

El Dr. D. Clemente MURIEL VILlORIA, Director del Departamento de Cirugía de la Universidad de Salamanca,

CERTIFICA:

Que la presente Memoria, elaborada por D $\mathrm{D}^{\mathrm{a}}$ María Cruz Lorenzo Luengo para optar a la Tesis Doctoral, con el título "Aplicación del láser de femtosegundo en esmalte: análisis morfológico y mejora de la eficacia adhesiva bracket-esmalte", ha sido realizada bajo la dirección de los Drs. D. Alberto Albaladejo Martínez, D. Pablo Moreno Pedraz y D. José Miguel Sánchez Llorente en el Departamento de Cirugía de la Universidad de Salamanca.

Y para que así conste, expide y firma la presente certificación en Salamanca a 10 de enero de 2014

Fdo.: Dr. D. Clemente Muriel Villoria 



\section{DECLARACIÓN}

Los Drs. D. Alberto Albaladejo Martínez, D. Pablo Moreno Pedraz y D. José Miguel Sánchez Llorente, doctores y profesores de la Universidad de Salamanca,

\section{CERTIFICAN:}

Que el trabajo titulado "Aplicación del láser de femtosegundo en esmalte: análisis morfológico y mejora de la eficacia adhesiva bracket-esmalte", ha sido realizado por D ${ }^{a}$ María Cruz Lorenzo Luengo, bajo nuestra dirección, reuniendo a nuestro juicio los requisitos y méritos suficientes para que la autora del mismo pueda optar al Grado de Doctor por la Universidad de Salamanca.

Y para que así conste, firmamos la presente certificación en Salamanca a 10 de enero de 2014

Fdo.: Prof. Dr. A. Albaladejo Fdo.: Prof. Dr. P. Moreno Fdo.: Prof. Dr. J.M. Sánchez 



\section{Agradecimientos}

$\mathrm{Al}$ escribir este apartado tengo la sensación de estar llegando al final (o principio) de una etapa de mi vida. Una etapa de mucho trabajo, esfuerzo y constancia en la que me he encontrado con personas, cuya colaboración y ayuda han hecho que todo fuera un poquito más fácil. Por ello quiero agradecérselo muy sinceramente:

Al Dr. D. Alberto Albaladejo, por asumir la dirección de este trabajo, por la dedicación y orientaciones recibidas para su elaboración, así como por el continuo ánimo transmitido hasta conseguirlo.

Al Dr. D. Pablo Moreno, por enseñarme todo lo que sé de láser. Por el excepcional criterio aportado en la investigación, por tu enorme ayuda y, sobre todo, por tu amistad, apoyo y absoluta confianza en mí.

Al Dr. D. José Miguel Sánchez Llorente, por tu incansable ayuda y predisposición siempre que lo he necesitado y principalmente, por tu amistad. Eres el "Pepito grillo" de mi conciencia investigadora y te lo agradezco infinito.

A María Portillo, por ser como una hermana dentro y fuera de la investigación. Por las horas, días, semanas, meses y años de esfuerzo común hasta conseguir nuestros objetivos. Porque las dos sabemos que unidas se superan todas las dificultades. Como ya te dije alguna vez... no se puede tener mejor amiga que tú.

Al grupo de Microprocesado de Materiales con Láser de la Universidad de Salamanca, y particularmente a Ana García, por vuestro gran trabajo en la realización del microestructurado de las muestras. 
Al Centro de Láseres Pulsados (CLPU) y en especial, a José Antonio Pérez Hernández, por permitirme la observación de los especímenes de manera desinteresada.

Al Dr. Don Javier Montero, por tu asesoramiento en el análisis estadístico de los resultados, así como por tus consejos.

A mis padres, porque sois el modelo a seguir durante toda mi vida, por los valores que me habéis transmitido y por vuestro apoyo y absoluto amor. Gracias a vosotros soy lo que soy hoy en día.

A mi marido Víctor. Muchas de las horas aquí invertidas te las he robado a ti, y a pesar de ello siempre me esperas con una sonrisa y con todo el apoyo del mundo. Eres el eje sobre el que gira mi vida y te doy gracias por tu amor incondicional y tu fe en mí.

A mi hermana, por tu amor, confianza y lealtad plena. Por escucharme, entenderme y cuidarme tan bien en los buenos y malos momentos y por tenerte a mi lado siempre que te necesito.

A Pedro V, Toño, Pedro, Patri, Bea y Dani, por mostrar interés hacia lo que hago y por el apoyo y ánimo recibidos en todo momento. Y a mi sobrina Aitana, por alegrarnos los días con tu llegada.

A mis amigos, por hacerme olvidar, con vuestra alegría, mis agobios y preocupaciones. Porque en estos años también ha habido grandes momentos fuera del mundo de la investigación, y en especial, a mi amiga Teresa García, ya que mi tesis no hubiera sido los mismo sin tus premolares, gracias por esa recolección tan bien hecha. 
A Arturo de Paz y José Antonio Blanco, por esos cordales que necesité, y sobre todo por conservar nuestra amistad como el primer día y compartir tantos buenos momentos juntos pese a vernos tan poco.

$\mathrm{Y}$ en general, a todos aquellos que de alguna manera han pasado por mi vida y me han aportado conocimiento, ánimo, confianza y alegría durante estos años de duro trabajo.

A todos ellos, mi más sincero agradecimiento. 

Dedicado a

A Víctor

A mis padres y hermana 



\section{APLICACIÓN DEL LÁSER DE FEMTOSEGUNDO EN ESMALTE: ANÁLISIS MORFOLÓGICO Y MEJORA DE LA EFICACIA ADHESIVA BRACKET-ESMALTE}

TESIS DOCTORAL

Ma CRUZ LORENZO LUENGO

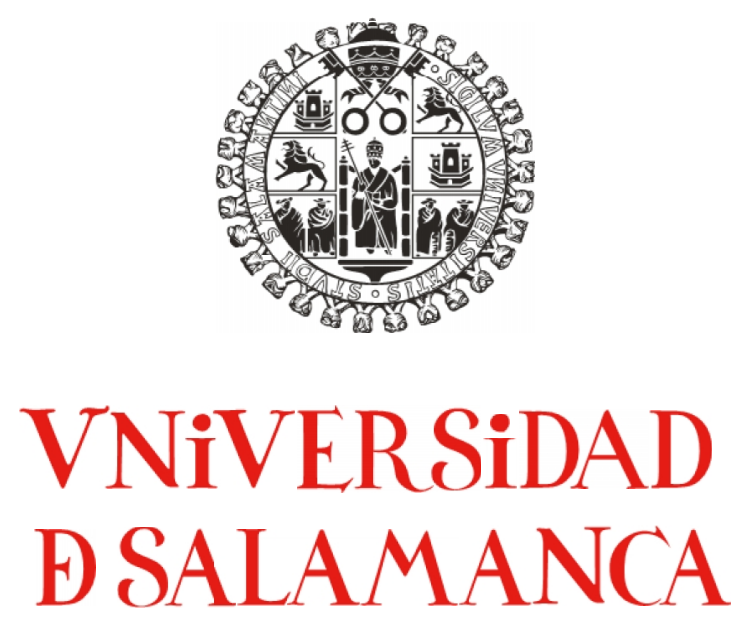

Directores:

Dr. D. Alberto Albaladejo Martínez

Dr. D. Pablo Moreno Pedraz

Dr. D. José Miguel Sánchez LLorente

FACULTAD DE MEDICINA

DEPARTAMENTO DE CIRUGÍA

10 de Enero de 2014 



\section{RESUMEN}

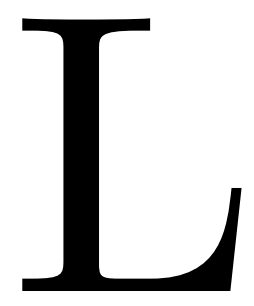

a continua evolución de la tecnología láser ha supuesto el desarrollo de innumerables aplicaciones en todos los sectores tecnológicos incluyendo los relacionados con el ámbito biomédico.

Dentro de la gran variedad de sistemas láser existentes, unos cuantos, por sus especiales características a la hora de interaccionar con los tejidos biológicos, han despertado un enorme interés en diferentes especialidades quirúrgicas y, en particular, en el campo de la odontología. Entre estos sistemas, aquellos basados en la tecnología de pulsos ultracortos (es decir, pulsos cuya duración es inferior al picosegundo, $10^{-12} \mathrm{~s}$ ) han irrumpido en los últimos años como una seria alternativa a procedimientos tradicionales de modificación o preparación de los tejidos dentales a resultas de sus extraordinarias propiedades de interacción, en concreto, la ausencia o minimización de los efectos mecánicos y térmicos adversos que son habituales cuando se emplean otras técnicas.

Para la realización de la presente tesis doctoral nos propusimos investigar si este tipo de láseres podría constituir una herramienta de utilidad en el campo de la Odontología, en particular, si podría considerarse como una alternativa a los procesos tradicionales de adhesión a esmalte en el cementado de aditamentos ortodónticos, y a la preparación cavitaria en esta superficie, en la que el proceso tradicional se lleva a cabo mediante turbina y fresas. 
La técnica mecánica convencional de realización de cavidades presenta numerosos inconvenientes que llevan a una remoción no selectiva del tejido, dolor, necesidad de anestesia, producción de cracks y fisuras o efectos térmicos no deseados. Por otro lado, en lo que se refiere a la adhesión de brackets en ortodoncia, la práctica más extendida es realizarla mediante un acondicionamiento previo de la superficie biológica del esmalte con ácido ortofosfórico. Esta técnica también presenta diversas desventajas, entre las que destaca la desmineralización del tejido más superficial que provoca una mayor sensibilidad a largo plazo de ataques ácidos y aparición de caries. Por estos motivos, se hace necesario buscar procedimientos alternativos que sean capaces de mantener la misma eficacia adhesiva proporcionada por el ácido ortofosfórico pero que a la vez, sean más conservadores y menos nocivos para la superficie del esmalte. Y ése es el contexto en el que los pulsos láser ultracortos se postulan como una técnica alternativa.

Los objetivos concretos planteados al iniciar esta tesis doctoral fueron: 1) evaluar mediante microscopía óptica y electrónica los cambios morfológicos que ocurren en el esmalte tras la instrumentación mecánica y la irradiación con láser de pulsos ultracortos con diferentes parámetros de proceso; 2) comparar la eficacia adhesiva del cementado de brackets de ortodoncia en la superficie de esmalte tras la preparación de la superficie con tres técnicas diferentes, el convencional grabado con ácido ortofosfórico, la ablación extensiva de la superficie con láser de Er:YAG y finalmente, el microestructurado con pulsos láser ultracortos; y; 3) teniendo en cuenta la gran cantidad de parámetros de proceso que intervienen en el microestructurado con pulsos láser ultracortos, determinar la influencia en la fuerza de adhesión en la interfase bracket-esmalte de uno de los parámetros más relevantes, como es la densidad del patrón microestructurado en la superficie del esmalte. 
Para la realización de la tesis se emplearon 12 terceros molares incluidos y 123 premolares extraídos por causa ortodóntica o periodontal, con los que se llevaron a cabo tres protocolos de investigación in vitro, uno en molares para estudiar cómo actúa el láser de pulso ultracorto en la preparación cavitaria como sustituto al método convencional de turbina y fresa, y dos con premolares para evaluar su empleo como alternativa al tradicional acondicionamiento con ácido ortofosfórico previo al cementado de brackets, empleando los párametros óptimos.

En primer lugar, se diseñó el experimento para la preparación cavitaria en la que se emplearon los 12 terceros molares incluidos, que fueron seccionados transversalmente por la línea amelocementaria, desechando la raíz. La corona se dividió longitudinalmente en sentido vestibulolingual en láminas de aproximadamente $1 \mathrm{~mm}$ de grosor. Posteriormente, las muestras fueron pulidas y divididas en dos grupos de acuerdo a la preparación cavitaria: 1) preparación cavitaria mecánica; y 2) preparación cavitaria con láser de pulso ultracorto. Finalmente, se preservaron en suero salino fisiológico para prevenir la deshidratación hasta la realización de su análisis microscópico.

Observando los resultados favorables de este estudio, se planteó la primera investigación de adhesión en Ortodoncia, para la que se utilizaron 60 premolares que fueron pulidos y asignados al azar en tres grupos, de acuerdo al tratamiento láser aplicado en el esmalte: 1) sin láser (control); 2) con láser de Er:YAG; y 3) con láser de pulso ultracorto. Cada grupo se dividió en dos subgrupos en función de la aplicación de ácido ortofosfórico al 37\% o no. Posteriormente, se utilizaron sesenta brackets que se cementaron en la superficie vestibular de los premolares mediante un sistema adhesivo de grabado total (Transbond ${ }^{\mathrm{TM}} \mathrm{XT}$ ). Una vez posicionados se

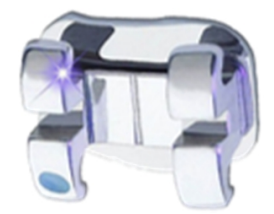


fotopolimerizaron con una unidad LED. Después de 72 horas las muestras se sometieron a ensayos mecánicos.

Para el segundo protocolo de adhesión en Ortodoncia, 63 premolares fueron pulidos y asignados al azar en nueve grupos dependiendo de la densidad del patrón de microestructurado generado con el láser de pulso ultracorto, determinado por el paso (s) entre barridos sucesivos de la superficie en cualquiera de las direcciones ortogonales que constituyen el patrón de canales entrecruzados: 1) no láser (control); 2) $\mathrm{s}=15 \mu \mathrm{m}$; 3) $\mathrm{s}=30 \mu \mathrm{m}$; 4) $\mathrm{s}=45 \mu \mathrm{m}$; 5) $\mathrm{s}=60 \mu \mathrm{m}$; 6) $\mathrm{s}=90 \mu \mathrm{m}$; 7) $\mathrm{s}=120 \mu \mathrm{m}$; 8) $\mathrm{s}=150 \mu \mathrm{m} ; 9) \mathrm{s}=180 \mu \mathrm{m}$. Posteriormente, se emplearon 63 brackets que se cementaron a la superficie vestibular de los premolares utilizando el mismo sistema adhesivo que en el primer ensayo de adhesión y se fotopolimerizaron con la misma unidad LED. Tras 72 horas se testaron los especímenes.

Para ambos protocolos de adhesión en Ortodoncia: 1) los valores de los test de resistencia a la cizalla se obtuvieron utilizando una máquina universal de ensayo (velocidad de la cruceta $=0,5 \mathrm{~mm} / \mathrm{min}$ ) hasta que se produjo el descementado del bracket; 2) se estudió el tipo de fallo y la morfología de la superficie de esmalte del espécimen descementado, que se observaron con microscopía óptica y electrónica de barrido (MEB). Los datos se analizaron estadísticamente con ANOVA, test de Bonferroni, tests de Student, pruebas de Chi cuadrado y de regresión lineal múltiple $(\mathrm{p}<0,05)$.

Los resultados obtenidos en los tres estudios se resumen en: a) en el estudio de preparación cavitaria se evaluó la capacidad del láser de pulso ultracorto para producir cavidades de extremada precisión en el esmalte dental. No se apreciaron signos de daños colaterales ni fisuras; b) en la primera pesquisa de adhesión en Ortodoncia se verificó que los especímenes tratados sin ácido pero acondicionados 
con láser de pulso ultracorto, obtuvieron unos valores de resistencia al cizallamiento mayores que los tratados con láser de Er:YAG o los que no fueron tratados con ninguna fuente láser. Cuando posteriormente se aplicó grabado ácido, se obtuvo la misma eficacia adhesiva independientemente de si el esmalte no había sido irradiado con láser o se había empleado cualquiera de ambas fuentes láser para acondicionar la superficie ; y c) en el segundo protocolo de adhesión en Ortodoncia, se comprobó que los mayores valores de resistencia a la fuerza de cizalla se obtuvieron para patrones de microestructurado muy densos $(\mathrm{s}=15-90 \mu \mathrm{m})$ mientras que para los patrones menos densos $(>90 \mu \mathrm{m})$ se conserva la mayor parte del esmalte dental, y en todos los casos, no se observó daño aparente en los límites de la zona microestructurada.

Los resultados anteriores llevan a las siguientes conclusiones: 1) El láser de pulso ultracorto tiene la capacidad de producir cavidades de alta precisión en el esmalte, con minimización y/o ausencia de efectos térmicos y mecánicos en los tejidos adyacentes, a diferencia de la turbina, que lleva a la formación de microfracturas en la superficie del esmalte. Se presenta como una herramienta óptima para el tratamiento de la caries dental y como alternativa a la técnica mecánica convencional con turbina para disminuir el daño que se produce durante la remoción del tejido duro dentario; 2) El láser de pulso ultracorto sin el empleo de un acondicionamiento ácido previo permite obtener eficacias adhesivas similares a las obtenidas con el grabado con ácido ortofosfórico eliminando, a su vez, los efectos adversos provocados por éste, con lo cual se plantea como una buena alternativa para el cementado de brackets de ortodoncia en el esmalte. El tratamiento con láser de Er:YAG obtiene unas fuerzas de adhesión esmalte-brackets inferiores a las generadas por el tradicional acondicionamiento ácido a no ser que previamente se acompañe de éste; 3) Para obtener una eficacia adhesiva adecuada en el cementado

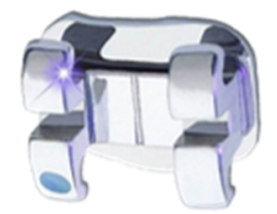


de brackets sobre el esmalte con el láser de pulsos ultracortos, se deben obtener densidades en el patrón de microestructurado elevadas con barridos separados de 15 a $90 \mu \mathrm{m}$. Sin embargo, para obtener una correcta eficacia adhesiva esmaltebracket, evitar el daño iatrogénico excesivo, realizar un procesado más rápido de la superficie dentaria y preservar gran cantidad de esmalte intacto, los patrones excesivamente densos no son adecuados, siendo preferibles densidades más bajas. Si los requisitos relativos a las fuerzas de adhesión no son tan exigentes, los patrones muy poco densos $(\mathrm{s}>>90 \mu \mathrm{m})$ proporcionan tiempos de procesado más cortos, menor riesgo de daño iatrogénico y una mejor conservación de la superficie original del esmalte.

La presente investigación solamente ha explorado y evaluado una pequeña parte de las prestaciones que el tratamiento con pulsos ultracortos del esmalte dental puede ofrecer. A la luz de los resultados obtenidos, futuras investigaciones deberían centrarse en el estudio sistemático de la influencia en las propiedades de adhesión de la modificación de los demás parámetros de procesado del láser, tanto los relacionados con las propiedades físicas de los propios pulsos láser como de los parámetros geométricos del procesado. Obviamente, las peculiares características de esta herramienta hacen que muchos otros campos de la Odontología puedan ser terreno para la experimentación con esta técnica como por ejemplo, en el campo de la Prótesis para el grabado de cerámica feldespática para la adhesión de carillas a la superficie dentaria. 


\section{Tabla de contenido}

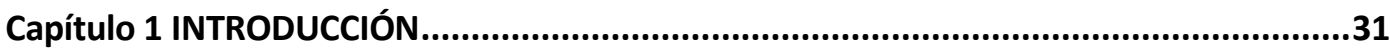

1.1. EL ESMALTE DENTAL ..............................................................................................

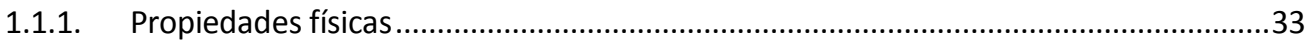

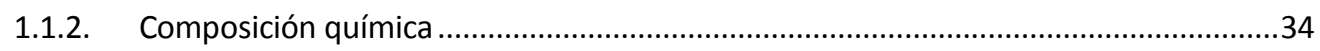

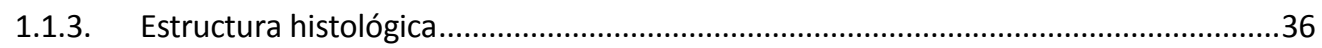

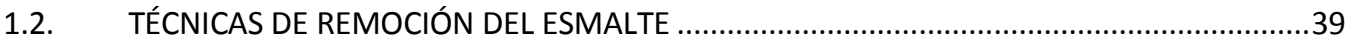

1.2.1. Remoción por medios mecánicos..........................................................................39

1.2.2. Remoción por láser ............................................................................................... 40

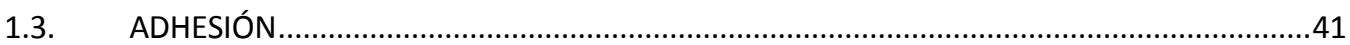

1.3.1. Concepto de adhesión y su proyección en Odontología ..............................................41

1.3.2. Sistemas adhesivos empleados en la adhesión a esmalte. Clasificación .....................44

1.3.3. Materiales de adhesión. Clasificación ......................................................................47

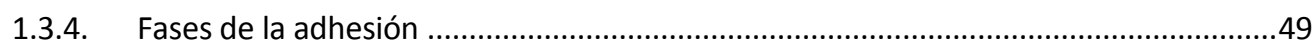

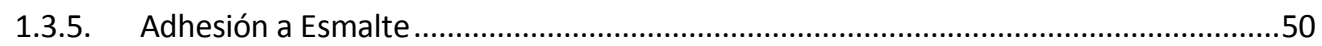

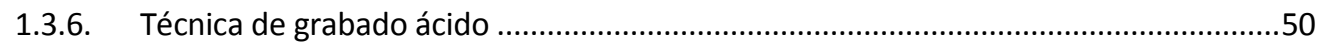

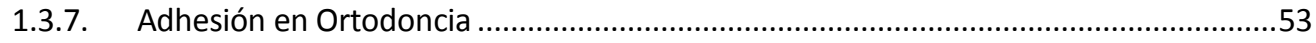

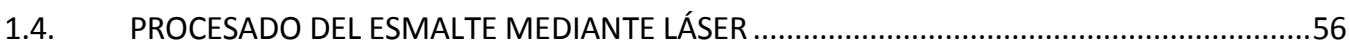

1.4.1. Introducción al láser y sus propiedades ................................................................56

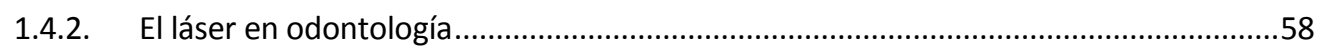

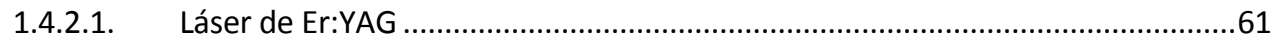

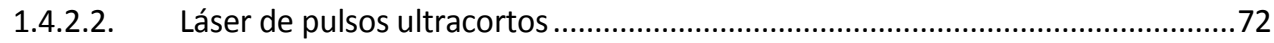

Capítulo 2 OBJETO Y JUSTIFICACIÓN ......................................................................101

Capítulo 3 PUBLICACIONES ORIGINALES...............................................................105

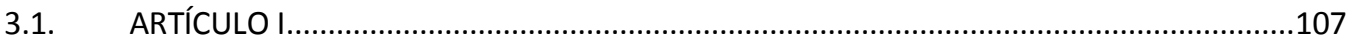

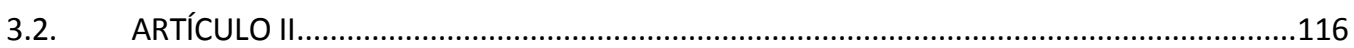

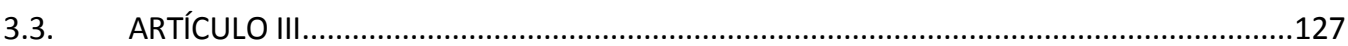

Capítulo 4 DISCUSIÓN ..................................................................................141

Capítulo 5 CONCLUSIONES ........................................................................155

Capítulo 6 BIBLIOGRAFÍA ...........................................................................159

Capítulo 7 ANEXOS .............................................................................................199 


$$
\begin{aligned}
& \text { VNIVERSIDAD }
\end{aligned}
$$

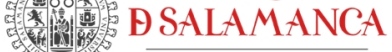

CAMPUS DE EXCELENCIA INTERNACIONAL

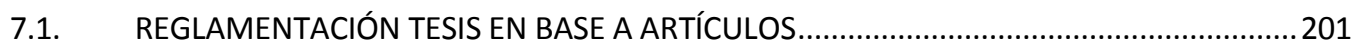

.205

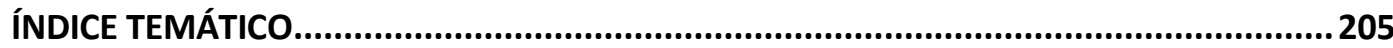




\section{Lista de figuras}

Figura 1: Composición química del esmalte dental.................................................................34

Figura 2: Morfología de los prismas en "ojo de cerradura" y disposición de los mismos. ..............36

Figura 3: Evolución de los adhesivos, grabado total. ...............................................................45

Figura 4: Evolución de los adhesivos, adhesivos autograbantes. ...............................................46

Figura 5: Tipos de grabado en esmalte dental. a) Tipo I; b) Tipo II; c) Tipo III; d) Tipo IV; e) Tipo V. Tomado de Meléndez y cols., 2002.

Figura 6: Aplicación de los distintos láseres en Odontología (En negrita: aplicación principal). ...60

Figura 7: (a) Láser de Er:YAG (Fidelis plus III) (b) pieza de mano R02 en modo no contacto. 62

Figura 8: Gráfica del coeficiente de absorción lineal de la hidroxiapatita carbonatada en función de la longitud de onda. Tomada de Parker, 2007.

Figura 9: Representación esquemática de la técnica de amplificación regenerativa de pulsos ultracortos CPA (Chirped Pulse Amplification).

Figura 10: Sistema de pulsos láser ultracortos de la Universidad de Salamanca...........................74

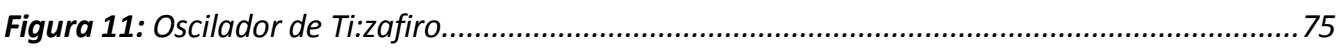

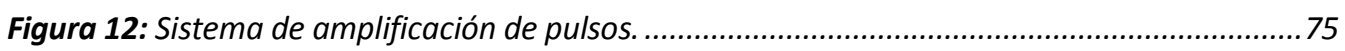

Figura 13: Láser de bombeo del amplificador regenerativo. Laser de Nd:YLF..............................76

Figura 14: Distribución transversal de la energía de tipo gaussiana (modo transversal TEMO0).. 76

Figura 15: Sistemas de reducción de energía de los pulsos ultracortos. Arriba: Filtros neutros para reducciones bastas. Abajo: Sistema de lámina de media onda y polarizador para ajuste fino. ....77

Figura 16: Visión general del banco de microprocesado................................................................ 78

Figura 17: Sistema de focalización y emplazamiento de la muestra...........................................79

Figura 18: Sistema de visualización y enfoque. Espejo (arriba), divisor de haz y cámara CCD. ..... 79

Figura 19: Sistema de focalización (doblete acromático). .........................................................80

Figura 20: Sistema de posicionamiento de la muestra XYZ..........................................................81

Figura 21: Esquema de percusión y trepanado. .........................................................................82

Figura 22: Sistema de trepanado óptico del Grupo de Microprocesado de Materiales con Láser de la Universidad de Salamanca. .83

Figura 23: Representación esquemática del proceso de absorción y de ionización multifotónica de un material dieléctrico.

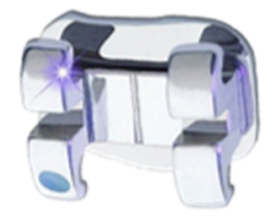




\section{VNIVERSIDAD}

BSALAMANCA

Figura 24: Representación esquemática del proceso de ablación por explosión de Coulomb (Cortesía del Grupo de Microprocesado de Materiales con Láser). .87

Figura 25: Procesos de cesión de energía de los electrones a la red cristalina por colisión y de termalización electrónica. 88

Figura 26: Representación esquemática del proceso de ablación por explosión de fase (Cortesía del Grupo de Microprocesado de Materiales con Láser).

Figura 27: Eyección de material en zirconia por explosión de fase al ser irradiada la superficie con un pulso ultracorto suficientemente intenso. 90

Figura 28: Distribución de la energía de un pulso láser gaussiano sobre la superficie de un material al pasar por una apertura circular de diámetro inferior a la sección del haz. 91

Figura 29: Estructuras producidas por ablación con pulsos ultracortos sobre la superficie de nitruro de silicio .92

Figura 30: Esquema del barrido de la superficie generado con el láser de pulso ultracorto. .93

Figura 31: Sistema de humidificación empleado en el procesado de esmalte para los estudios de adhesión. .94

Figura 32: Cráteres realizados en metal con láser de nano, pico y femtosegundo, respectivamente. Tomado de Chichkov y cols. (1996). .95

\section{Lista de figuras en artículos}

Figura III.1.1: Micrografía electrónica de barrido de las cavidades realizadas en el esmalte con láser de femtosegundo.

Figura III.1.2: Micrografía electrónica de barrido de las cavidades realizadas en el esmalte con láser de femtosegundo con diferentes parámetros.

Figura III.I.3: Micrografía electrónica de barrido de una cavidad circular en el esmalte provocada por la ablación con láser de femtosegundo.

Figura III.2.1: Modelo esquemático del experimento.

Figura III.2.2: Micrografías electrónicas de barrido de un especímen descementado tratado "sin láser/sin ácido".

Figura III.2.3: Micrografías electrónicas de barrido de un especímen descementado tratado con “láser Er:YAG/sin ácido". 
Figura III.2.4: Micrografías electrónicas de barrido de un especímen descementado tratado con "láser Ti:Zafiro/sin ácido".

Figura III.2.5: Micrografías electrónicas de barrido de un especímen descementado tratado con “láser Ti:Zafiro/con ácido".

Figura III.3.1: Curva de ajuste con un intervalo de confianza del 95\% de los valores de resistencia al cizallamiento de acuerdo a una regresión cuadrática basada sólo en el paso (s).

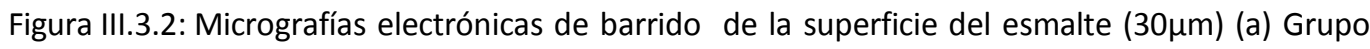
control y después del procesado con láser de pulso ultracorto con los siguientes pasos: (b) s=180 $\mu \mathrm{m}$; (c) $s=150 \mu \mathrm{m}$; (d) $\mathrm{s}=120 \mu \mathrm{m}$; (e) $\mathrm{s}=90 \mu \mathrm{m}$; (f) $\mathrm{s}=60 \mu \mathrm{m}$; (g) $\mathrm{s}=45 \mu \mathrm{m}$; (h) $\mathrm{s}=30 \mu \mathrm{m}$; (i) $\mathrm{s}=15 \mu \mathrm{m}$.

Figura III.3.3: Micrografías electrónicas de barrido de los especímenes descementados (200 $\mu \mathrm{m}$ ) (a) Grupo control y procesado láser (b) $s=180 \mu \mathrm{m}$; (c) $\mathrm{s}=150 \mu \mathrm{m}$; (d) $\mathrm{s}=120 \mu \mathrm{m}$; (e) $\mathrm{s}=90 \mu \mathrm{m}$; (f) $\mathrm{s}=60 \mu \mathrm{m}$; (g) $\mathrm{s}=45 \mu \mathrm{m}$; (h) $\mathrm{s}=30 \mu \mathrm{m}$; (i) $\mathrm{s}=15 \mu \mathrm{m}$.

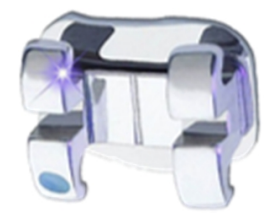





\section{Lista de tablas}

Tabla 1: Tipos de láseres más habituales con su longitud de onda y duración temporal de la emisión 57

Tabla 2: Revisión bibliográfica de los artículos referentes a la preparación cavitaria con láser de Er:YAG. .69

Tabla 3: Revisión bibliográfica de los artículos revisados sobre láser de Er:YAG como alternativa al grabado ácido para el acondicionamiento del esmalte .70 Tabla 4: Revisión bibliográfica de los artículos referentes a la preparación cavitaria con láser de pulso ultracorto. .97

\section{Lista de tablas en artículos}

Tabla III.2.1: Fabricante, composición principal y modo de aplicación de los materiales testados.

Tabla III.2.2: Media y desviación estándar (SD) de los valores de resistencia a la cizalla obtenidos en los grupos experimentales.

Tabla III.2.3: Tabulación cruzada del efecto del grabado ácido dentro de los grupos de tratamiento con láser de acuerdo con una variable dicotómica generada a partir de los valores de ARI (puntuación 0-1 Vs 2-3).

Tabla III.3.1: Fabricante, composición principal y modo de aplicación de los materiales Testados.

Tabla III.3.2: Media y desviación estándar (SD) de los valores de resistencia a la cizalla (MPa) obtenidos en los grupos experimentales. ANOVA con corrección de Bonferroni.

Tabla III.3.3: Tabulación cruzada del efecto de los grupos de tratamiento de la superficie de acuerdo con una variable dicotómica generada a partir de los valores de ARI (0-1 Vs 2-3).

Tabla III.3.4: Tiempo medio de tratamiento con láser para una superficie completa de un premolar para los diferentes patrones de procesado realizados en el esmalte.

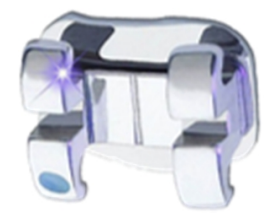





\section{Lista de acrónimos}

$\begin{array}{ll}\text { ARI } & \text { Adhesive Remnant Index } \\ \text { Bis-GMA } & \text { Bisfenol-A-Glicidil-Metacrilato } \\ \text { CPA } & \text { Chirped Pulse Amplification } \\ \text { CW } & \text { Continuous Wave } \\ \text { EDTA } & \text { Ácido etilendiaminotetraacético } \\ \text { Er:YAG } & \text { Erbium-doped yttrium aluminium garnet } \\ \text { Er, Cr:YSGG } & \text { Erbium, chromium-doped yttrium, scandium, gallium, } \\ \text { Karnet } & \text { Food and Drug Administration } \\ \text { LDA } & \text { Hong Pulse } \\ \text { He-Ne } & \text { Helio-Neón } \\ & \end{array}$


MSP

Medium-Short Pulse Mode

MTBS

Microtensile Bond Strength Test

Nd:YAG

Neodymium-doped Yttrium-Aluminium-Garnet

Nd:YAP

Neodymium-doped Yttrium-Aluminium-Perovskite

Nd:YLF

Neodymium-doped Yttrium-Lithium Fluoride

Nd:YVO

Neodymium-doped Yttrium Orthovanadate

QSP

Quantum-square Pulse Mode

SBS

Shear Bond Strength test

SEM

Scanning Electron Microscopy

SP

Short Pulse

TEGDMA

Triethylene Glicol Dimethacrylate

VLP

Very Long Pulse

VSP

Very Short Pulse 

Capítulo 1: Introducción

\subsection{EL ESMALTE DENTAL}

El esmalte dental es una estructura cristalina sumamente compleja. Es el tejido ectodérmico que cubre la corona anatómica del diente. Presenta unas propiedades físicas, una composición química y una estructura histológica que lo individualizan del resto de tejidos del genoma. Deriva del ectodermo y se forma a partir del llamado órgano del esmalte. Debido a su complejidad química y a su comportamiento biológico, ha sido estudiado por numerosos investigadores (Gómez de Ferraris y cols., 2002; Berkovitz y cols., 2002). Se une al complejo dentino-pulpar en la unión amelodentinaria y al cemento en la unión amelo-cementaria.

\subsubsection{Propiedades físicas}

El esmalte proporciona al diente una superficie dura que permite la masticación y protege a los tejidos subyacentes. Tiene una coloración que va desde blanco azulada a blanco amarillenta, aunque depende del tono de la dentina subyacente. Es semitranslúcido y birrefrigente, ya que refracta la luz de forma distinta en direcciones diferentes. Es el tejido más duro, frágil y altamente mineralizado del organismo.

Es duro debido a su alto contenido mineral, encontrándose en un rango de 3 a 6 GPa (Xu y cols., 1998; Habelitz y cols., 2001; Mann y cols., 2006), 200 a 500 Knoop y un valor de 8 en la escala de Mohs. Llega a soportar fuerzas de hasta $150 \mathrm{~kg}$ (Zelander, 1974).

Es frágil ya que posee una resistencia a la tensión baja y un módulo de elasticidad alto, de entre 70 y 120 GPa (Xu y cols., 1998; Habelitz y cols., 2001; Park y cols.,

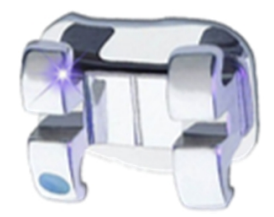


2008), por lo que necesita algún tejido subyacente (la dentina) que tenga alta resistencia compresiva y cierta resilencia (Saralegui y cols., 1997).

Es la estructura más radioopaca del organismo humano y posee cierta porosidad y una permeabilidad que permite el paso de agua e iones, pero excluye el paso de moléculas grandes. Varía de unas regiones a otras del tejido, siendo más rígido, más denso y menos poroso en superficie. La dureza y la densidad también disminuyen desde la superficie hacia el interior y desde los vértices de las cúspides y del borde incisal hacia las líneas cervicales.

\subsubsection{Composición química}

El esmalte dental está altamente mineralizado. Químicamente está constituido por un 95\% de matriz inorgánica, 1 a 2\% de matriz orgánica y de 3 a 5\% de agua (Bowes y cols., 1935; Gómez de Ferraris y cols., 2002; Berkovitz y cols., 2002). (Figura 1).

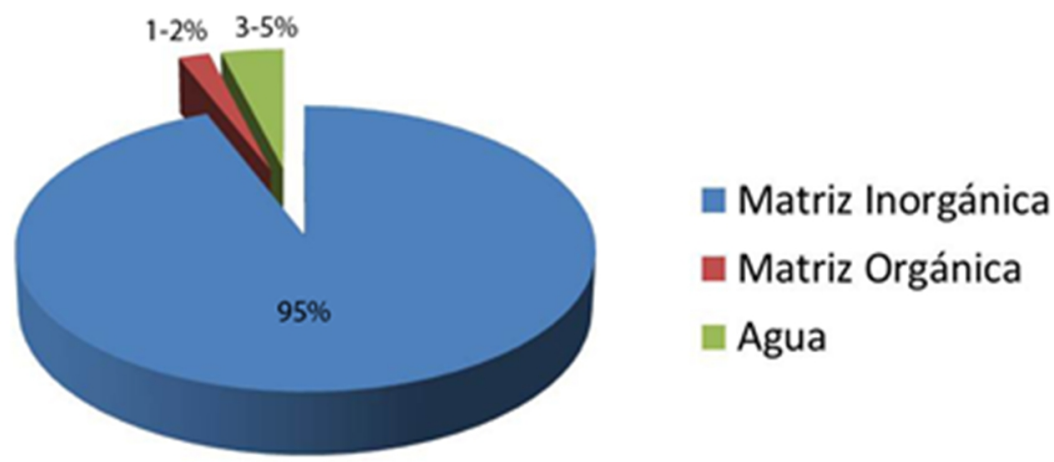

Figura 1: Composición química del esmalte dental.

La matriz inorgánica está constituida por sales minerales cálcicas, principalmente fosfato y carbonato. Estas sales muestran una disposición apatítica que responde a la fórmula general $\mathrm{Ca}_{10}\left(\mathrm{PO}_{4}\right)_{6}(\mathrm{OH})_{2}$ (Nicolás, 2010). Se depositan en la matriz del 


\section{Capítulo 1: Introducción}

esmalte y, tras el proceso de cristalización, se transforman en cristales inorgánicos de hidroxiapatita constituyendo prismas, bastones o varillas de esmalte, que se corresponden con la unidad estructural básica del esmalte. Dentro de esta unidad estructural se encuentra: el esmalte prismático y el esmalte aprismático. Se utiliza con frecuencia el término prisma, pero realmente la unidad estructural básica del esmalte no posee forma geométrica regular y no se asemeja a un prisma.

Entre los elementos inorgánicos también se puede encontrar aluminio, bario, magnesio, estroncio, radio, vanadio, plomo, hierro, sodio, potasio y flúor. Estos minerales se incorporan al esmalte por intercambio iónico o por adsorción sobre la superficie de los cristales. Los iones flúor pueden sustituir a los grupos hidroxilos en el cristal de hidroxiapatita convirtiéndolo en un cristal de fluorhidroxiapatita, que es más resistente a la acción de los ácidos ya que se hace menos soluble. Las concentraciones más altas de flúor se localizan en las 50 um más superficiales del esmalte (Gómez de Ferraris y cols., 2002).

El componente orgánico está formado principalmente por componentes de naturaleza proteica. Además de la albúmina, que también aparece en la dentina, las proteínas del esmalte se clasifican en dos grupos: amelogeninas y enamelinas. En menor proporción se encuentran ameloblastinas, tuftelinas, parvalbúminas, proteínas séricas, enzimas y pequeñas cantidades de condroitín 4-sulfato, condroitín 6-sulfato y lípidos. Estas proteínas se distribuyen en los espacios que deja libre el material inorgánico.

El agua por su parte, está presente en la periferia del cristal constituyendo la denominada "capa de hidratación", la cual disminuye progresivamente con la edad (Gómez de Ferraris y cols., 2002).

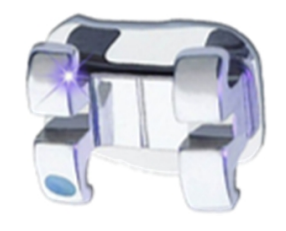




\subsubsection{Estructura histológica}

Respecto a su estructura, ya se ha comentado que la mayor parte de su volumen está ocupado por cristales de apatita en su forma hidroxi, fluoruro y carbonatada, siendo la más abundante la hidroxiapatita, que constituye los prismas de esmalte. Existen diversas formas de interpretar la morfología, organización y agrupamiento de estos prismas. La morfología se debe a la diferente orientación de los numerosos cristales de hidroxiapatita que forman cada prisma (Gwinnett y cols., 1992). El aspecto de los prismas y de la región interprismática, en un corte transversal, se ha comparado con el contorno del ojo de una cerradura (Meckel y cols., 1965), el cual se divide en cabeza y cola. La cabeza se estrecha a nivel medio y vuelve a ensancharse constituyendo la cola (Bhaskar, 1986; Gómez de Ferraris y cols., 2002). Dichas cabezas se ubican entre las colas de los prismas suprayacentes y las colas de cada prisma entre las cabezas de los prismas subyacentes (Figura 2) (Mjôr y cols., 1974).

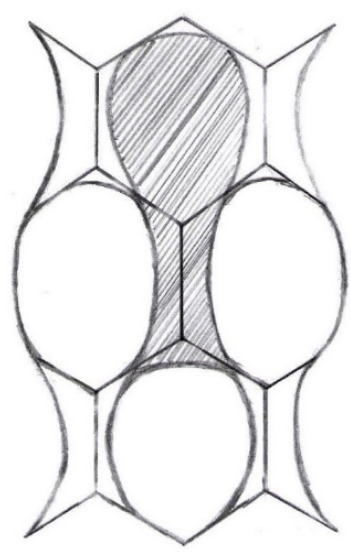

Figura 2: Morfología de los prismas en "ojo de cerradura" y disposición de los mismos. 


\section{Capítulo 1: Introducción}

Cada prisma tiene un trayecto ondulante con tendencia a agruparse en capas orientadas perpendicularmente a la superficie del diente. En el esmalte más cervical, las capas tienen, en su mayoría, dirección horizontal siendo sólo unas pocas las que se inclinan apicalmente (Fosse, 1968).

La orientación de los prismas ofrece un aspecto diferente según se estudien dientes primarios o permanentes:

- En los dientes primarios, a nivel cervical, las hileras de prismas son horizontales, mientras que en la región cuspídea son casi verticales, es decir, perpendiculares a la unión amelodentinaria.

- En los dientes permanentes, en la zona cervical las hileras de los prismas se inclinan hacia apical desviándose de la horizontal. A nivel cuspídeo, presentan la misma orientación vertical o perpendicular que en los dientes primarios.

La anchura de los prismas de esmalte oscila entre 4 y $7 \mu \mathrm{m}$, según la zona del diente. En las 5 micras de esmalte más próximo a la dentina no hay estructura prismática, y a nivel de la superficie externa su estructura es irregular o inexistente. Al esmalte de estas zonas se le denomina aprismático, y es el patrón microestructural más simple. En este tipo de esmalte, los cristales tienden a ser paralelos, radiales y perpendiculares al límite amelodentinario (García, 1997).

El esmalte aprismático es aquel en el que la sustancia adamantina mineralizada no constituye ni configura prismas. Se localiza en la superficie externa del esmalte prismático y posee un espesor de entre 30 y $100 \mu \mathrm{m}$. Está presente en todos los dientes primarios (en la zona superficial de toda la corona) y en un $70 \%$ de los dientes permanentes. En estos últimos se encuentra ubicado, en mayor medida, en

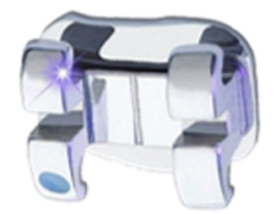


las regiones cervicales y en zonas de fisuras y microfisuras y en menor medida, en las superficies cuspídeas (García, 1997).

El esmalte prismático es el conjunto de prismas que constituye la mayor parte de la matriz mineralizada. Está organizado en capas separadas por límites bien definidos. En este esmalte se presentan volúmenes donde los prismas son paralelos unos con otros, como en el esmalte radial y el esmalte tangencial o pueden entrecruzarse unos con otros de manera regular como en el esmalte con Bandas de Hunter Schreger, o irregular como en el esmalte Irregular. A su vez, en el esmalte irregular, el entrecruzamiento de prismas puede ser en haces o en prismas individuales (García, 1997). 


\subsection{TÉCNICAS DE REMOCIÓN DEL ESMALTE}

Actualmente, el objetivo de la Odontología Conservadora se centra en el desarrollo de nuevos materiales restauradores y métodos de eliminación de caries que sean capaces de recuperar la estética y la función de los dientes tratados.

\subsubsection{Remoción por medios mecánicos}

Desde los inicios de la terapéutica dental el instrumental rotatorio ha sido la técnica principal para la eliminación de caries y la preparación cavitaria (Carneiro y cols., 2003). Esta técnica se pone en estudio continuamente ya que es un tema controvertido. Por un lado presenta ventajas como, por ejemplo, el control táctil y visual del profesional al realizar la cavidad así como la obtención de cortes precisos; pero por otro lado, trae consigo numerosos inconvenientes como son la eliminación no selectiva de tejido duro dental, incomodidad para el paciente por la generación de calor, presión, vibración y ruido, y por último, dolor y necesidad de anestesia. Factores que hacen que el paciente no esté cómodo a la hora de realizar dicho tratamiento (Anusavice, 1997; Carneiro y cols., 2003).

Estos problemas han hecho que, a través de los años, se desarrollen nuevas técnicas de eliminación de tejido dentario como alternativa al procedimiento convencional con turbina (Peters y cols., 2001).

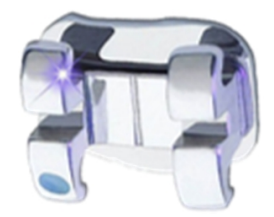




\subsubsection{Remoción por láser}

Entre las diferentes opciones existentes hay que destacar el empleo de la tecnología láser y, en particular, los láseres de la familia del Erbium. En 1997, la Food and Drug Administration (FDA) aprobó la utilización del láser de Er:YAG para la ablación de los tejidos duros dentales. Actualmente, este láser junto con el láser de Er, Cr:YSGG están aceptados clínicamente para su utilización sobre estos tejidos. No obstante, estos métodos requieren mayor tiempo de preparación respecto a los considerados como convencionales (Kimura y cols., 2002), además de producir daños térmicos y mecánicos en el esmalte que hacen necesaria la utilización conjunta con spray de agua-aire (Dostalova y cols., 1996). Recientemente, la alternativa que se propone es el láser de pulso ultracorto, ya que anula o disminuye significativamente los efectos térmicos y mecánicos que generan las técnicas anteriores. No obstante, dichas técnicas se estudian en apartados posteriores de la presente tesis. 


\subsection{ADHESIÓN}

\subsubsection{Concepto de adhesión y su proyección en Odontología}

Se define la adhesión como el estado en el que dos superficies se mantienen unidas mediante fuerzas o energías interfaciales basadas en mecanismos químicos, mecánicos o ambos. El adhesivo es el material que une esas dos superficies. Una vez aplicado, es capaz de mantenerlas juntas resistiendo a su separación (Packham, 1992; Kinloch, 1987). La superficie o sustrato que se adhiere se denomina adherente y el espacio virtual que hay entre estas dos superficies, interfase.

Para que se produzca una buena adhesión tiene que existir un íntimo contacto entre las superficies a unir y una buena humectabilidad (Toledano y cols., 2001). La adhesión puede estar basada en dos procedimientos:

\section{Procedimiento MeCÁnico:}

Consiste en la penetración o imbricación del adhesivo en las irregularidades de la superficie del adherente. Da lugar a la adhesión mecánica que puede ser macromecánica y micromecánica. Cuando las irregularidades son apreciables a simple vista se denomina adhesión macromecánica, mientras que si las irregularidades superficiales responsables de la adhesión son microscópicas, se denomina adhesión micromecánica (Nakabayashi y cols., 1998). La adhesión presente en esmalte y dentina principalmente se basa en una unión micromecánica (Joubert, 2010). 


\section{Procedimiento Químico:}

Se basa en la adhesión mediante la formación de enlaces químicos entre el adhesivo y el adherente. Produce adhesión química. Los enlaces implicados pueden ser primarios o fuertes (iónicos y covalentes) y secundarios o débiles (uniones por puentes de hidrógeno, interacciones por dipolos, fuerzas de van der Waals) (Nakabayashi y cols., 1998). El esmalte, a través de los radicales hidroxilos de la hidroxiapatita, es una estructura potencialmente receptiva a uniones químicas (Henostroza, 2010).

Los diferentes mecanismos de unión no están del todo claros. No obstante, los dos son perfectamente compatibles $\mathrm{y}$, sin duda alguna, pueden darse de forma simultánea.

En Odontología se utiliza con frecuencia el término adhesión para referirnos a uniones de tipo mecánico, donde la unión se produce solamente por medio de microrretención, sin ninguna interacción química entre los sustratos. Un ejemplo de ésta, es la unión que se forma entre el esmalte grabado y la resina fluida (Van Meerbeek y cols., 1994).

\section{FACTORES QUE INFLUYEN EN LA ADHESIÓN}

Existen diversas propiedades físicas que influyen en la adhesión puesto que ésta se deja influir en gran medida por las características de los sustratos que se van a unir. Dichas propiedades físicas son principalmente: la tensión superficial, la humectabilidad y la capilaridad.

Se define cuantitativamente la tensión superficial como el trabajo que debe realizarse para llevar moléculas en número suficiente desde el interior del líquido hasta la superficie para crear una nueva unidad de superficie. Los átomos que forman un 
Capítulo 1: Introducción

cuerpo se atraen entre sí y a su vez, atraen a otros átomos circundantes por medio de fuerzas electrostáticas. El interior de la masa está en esquilibrio debido a la compensación de unas fuerzas con otras. Sin embargo, los átomos que se mantienen en la superficie quedan con fuerzas sin compensar, ya que sólo están rodeados de otros átomos por un lado, por lo tanto mantienen una energía no contrarrestada en superficie. Dicha energía no contrarrestada es lo que se define en líquidos como tensión superficial y, en sólidos como energía superficial.

Para que haya adhesión entre un líquido y un sólido debe existir un íntimo contacto entre las dos superficies y, para ello, la tensión superficial del líquido debe ser menor que la energía libre del sólido (Erickson, 1992). El esmalte posee gran cantidad de materia orgánica y poco contenido en agua, por lo tanto, tiene una gran energía superficial.

Se denomina humectancia a la capacidad que tiene un líquido para mojar un sólido. Está relacionado con la energía superficial de cada sustrato. A mayor humectancia, mayor capacidad de que el líquido se extienda por la superficie del sólido (Padday, 1992).

Se denomina capilaridad al fenómeno que se produce cuando un líquido se pone en contacto con un tubo de pequeño diámetro y tiende a introducirse por él. Está directamente relacionado con la tensión superficial. Cuanto menor sea ésta, mayor será la tendencia a introducirse por el capilar (García, 1997). Al tratar el esmalte con cualquier tipo de ácido se crean microporosidades que actúan como capilares.

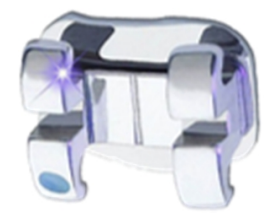




\subsubsection{Sistemas adhesivos empleados en la adhesión a esmalte. Clasificación}

Un sistema adhesivo se define como el conjunto de materiales que sirven para realizar todos los pasos de la adhesión del material restaurador al diente, como son la preparación de la superficie del esmalte y dentina, adhesión química y/o micromecánica a esmalte y dentina y adhesión química al material restaurador (Toledano y cols., 2003). La incapacidad de las resinas compuestas para adherirse directamente a los sustratos dentales, hizo que la aplicación de un sistema adhesivo fuera un paso intermedio indispensable en los procedimientos clínicos donde se utilizasen dichos materiales. El procedimiento adhesivo consta de tres componentes básicos:

\section{1) AGENTE GRABADOR}

Modifica química y morfológicamente la estructura del esmalte para permitir a los siguientes materiales adherirse mecánica y químicamente a ella. Habitualmente se usan ácidos fuertes, como el ácido ortofosfórico al 37\%, aunque también se siguen usando en la composición de los imprimadores ácidos débiles (cítrico, maleico, etc). En este apartado podemos incluir distintos tipos de láseres que podrían sustituir a estos ácidos.

\section{2) IMPRIMADOR O PRIMER}

Prepara el sustrato para recibir de forma más efectiva la resina. Hace que el adhesivo penetre con facilidad en las irregularidades del esmalte desmineralizado. Debe ser altamente hidrofílico y compatible con las resinas hidrofóbicas. 
Capítulo 1: Introducción

3) RESINA

Es la que produce la adhesión. Su principal requisito es que sea humectante. Puede contener monómeros hidrofílicos e hidrofóbicos, además de otros componentes que mejoran sus propiedades y comportamiento, como pueden ser: activadores o agentes de la polimerización, rellenos inorgánicos y disolventes.

Existen diversas clasificaciones para los sistemas adhesivos: según el sistema de activadores, según su evolución y consiguiente aparición en el mercado (por generaciones), según su acción sobre el barrillo dentinario, según su constitución física (número de botes) o según el mecanismo de adhesión. Una de las clasificaciones más completas es la que utiliza la composición y técnica de aplicación, y los clasifica en: 1) adhesivos no autograbadores, de grabado total o convencionales y; 2) adhesivos autograbadores (Figura 3 y Figura 4).

\section{Adhesivos de grabado total}

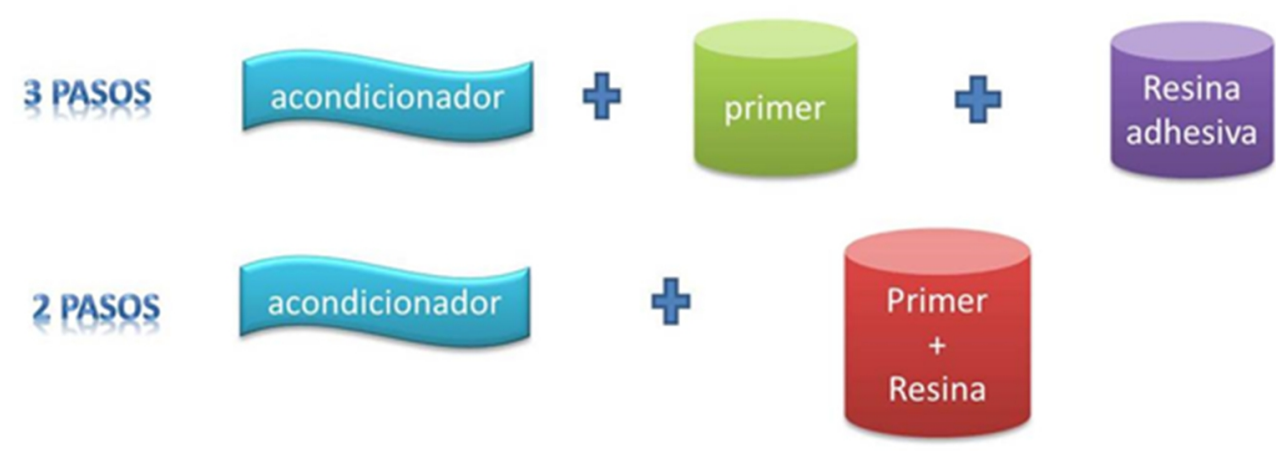

Figura 3: Evolución de los adhesivos, grabado total.

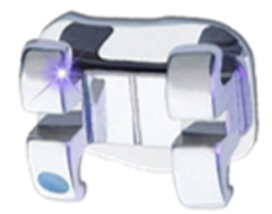




\section{Adhesivos autograbantes}

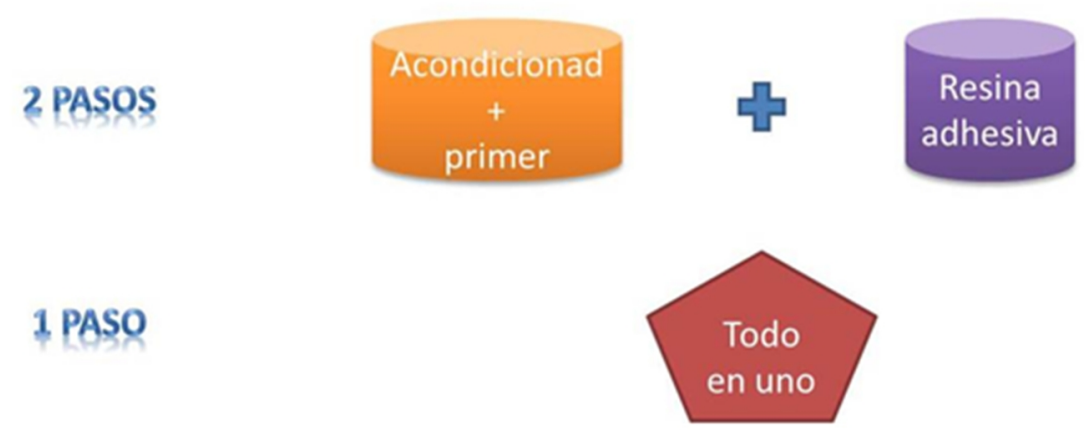

Figura 4: Evolución de los adhesivos, adhesivos autograbantes.

\section{A. Adhesivos de Grabado total, nO Autograbantes O CONVENCIONALES.}

- Grabado total en tres pasos

Si se emplean estos adhesivos, la sistemática a seguir es la siguiente: se acondiciona la superficie del esmalte con una aplicación de ácido fosfórico al 37\% durante 30 segundos (el tiempo puede variar dependiendo de las normas de cada fabricante), se realiza un posterior lavado con agua y se elimina el exceso de humedad, se aplica el imprimador y, por último, el adhesivo, que penetra en los poros creados por el ácido gracias a su baja tensión superficial, capacidad humectante y capilaridad. Al penetrar en las porosidades, forma los llamados tags de resina (Van Meerbeek y cols., 2002).

- Grabado total en dos pasos

El proceso anterior de tres pasos se simplificó en dos, al unificarse el imprimador y el adhesivo (De Munck y cols., 2005). En este sistema el grabado se hace de la forma tradicional y tras él, se aplica un segundo componente en el cual se mezclan 
Capítulo 1: Introducción

imprimador y adhesivo hidrofóbico. Este sistema es el más utilizado rutinariamente en ortodoncia ya que posee las mismas propiedades mecánicas que el adhesivo de grabado total en tres pasos y a su vez, ahorra tiempo de sillón.

\section{B. Adhesivos Autograbantes.}

Eliminan la fase de lavado ya que realizan el grabado y la imprimación de forma simultánea mediante la incorporación de monómeros ácidos. Existen varios tipos de clasificación, como por ejemplo, en función de su pH, definiéndose como fuertes a los que tienen un $\mathrm{pH}$ muy bajo $(<1)$, y medios a los que el $\mathrm{pH}$ está en torno a 2 (Yoshida y cols., 2004). Otra clasificación es en función de si se aplican en dos pasos o en uno solo. En el primer caso, se emplea el acondicionador e imprimador en un paso y el adhesivo en otro. En el segundo caso, encontramos los tres componentes (monómero hidrofílico, hidrofóbico y ácido) en un solo paso. Las ventajas de estos sistemas adhesivos autograbadores están en la simplificación del proceso adhesivo, tiempos de trabajo y disminución de la sensibilidad postoperatoria.

\subsubsection{Materiales de adhesión. Clasificación}

Existen varias clasificaciones de los materiales de adhesión, pero nos vamos a centrar en la clasificación según su composición y según su polimerización.

- Según su composición:

- Resinas de composite: son las más utilizadas en ortodoncia. Están constituidas principalmente por la matriz orgánica y el relleno mineral inorgánico y producen una adhesión micromecánica. Pueden ser:

- Acrílicas: compuestas por un monómero más polvo de metacrilato.

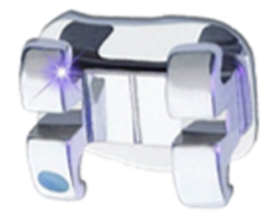


- A partir del monómero Bis-GMA: son las más utilizadas para los brackets metálicos ya que consiguen una adecuada retención mecánica (Plasencia, 1977). Pueden polimerizar en cadenas cruzadas originando una red tridimensional (Calderón, 1997).

- Ionómeros de vidrio: hasta el momento, es el único material que se autoadhiere. Se produce una adhesión química. Se suministran como polvo y líquido para mezclar. La polimerización es química (Powers y cols., 1997).

- Ionómeros híbridos: se compone de una pasta y de un líquido (Powers y cols., 1997). Su polimerización se produce por dos reacciones independientes: una reacción ácido-base común a los ionómeros de vidrio y la polimerización de las resinas que incorporan. Valletta y cols. encontró que las fuerzas de adhesión de resinas compuestas eran significativamente superiores a las obtenidas con cemento de vidrio modificado por resinas (Valletta y cols., 2007).

○ Compómeros: liberan flúor, lo que es interesante para el cementado de brackets (Powers y cols., 1997).

- Según su polimerización:

○ Polimerización química.

○ Fotopolimerización.

- Polimerización dual. 
Capítulo 1: Introducción

En el caso de las resinas de composite fotopolimerizables, que son las utilizadas en nuestro estudio, el material está compuesto de un adhesivo y una resina compuesta. La resina se aplica en la base del bracket y éste se coloca sobre la superficie del diente para posteriormente ser polimerizada. La extensión de la polimerización dependerá de varios factores como la exposición, la concentración de fotoiniciador y la intensidad de la luz (Eliades, 2006).

\subsection{4. $\quad$ Fases de la adhesión}

La adhesión no se entiende como la simple aplicación de un pegamento para unir dos superficies. En numerosas ocasiones hay que realizar pretratamientos antes de la aplicación del adhesivo. Básicamente, el proceso de unión se basa en tres pasos fundamentales:

1. Acondicionamiento del adherente. Consiste en alterar su morfología y/o su estructura química.

2. Imprimación del adherente, mediante la aplicación de una sustancia química previa para hacer el sustrato más receptivo al adhesivo.

3. Aplicación del adhesivo sobre la superficie adherente.

Estos tres pasos no tienen porqué darse siempre de manera claramente diferenciada. Se pueden encontrar de forma simultánea o bien faltar alguno de ellos (Van Meerbeek y cols., 1992; Toledano y cols., 2003).

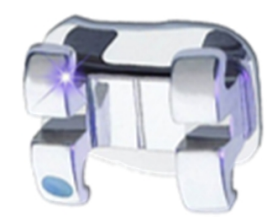




\subsubsection{Adhesión a Esmalte}

La superficie intacta del esmalte es un mal sustrato para la adhesión, ya que está recubierto por una capa orgánica, cutícula y placa bacteriana, de muy baja energía superficial (Toledano y cols., 2003). Este hecho, unido a la existencia de la capa aprismática en la superficie del esmalte y el mayor contenido en flúor, hace que sea más resistente al grabado (García, 1997) y exige eliminar esa capa superficial cuando se pretende una técnica adhesiva. No obstante, actualmente se conoce que la adhesión a este sustrato es más efectiva y predecible en comparación a la que se consigue en dentina.

La adhesión a esmalte se produce por el anclaje micromecánico que proporcionan las irregularidades que se originan con el grabado ácido previo a la técnica adhesiva, dando lugar a una adhesión de gran efectividad, confiabilidad y mínima susceptibilidad (Henostroza, 2010). Esta adhesión ha sido y es uno de los puntos más estudiados por los investigadores y es la variable más importante que regula el éxito de los tratamientos restauradores. No obstante, al realizar la técnica adhesiva convencional nos encontramos con diversos problemas tales como la microfiltración, que conduce tanto a la pérdida de adherencia de los brackets al esmalte, como al fracaso de las restauraciones compuestas.

\subsubsection{Técnica de grabado ácido}

El grabado ácido fue descrito por primera vez por Buonocuore en 1955 (Buonocuore, 1955). A partir de entonces se establece la posibilidad de obtener adhesión entre la resina y el esmalte dentario una vez que éste ha sido acondicionado con ácido fosfórico al $85 \%$ durante 30 segundos. Unos años después, nacieron las primeras 
Capítulo 1: Introducción

resinas compuestas que hicieron que se fuera aceptando el efecto beneficioso del grabado del esmalte (Bowen, 1962).

Con el paso del tiempo se ha ido reduciendo tanto la concentración de ácido ortofosfórico como el tiempo de aplicación, así hoy en día, se recomienda una concentración de entre el 30-40\% (Silverstone y cols., 1975) durante 15-30 segundos. Con esto se logra una desmineralización y disolución de la matriz inorgánica, que crea microporos y microsurcos en la estructura del esmalte. Diversos estudios han determinado que este ácido remueve aproximadamente $10 \mu \mathrm{m}$ de la superficie del esmalte y, morfológicamente, crea una capa porosa de entre 5 y 50 um de profundidad (Gwinnett, 1971).

Silverstone propuso una escala de tipo nominal para patrones de grabado ácido en el esmalte (Silverstone y cols., 1975) que se define de la siguiente manera (Figura 4):

- Tipo I: Es el patrón más común. Se remueve principalmente el centro del prisma mientras que la periferia permanece intacta.

- Tipo II: Se disuelve la periferia del prisma y el centro no se modifica.

- Tipo III: se produce una erosión indiscriminada, de centros y periferias de los prismas.

- Tipo IV: Se observa una superficie con hoyos y marcas no uniformes.

- Tipo V: Caracterizado por una superficie lisa. No hay evidencia de los prismas.

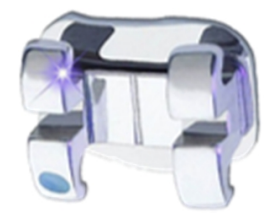




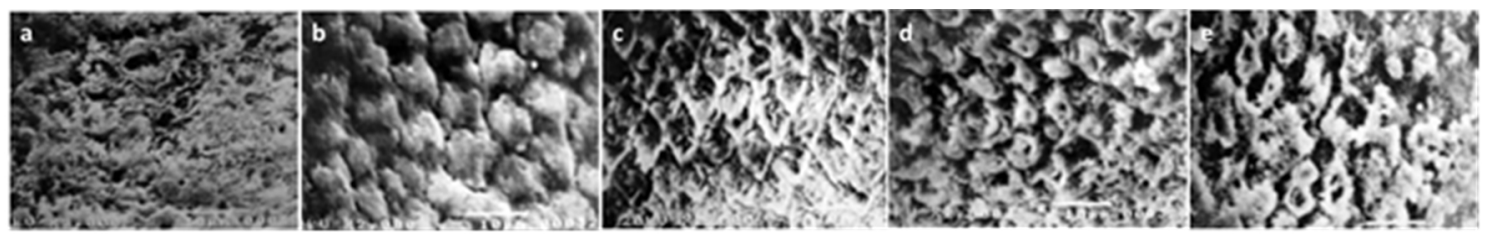

Figura 5: Tipos de grabado en esmalte dental. a) Tipo I; b) Tipo II; c) Tipo III; d)

Tipo IV; e) Tipo V. Tomado de Meléndez y cols., 2002.

No obstante, a pesar de ser un buen método para preparar la superficie del esmalte, el grabado ácido trae consigo ciertos inconvenientes, como son (Lehman y cols., 1981; Shey y cols., 1982; Oho y cols., 1990; Pashley, 1992; Goswami y cols., 2011):

- Posibilidad de desmineralización de los tejidos dentales que deja al esmalte susceptible a la caries.

- Remoción de la capa superficial del esmalte.

- Variación en la profundidad del grabado.

- Contaminación posterior de la superficie grabada con agua o aceite.

- Inadecuado lavado o secado, que puede afectar de forma contraria a la fuerza de adhesión.

- Retención de los pedículos de resina dentro de los poros creados en el esmalte que no pueden ser eliminados en su totalidad y pueden teñirse.

- Filtraciones en la interfase resina-esmalte que pueden generar corrosión y tinción del bracket.

- Pérdida de esmalte por la fractura del mismo cuando se descementa el bracket, así como rugosidades en la superficie que facilitan la acumulación de placa. 
Capítulo 1: Introducción

Es por ello, que se ha investigado sobre la aplicación de ácidos más débiles o con concentraciones más bajas que la actual, así como ácidos con agentes antibacterianos que consigan disminuir la desmineralización que se produce y mantengan las fuerzas adhesivas (Vicente y cols., 2008). Algunos estudios comprobaron que ácidos como el fosfórico al 10\%, el nítrico al 2.5\% y el maleico al 10\% grababan el esmalte con la misma eficacia que el ácido fosfórico al 37\% (Berry y cols., 1990; Blosser, 1990; Gwinnett y cols., 1992). Sin embargo, hay otros estudios in vitro que concluyen que ácidos con concentraciones menores, producen valores de adhesión más bajos cuando se aplican durante el tiempo recomendado por el fabricante (Triolo y cols., 1993) y originan patrones morfológicos cualitativamente distintos a los obtenidos con el ácido ortofosfórico al 37\% (Perdigao y cols., 2001).

\subsubsection{Adhesión en Ortodoncia}

En ortodoncia, la adhesión se refiere al medio de unión entre el esmalte y la base del bracket. Ésta se logra por la unión mecánica del adhesivo a las irregularidades del esmalte superficial del diente y por las uniones mecánicas formadas en la base del aditamento ortodóntico (Proffit, 1986). En esta disciplina se prefiere una adhesión mecánica debido a que no se busca la unión permanente, sino una unión que se pueda romper de manera sencilla al final del tratamiento siendo lo más conservador posible con la superficie de esmalte (Graber y cols., 2006).

En los inicios de la ortodoncia se utilizaban bandas pegadas a los dientes para poder moverlos. Los brackets han experimentado muchas variaciones a lo largo de los años y hoy en día, son la base de la ortodoncia contemporánea. Según las necesidades estéticas del paciente, la complejidad y tiempo de tratamiento estimado para un caso concreto y las características de cada sistema ortodóncico, elegiremos un tipo

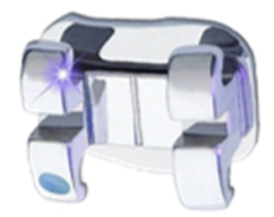


de bracket u otro, teniendo varios tipos: plásticos, cerámicos o metálicos. Los metálicos son los de mayor uso en ortodoncia debido a sus propiedades mecánicas y clínicas (Oh y cols., 2005). La adhesión de estos brackets al esmalte depende de la adecuada retención mecánica, la cual se consigue fundamentalmente gracias a la malla de su base (Gwinnett, 1988; Odegaard y cols., 1988; Keim y cols., 2002; Graber y cols., 2006).

$\mathrm{Al}$ adherir un bracket al esmalte se producen dos interfases:

- esmalte-resina

- resina- bracket

En función de dónde se produzca el fallo va a variar la cantidad de adhesivo a eliminar, y por lo tanto, el tiempo invertido y el posible daño al esmalte, así como la filtración, que puede aumentar la probabilidad de que aparezca caries. La fuerza de adhesión mínima de los brackets para poder desarrollar un tratamiento ortodóntico clínico debe estar dentro del intervalo de 6-8 MPa (Reynolds, 1976).

\section{INTERFASE RESINA- $B R A C K E T$}

Actualmente, la adhesión resina- bracket está muy mejorada. La retención de la base de los brackets actuales es aceptable y puede incrementarse mediante fotograbado, chorreados con arena y óxido de aluminio y aplicación de silano (MacColl y cols., 1998).

\section{INTERFASE ESMALTE-RESINA}

La unión esmalte-resina, es un tema en continuo estudio, ya que a pesar de los avances que se producen, sigue presentando carencias, tanto en eficacia adhesiva 
Capítulo 1: Introducción

como en el empleo de un agente acondicionador que produzca el menor daño posible al esmalte, al mismo tiempo que mantenga unos valores de adhesión aceptables.

Como se ha comentado anteriormente, la desmineralización del esmalte con ácido ortofosfórico al 37\% hace que su superfice se vuelva más susceptible a la caries. Así, se estudian métodos alternativos para prepararlo que minimicen o eliminen dicha desmineralización y mantengan la eficacia adhesiva, como son:

- Otros tipos de ácidos a diferentes tiempos y concentraciones: Maléico (Benderli y cols., 1999); Poliacrílico (Maijer y cols., 1986); Sulfúrico (Artun y cols., 1984); Nítrico (Gardner y cols., 2001); EDTA (Cehreli y cols., 2000).

- Otros tipos de resinas, como las de autograbado, que produzcan menos pérdida de esmalte que el ácido fosfórico y no requieran pretratamiento de la superficie (Bishara y cols., 2006; Goracci y cols., 2013).

- Cementos de vidrio ionómero que minimicen y prevengan la desmineralización y liberen flúor (Pithon y cols., 2006).

- Diferentes láseres, con distintos parámetros, que eliminarían la desmineralización del esmalte y los consiguientes problemas asociados: Er:YAG (Martínez-Insúa y cols., 2000; Dunn y cols., 2005; Başaran y cols., 2011); Er, Cr:YSGG (Başaran y cols., 2011); Argon (Talbot y cols., 2000). 


\section{MEDIANTE LÁSER}

\subsubsection{Introducción al láser y sus propiedades}

El láser (Light Amplification by Stimulated Emission of Radiation) se puede definir como un dispositivo que utiliza la emisión estimulada de radiación en un medio apropiado, llamado medio activo, para generar un haz de luz caracterizado por su coherencia temporal y espacial, monocromaticidad y elevada direccionalidad (Schawlow y cols., 1958; Orza, 1986). Esta radiación electromagnética es emitida en longitudes de onda entre $100 \mathrm{~nm}$ y $1 \mathrm{~mm}$ Existe una gran cantidad de medios activos, sólidos, líquidos y gaseosos, que producen emisión estimulada de luz. Dependiendo del medio activo, la emisión se produce en diferentes longitudes de onda, lo que hace que hoy en día dispongamos de fuentes láser en cualquier zona del espectro. En el caso de los láseres empleados para la realización de esta tesis, los medios activos tanto del Er:YAG como del Ti:Zafiro, son medios sólidos produciéndose la emisión, respectivamente a 2940 y $795 \mathrm{~nm}$, por tanto, ambos en el infrarrojo.

Aparte de la longitud de onda, los láseres poseen otras propiedades físicas que determinan de una u otra forma su aplicación tecnológica. Entre ellas, las más relevantes son, probablemente, el tipo de emisión en continuo o de forma pulsada (y, en este caso, la duración de los pulsos), y la potencia de la emisión, es decir, la cantidad de energía que porta la emisión por unidad de tiempo. En el caso de la presente tesis, dado que se han utilizado láseres de emisión pulsada, resulta conveniente describir los distintos tipos existentes en función de la duración de los 
Capítulo 1: Introducción

pulsos. Para ello se incluye la Tabla 1 donde se presentan los tipos de láser más habituales con la duración de sus emisiones. La duración del pulso es un parámetro muy importante cuando el láser se emplea en el procesado de materiales, como es el caso de esta investigación. En los próximos apartados describiremos la influencia de este parámetro en la interacción con el esmalte dental.

Tabla 1: Tipos de láseres más habituales con su longitud de onda y duración temporal de la emisión

Tipo de Láser Longiutd de onda Duración del pulso

\begin{tabular}{|c|c|c|}
\hline Argon ion & $488 / 514 \mathrm{~nm}$ & CW \\
\hline $\mathrm{He}-\mathrm{Ne}$ & $633 \mathrm{~nm}$ & CW \\
\hline $\mathrm{CO}_{2}$ & $10.6 \mu \mathrm{m}$ & CW o pulsado \\
\hline Diodo láser & $670-900 \mathrm{~nm}$ & CW o pulsado \\
\hline Rubí & $694 \mathrm{~nm}$ & $1-250 \mu \mathrm{s}$ \\
\hline$N d: Y A G$ & $1064 \mathrm{~nm}$ & $100 \mathrm{~ns}-250 \mu \mathrm{s}$ \\
\hline Ho:YAG & $2120 \mathrm{~nm}$ & $100 \mathrm{~ns}-250 \mu \mathrm{s}$ \\
\hline Er, Cr:YSGG & $2780 \mathrm{~nm}$ & $100 \mathrm{~ns}-250 \mu \mathrm{s}$ \\
\hline$E r: Y A G$ & $2940 \mathrm{~nm}$ & $100 \mathrm{~ns}-250 \mu \mathrm{s}$ \\
\hline$N d: Y A G$ & $1064 \mathrm{~nm}$ & $30-100$ ps \\
\hline Láser de electrones libres & $800-6000 \mathrm{~nm}$ & $2-10 p s$ \\
\hline Ti:Sapphire & $700-1000 \mathrm{~nm}$ & $10 \mathrm{fs}-100 \mathrm{ps}$ \\
\hline
\end{tabular}




\subsubsection{El láser en odontología}

La tecnología láser lleva empleándose en Odontología desde hace años, utilizándose diferentes tipos de láser en diversos campos dentro de la disciplina.

En 1958, Charles H. Townes y Arthur Schawlow describieron los principios físicos del láser. Dos años después, Theodore Maiman, basándose en los estudios de estos dos investigadores, se lanza a construir el primer láser eficiente, de rubí y con una longitud de onda de $694 \mathrm{~nm}$ (Maiman, 1960).

Entre los años 1960 y 1970 se desarrollaron los láseres de Nd-YAG, He-Ne, diodo, Argón y $\mathrm{CO}_{2}$. Sus creadores y la comunidad de investigadores comienzan a buscar inmediatamente aplicaciones en el área de la odontología, sobre todo en relación a la prevención de la caries y a los efectos que producían en esmalte y dentina (Sognnaes y cols., 1965; Stern y cols., 1972; Goodman, 1977). En 1965, L. Goldman utiliza por primera vez, in vivo, el láser de rubí sobre las superficies dentales y observa que la aplicación de un par de pulsos de dicho láser sobre esta superficie no producía dolor pero sí pequeños daños en la superficie irradiada (Goldman, 1965).

El láser de Er:YAG se introdujo en los años 80. Así, entre 1988 y 1991 Hibst y Keller demostraron que se podía eliminar estructura dental con Er:YAG sin producir un aumento significativo de la temperatura en esmalte y dentina, siempre y cuando se utilizara adecuadamente con spray de agua fría (Hibst y cols., 1989). Fue la primera vez que se utilizó un láser de baja energía para realizar agujeros sobre sobre estas superficies dentarias.

En los años 90 el desarrollo de los láseres de pulsos ultracortos supone una innovación sin precedentes en el campo de procesado de materiales, no tardando en 
Capítulo 1: Introducción

llegar su introducción en el campo de la Odontología (Kohns y cols., 1997; Momma y cols., 1997; Serbin y cols., 2002).

En la Figura 6 se muestran las principales aplicaciones de los láseres en Odontología, exceptuando las de los láseres de Er:YAG y de pulsos ultracortos, que se expondrán en un apartado propio.

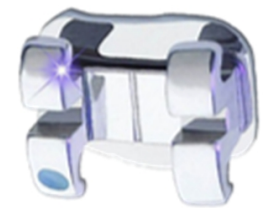




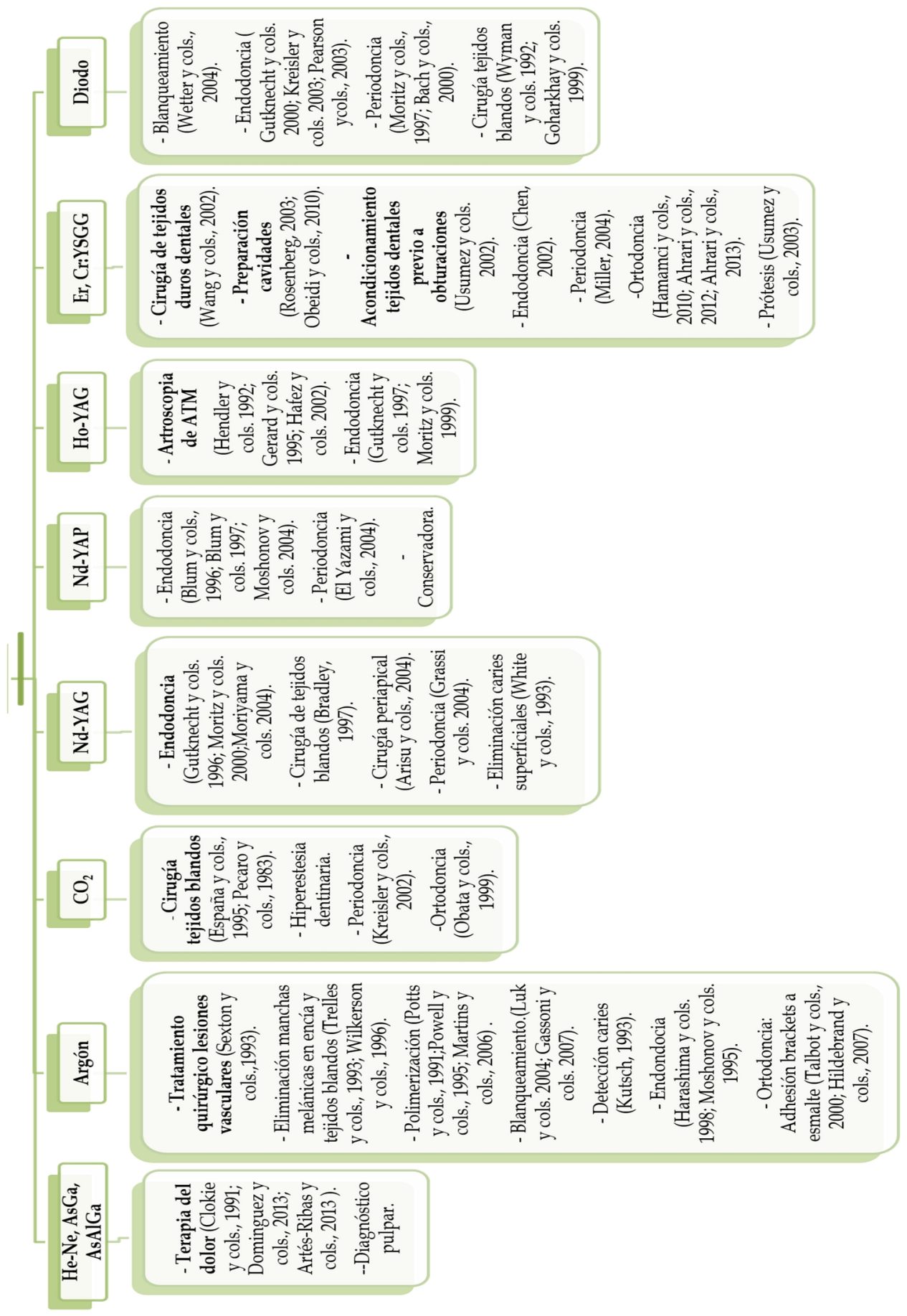

Figura 6: Aplicación de los distintos láseres en Odontología (En negrita: aplicación principal). 
Capítulo 1: Introducción

\subsubsection{Láser de Er:YAG}

\section{CARACTERÍSTICAS.}

Es un láser de emisión pulsada cuyo medio activo es un granate de Ytrio y Aluminio dopado con Erbium. Emite en el infrarrojo con una longitud de onda de $2940 \mathrm{~nm}$. Siguiendo la clasificación en cuanto a medidas de seguridad se refiere, tanto de la Unión Europea, normas ISO, como de los EE.UU., normas ANSI, se le considera un láser de clase IV.

En el presente estudio se ha utilizado el láser de Er:YAG Fidelis Plus III (Fotona, Ljubljana, Slovenia) que tiene como características principales una fluencia máxima de $48 \mathrm{~J} / \mathrm{cm}^{2}$; máximo pulso de energía de $1.5 \mathrm{~J}$; anchos de pulso de 50 us (SSP), 100

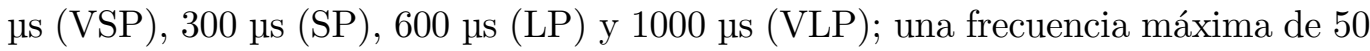
Hz y una máxima potencia promedio de $20 \mathrm{~W}$.

Los parámetros utilizados en el caso de nuestro trabajo, para el acondicionamiento del esmalte, fueron una potencia de salida de $0.8 \mathrm{~W}$, en modo VSP, con una duración del pulso de 100 ps y una frecuencia de $10 \mathrm{~Hz}$, conectado a una pieza de mano, modelo R02, en modo no contacto, con irrigación y a una distancia focal de aproximadamente $10 \mathrm{~mm}$.

Desde la fuente de emisión, los pulsos se trasmiten por medio de fibra óptica o mediante óptica integrada en un brazo articulado. La trasmisión por fibra óptica es una gran ventaja como veremos al comparar con los láseres de pulsos ultracortos, pero aún así, es necesaria la refrigeración de la fibra mediante dispositivos de circulación de agua o aire, debido a la alta absorción de la radiación en las paredes de la misma a esa longitud de onda. Así, se puede conducir el haz hasta una pieza de mano y de ahí al tejido diana (Miserendino y cols., 1995).

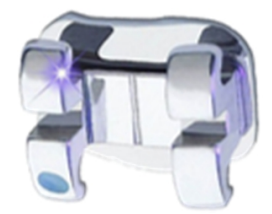




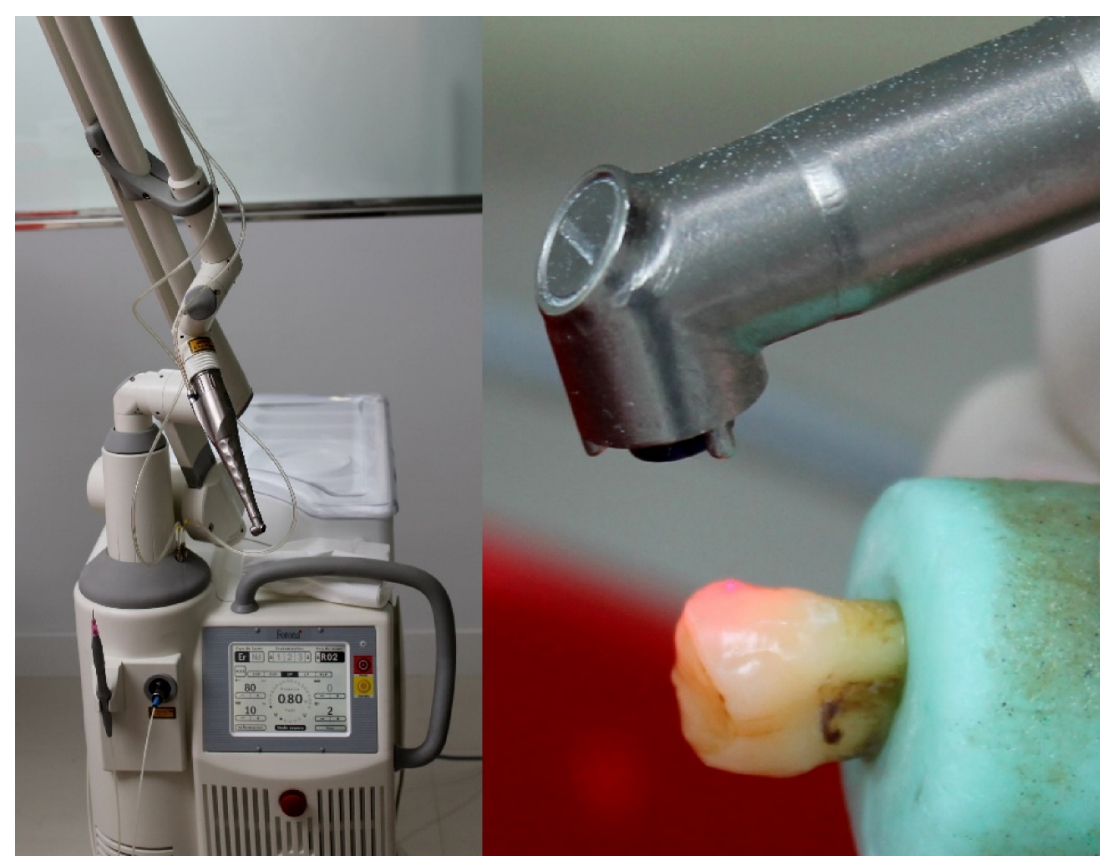

Figura 7: (a) Láser de Er:YAG (Fidelis plus III) (b) pieza de mano R02 en modo no contacto.

\section{INTERACCIÓN CON LA MATERIA.}

En general, cuando la radiación electromagnética incide sobre la superficie de un material, parte de la onda es reflejada y parte transmitida y de ésta, parte a su vez es absorbida (Ley de Beer-Lambert) produciendo el calentamiento del material. El coeficiente de absorción lineal depende de la longitud de onda, de la intensidad de la radiación y de las características microscópicas del propio material (Steen, 1998; Rubahn, 1999).

De forma muy simplificada, el proceso de interacción lineal de la radiación de un láser con un material tiene lugar de la forma que se describe a continuación. Cuando la radiación incide sobre un material, es absorbida por los electrones ligados elásticamente a los núcleos atómicos, de forma que emplean esa energía para realizar un movimiento vibratorio (efecto Bremsstrahlung inverso). El electrón vibrando 
Capítulo 1: Introducción

podrá reemitir esa radiación absorbida en cualquier dirección o bien cederla por colisiones inelásticas a los átomos o moléculas de la estructura cristalina. En este último caso, esos átomos o moléculas comienzan a vibrar, vibración que se transmitirá a toda la estructura cristalina por las ligaduras entre átomos y/o moléculas de la misma. Estas vibraciones estructurales elevan la temperatura de la red cristalina y su propagación a lo largo de la misma es lo que llamamos conducción del calor.

Si se absorbe una gran cantidad de energía del láser, entonces la vibración de los átomos y moléculas tiene tal amplitud que fuerza las ligaduras entre ellos hasta el punto de que el material pierde rigidez quedando por tanto fundido (temperatura de fusión). Un incremento aún mayor de la temperatura del material supondrá la desaparición de cualquier ligadura entre átomos o moléculas diciéndose entonces que el material se ha evaporado (temperatura de evaporación).

Como es natural, hay toda una serie de parámetros que condicionan cada una de las etapas del proceso descrito anteriormente y que tienen que ver con las propiedades del propio material y las características de la emisión láser. En concreto, cuando deseamos eliminar un material con un láser, las propiedades ópticas (coeficiente de absorción lineal, reflectividad) y térmicas (puntos de fusión y evaporación, conductividad térmica, difusividad térmica) del material son cruciales a la hora de determinar la fuente láser más adecuada y sus características (potencia, longitud de onda, duración de la emisión).

A partir de los años 80 son muchas las investigaciones que demuestran que el láser de Er:YAG es adecuado para su utilización en la ablación de los tejidos duros dentales (Hibst y cols., 1989) debido a que el agua posee un coeficiente de absorción

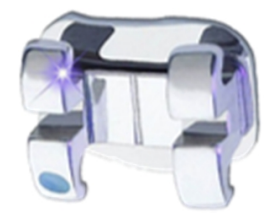


muy elevado a la longitud de onda de emisión de este láser (Figura 8), al igual que como es lógico, sucede con la hidroxiapatita (Parker, 2007).

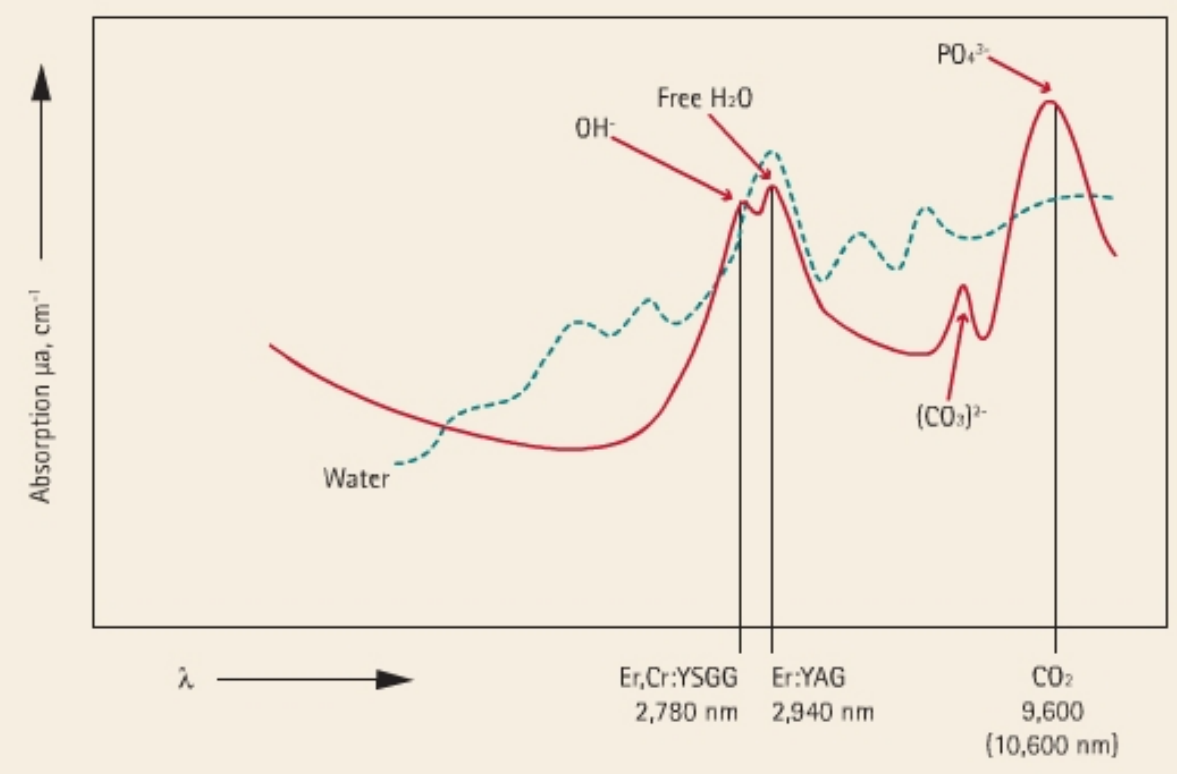

Figura 8: Gráfica del coeficiente de absorción lineal de la hidroxiapatita carbonatada en función de la longitud de onda. Tomada de Parker, 2007.

En el caso del esmalte, la energía láser, aplicada en brevísimas pulsaciones es absorbida por el agua del tejido superficial, lo que conduce al calentamiento de la misma hasta alcanzar la temperatura de vaporización. El agua, al vaporizarse, se expande dentro del tejido dando lugar a un aumento de la presión en su interior, lo que produce la expansión del material a nivel micrométrico y, por consiguiente, su eliminación sin un excesivo calentamiento del tejido remanente (Frentzch y cols., 1990; Hibst y cols., 1998). Hibst y Keller en una de sus investigaciones (Hibst y cols., 1989), determinaron los niveles de ablación tanto en esmalte como en dentina 
Capítulo 1: Introducción

y observaron que la tasa de ablación en la dentina es mayor (y más efectiva) que en el esmalte, debido a que su contenido híbrido es mayor (25\% frente al $8 \%$ en el esmalte).

No obstante y como ya se ha comentado anteriormente, el empleo de este láser requiere de la irrigación simultánea del tejido para mitigar el incremento de temperatura que produce la acumulación de pulsos en la zona tratada al aplicarlo en los tejidos duros dentarios (Dostalova y cols., 1996; Cavalcanti y cols., 2003; Attrill y cols., 2004) y como consecuencia, la aparición de microfracturas y cracks (Boehm y cols., 1977; Anic y cols., 1992; Sandford y cols., 1994; Cox y cols., 1994), así como para favorecer la continuidad del proceso de ablación al retirar el material fundido y resolidificado, o redepositado de la zona de procesado, que podría entorpecer la absorción de la radiación por el esmalte virgen. Este efecto indeseado, sumado al tiempo que tarda en realizar la preparación cavitaria o el acondicionamiento de la superficie del esmalte, el cual es comparativamente mayor que el empleado con las técnicas convencionales, hacen que no sea un método ideal para la preparación del esmalte y nos anime a buscar nuevos procedimientos que resuelvan dichos inconvenientes.

\section{APLiCACIONES EN OdONTOLOGía.}

El láser de Er:YAG tiene distintas aplicaciones en odontología, tales como:

- Conservadora

- Preparación de cavidades (Tabla 2). Puede cortar los tejidos duros dentarios sin producir fusión ni carbonización de los mismos y dejando la superficie de corte rugosa (Hibst y cols., 1989; Takeda y cols. a y b, 1998; Freitas y cols., 2007; Colucci y cols., 2009; Amaral y cols., 2010; Yaman

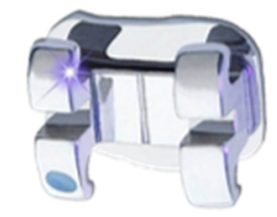


y cols., 2012; Rizcalla y cols., 2012). Además, Se reduce la cantidad de anestesia local utilizada en el tallado de esmalte o dentina.

- Eliminación de composites y de pastas de endodóncicas: se pueden remover composites, ionómeros, silicatos, óxido de zinc y resinas compuestas, estando contraindicado su uso para la eliminación de amalgama de plata, incrustaciones metálicas, etc., debido a la gran reflexión de la energía que se produce en su superficie (Warembourg y cols., 2001; Rizoiu y cols., 1998).

○ Grabado del esmalte (Tabla 3): se obtienen patrones similares al grabado con ácido ortofosfórico (Hossain y cols., 1999; Blum y cols., 2001; Groth y cols., 2001; de Munck y cols., 2002; Hossain y cols., 2003; Kim y cols., 2006; Firat y cols., 2012; Sağır y cols., 2013).

○ Adhesión de diferentes composites a esmalte (Coluzzi, 2002).

- Acondicionamiento de la dentina para obturaciones con adhesivos (Groth y cols., 2001; De Munck y cols., 2002).

- Cirugía

- Puede cortar tanto tejido blando como el hueso sin producir necrosis ósea (Rizoiu y cols., 1996; Rupprecht y cols., 2003). En la cirugía de tejidos blandos es habitual el sangrado debido a su escaso efecto hemostático (Keller y cols., 1994). Junto con el láser de Er, Cr:YSGG, es el más indicado para la eliminación de tejido duro dental.

- En la segunda cirugía de implantes, para eliminar el capuchón mucoso que recubre al implante (Arnabat y cols., 2003). 
Capítulo 1: Introducción

- Los tratamientos que se pueden llevar a cabo sobre tejidos blandos son los siguientes:

- Biopsia de lesiones benignas.

- Exéresis de masas de tejido blando como fibromas, épulis, etc.

- Vaporización de leucoplasias.

- Tratamiento de lesiones aftosas y de lesiones herpéticas.

- Frenectomías.

- Desbridamiento de abscesos.

- Gingivectomías y gingivoplastias.

- Alargamiento de la corona clínica.

- Cirugía preprotésica.

- Endodoncia

- Se usa por su efecto bactericida (Hibst y cols., 1997; Mehl y cols., 1999).

- Mediante el acoplamiento de fibras ópticas de diferentes diámetros que distribuyen la energía en el interior del conducto radicular, podemos efectuar pequeñas ablaciones en sus paredes, permitiendo la preparación biomecánica con menor esfuerzo y facilitando por un lado la instrumentación manual, y por otro el secado del conducto radicular con un importante efecto bactericida (Warembourg y cols., 2001).

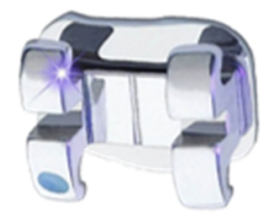


- Periodoncia (Eversole y cols., 1995: Schwarz y cols., 2003)

- En el tratamiento periodontal, elimina el cálculo sin lesionar la superficie del cemento radicular y desinfecta las bolsas periodontales.

- Corte y recontorneado óseo.

- Gingivectomías y gingivoplastias, reduciendo el tamaño de las bolsas periodontales de forma rápida.

- Sobre los tejidos duros es posible efectuar osteoplastias, ostectomías y amputaciones radiculares.

- Odontopediatría

- Eliminación y tratamiento de la caries en los dientes temporales (Hossain y cols., 2002).

- Sellado preventivo de fosas y fisuras. Al aplicar el láser de Er:YAG en las fosas y fisuras dentarias se produce una superficie porosa que permite una excelente adhesión de la resina selladora (Groth y cols., 2001).

- Ortodoncia

- Acondicionamiento del esmalte previo al cementado de brackets (Hamamci y cols., 2010; Lasmar y cols., 2012; Türköz y cols., 2012; Sağır y cols., 2013).

- Descementado de brackets (Oztoprak y cols., 2010). 
Capítulo 1: Introducción

Tabla 2: Revisión bibliográfica de los artículos referentes a la preparación cavitaria con láser de Er:YAG

\begin{tabular}{|c|c|c|c|}
\hline Autor & Título & Año & Resultados y conclusiones \\
\hline $\begin{array}{l}\text { De Munck y } \\
\text { cols. }\end{array}$ & $\begin{array}{l}\text { Microtensile bond strength } \\
\text { of two adhesives to } \\
\text { Erbium:YAG lased vs. bur-cut } \\
\text { enamel and dentin. }\end{array}$ & 2002 & $\begin{array}{l}\text { Los adhesivos se adhieren de forma menos } \\
\text { efectiva al esmalte tratado con láser que al } \\
\text { tratado con turbina y fresa. EI } \\
\text { acondicionamiento con láser de Er:YAG es } \\
\text { menos efectivo que con ácido } \\
\text { ortofosfórico. }\end{array}$ \\
\hline $\begin{array}{l}\text { Hossain } y \\
\text { cols. }\end{array}$ & $\begin{array}{l}\text { A study on surface roughness } \\
\text { and microleakage test in } \\
\text { cavities prepared by Er:YAG } \\
\text { laser irradiation and etched } \\
\text { bur cavities. }\end{array}$ & 2003 & $\begin{array}{l}\text { La preparación de cavidades superficiales } \\
\text { con láser de Er:YAG es capaz de disminuir } \\
\text { las microfiltración de las restauraciones de } \\
\text { composite, y su eficiencia es similar a las } \\
\text { cavidades realizadas con turbina y fresa. }\end{array}$ \\
\hline Dunn y cols. & $\begin{array}{l}\text { Shear bond strength and } \\
\text { SEM evaluation of composite } \\
\text { bonded to Er:YAG laser - } \\
\text { prepared dentin and enamel. }\end{array}$ & 2005 & $\begin{array}{l}\text { La preparación cavitaria con turbina } \\
\text { obtiene mejores valores de adhesión que } \\
\text { con láser de Er:YAG. La adhesión al esmalte } \\
\text { ablacionado con este láser es inferior a la } \\
\text { que se produce con la técnica mecánica } \\
\text { convencional. }\end{array}$ \\
\hline Parker S. & $\begin{array}{l}\text { Surgical lasers and hard } \\
\text { dental tissue }\end{array}$ & 2007 & $\begin{array}{l}\text { Las tasas de ablación de tejido dentario con } \\
\text { instrumental rotatorio continúan siendo } \\
\text { más rápidas. Con respecto al láser, la } \\
\text { preparación cavitaria asistida por éste, } \\
\text { junto con el control de la caries y las } \\
\text { técnicas de adhesión hacen que su } \\
\text { utilización esté cada vez más aceptada }\end{array}$ \\
\hline Ozel y cols. & $\begin{array}{l}\text { Leakage pathway of different } \\
\text { nano-restorative materials in } \\
\text { class } \mathrm{V} \text { cavities prepared by } \\
\text { Er:YAG laser and bur } \\
\text { preparation. }\end{array}$ & 2009 & $\begin{array}{l}\text { Las cavidades preparadas con turbina } \\
\text { mostraron menos microfiltración que las } \\
\text { preparadas con láser de Er:YAG en esmalte. }\end{array}$ \\
\hline $\begin{array}{l}\text { Colucci } \\
\text { cols. }\end{array}$ & $\begin{array}{l}\text { Water flow on } \\
\text { erbium:yttrium-aluminum- } \\
\text { garnet laser irradiation: } \\
\text { effects on dental tissues. }\end{array}$ & 2009 & $\begin{array}{l}\text { La remoción del tejido dentario sano y } \\
\text { cariado con un láser de Er:YAG es menor } \\
\text { que con la técnica mecánica convencional. } \\
\text { A pesar de que el uso del spray de agua en } \\
\text { la irradiación con este láser está bien } \\
\text { establecida, se necesitan más estudios que } \\
\text { complementen los ajustes de los } \\
\text { parámetros con el fin de mejorar la técnica. }\end{array}$ \\
\hline $\begin{array}{l}\text { Amaral } \\
\text { cols. }\end{array}$ & $\begin{array}{l}\text { Bond durability in } \\
\text { erbium:yttrium-aluminum- } \\
\text { garnet laser-irradiated } \\
\text { enamel. }\end{array}$ & 2010 & $\begin{array}{l}\text { La preparación cavitaria con láser de } \\
\text { Er:YAG influye de forma similar a la } \\
\text { preparación con fresa y turbina en la } \\
\text { adhesión de un adhesivo de grabado total. }\end{array}$ \\
\hline
\end{tabular}

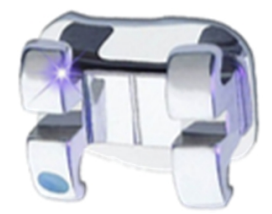




\begin{tabular}{|c|c|c|c|c|}
\hline $\begin{array}{l}\text { Rizcalla } \\
\text { cols. }\end{array}$ & $y$ & $\begin{array}{l}\text { Improving the efficiency of } \\
\text { an Er:YAG laser on enamel } \\
\text { and dentin. }\end{array}$ & 2012 & $\begin{array}{l}\text { El aumento de los valores de los } \\
\text { parámetros evaluados no mejoró la } \\
\text { eficiencia. Una puesta a punto de todos los } \\
\text { parámetros con el fin de obtener una } \\
\text { buena tasa de ablación con mínimo daño } \\
\text { en la superficie del esmalte parece ser la } \\
\text { clave para lograr una eficacia óptima para } \\
\text { la preparación de la cavidad con un láser de } \\
\text { Er:YAG. }\end{array}$ \\
\hline $\begin{array}{l}\text { Yaman } \\
\text { cols. }\end{array}$ & $y$ & $\begin{array}{l}\text { Effect of the erbium:yttrium } \\
\text {-aluminum - garnet laser or } \\
\text { diamond bur cavity } \\
\text { preparation on the marginal } \\
\text { microleakage of class } \mathrm{V} \\
\text { cavities restored with } \\
\text { different adhesives and } \\
\text { composite systems. }\end{array}$ & 2012 & $\begin{array}{l}\text { El láser de Er:YAG muestra mayor } \\
\text { microfiltración que los procedimientos con } \\
\text { fresa de diamante. }\end{array}$ \\
\hline
\end{tabular}

Tabla 3: Revisión bibliográfica de los artículos revisados sobre láser de Er:YAG como alternativa al grabado ácido para el acondicionamiento del esmalte

\begin{tabular}{|c|c|c|c|}
\hline Autor & Título & Año & Resultados y conclusiones \\
\hline $\begin{array}{l}\text { Attrill } \\
\text { cols. }\end{array}$ & $\begin{array}{l}\text { Er:YAG }(\lambda=2.94 \mu \mathrm{m}) \text { laser } \\
\text { etching of dental enamel as } \\
\text { an alternative to acid } \\
\text { etching. }\end{array}$ & 2000 & $\begin{array}{l}\text { El grabado ácido convencional obtuvo } \\
\text { mayores valores de resistencia a la cizalla } \\
\text { que el grabado con láser de Er:YAG.Se } \\
\text { apoya el uso de este láser como una } \\
\text { alternativa al grabado ácido convencional, } \\
\text { y la progresión a la investigación in vivo, a } \\
\text { pesar de que las limitaciones de la técnica } \\
\text { deben ser reconocidas. }\end{array}$ \\
\hline $\begin{array}{l}\text { Martínez- } \\
\text { Insúa y } \\
\text { cols. }\end{array}$ & $\begin{array}{l}\text { Differences in bonding to } \\
\text { acid-etched or Er:YAG-laser- } \\
\text { treated enamel and dentin } \\
\text { surfaces. }\end{array}$ & 2000 & $\begin{array}{l}\text { La adhesión a los tejidos duros dentales } \\
\text { tras el grabado con láser de Er:YAG es } \\
\text { inferior a la obtenida con el grabado ácido } \\
\text { convencional. Las superficie de esmalte } \\
\text { preparada con este láser muestra fisuras } \\
\text { extensas, lo que no es favorable para la } \\
\text { adhesión. }\end{array}$ \\
\hline Lee y cols. & $\begin{array}{l}\text { Bond strengths of } \\
\text { orthodontic bracket after } \\
\text { acid-etched, Er:YAG laser- } \\
\text { irradiated and combined } \\
\text { treatment on enamel } \\
\text { surface. }\end{array}$ & 2003 & $\begin{array}{l}\text { La resistencia media a la adhesión de la } \\
\text { ablación con láser de ER:YAG no es muy } \\
\text { diferente de la del grabado ácido. Este láser } \\
\text { puede ser una alternativa al grabado ácido } \\
\text { convencional. }\end{array}$ \\
\hline $\begin{array}{l}\text { Dunn } \\
\text { cols. }\end{array}$ & $\begin{array}{l}\text { Shear bond strength and } \\
\text { SEM evaluation of composite }\end{array}$ & 2005 & $\begin{array}{l}\text { El grabado ácido obtiene mejores valores } \\
\text { de adhesión que el láser de Er:YAG.La } \\
\text { adhesión al esmalte grabado utilizando }\end{array}$ \\
\hline
\end{tabular}




\begin{tabular}{|c|c|c|c|}
\hline & $\begin{array}{l}\text { bonded to Er:YAG laser- } \\
\text { prepared dentin and enamel. }\end{array}$ & & $\begin{array}{l}\text { este láser es inferior a la que se produce } \\
\text { con el ácido ortofosfórico. }\end{array}$ \\
\hline $\begin{array}{l}\text { Gokcelik } \\
\text { cols. }\end{array}$ & $\begin{array}{l}\text { The influence of Er:YAG laser } \\
\text { conditioning versus self- } \\
\text { etching adhesives with acid } \\
\text { etching on the shear bond } \\
\text { strength of orthodontic } \\
\text { brackets. }\end{array}$ & 2007 & $\begin{array}{l}\text { Tanto el grabado ácido como el láser de } \\
\text { Er:YAG pueden ser empleados para la } \\
\text { adhesión de los brackets al esmalte. }\end{array}$ \\
\hline Berk y cols. & $\begin{array}{l}\text { Comparison of sandblasting, } \\
\text { laser irradiation, and } \\
\text { conventional acid etching for } \\
\text { orthodontic bonding of } \\
\text { molar tubes. }\end{array}$ & 2008 & $\begin{array}{l}\text { La irradiación con este láser con potencias } \\
\text { de } 1,5 \text { a } 2 \mathrm{~W} \text { puede ser utilizada en el } \\
\text { esmalte como alternativa al grabado ácido. }\end{array}$ \\
\hline $\begin{array}{l}\text { Hamamci y } \\
\text { cols. }\end{array}$ & $\begin{array}{l}\text { In vitro evaluation of } \\
\text { microleakage under } \\
\text { orthodontic brackets using } \\
\text { two different laser etching, } \\
\text { self etching and acid etching } \\
\text { methods. }\end{array}$ & 2010 & $\begin{array}{l}\text { La irradiación con láser de Er:YAG en el } \\
\text { esmalte crea una superficie heterogénea } \\
\text { con microcracks, al compararlo con el } \\
\text { grabado ácido. Puede ser una alternativa al } \\
\text { grabado ácido, pero se requieren más } \\
\text { estudios sobre la evaluación de la } \\
\text { microfiltración antes de usarlo como } \\
\text { acondicionador del esmalte. }\end{array}$ \\
\hline $\begin{array}{l}\text { Başaran } \\
\text { cols. }\end{array}$ & $\begin{array}{l}\text { Shear bond strength of } \\
\text { bonding to enamel with } \\
\text { different laser irradiation } \\
\text { distances }\end{array}$ & 2011 & $\begin{array}{l}\text { Con el láser de Er:YAG se produce menor } \\
\text { fuerza de adhesión que con el grabado } \\
\text { ácido. La distancia de irradiación con láser } \\
\text { influye en la fuerza de adhesión. }\end{array}$ \\
\hline $\begin{array}{l}\text { Lasmar } \\
\text { cols. }\end{array}$ & $\begin{array}{l}\text { Enamel demineralization and } \\
\text { bracket bond strength when } \\
\text { etching with acid and /or } \\
\text { Er:YAG laser }\end{array}$ & 2012 & $\begin{array}{l}\text { El acondicionamiento con láser de Er:YAG } \\
\text { produce valores de adhesión inferiores al } \\
\text { grabado ácido, pero son suficientes para } \\
\text { generar una retención eficiente. La mayor } \\
\text { retención se produce cuando se combina el } \\
\text { láser de Er:YAG y el ácido. }\end{array}$ \\
\hline $\begin{array}{l}\text { Türköz } \\
\text { cols. }\end{array}$ & $\begin{array}{l}\text { Evaluation of different } \\
\text { enamel conditioning } \\
\text { techniques for orthodontic } \\
\text { bonding. }\end{array}$ & 2012 & $\begin{array}{l}\text { Los grupos acondicionados con láser y } \\
\text { grabado ácido obtuvieron los mayores } \\
\text { valores de adhesión. Aunque el } \\
\text { acondicionamiento con láser proporciona } \\
\text { altos valores de adhesión, el proceso } \\
\text { genera mayor daño para el diente. Las } \\
\text { técnicas de grabado ácido y de } \\
\text { autograbado parecen ser más seguras para } \\
\text { la adhesión de brackets. }\end{array}$ \\
\hline
\end{tabular}

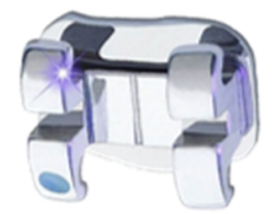




\subsubsection{Láser de pulsos ultracortos}

\section{CARACTERÍSTICAS.}

Al igual que el láser de Er:YAG, los láseres de pulsos ultracortos aprovechan la emisión estimulada de un medio activo sólido. En el caso del que se ha utilizado en esta tesis, el medio activo es un cristal de zafiro $\left(\mathrm{Al}_{2} \mathrm{O}_{3}\right)$ dopado con Titanio (Ti:Zafiro). La diferencia con el Er:YAG y con otros láseres de estado sólido convencionales reside en la duración de los pulsos que se obtienen, considerándose como pulsos ultracortos todos aquéllos cuya duración es inferior al picosegundo, por razones que veremos en el siguiente apartado.

Aunque la emisión del Ti:Zafiro es sintonizable en la banda del espectro entre 650 y $1100 \mathrm{~nm}$, la mayor eficiencia de emisión se obtiene en torno a los $800 \mathrm{~nm}$. El bombeo del Ti:Zafiro se realiza mediante otros láseres que emitan entre 514-532 nm donde el cristal tiene el mayor coeficiente de absorción, por lo que se emplean bien láseres de ión Argón (514.5 nm) o bien láseres de estado sólido como Nd:YAG, Nd:YLF o Nd:YVO (527-532 nm).

La emisión de un láser de Ti:Zafiro es poco energética, siendo la energía obtenida por pulso del orden de los nanojulios a una tasa de repetición de decenas de MHz. Aunque útiles para muchas otras aplicaciones tecnológicas, estas energías de pulso son insuficientes para provocar la ablación de los materiales por lo que la salida pulsada de estos láseres se ve sometida a continuación a un proceso de amplificación de la energía de una fracción de los pulsos que emite. Es lo que se conoce como amplificación regenerativa tipo CPA (Chirped Pulse Amplification) que fue desarrollada a finales de los años ochenta por G. Mourou y su equipo (Strickland y cols., 1985), (ver esquema de la Figura 9), proceso por el cual se seleccionan en una cavidad óptica un número reducido de pulsos de la emisión del oscilador de 
Capítulo 1: Introducción

Ti:Zafiro (normalmente mil cada segundo), se hacen pasar por una red de difracción que los estira en el tiempo convirtiéndolos en pulsos de algunos nanosegundos y entonces, mediante un láser de bombeo de gran potencia, se irradia otro cristal de Ti:Zafiro por el que pasan los pulsos aumentando su energía hasta el orden de los milijulios. Finalmente, los pulsos ya amplificados se hacen pasar por otra red de difracción que acorta su duración para convertirlos de nuevo en pulsos de duración por debajo del picosegundo.

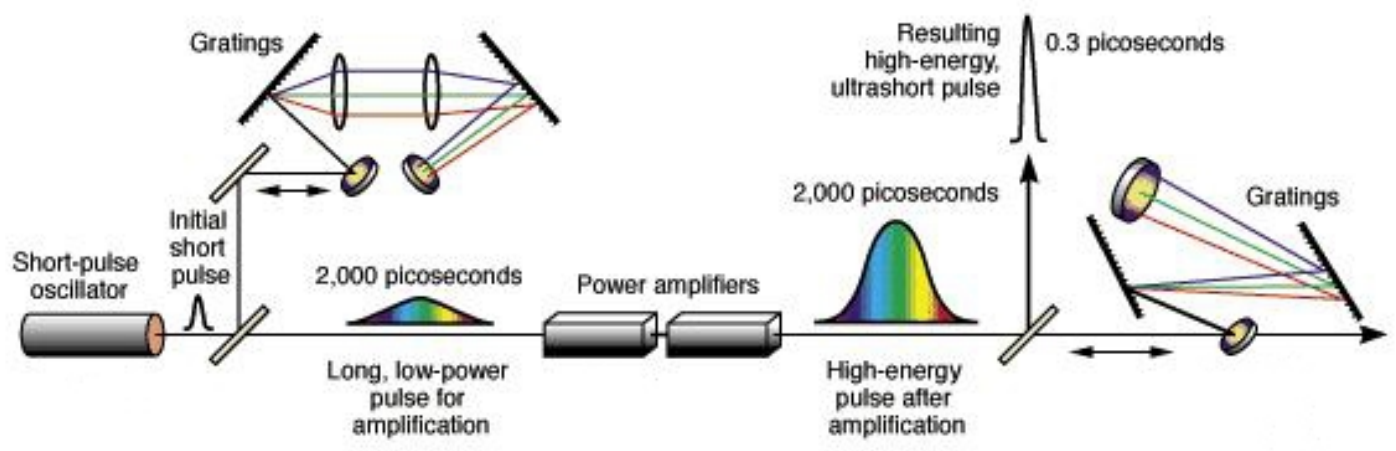

Figura 9: Representación esquemática de la técnica de amplificación regenerativa de pulsos ultracortos CPA (Chirped Pulse Amplification).

La razón fundamental para seguir esta estrategia de amplificación es que los elementos ópticos necesarios para conducir los pulsos ultracortos en la cavidad amplificadora se dañan o destruyen si se amplifican directamente esos pulsos, debido a la altísima concentración de energía que se produciría en el tiempo.

En la presente tesis, se utilizó el sistema de pulsos ultracortos ubicado en el sótano del Edificio Trilingüe perteneciente a la Facultad de Ciencias de la Universidad de Salamanca. Este equipo es mantenido y utilizado por personal de los Grupos de Investigación en Óptica Extrema y de Microprocesado de Materiales con Láser de la Universidad de Salamanca para sus propias investigaciones y para dar servicio

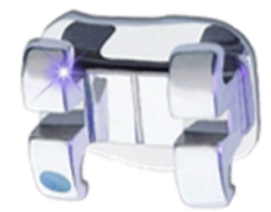


tecnológico a empresas, centros tecnológicos y grupos de investigación tanto nacionales como extranjeros (Figura 10).

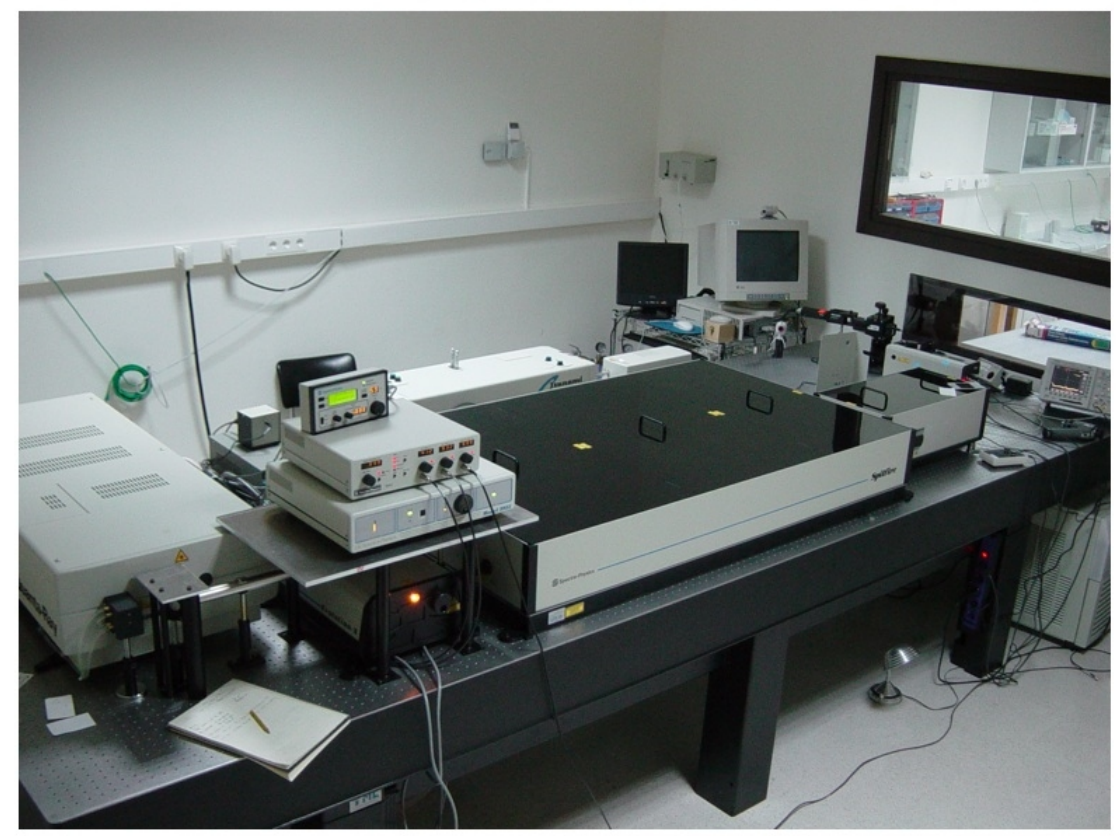

Figura 10: Sistema de pulsos láser ultracortos de la Universidad de Salamanca.

El sistema consiste en un oscilador de Ti:Zafiro de la firma Spectra Physics, modelo Tsunami (Figura 11) que, bombeado por un láser de Nd:YVO de Spectra Physics, modelo Millennia, genera pulsos de un centenar de femtosegundos $\left(1 \mathrm{fs}=10^{-15} \mathrm{~s}\right)$, con longitudes de onda en el infrarrojo cercano (795 nm) y energías del orden de los 10 nanojulios, con una tasa de repetición del orden de $80 \mathrm{MHz}$ (es decir, 80 millones de pulsos por segundo). 
Capítulo 1: Introducción

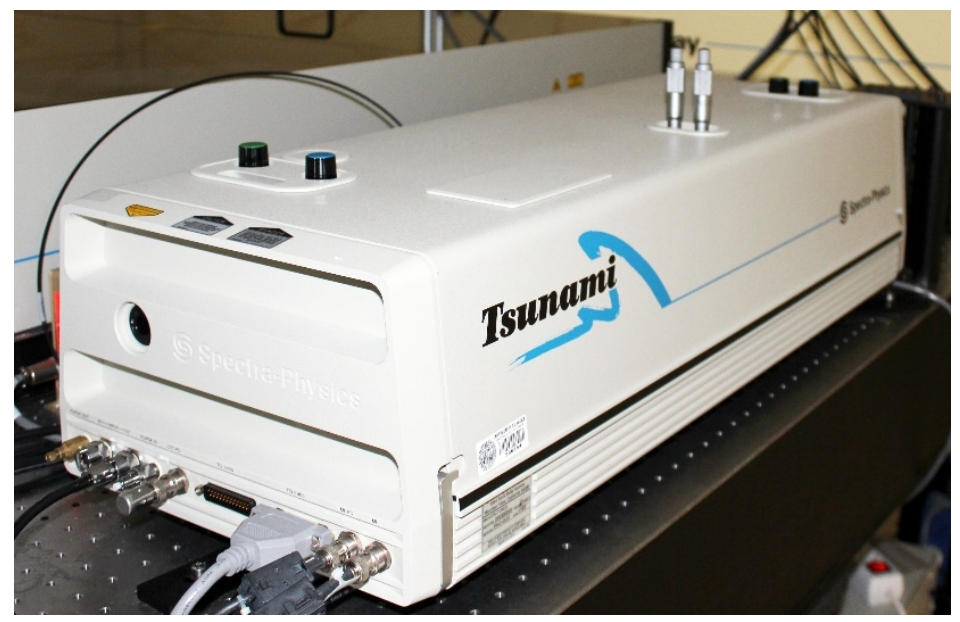

Figura 11: Oscilador de Ti:zafiro.

El sistema de amplificación de los pulsos es el modelo Spitfire de la misma firma, Spectra Physics (Figura 12), que emplea como bombeo para la amplificación un láser de Nd:YLF, modelo Evolution X (Figura 13). El resultado es una salida de pulsos de unos 120 fs con energías máximas por pulso de $1 \mathrm{~mJ}$ y una tasa de repetición de $1 \mathrm{kHZ}$, que son los que se utilizan para el procesado de materiales.

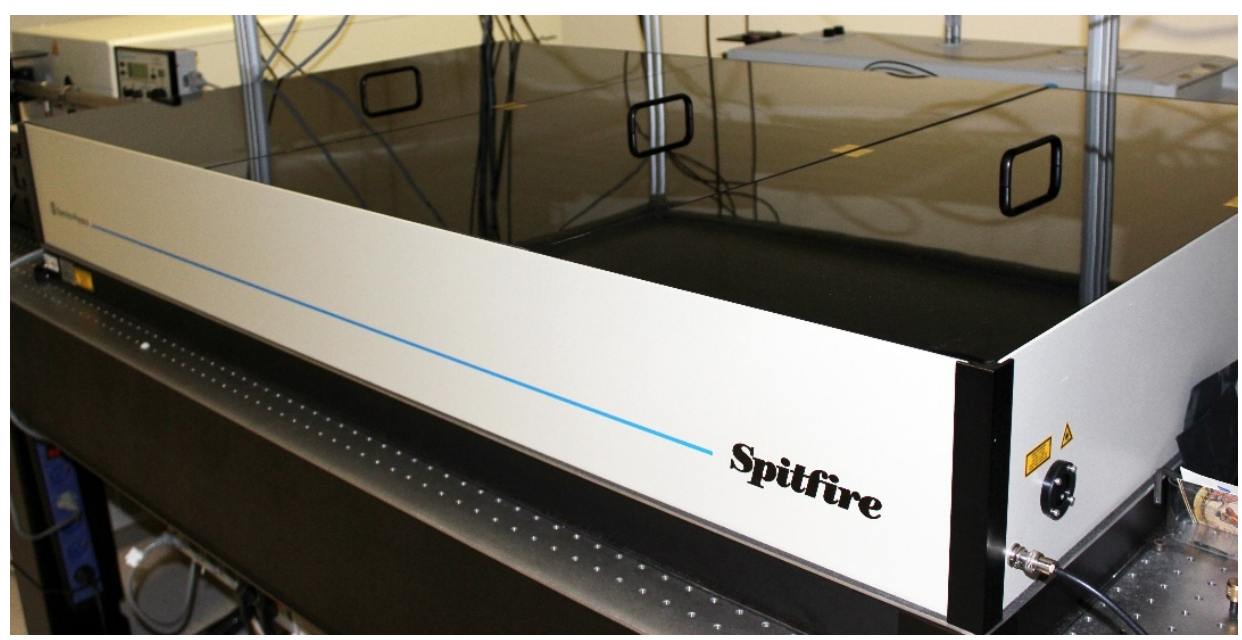

Figura 12: Sistema de amplificación de pulsos.

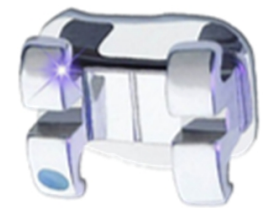




\section{VNiVERSiDAD}

BSALAMANCA

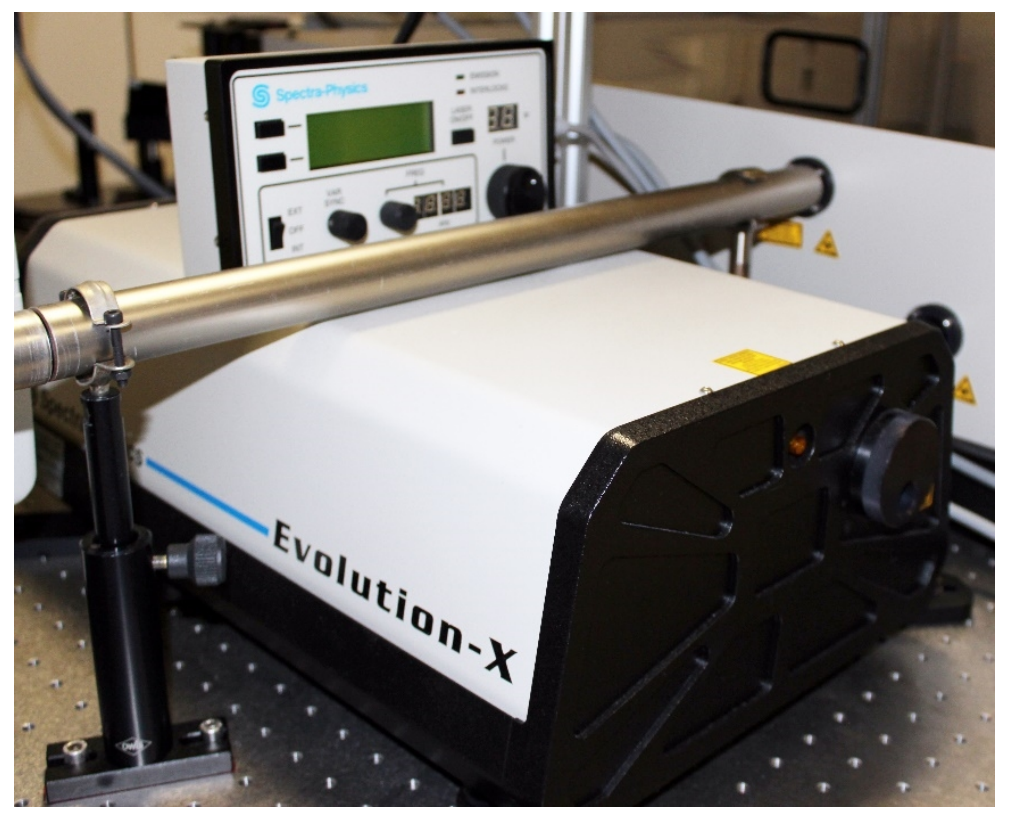

Figura 13: Láser de bombeo del amplificador regenerativo. Laser de Nd:YLF.

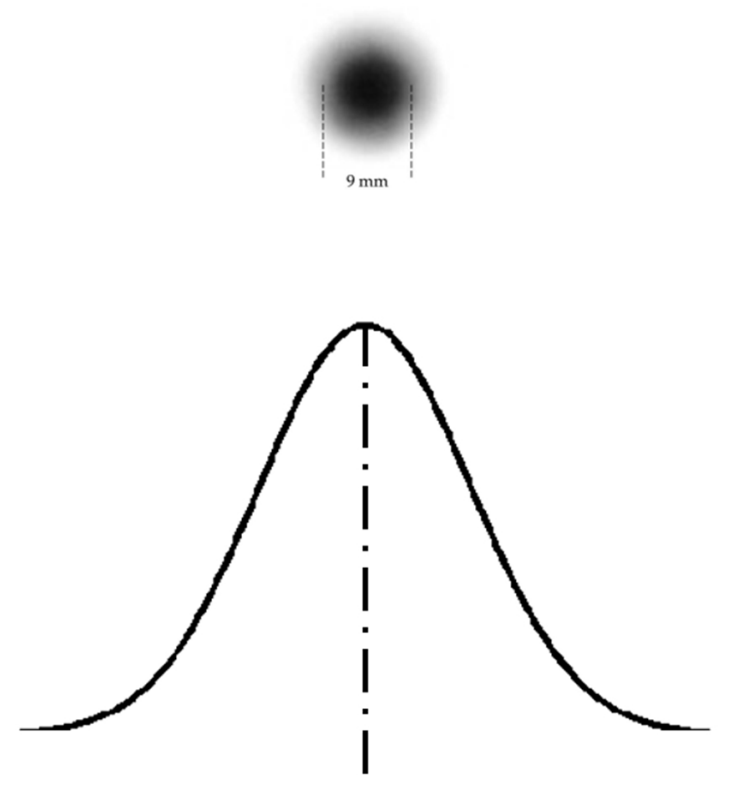

Figura 14: Distribución transversal de la energía de tipo gaussiana (modo transversal TEM00). 
Capítulo 1: Introducción

Los pulsos salen del sistema de amplificación con polarización lineal (el campo de eléctrico oscila en una dirección determinada del espacio), siendo la distribución transversal de energía de tipo gaussiana (modo transversal TEM00), con una anchura del haz de unos 9 mm (Figura 14).

Dado que la energía de los pulsos ultracortos es excesiva para la ablación de cualquier material, se emplean dos métodos para reducir y controlar de forma precisa esa energía. Por un lado, se produce una reducción basta de la energía mediante el empleo de filtros neutros para, a continuación, emplear una combinación de lámina de media onda y polarizador lineal para realizar el ajuste fino de la energía

(Figura 15).

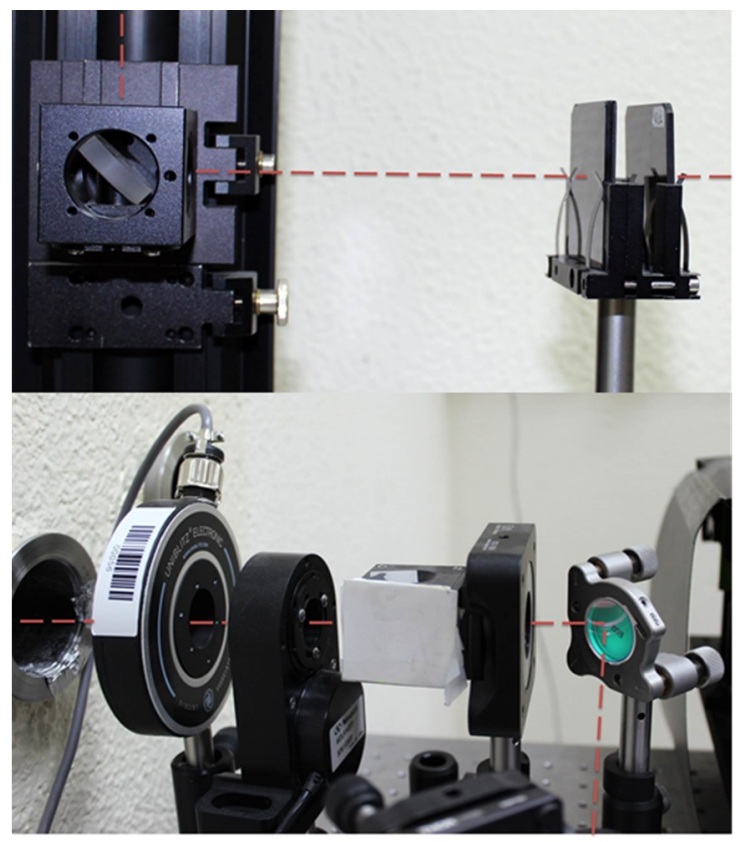

Figura 15: Sistemas de reducción de energía de los pulsos ultracortos. Arriba: Filtros neutros para reducciones bastas. Abajo: Sistema de lámina de media onda y polarizador para ajuste fino.

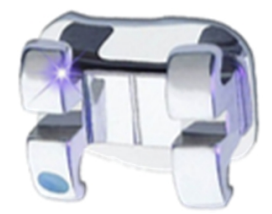




\section{VNIVERSIDAAD \\ BSALAMANCA}

En la Figura 15 se observa, de arriba a abajo a) espejo y filtros neutros b) obturador mecánico, lámina lambda medios y polarizador lineal y espejo

Los pulsos láser viajan a través del aire y con la ayuda de espejos con recubrimientos específicos (Figura 16) tanto para la intensidad como para la longitud de onda de estos pulsos, se conducen hasta el sistema de focalización. En este caso, la transmisión por fibra óptica está vedada como consecuencia de la alta intensidad de los pulsos que dañaría la fibra.

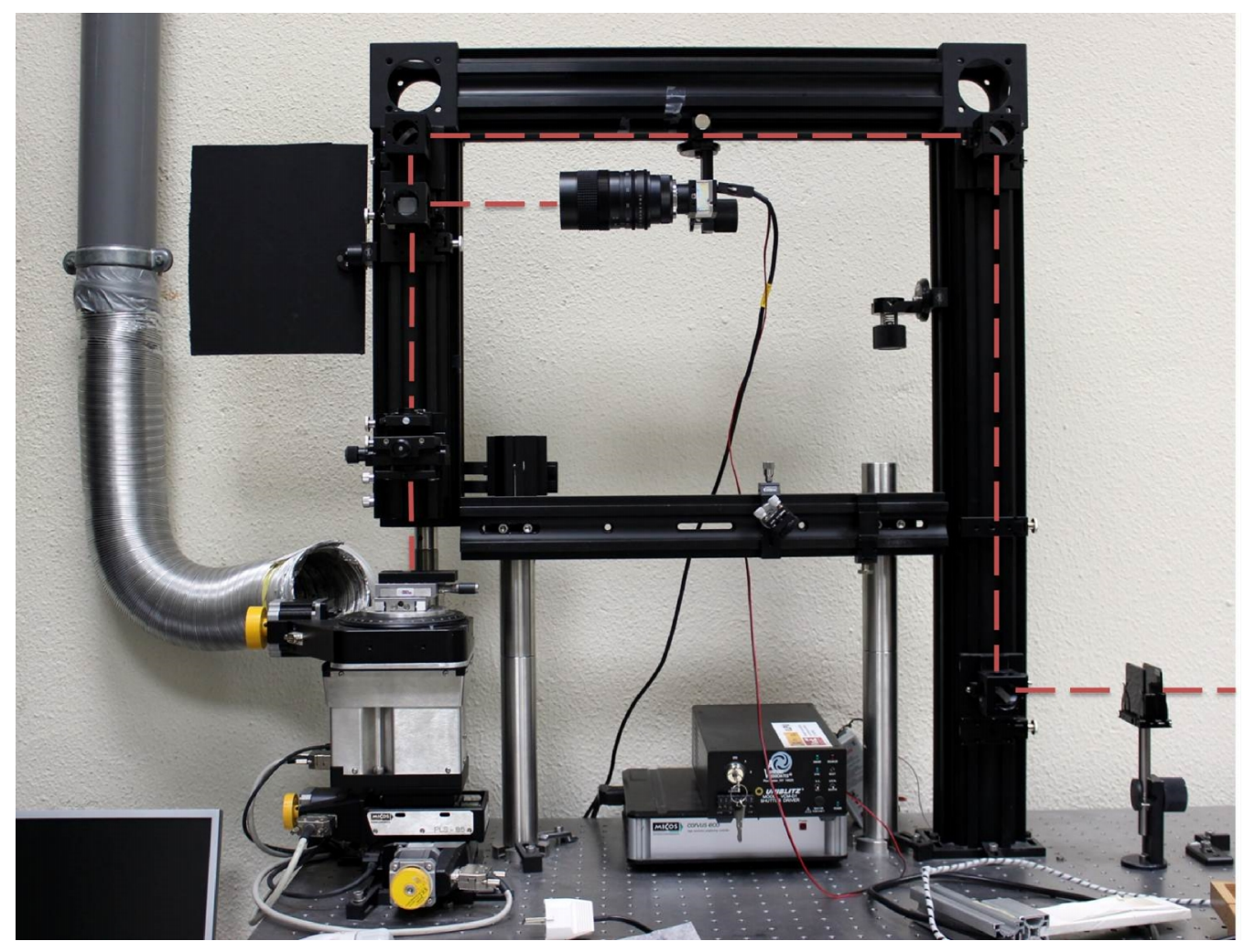

Figura 16: Visión general del banco de microprocesado.

El sistema de focalización está constituido por la lente de focalización y la óptica para la visualización de la zona de procesado (Figura 17). En cuanto a esta última consiste en un divisor de haz y una cámara CCD Philips Luca (Figura 18) que 
Capítulo 1: Introducción

permite recoger fuera del eje óptico la imagen de la superficie a procesar, facilitando el posicionamiento de la muestra y la focalización del haz.

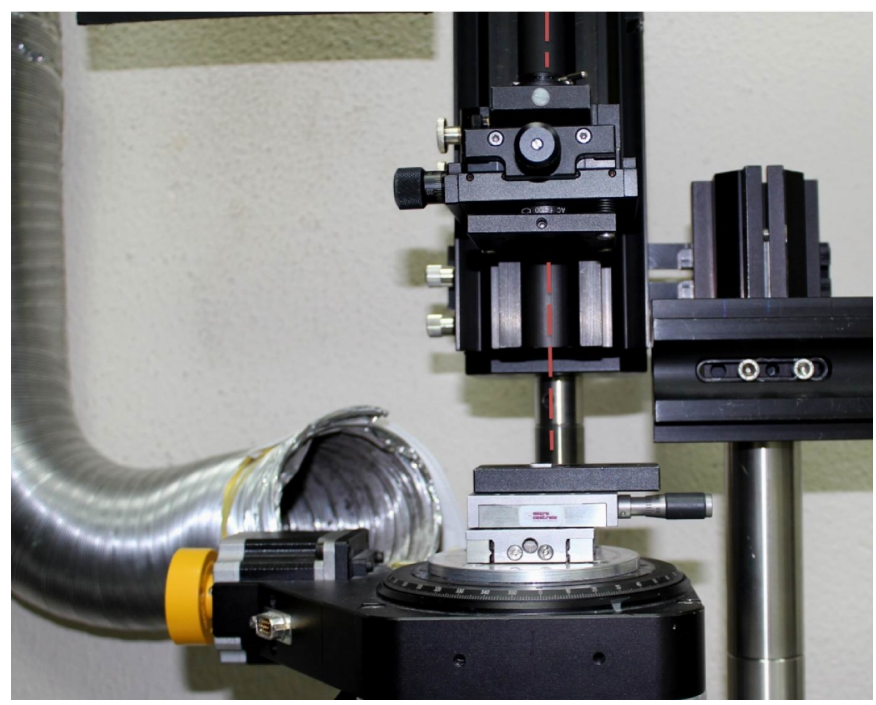

Figura 17: Sistema de focalización y emplazamiento de la muestra.

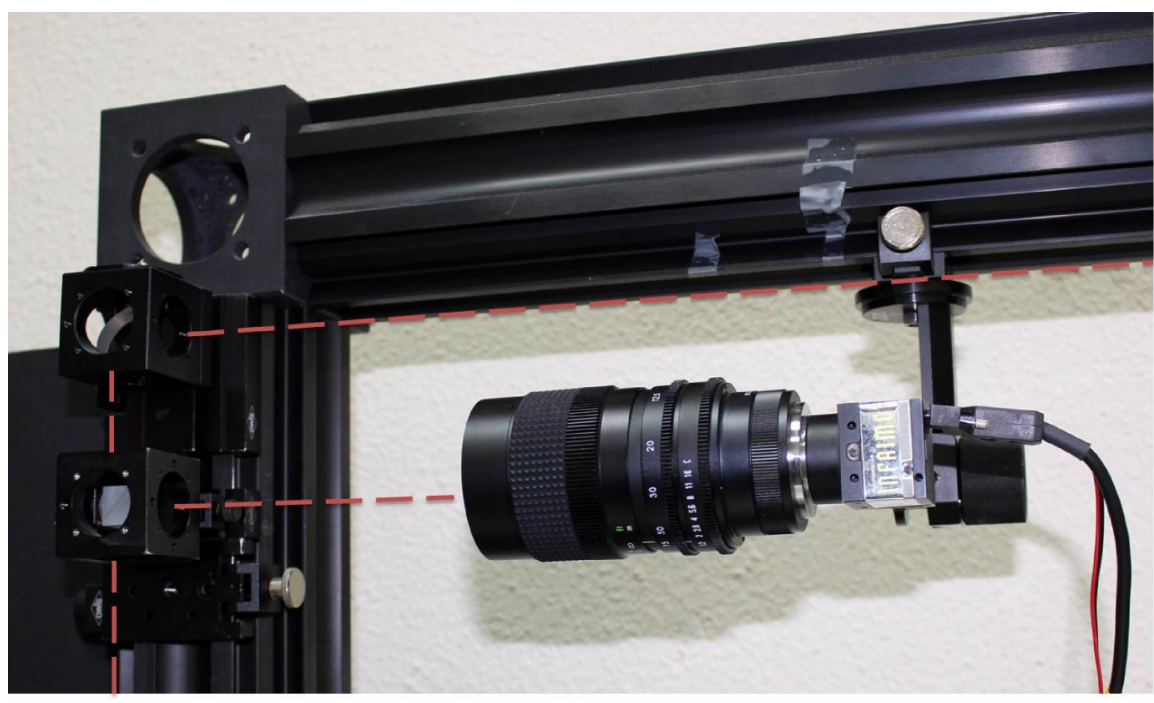

Figura 18: Sistema de visualización y enfoque. Espejo (arriba), divisor de haz y cámara CCD.

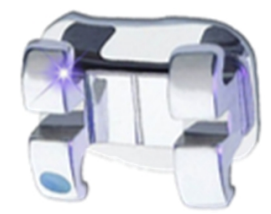




\section{VNIVERSIDAD}

BSALAMANCA

La lente de focalización es también específica, tanto para la longitud de onda, como para la duración de los pulsos y la densidad de energía a utilizar. En este caso, se emplea un doblete acromático cuya distancia focal es de 100 mm y se sitúa con el eje óptico perpendicular a la mesa óptica. La profundidad de foco de esta lente es de algunos milímetros, lo que permite mantener una densidad de energía uniforme en espesores grandes, facilitando así la ablación controlada de los materiales.

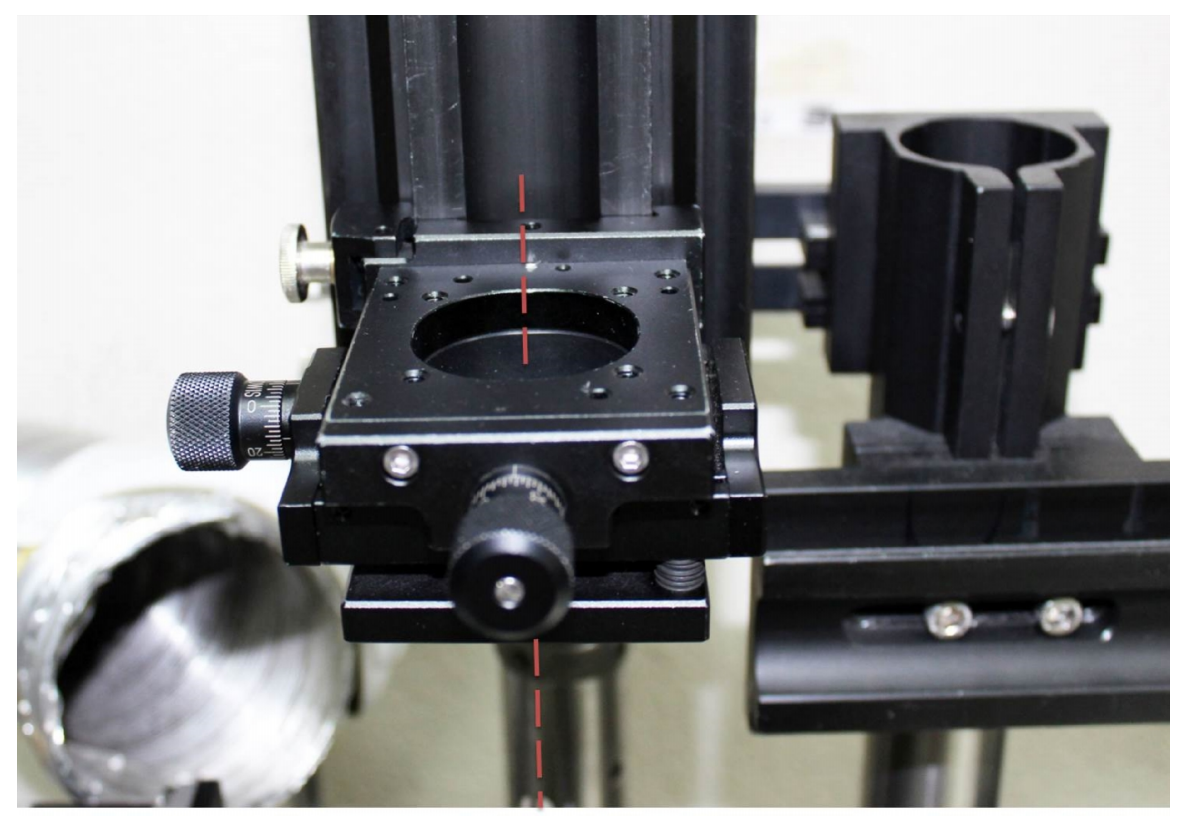

Figura 19: Sistema de focalización (doblete acromático).

Las muestras se sitúan sobre una mesa con desplazamiento motorizado controlado por software en los tres ejes XYZ Micos ES100 de Nanotec, de forma que los pulsos inciden perpendicularmente a la superficie de la muestra (Figura 20). Los movimientos horizontales XY permiten barrer en superficie mientras que el movimiento Z permitirá la focalización de los pulsos exactamente en la superficie de las muestras. 


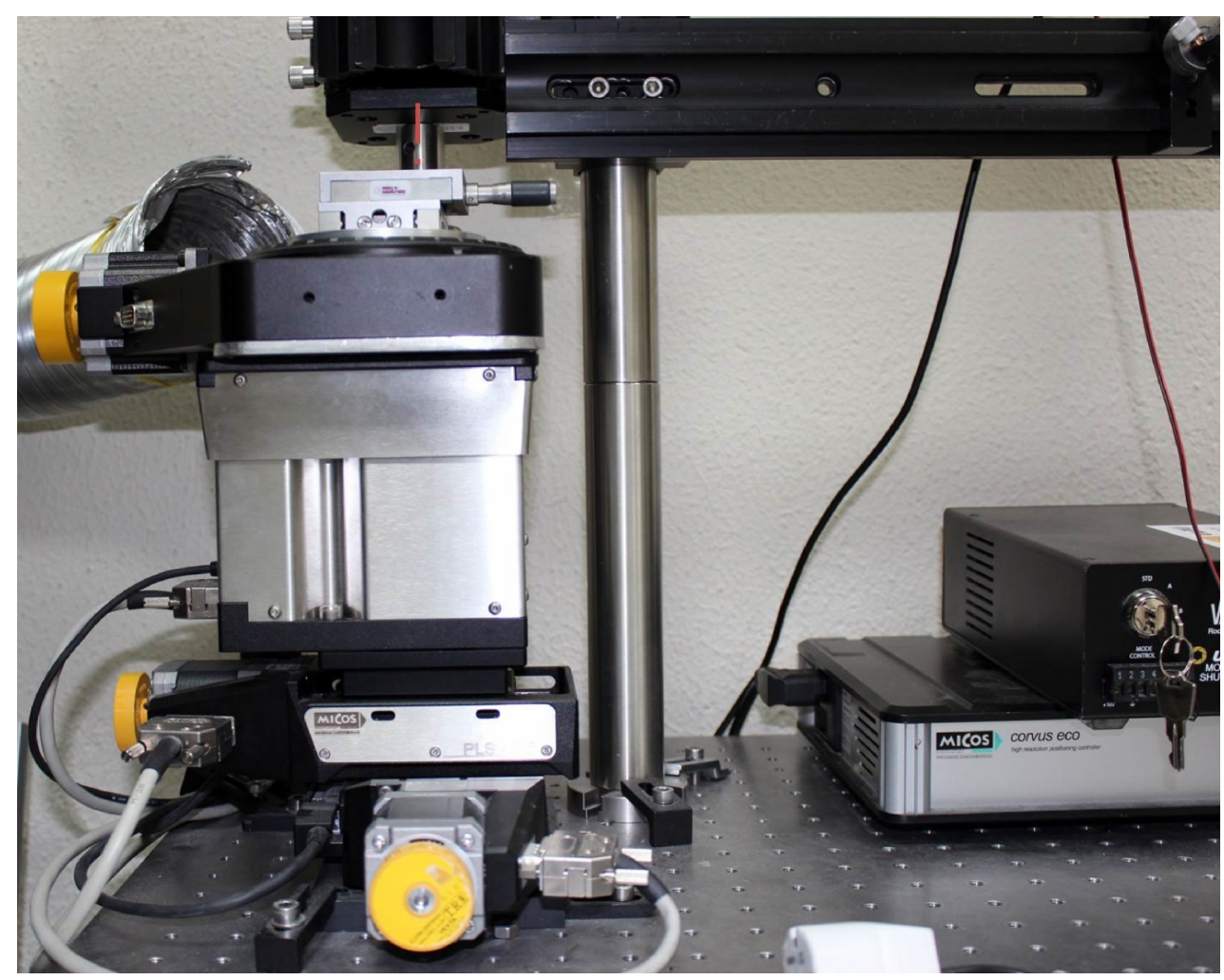

Figura 20: Sistema de posicionamiento de la muestra XYZ.

En el caso en el que la geometría de las microestructuras son poros de gran diámetro y/o gran profundidad, hay que adoptar estrategias específicas para su realización (Figura 21). Si nos limitamos a hacer incidir pulsos en el mismo punto de la superficie obtendremos cráteres cuyo diámetro vendrá limitado por el tamaño del punto focal de la lente, quien a su vez, depende proporcionalmente del diámetro del haz a la entrada de la lente y de la distancia focal de la misma. En el caso de la lente de focalización empleada estaríamos hablando de poros de diámetro del orden de las 75 micras para la máxima energía de pulso disponible.

Por otra parte, la profundidad máxima alcanzable con esta estrategia de percusión está limitada debido al efecto de saturación del poro (tapering), siendo difícil superar

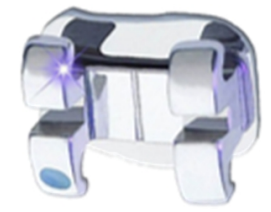


las 100 micras de profundidad para energías de pulso muy elevadas (Vázquez de Aldana y cols., 2005).
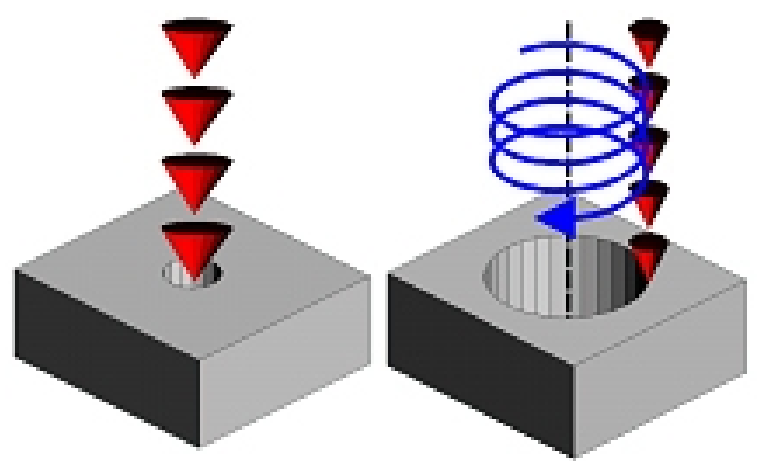

Figura 21: Esquema de percusión y trepanado.

Para producir diámetros como los requeridos en el estudio de preparación cavitaria, del orden de 500 micras, se adoptó la estrategia de trepanado, consistente en hacer incidir los pulsos láser no sobre un punto fijo de la superficie, sino a lo largo de una circunferencia del diámetro deseado. Esto, en piezas de pequeño espesor es capaz de producir agujeros pasantes a través de la muestra. No obstante, esta estrategia no solventa el problema de la saturación y además, en el caso de agujeros ciegos, no permite obtener un poro de fondo plano. En cuanto al problema de la saturación, en esta aplicación no tiene importancia en principio, ya que es incluso deseable que el poro tenga cierta geometría cónica para facilitar su observación al microscopio. En cuanto al problema del fondo plano, se ha hecho una variante del trepanado consistente en que la curva a describir por el haz sobre la superficie sea una espiral o una sucesión de circunferencias concéntricas en lugar de una simple circunferencia.

Para llevar a cabo esta estrategia se ha empleado el sistema de trepanado óptico del Grupo de Microprocesado de Materiales con Láser de la Universidad de Salamanca (Figura 22). Consiste en un conjunto de cuñas ópticas desplazables a lo largo del 
Capítulo 1: Introducción

eje óptico de modo que se puede lograr que el haz incida sobre la superficie de la muestra con una inclinación de hasta $4^{\circ}$ y una excentricidad de hasta 200 micras. A la vez, las cuñas giran a velocidades hasta las $3000 \mathrm{rpm}$, lo que permite producir el efecto deseado.

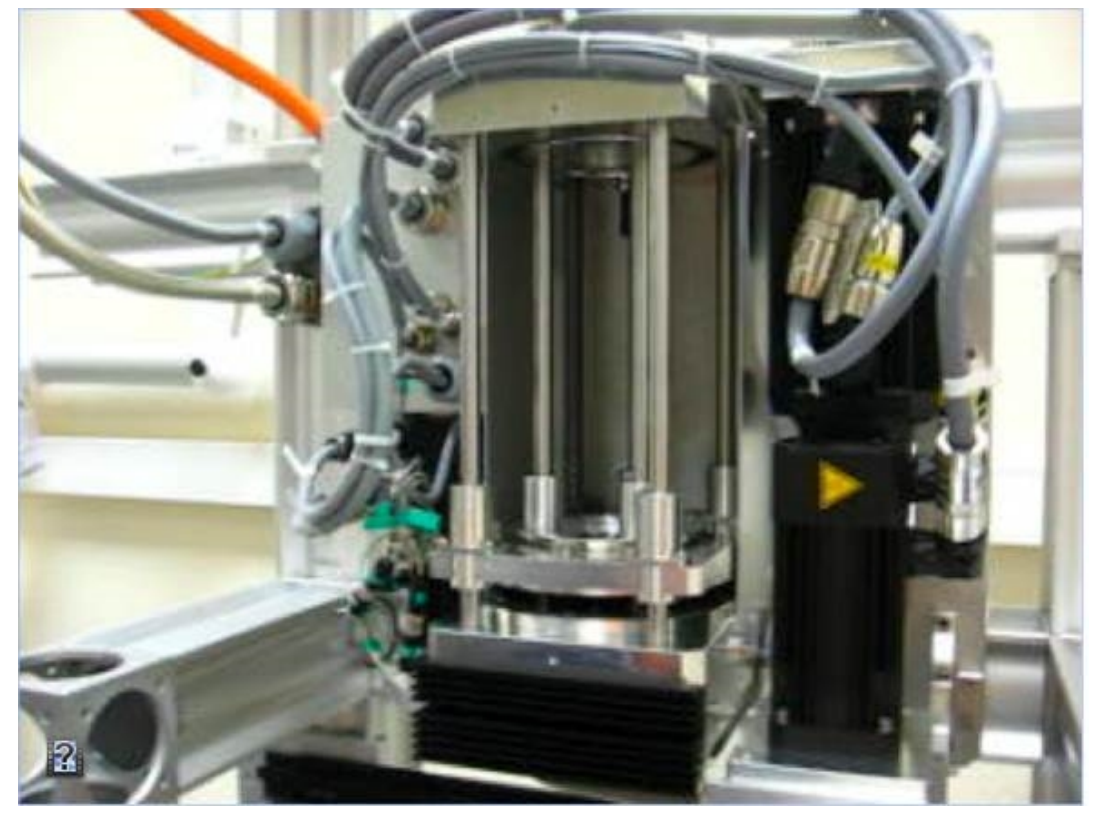

Figura 22: Sistema de trepanado óptico del Grupo de Microprocesado de Materiales con Láser de la Universidad de Salamanca.

\section{INTERACCIÓN CON LA MATERIA.}

El mecanismo de interacción de los pulsos ultracortos con la materia es radicalmente diferente al de los láseres convencionales, como el Er:YAG, lo que hace que a su vez la forma de producirse la ablación de los materiales y los efectos colaterales que genera sean también radicalmente diferentes.

La interacción de estos pulsos ultracortos con distintos materiales ha sido objeto de numerosos estudios en los últimos años (Bloembergen, 1974; Pronko y cols., 1995; Stuart y cols., 1995; Momma y cols., 1996; Stuart y cols., 1996; Chichkov y cols.,

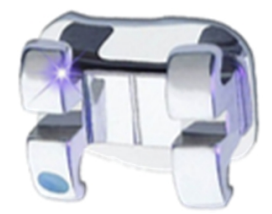


1996; Varel y cols., 1997; Nolte y cols., 1997; Hertel y cols., 2001; Gamaly y cols., 2002). Para este trabajo de investigación nos centraremos en describir el proceso de interacción que conduce a la remoción de material, lo que se conoce como ablación ultrarrápida. Este fenómeno requiere no solamente que los pulsos sean ultracortos sino que además sean capaces de depositar la energía suficiente por unidad de superficie del material.

En el caso de los láseres convencionales, los electrones absorben la energía de los pulsos solamente si la frecuencia del campo electromagnético (básicamente, el inverso de la longitud de onda) coincide con la diferencia de energía entre niveles energéticos del átomo o de la molécula, diciéndose en este caso que el electrón absorbe un cuanto de luz, un fotón. Si no es así, no se absorbe. Esto hace que el parámetro fundamental para que se produzca la absorción lineal de la radiación de, por ejemplo, el láser de Er:YAG, sea la longitud de onda. En ese caso, la intensidad (potencia por unidad de superficie) o fluencia (energía depositada por unidad de superficie) solamente influyen en la cantidad de energía que pueden absorber esos electrones, lo que determina la amplitud de su movimiento oscilatorio provocado por el campo electromagnético, que luego transmiten a la red cristalina calentándola. De esa forma, a mayor intensidad, mayor temperatura se alcanza en la zona irradiada o más rápido se alcanza una determinada temperatura.

En el caso que nos ocupa, cuando los pulsos ultracortos inciden sobre los materiales, su energía es igualmente absorbida por los electrones de los átomos y moléculas de la capa superficial del material. Produciéndose también la absorción lineal de la radiación con la consabida dependencia de la longitud de onda, en el caso de estos pulsos, si la intensidad o fluencia tienen un valor suficientemente alto (por encima de lo que se conoce como umbral) entonces los electrones pueden absorber más de 
Capítulo 1: Introducción

un fotón para promocionarse a niveles energéticos superiores. En este caso, existiendo también dependencia con la longitud de onda, el factor fundamental para que el fenómeno se produzca es que la intensidad sea lo suficientemente alta, es decir que haya muchos fotones disponibles para ser absorbidos por los electrones. Ocurre entonces que cualquier material puede absorber la energía de estos pulsos ultracortos y la absorción será más intensa cuanto mayor sea la intensidad de los pulsos, y todo ello teniendo lugar en una fracción de tiempo inferior a la ya de por sí reducida duración de los pulsos.

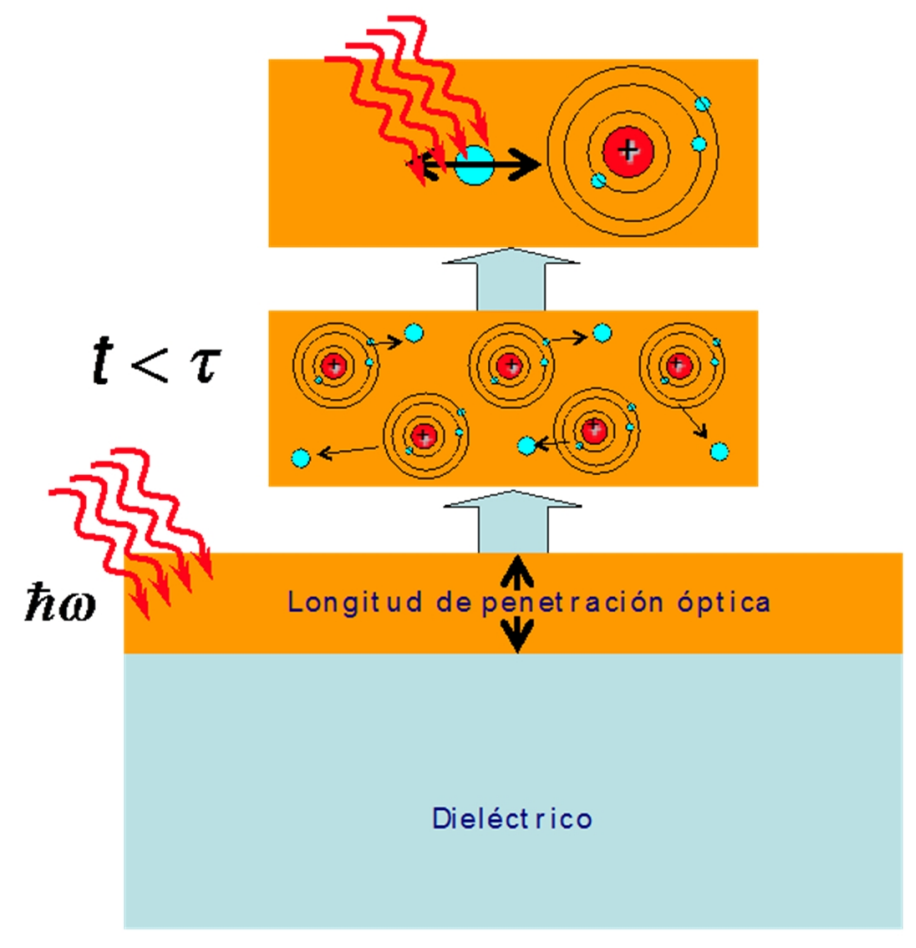

Figura 23: Representación esquemática del proceso de absorción y de ionización multifotónica de un material dieléctrico.

En la Figura 23 (Cortesía del Grupo de Microprocesado de Materiales con Láser), se presenta el proceso de absorción y de ionización multifotónica de un material dieléctrico como el esmalte cuando sobre él inciden pulsos ultracortos intensos.

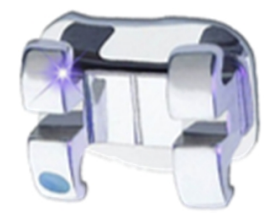


De esta manera, si la intensidad es lo suficientemente alta se puede producir el hecho de que algunos de los electrones realizando movimientos oscilatorios de enorme amplitud en el seno del campo electromagnético del láser, acaben dejando de estar ligados a los iones, convirtiéndose en electrones libres, en el proceso que se conoce como ionización multifotónica. Estos electrones seguirán experimentando la acción del campo mientras dure el pulso de forma que en su movimiento oscilatorio pueden, por colisión, provocar que otros electrones débilmente ligados a los iones, acaben a su vez desligados. De esta forma en el transcurso del tiempo en que el pulso interactúa con el material superficial, nos encontraremos con que disponemos de un número muy elevado de electrones libres que además migran a la superficie del material (como en los metales).

Si el número de electrones libres es muy elevado, del orden del número de iones, entonces la atracción eléctrica sobre los iones unida a la repulsión entre iones cargados positivamente provocará que se rompan los enlaces que mantienen unidos los iones siendo expulsados de la zona de procesado como un plasma a alta velocidad, como también sucede con el plasma de electrones libres. Todo este proceso tiene lugar en un intervalo de tiempo no mucho mayor que la duración de los pulsos (Chen y cols., 1999). 
Capítulo 1: Introducción

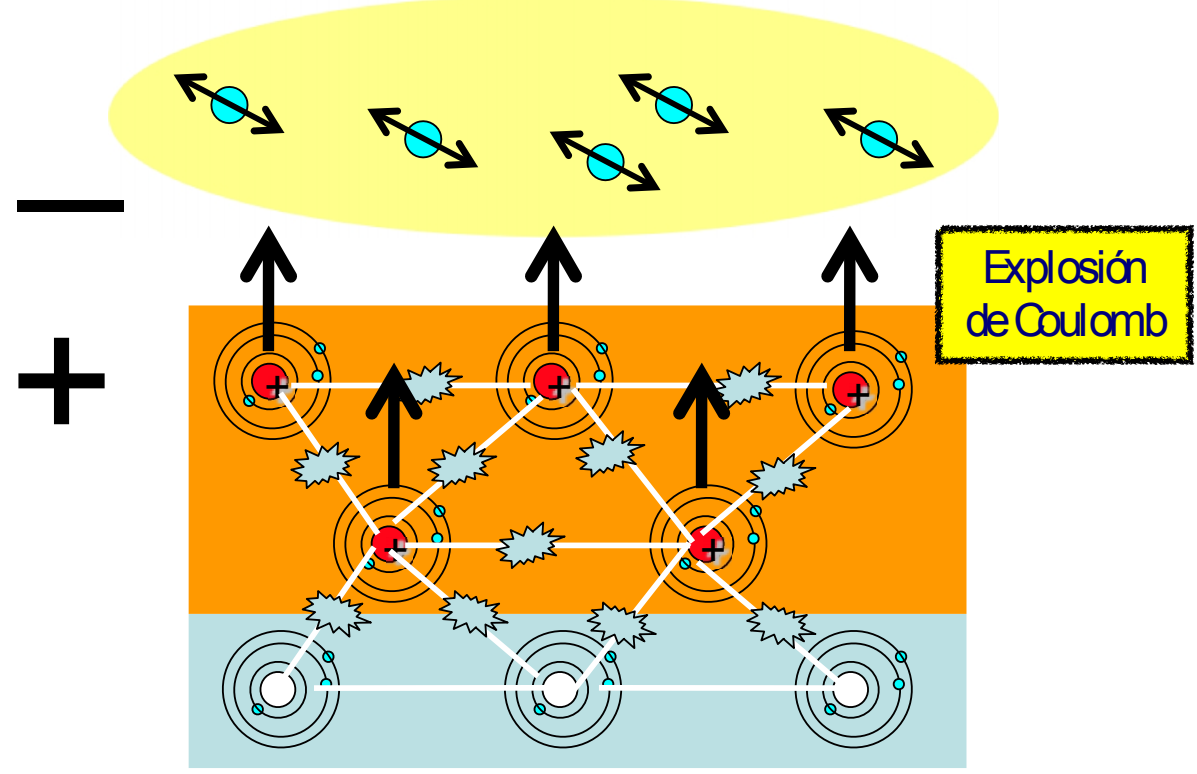

Figura 24: Representación esquemática del proceso de ablación por explosión de

Coulomb (Cortesía del Grupo de Microprocesado de Materiales con Láser).

Como el promedio de tiempo que tarda un electrón en ceder su energía a la red cristalina es mayor del picosegundo para cualquier material (varía desde pocos ps a los cientos de ps según el material) resulta entonces que el proceso de absorción, ionización y eyección del material tiene lugar sin que haya habido prácticamente transmisión de energía a la red cristalina y, por tanto, no se produce incremento de temperatura ni transmisión de calor al material que rodea a la zona procesada. Se trata de un proceso de ablación de naturaleza intrínsecamente no térmica conocido como explosión de Coulomb.

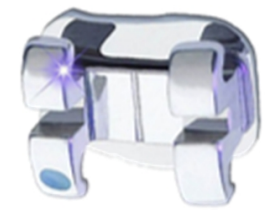




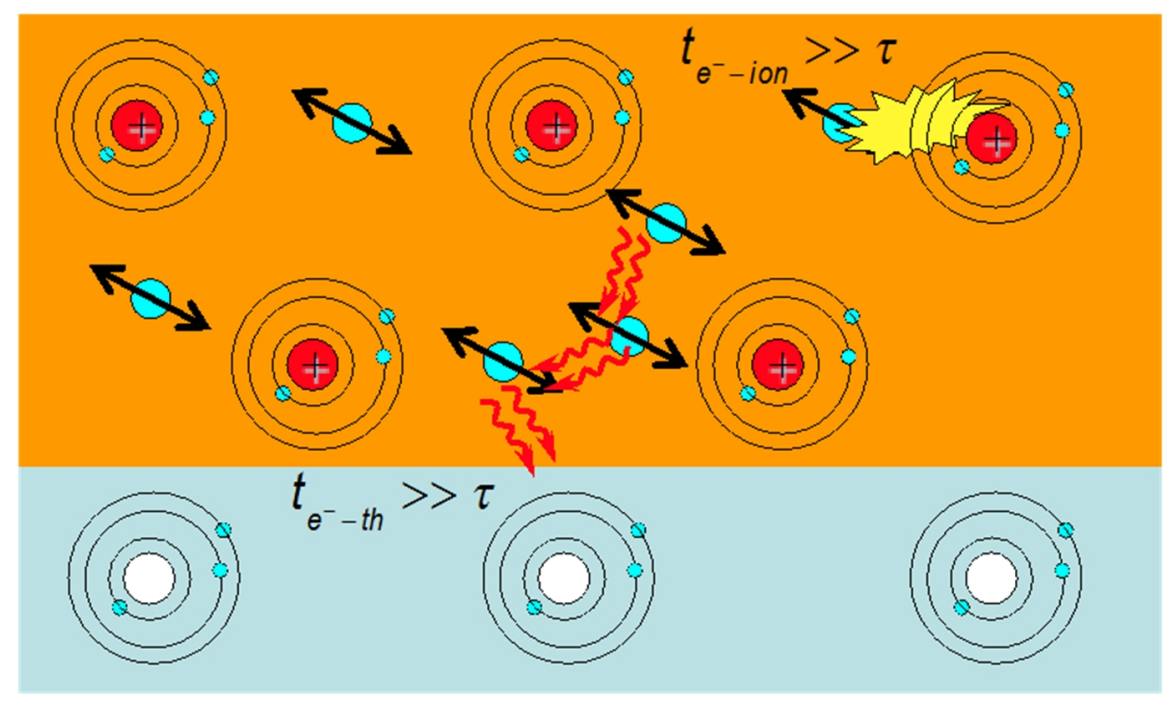

Figura 25: Procesos de cesión de energía de los electrones a la red cristalina por colisión y de termalización electrónica.

En la Figura 25 (Cortesía del Grupo de Microprocesado de Materiales con Láser), se presenta una representación esquemática de los procesos de cesión de energía de los electrones a la red cristalina por colisión y de termalización electrónica. Ambos procesos tienen una probabilidad muy baja de ocurrir en un tiempo inferior a la duración de los pulsos ultracortos,

No obstante, hay que señalar que este proceso de ablación no térmico no es la única forma de eliminar el material de la superficie mediante estos pulsos ultracortos. De hecho, en cuanto la intensidad supera el umbral para que se desencadene la ionización no lineal, este proceso coulombiano, cuya tasa de eliminación de material es muy baja, empieza a competir con otro, ya de naturaleza térmica, conocido como explosión de fase. En efecto, cuando la intensidad de los pulsos se eleva, el número de electrones libres que se generan es también muy elevado y éstos siguen absorbiendo más y más energía hasta un punto en que empiezan a radiar esa energía en todas direcciones y de forma incoherente. 


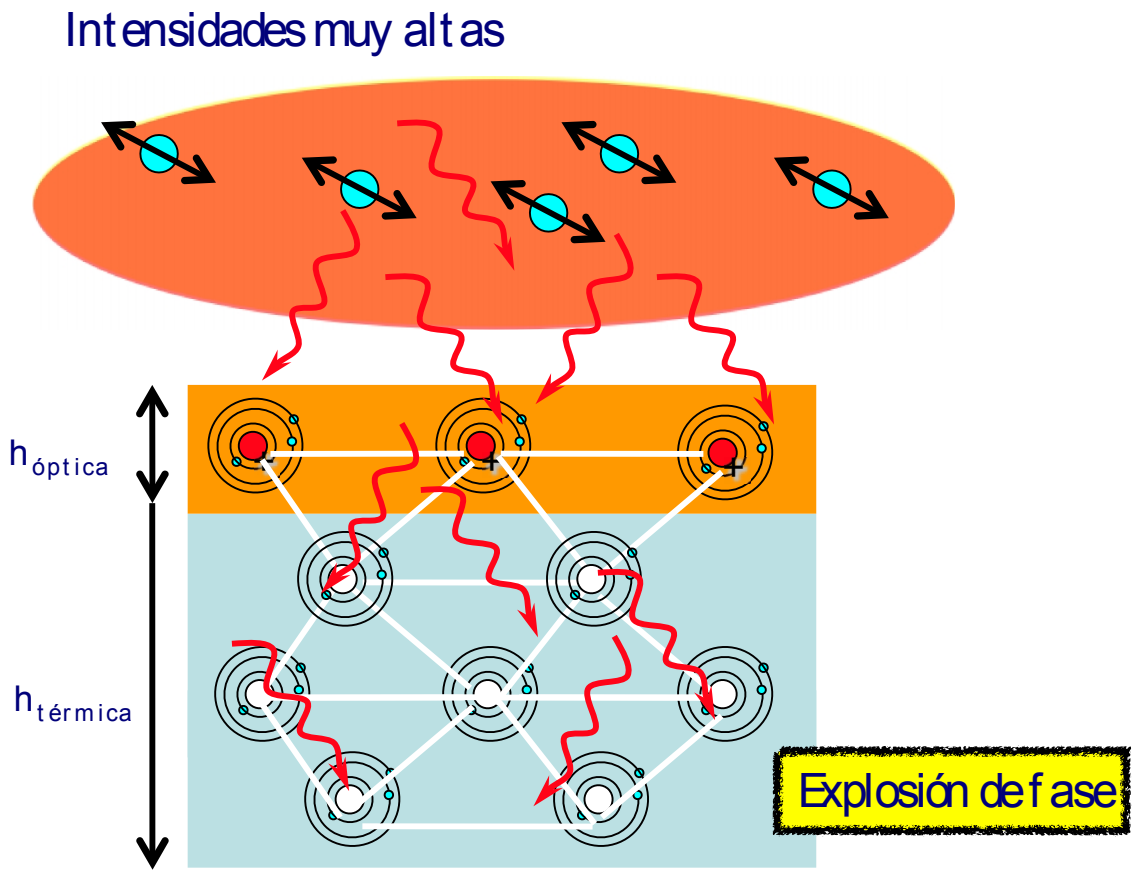

Figura 26: Representación esquemática del proceso de ablación por explosión de fase (Cortesía del Grupo de Microprocesado de Materiales con Láser).

Parte de esa radiación se dirige hacia la superficie del material donde es absorbida linealmente por el material elevándose su temperatura de una forma muy brusca lo que provoca la fusión y/o vaporización casi inmediata del material. En este caso, el material es eyectado sin haber podido conducirse la energía absorbida más allá de unas pocas micras de la zona irradiada. El resultado es que se elimina el material en cantidades mucho mayores que en el proceso de explosión de Coulomb y los efectos térmicos sobre las zonas circundantes, aunque no inexistentes, están mucho más limitados espacialmente que en la ablación convencional.

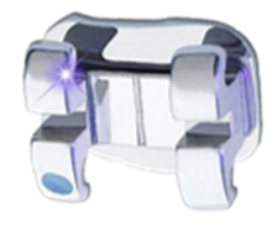



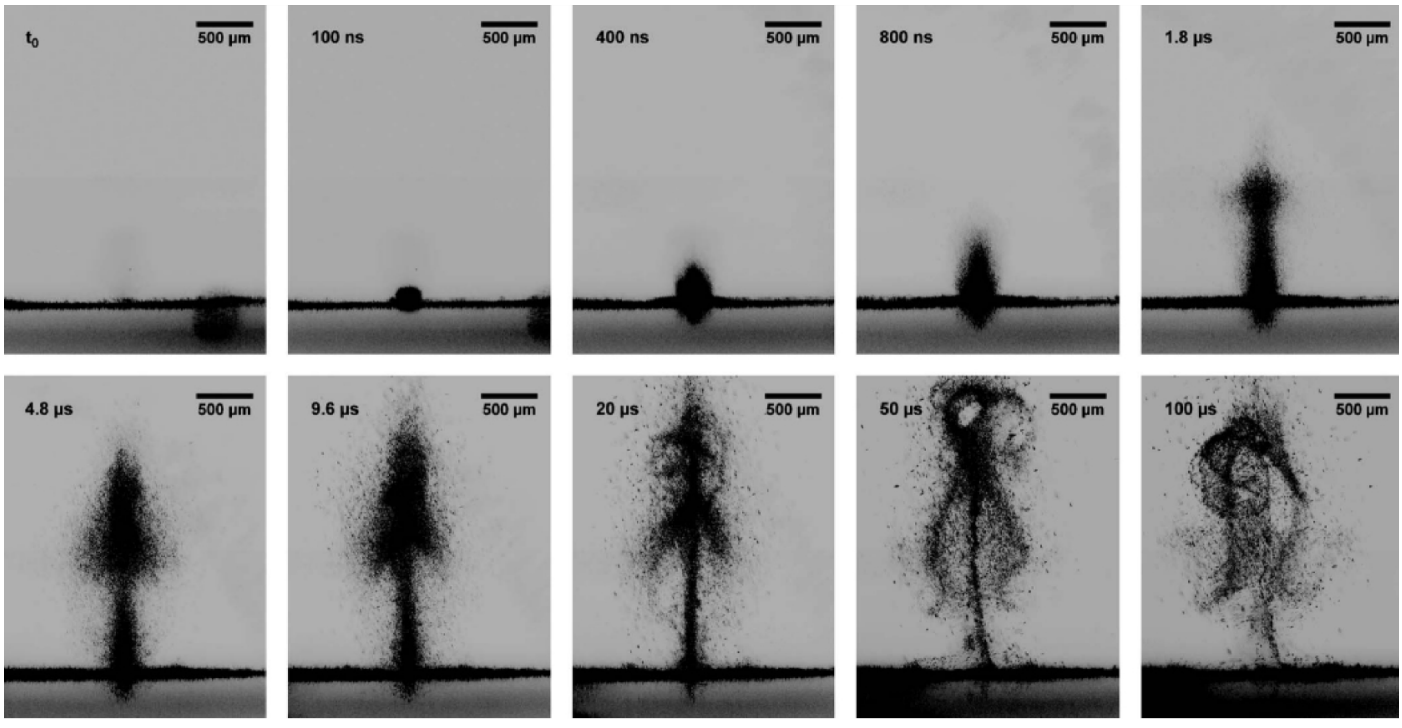

Figura 27: Eyección de material en zirconia por explosión de fase al ser irradiada la superficie con un pulso ultracorto suficientemente intenso.

La Figura 27 presenta una secuencia de imágenes obtenidas por dispersión de la luz, mostrando la eyección de material en zirconia por explosión de fase al ser irradiada la superficie con un pulso ultracorto suficientemente intenso (Tomada de Heiroth y cols., 2010).

El proceso de ablación ultrarrápida permite eliminar pues, cualquier material con una elevadísima precisión y sin apenas producir efectos colaterales de tipo térmico o mecánico, al no ser un factor determinante la conducción de calor, pues la energía absorbida del láser es eliminada de la zona de proceso casi íntegramente por transporte de material, es decir, con el propio plasma de electrones o con los iones eyectados de la red cristalina.

Hemos indicado que en la base de este mecanismo de ablación están procesos fuertemente no lineales con la intensidad o fluencia de los pulsos. Esto hace que al contrario que la ablación convencional con láser, el proceso se desencadene de forma 
Capítulo 1: Introducción

brusca cuando ese parámetro alcanza un valor que denominamos umbral. Esa es la razón de que el procedimiento sea a su vez tan preciso desde el punto de vista espacial pues, una vez conocido ese valor umbral para un determinado material, el control de la intensidad sobre la superficie del material permite determinar las zonas que se desean ablacionar dejando el resto del material prácticamente inalterado (Figura 28).

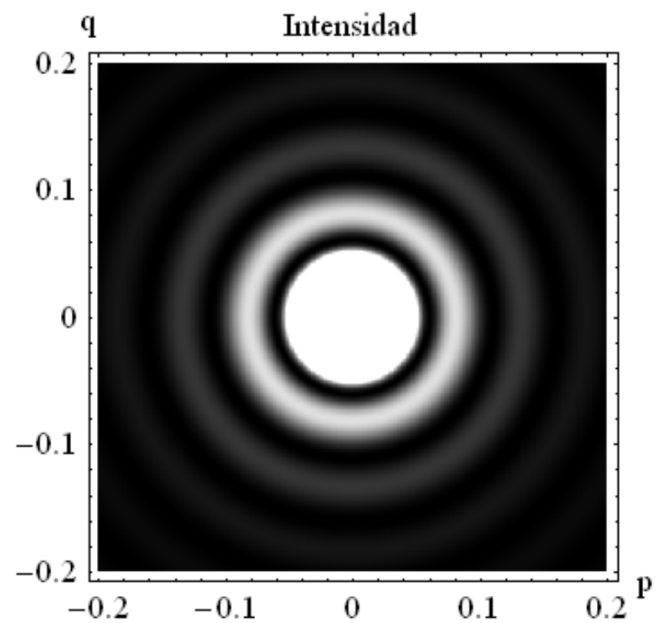

Figura 28: Distribución de la energía de un pulso láser gaussiano sobre la superficie de un material al pasar por una apertura circular de diámetro inferior a la sección del haz.

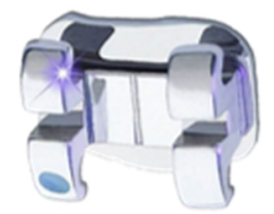




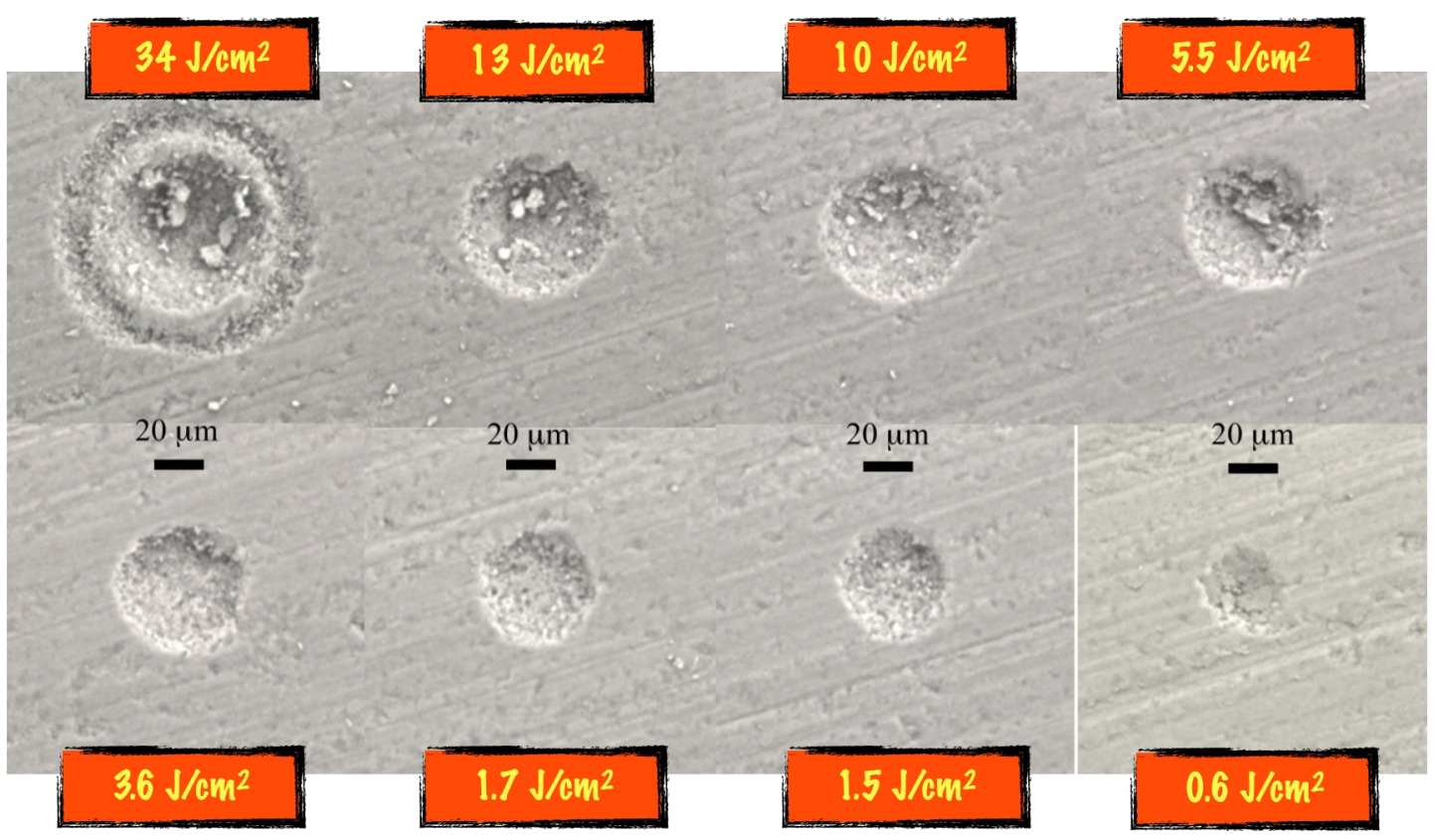

Figura 29: Estructuras producidas por ablación con pulsos ultracortos sobre la superficie de nitruro de silicio.

En la Figura 29 se presentan la estructuras producidas por ablación para la misma apertura mostrada en la figura Figura 28 y diferentes energías de pulso (Cortesía del Grupo de Microprocesado de Materiales con Láser).

En el caso del esmalte dental, la elección de la energía de los pulsos, la velocidad de barrido y el espaciado entre las líneas de barrido de la muestra con el haz láser deben asegurar que producimos eliminación del material.

En el caso de la preparación de cavidades, se han empleado energías de pulso dentro del intervalo 0.007-0.05 mJ. Como es natural, a mayor energía de pulso, mayor diámetro (cráteres) o anchura (surcos) de las microestructuras ablacionadas, y también mayor profundidad para un número igual de pulsos incidentes. 
Capítulo 1: Introducción

Por otra parte, el número de pulsos incidentes o, en su caso, las velocidades de barrido cuando estamos realizando estructuras de surcos, determina la profundidad de las microestructuras. En este trabajo se han empleado valores de la velocidad de barrido de 0.05 y $0.1 \mathrm{~mm} / \mathrm{s}$.

En el caso de las estructuras de surcos, un parámetro también relevante es la separación entre surcos, que viene determinada por la separación entre las trayectorias de barrido con el láser y la propia energía de pulso utilizada. En nuestro caso, se han utilizado dos valores de esa separación, 10 y 20 um que aseguran la superposición de las distintas líneas de barrido y, por tanto, permiten obtener surcos de paredes con pendiente más suave.

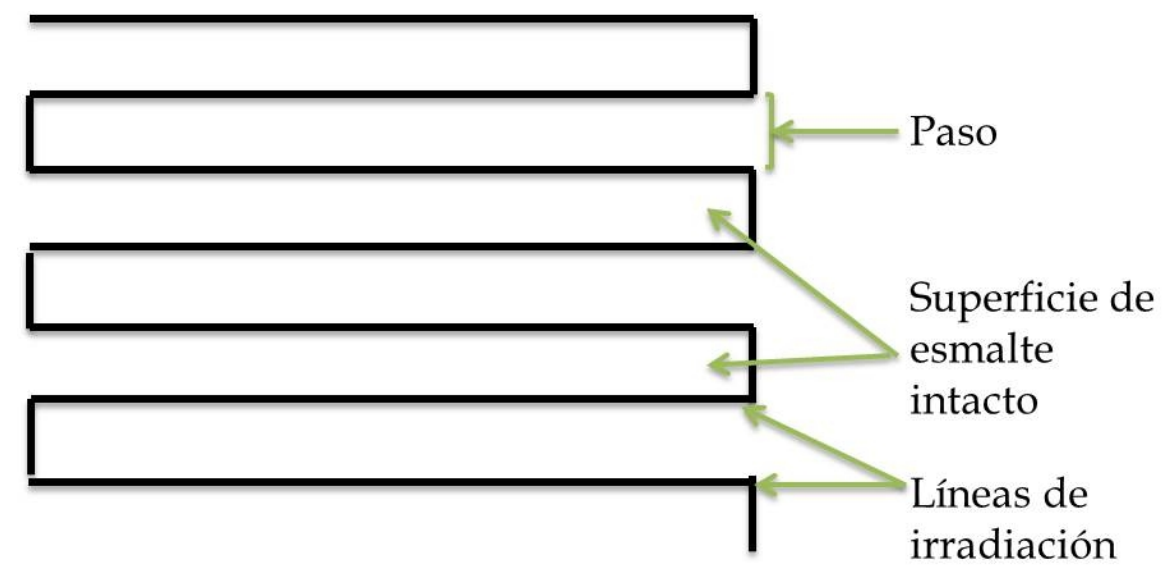

Figura 30: Esquema del barrido de la superficie generado con el láser de pulso ultracorto.

En el caso de los estudios de adhesión a esmalte, el tipo de estructura ablacionada fue siempre un patrón de surcos cruzados empleándose una energía de $0.03 \mathrm{~mJ}$ y una velocidad de barrido de $0.5 \mathrm{~mm} / \mathrm{s}$. Estos parámetros, al igual que la separación entre surcos de $15 \mu \mathrm{m}$, se escogieron de forma que aseguraramos un tiempo de proceso razonable y una ablación moderada del esmalte que generara estructuras

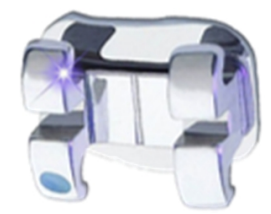


poco profundas y sin grandes cambios de pendiente. Una vez demostrado el buen comportamiento de la técnica como acondicionador del esmalte, se decidió variar la densidad del patrón microestructurado en la superficie, modificando el interlineado desde los $15 \mu \mathrm{m}$ hasta $180 \mu \mathrm{m}$. En el siguiente esquema se indica la forma en la que el haz barre la superficie (Figura 30).

El estudio de preparación cavitaria se realizó en condiciones de humedad ambiente mientras que para la preparación del esmalte en los estudios de adhesión se mantuvieron las muestras en un estado de índice de humedad muy elevado durante el procesado por medio de un humidificador con la salida del vapor dirigida hacia la zona de proceso (Figura 31 ).

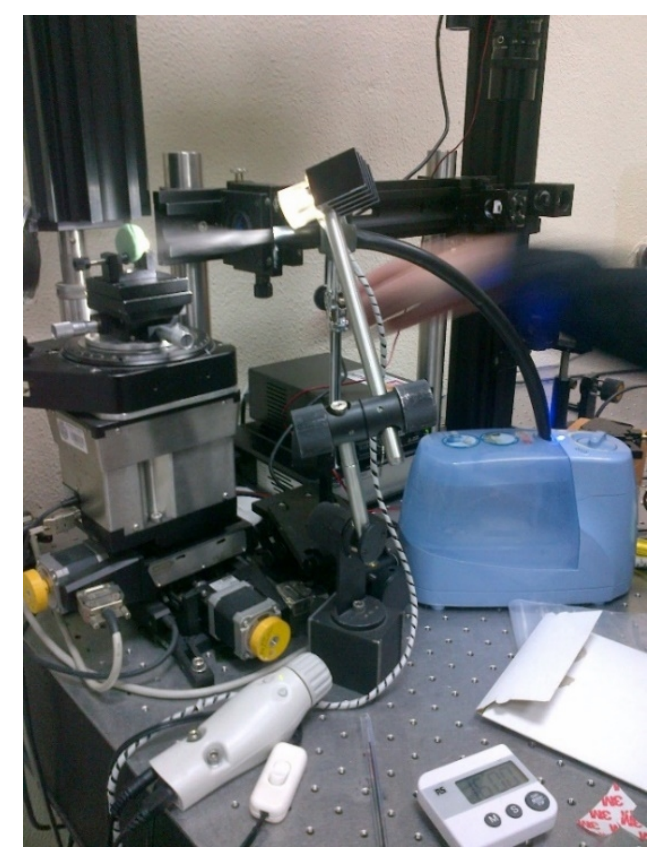

Figura 31: Sistema de humidificación empleado en el procesado de esmalte para los estudios de adhesión.

En resumen, el láser de pulsos ultracortos tiene numerosas ventajas, entre las que destacan: 
Capítulo 1: Introducción

1. Permite realizar todo tipo de microestructuras sobre la superficie de los materiales con una precisión geométrica elevadísima.

2. Es posible procesar todo tipo de materiales, incluidos tejidos biológicos ya que el proceso depende esencialmente de la intensidad y no de la longitud de onda del láser

3. Los daños colaterales que sufre el material que circunda la zona ablacionada son mínimos como consecuencia de la práctica ausencia de transmisión de energía desde el sistema de electrones a la red cristalina.

En la siguiente imagen (Figura 32) se observa la gran precisión en la ablación con un láser de femtosegundo con respecto a los láseres de nano y picosegundo sobre un metal (Srinivasan y cols., 1987; Kuper y cols., 1987; Chichkov y cols., 1996; Nolte y cols., 1997; Shirk y cols., 1998).
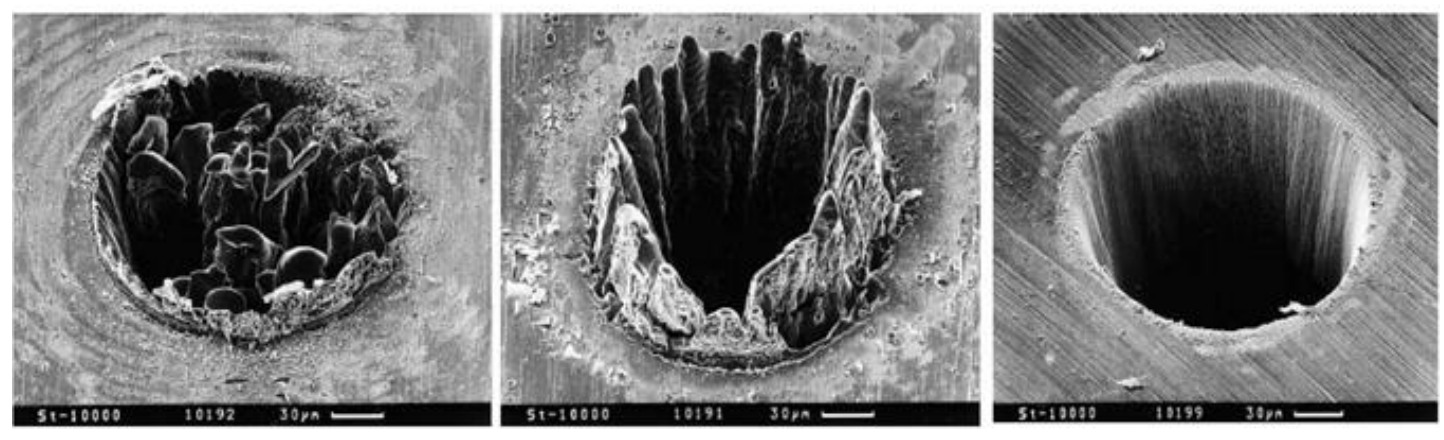

Figura 32: Cráteres realizados en metal con láser de nano, pico y femtosegundo, respectivamente.Tomado de Chichkov y cols. (1996).

\section{Aplicaciones en OdOntología.}

El láser de pulsos ultracortos se ha hecho popular para aplicaciones médicas fundamentalmente desde su introducción en el campo de la Oftalmología (femtoLASIK) en el año 2003 (Heisterkamp y cols., 2003; Ratkay-Traub y cols., 2003).

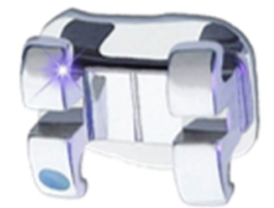


No obstante, la ablación ultrarrápida ha sido utilizada profusamente en biología (Tsai y cols., 2004), comprendiendo desde el corte de orgánulos subcelulares en las células cultivadas (Tirlapur y cols., 2002; Watanabe y cols., 2004; Hoy y cols., 2008) y procesos en organismos multicelulares (Yanik y cols., 2004; Gabel y cols., 2008; Guo y cols., 2008; Bourgeois y cols., 2008) hasta la ablación de hueso, dentina y esmalte (Neev y cols., 1996; Perry y cols., 1999; Niemz, 2004; Nicolodelli y cols., 2011), córnea (Stern y cols., 1989; Kautek y cols., 1994; Juhasz y cols., 1999; Lubatschowski y cols., 2000; Maatz y cols., 2000), epitelios (Frederickson y cols., 1993), y tejidos neuronales (Suhm y cols., 1996; Oraevsky y cols., 1996; Loesel y cols., 1998; Tsai y cols., 2003) y vasculares (Nishimura y cols., 2006).

El estudio de las aplicaciones de este tipo de láser en Odontología se remonta a los años 90 (Niemz, 1998) (Tabla 4). El aumento de popularidad de los láseres de Er:YAG hizo que se perdiera interés en la tecnología de pulsos ultracortos. Sin embargo, las fuentes de láser que proporcionan este tipo de pulsos se fueron desarrollando rápidamente, con una tendencia al aumento de potencia media de salida y de tasas de repetición más altas. Así, aparecen estudios que investigan otras longitudes de onda, duraciones del pulso y otros parámetros (Lizarelli y cols., 2000; Rode y cols., 2002; Henning y cols., 2001). La mayoría, enfocados a la preparación cavitaria para descubrir si produce buenos niveles de ablación tanto en esmalte como en dentina (Niemz, 1995; Willms y cols., 1996; Lizarelli y cols., 1999; Marion y cols., 1999; Krüger y cols., 1999; Lizarelli y cols., 2000; Ji y cols., 2012; Nicolodelli y cols., 2012; Rego Filho y cols., 2013; Schelle y cols., 2013; Braun y cols., 2013; Sun y cols., 2013; Bello-Silva y cols., 2013). Otros se centran en el microestructurado de implantes dentales de zirconio (Delgado-Ruiz y cols., 2011) y en la realización de osteotomías en sustitución a la técnica mecánica convencional y a los láseres de Erbium (Wieger y cols., 2007; Girard y cols., 2007b). A lo largo de los años, se ha 
Capítulo 1: Introducción

observado que al utilizar los pulsos ultracortos, los efectos térmicos disminuyen considerablemente, en comparación con el láser de Erbium (Kermani y cols., 1993; Dostalova y cols., 1996; Strassl y cols., 2005; Kohns y cols., 1997; Lizarelli y cols., 2000). Además, con el láser de pulso ultracorto se produce un bajo nivel de ruido en comparación con el que generan otros sistemas láser y el dolor se reduce al mínimo debido a la localización de la deposición de la energía. No obstante, la investigación actual sobre este sistema para aplicaciones dentales todavía está en un nivel muy básico y no se entienden de forma clara muchos de los factores que influyen en el proceso de ablación y en la generación de calor.

La presente tesis se centró en estudiar qué ocurre en el campo de la adhesión, en el que éste láser está muy poco estudiado ya que actualmente sólo existen tres referencias respecto a adhesión a dentina (Gerhardt-Szep y cols., 2012; Portillo y cols., 2012; Portillo y cols., 2013) y una centrada en adhesión a esmalte (Kabas y cols., 2013).

Tabla 4: Revisión bibliográfica de los artículos referentes a la preparación cavitaria con láser de pulso ultracorto.

\begin{tabular}{|c|c|c|c|}
\hline Autor & Título & Año & Resultados y Conclusiones \\
\hline $\begin{array}{l}\text { Krüger } \quad y \\
\text { cols. }\end{array}$ & $\begin{array}{l}\text { Femtosecond-pulsed laser } \\
\text { ablation of dental } \\
\text { hydroxyapatite and single- } \\
\text { crystalline fluoroapatite. }\end{array}$ & 1999 & $\begin{array}{l}\text { El esmalte puede ser ablacionado con éxito } \\
\text { con láseres de femtosegundos. La } \\
\text { aplicación de este tipo de láseres elimina } \\
\text { casi por completo el daño térmico al tejido } \\
\text { adyacente y las microfisuras. Este sistema } \\
\text { puede ser una alternativa a la técnica } \\
\text { mecánica convencional para mejorar la } \\
\text { calidad de los tratamientos dentales. }\end{array}$ \\
\hline $\begin{array}{l}\text { Lizarelli y } \\
\text { cols. }\end{array}$ & $\begin{array}{l}\text { A comparative study of } \\
\text { nanosecond and picosecond } \\
\text { laser ablation in enamel: } \\
\text { Morphological aspects. }\end{array}$ & 2000 & $\begin{array}{l}\text { Los pulsos de picosegundos promueven } \\
\text { una remoción del esmalte bien definida } \\
\text { con poca modificación del tejido } \\
\text { adyacente, lo que sugiere ventajas para su } \\
\text { utilización en odontología. }\end{array}$ \\
\hline Rode y cols. & $\begin{array}{l}\text { Subpicosecond laser ablation } \\
\text { of dental enamel. }\end{array}$ & 2002 & $\begin{array}{l}\text { No se observaron efectos térmicos ni } \\
\text { cracks en el esmalte con la aplicación este } \\
\text { láser. Este estudio indica la posibilidad de }\end{array}$ \\
\hline
\end{tabular}




\begin{tabular}{|c|c|c|c|}
\hline & & & $\begin{array}{l}\text { efectuar la ablación del esmalte dental con } \\
\text { mucha precisión con láseres de pulso } \\
\text { ultracorto. }\end{array}$ \\
\hline Rode y cols. & $\begin{array}{l}\text { Precision ablation of dental } \\
\text { enamel using a } \\
\text { subpicosecond pulsed laser }\end{array}$ & 2003 & $\begin{array}{l}\text { La preparación de la superficie de los } \\
\text { dientes ablacionados no mostró grietas ni } \\
\text { efectos térmicos aparentes. Este estudio } \\
\text { indica la posibilidad de láseres de pulso } \\
\text { ultracorto para efectuar una ablación de } \\
\text { precisión en el esmalte dental. }\end{array}$ \\
\hline $\begin{array}{l}\text { Sakae } \quad y \\
\text { cols. }\end{array}$ & $\begin{array}{l}\text { Thermal ablation of } \mathrm{FEL} \\
\text { irradiation using gypsum as } \\
\text { an indicator }\end{array}$ & 2007 & $\begin{array}{l}\text { El láser de pulso ultracorto disminuye los } \\
\text { efectos térmicos. }\end{array}$ \\
\hline Ji y cols. & $\begin{array}{l}\text { Ti:sapphire femtosecond } \\
\text { laser ablation of dental } \\
\text { enamel, dentine, and } \\
\text { cementum. }\end{array}$ & 2012 & $\begin{array}{l}\text { El esmalte tiene mayor umbral de ablación } \\
\text { que la dentina y el cemento y la geometría } \\
\text { de corte es menos uniforme en } \\
\text { comparación con los mismos. La ablación } \\
\text { con láser de femtosegundo no afecta a la } \\
\text { composición química de los tejidos. Las } \\
\text { cargas térmicas para el esmalte son } \\
\text { menores que con láser de nano y } \\
\text { picosegundo. }\end{array}$ \\
\hline $\begin{array}{l}\text { Bello-Silva } \\
\text { y cols. }\end{array}$ & $\begin{array}{l}\text { Precise ablation of dental } \\
\text { hard tissues with ultra-short } \\
\text { pulsed lasers. Preliminary } \\
\text { exploratory investigation on } \\
\text { adequate laser parameters. }\end{array}$ & 2013 & $\begin{array}{l}\text { En esmalte se observó la mejor correlación } \\
\text { entre el aumento de temperatura y la } \\
\text { eficiencia en la ablación con el láser de } \\
\text { femtosegundo, independientemente de la } \\
\text { potencia. El láser de pulso ultracorto } \\
\text { parece ser adecuado para la preparación } \\
\text { cavitaria en dentina y esmalte ya que } \\
\text { produce una ablación eficaz y un aumento } \\
\text { de temperatura bajo. }\end{array}$ \\
\hline Sun y cols. & $\begin{array}{l}\text { Influence of intra-pulpal } \\
\text { temperature when using } \\
\text { femtosecond laser in specific } \\
\text { parameters to prepare } \\
\text { cavities in tooth enamel: an } \\
\text { in vitro study. }\end{array}$ & 2013 & $\begin{array}{l}\text { En la preparación de una cavidad cuya } \\
\text { profundidad media es de } \\
\text { aproximadamente } 250 \text { micras, con un } \\
\text { sistema de láser de femtosegundo con } \\
\text { parámetros específicos, el IPT se eleva } \\
\text { mientras que la profundidad aumenta. Esto } \\
\text { podría ser controlado eficazmente por } \\
\text { enfriamiento con aire. }\end{array}$ \\
\hline $\begin{array}{l}\text { Rego Filho } \\
\text { y cols. }\end{array}$ & $\begin{array}{l}\text { Influence of the hydratation } \\
\text { state on the ultrashort laser } \\
\text { ablation of dental hard } \\
\text { tissues. }\end{array}$ & 2013 & $\begin{array}{l}\text { Los tejidos duros dentales con diferentes } \\
\text { estados de hidratación presentan cambios } \\
\text { en sus propiedades de ablación cuando se } \\
\text { irradian con láseres de pulso ultracorto. Se } \\
\text { observó un aumento local de efectos } \\
\text { térmicos cuando crece la deshidratación, } \\
\text { pero no se observó un aumento } \\
\text { significativo en el tamaño de las zonas } \\
\text { macroscópicas con daño térmico. }\end{array}$ \\
\hline Chen y cols. & $\begin{array}{l}\text { Effects of fluence and } \\
\text { scanning velocity on the } \\
\text { ablation efficiency of dentin }\end{array}$ & 2013 & $\begin{array}{l}\text { Con una elección adecuada de la fluencia y } \\
\text { de la velocidad de escaneado podemos }\end{array}$ \\
\hline
\end{tabular}


Capítulo 1: Introducción

\begin{tabular}{|c|c|c|c|c|}
\hline & & $\begin{array}{l}\text { and enamel by femtosecond } \\
\text { laser. }\end{array}$ & & $\begin{array}{l}\text { mejorar la eficiencia de la ablación en el } \\
\text { esmalte. }\end{array}$ \\
\hline $\begin{array}{l}\text { Schelle } \\
\text { cols. }\end{array}$ & & $\begin{array}{l}\text { Ultrashort pulsed laser } \\
\text { (USPL) application in } \\
\text { dentistry: basic } \\
\text { investigations of ablation } \\
\text { rates and thresholds on oral } \\
\text { hard tissue and restorative } \\
\text { materials. }\end{array}$ & 2013 & $\begin{array}{l}\text { Los láseres de pulso ultracorto } \\
\text { proporcionan niveles de ablación } \\
\text { suficientes para ser considerados como } \\
\text { una tecnología prometedora para } \\
\text { aplicaciones dentales }\end{array}$ \\
\hline
\end{tabular}

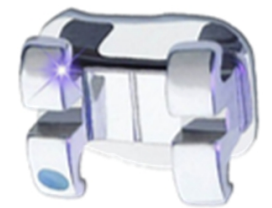





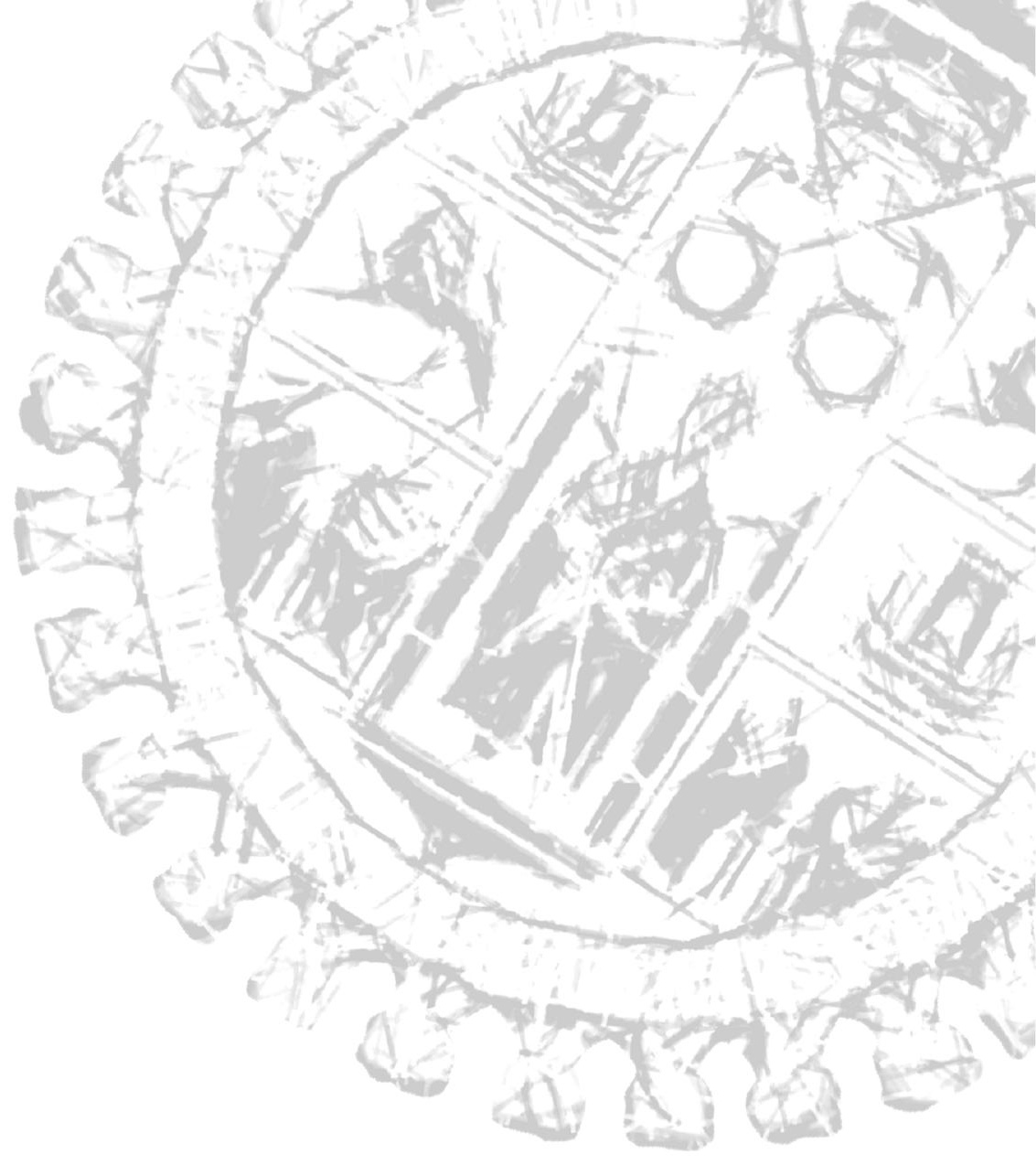

CAPÍTVLO 2

\section{OBJETO Y JVSTIFIICACÍ́N}

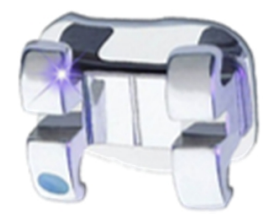





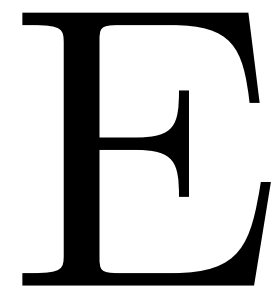

n odontología conservadora, la preparación cavitaria se realiza rutinariamente con una técnica mecánica convencional. Sin embargo, este procedimiento trae consigo varios inconvenientes para el esmalte, como son la remoción no selectiva del mismo, dolor y necesidad de anestesia, producción de cracks y fisuras o efectos térmicos no deseados. Estos problemas han creado la necesidad de buscar métodos alternativos que soslayen las vicisitudes creadas por la turbina, entre los que se encuentran los láseres de alta intensidad, como el láser de Er:YAG, que ha sido ampliamente estudiado pero que presenta inconvenientes, tales como efectos térmicos severos y no realizar tasas de ablación suficientes para competir con la técnica mecánica. Por otro lado, el láser de pulso ultracorto se presenta recientemente en odontología como una alternativa eficiente para disminuir esos efectos térmicos y mecánicos, a través de pulsos ultracortos que eliminan la creación de microcracks y no irradian apenas calor a los tejidos adyacentes.

En el campo de la Ortodoncia, la aplicación de ácido ortofosfórico es el método más común empleado para el acondicionamiento del esmalte previo al cementado de brackets. Esta técnica proporciona una correcta eficacia adhesiva en la interfase bracket-esmalte, sin embargo genera una desmineralización de la capa más superficial que provoca una mayor sensibilidad a largo plazo de ataques ácidos y aparición de caries, por lo que es necesario encontrar una alternativa que sea capaz de mantener o mejorar las fuerzas de adhesión presentadas por el método tradicional de acondicionamiento ácido y simultáneamente, minimice la pérdida de esmalte.

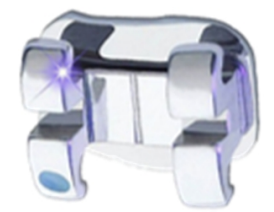


Los objetivos principales del presente trabajo de investigación in vitro fueron los siguientes:

1. Evaluar mediante microscopía óptica y electrónica los cambios morfológicos que ocurren en el esmalte tras la instrumentación mecánica y la irradiación con láser de pulsos ultracortos con diferentes parámetros.

2. Comparar la eficacia adhesiva del cementado de brackets de ortodoncia en la superficie de esmalte tras la preparación de la superficie con tres técnicas diferentes, el convencional grabado con ácido ortofosfórico, la ablación extensiva de la superficie con láser de Er:YAG y finalmente, el microestructurado con pulsos láser ultracortos

3. Teniendo en cuenta la gran cantidad de parámetros de proceso que intervienen en el microestructurado con pulsos láser ultracortos, determinar la influencia en la fuerza de adhesión en la interfase bracket-esmalte de uno de los parámetros más relevante, como es la densidad del patrón microestructurado en la superficie del esmalte. 


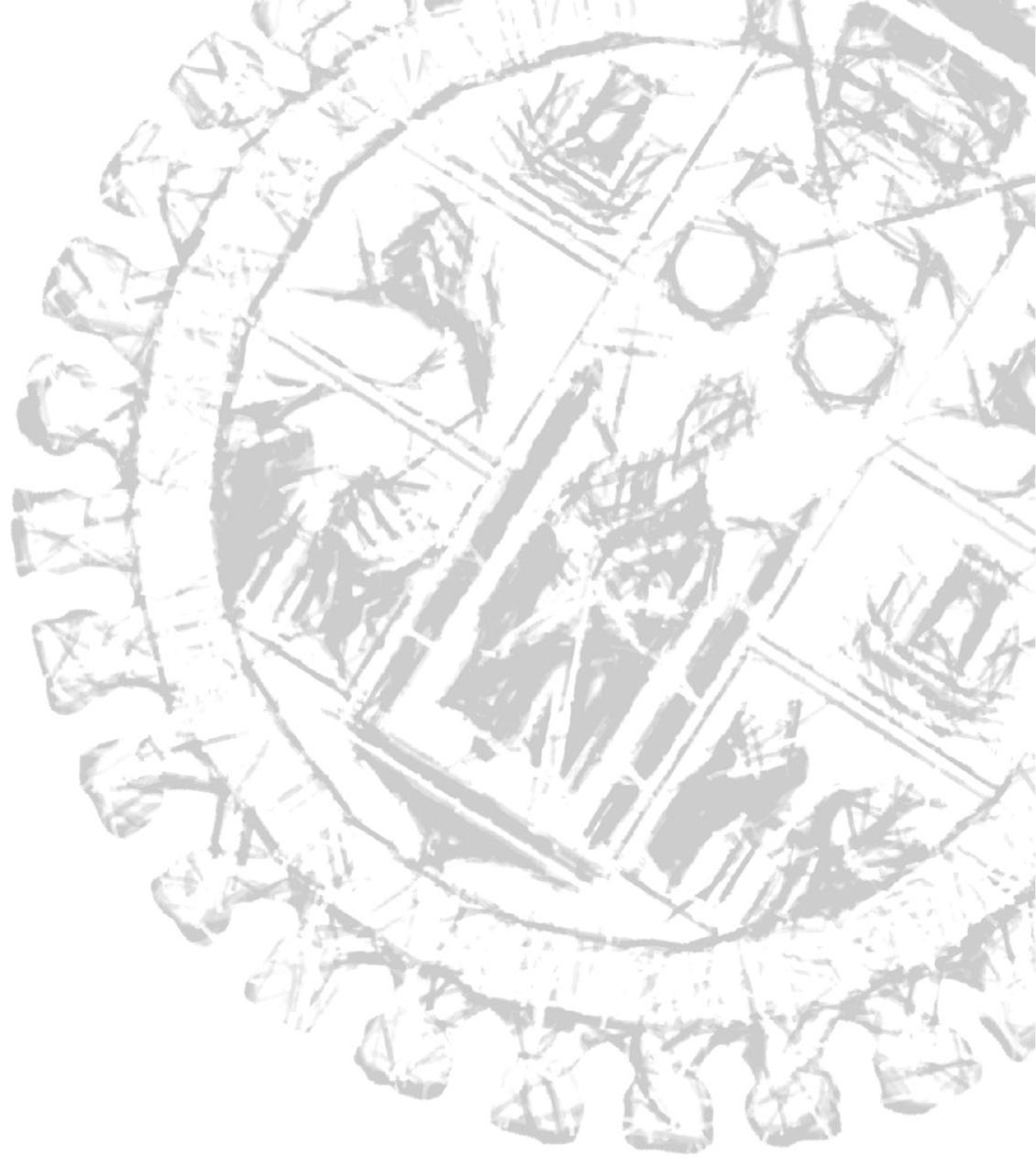

CAPÍTVLO 3

\section{PVBLÍCACIONES}

ORIGINALES

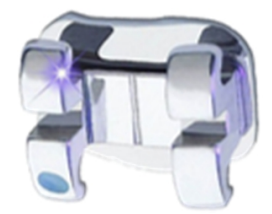



Capítulo 3: Publicaciones Originales

\subsection{ARTÍCULO I}

Luengo MC, Portillo M, Sánchez JM, Peix M, Moreno P, García A, Montero J, Albaladejo A. Evaluation of micromorphological changes in tooth enamel after mechanical and ultrafast laser preparation of surface cavities. Lasers Med Sci. 2013 Jan;28(1):267-73.

ISSN: 0268-8921.

Impact Index: 2.402. JCR Science Edition: 2012.

Category: Surgery.

Position in the category: 45 de 195 (T1/Q1).

\section{RESUMEN}

El objetivo de este estudio in vitro fue evaluar los cambios morfológicos que se producen en el esmalte tras la instrumentación mecánica y tras la irradiación con láser de pulso ultracorto con diferentes parámetros a través de microscopía óptica y electrónica de barrido.

Doce terceros molares totalmente impactados fueron recogidos y seccionados para obtener varias superficies de corte. Estas superficies fueron expuestas a pulsos de láser infrarrojo ( $\lambda=795 \mathrm{~nm}, 120 \mathrm{fs}$, tasa de repetición $1-\mathrm{kHz}$, potencia máxima de salida $1 \mathrm{~W})$ y a la técnica mecánica convencional. Se realizaron dos patrones geométricos muy diferentes con el láser de pulso ultracorto: cavidades rectangulares poco profundas y cilíndricas profundas.

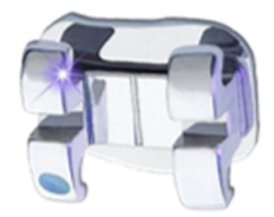


Los resultados de ambos procedimientos de mecanizado fueron examinados usando microscopía óptica y electrónica de barrido. Las imágenes de microscopía electrónica mostraron la capacidad del láser de pulso ultracorto para producir cavidades de alta precisión en el esmalte dental. No se observaron signos de daño colateral, carbonización, fusión o grietas, a pesar de las muy diferentes energías por pulso láser utilizadas (desde 7 a $400 \mu \mathrm{J}$ ), a diferencia de lo que se aprecia con la técnica mecánica convencional.

El láser de pulso ultracorto posee el potencial de convertirse en una herramienta óptima para el tratamiento de la caries dental y como alternativa a la turbina convencional para reducir el daño mecánico durante la remoción del tejido duro dental. 
Capítulo 3: Publicaciones Originales

Lasers Med Sci

DOI 10.1007/s10103-012-1144-x

ORIGINAL ARTICLE

\section{Evaluation of micromorphological changes in tooth enamel after mechanical and ultrafast laser preparation of surface cavities}

M' Cruz Lorenzo Luengo - M. Portillo - J. M. Sánchez •

M. Peix - P. Moreno - A. Garcia - J. Montero -

A. Albaladejo

Received: 17 November 2011 / Accepted: 21 June 2012

O Springer-Verlag London Led 2012

\begin{abstract}
The aim of this in vitro study was to evaluate the morphological changes that occur in tooth enamel after mechanical instrumentation and after femtosecond laser irradiation with different parameters via light and scanning electron microscopy (SEM). Twelve totally impacted third molars were collected and sectioned to provide several cut surfaces. These surfaces were exposed to infrared ( $\lambda=795 \mathrm{~nm}, 120 \mathrm{fs}, 1-\mathrm{kHz}$ repetition rate, maximum mean power I W) laser pulses and machined by means of a conventional mechanical technique. Two very different geometrical patterns were performed with femtosecond laser pulses: shallow rectangular cavities and deep cylindrical ones. The results of both machining procedures were examined using light and scanning electron microscopy. The SEM images show the femtosecond laser ability to produce high-precision cavities in tooth enamel. No signs of collateral damage, buming, melting, or cracks were observed despite the far different laser pulse energies used (ranging from 7 to $400 \mu$ J), unlike what is seen with conventional mechanical tochniques. The femtosecond laser has the potential to become
\end{abstract}

M. C. L. Luengo (저) - M. Portillo - M. Peix - J. Montero

A. Albaladejo
Faculty of Medicine, Dental Clinic, University of Salamanca

Faculty of Medicine, Dental Clink, University of Salamanca,

in Universidad de Coimbra SN,

Salamanca, Spain

e-mail: merurlorenrova botmuil com

A. Albaladejo

e-mail: albertoalbaladejo a hotmail con

P. Moreno - A. Garcia

Laser Microprocessing Research Group, University of Salamanca.

Plaza de la Merced SN

37008 Salamanca, Spain

J. M. Sänche:

Department of General and Atmospheric Physics, Sciences Faculty, Building Trilingual, University of Salamanca,

Plaza de la Mereed SN.

37008 Salamanca, Spain

Published coline: 04 July 2012 an optimal tool for the treatment of dental decay and as an altemative to the conventional drill to reduce mechanical damage during removal of the hard dental tissue.

Keywords Femtosecond - Laser - Enamel - Morphological alterations

\section{Introduction}

Restorative dentistry focuses on the development of new methods for caries removal and cavity preparation, as well as new restorative materials to ensure that treated teeth are restored, aesthetically and functionally with great precision [1]. When making cavities and removing carious tissuc, the conventional mechanical technique is not as accurate as desired and has certain drawbacks, such as the nonselective removal of hard dental tissue, pain, and the need for anesthesia, among others [2]. This has gradually given way to new dental techniques for the removal of material as an alternative to conventional mechanical procedures [3-5].

Among these methods, high-intensity lasers have been widely used and approved by professionals [6]. Indeed, in the future, lasers may replace dentists' drills so that a more selective removal of material can be achieved [7-9]. In recent years, ultrashort-pulsed lasers have proved to be a very promising tool owing to their ability to avoid the formation of microcracks around treated areas, since such cracks can evidently lead to the formation of a new caries [10].

In laser processing, pulse duration is a crucial parameter. This parameter determines the mechanism of interaction between the light emitted and the tissue [11]. In recent years, laser sources based on titanium/sapphire crystals (Ti/S) [12]. which produce extremely short pulses below the picosecond $\left(10^{-12}\right.$ s) scale, have been developed. These laser pulses, amplified up to energies of the order of millijoules and

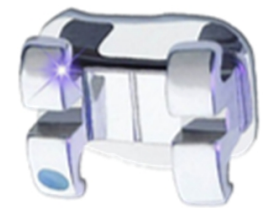


conveniently focused on the surface of materials, allow the ablation of these surfaces with extreme precision and reproducibility, and cause much less collateral damage to the adjacent material than any other thermal, chemical, or mechanical process [12, 13].

In brief, ultrafast ablation is based on the non-linear processes of light absomtion and ionization unleashed by the effect of irradiation with very short and intense pulses [14]. During the pulse, a thin layer on the surface of the tissue is almost fully ionized, giving rise to a dense clectronic plasma able to break the bonds between ions or molecules as a result of the intense electric field. These species leave the surface together with the electrons in a process known as Coulomb explosion, which is a completely non-thermal process [15]. The effects derived from thermal load on the surrounding areas are therefore nonexistent. If the intensity is very high, the electronic plasma may absorb further energy, which is then radiated outwards, leading to a sudden increase in the temperature of a deeper layer, in tum resulting in the violent expulsion of both vapor and liquid droplets in equilibrium. This process, called phase explosion, is a thermal phenomenon, but it takes place fast enough to limit the diffusion of heat to very few microns of the surrounding tissue $[16,17]$. Thus, the irreversible damage to dental pulp tissue - which is particularly sensitive to such thermal effects, as well as microfractures or "cracks" in hard dental tissues produced by conventional laser soures - becomes almost negligible.

The aim of this in vitro study was to evaluate with light and scanning electron microscopy (SEM) microscopy the morphological changes that occur in enamel after mechanical instrumentation and after femtosecond laser irradiation with different parameters.

\section{Materials and methods}

Collection and sample preparation

Twelve totally impacted third molars were collected; the pieces had been extracted over a period of one week at the Oral and Maxillofacial Surgery Unit of the Virgen de la Vega Hospital in Salamanca.

The third molar was extracted from patients aged between 20 and 25. The molars were kept in an appropriate environment (physiological saline solution at $37^{\circ} \mathrm{C}$ ) to avoid dryness until the time of preparation. Each tooth was cross-sectioned transversely into two parts: the crown and the level of the root line enamel. The coronal part of the tooth was cut longitudinally in the vestibulo-lingual direction, in sheets of approximately 1-mm thickness using a precision Accutom-50 cutter/grinder (Struers, Denmark. Copenhagen) and $330 \mathrm{~K}$ Struers diamond blades under a

Ospringer water coolant. One-millimeter-thick serial sections were taken at $3,200 \mathrm{rpm}$, with a driving speed of $0.460 \mathrm{~mm} / \mathrm{s}$ and high strength in order to obtain three to four slices from each specimen. The sheets containing only dentin were discarded. The samples were ground with sandpaper granulated at 300,400 , and 600 in a polishing machine.

To perform the experiments, each sample was divided in two groups according to dental cavity preparation:

- First group: mechanical cavity preparation.

- Sccond group: laser cavity preparation.

Each laser sample was treated using all the parameters investigated.

The samples were then preserved in physiological saline solution in an oven at $37^{\circ} \mathrm{C}$ (for a maximum period of 1 month) to prevent them from drying out until the microscopy studies were performed.

First group: mechanical dental cavity preparation

For traditional dental cavity preparation a Supertorque Kavo Lux 655B handpicee was used at a speed of $450,000 \mathrm{~mm}$. with a tungsten round bur of $0.5 \mathrm{~mm}$ (ref. H1314005 Lemgo, Germany), with a water coolant. These were made with perforations of about $500-600 \mu \mathrm{m}$ in diameter in the enamel samples.

Second group: dental cavity preparation by laser

The microstructuring of the samples was performed with a system consisting of a Ti/sapphire oscillator (Spectra Physics, Tsunami) and a regenerative amplifier (Spectra Physics, Spitfire), based on the CPA technique [18], which produces pulses of $120 \mathrm{fs}\left(1 \mathrm{fs}=10^{-15} \mathrm{~s}\right)$; a wavelength in the near infrared region (795 nm), and energics up to $1 \mathrm{~mJ}$, with a repetition rate of $1 \mathrm{kHz}$ (mean power $=1 \mathrm{~W}$ ). The pulses were focused perpendicularly onto the sample surface by means of an achromat doublet, with a focal length of $100 \mathrm{~mm}$.

The samples were placed on an XYZ stage (Nanotec Micos ES100) in order to provide a precise location of the cavity and to properly focus the laser pulses on the surface. Two kinds of microstructured samples were prepared: shallow rectangular cavities and deep cylindrical ones. Since the size of these structures was required to be larger than the spot size, different strategies were adopted. For the rectangular structures, we scanned the surface by moving the samples following a meandering path with different pitches or distance between neighboring laser scans $(0.02$ and $0.01 \mathrm{~mm}$ ). Pulse energies of $0.007,0.01,0.03$, and $0.05 \mathrm{~mJ}$ were used to induce shallow structures; for each energy, cavities were made with different scanning speeds $(0.05$ and $0.1 \mathrm{~mm} / \mathrm{s})$. 
Capítulo 3: Publicaciones Originales

Author's personal copy

Lasers Med Sci

To achicve large (diameters up to $500 \mu \mathrm{m}$ ) and decp (up to $400 \mu \mathrm{m}$ ) cylindrical cavitics, a helical drilling optics system (TGSW, Stuttgart) was used. This is an optomechanical device consisting of a number of optical wedges which can rotate (up to $3,000 \mathrm{rpm}$ ) and whose relative position along the rotating axis may be modified in order to force the laser spot to follow an eccentric path of variable diameter and at the same time to provide oblique incidence of the laser beam on the surface of the sample. Both features allow, on one hand, to drill microstructures with dimensions much larger than the laser spot size and, on the other hand, to overoome the depth limitations and tapering resulting of light propagation within the ablation crater (saturation effects) [19]. Since the number of free parameters bocame too large, we have always used the same rotating speed for the helical drilling system $(250 \mathrm{rpm})$ to fix the number of pulses irrediating a unit of area on the surface and the maximum beam inclination provided by the system $\left(4^{\circ}\right)$ to get the best approach to cylindrical geometry. We have also fixed the maximum laser beam offset $(200 \mu \mathrm{m})$ to machine holes with diameters around $500 \mu \mathrm{m}$. Bearing this in mind, we started the process either at the periphery or at the center of the crater, so that the laser spot followed respectively an inwards spiral path or an outwards one by decreasing increasing the beam offset during the process. In addition, we have checked the effect of processing with a single pass or two passes. The number of passes and the trend of beam offset variation play a significant role in the debris accumulation processes on the hole bottom as we will show in this work. Concerming the laser parameters, the pulse energies ranged from 0.1 to $0.4 \mathrm{~m}$. Pulse energy is the main parameter which determines the amount of material removed per laser pulse and therefore the hole depth. In this case, we need very high energies since the volume of enamel to be removed is very large.

In all cases, processing was carried out in air, without a water coolant.

Analysis of samples

Light microscopy

All samples were examined with an Axio MI (Carl Zeiss, Germany) light microscope, operating in the dark-field mode. We used Epiplan $\times 20$ and $\times 50$ HD objectives (Car. Zeiss Vision), attached to a 1,300 $\times 1,030$-pixel digital camera (AxioCam HR, Carl Zeiss Vision). The images were processed with AxioVision software. This software permits the measurement of the depth and diameter of the cavities.

Scanning electron microscopy

A ZEISS DSM 940 scanning electron microscope was used to obtain images of the processed areas of the samples at different levels of magnification.

\section{Results}

A qualitative result of the effects of two different techniques for cavity preparation was observed in this study: on onc hand, with a femtosecond laser at $795 \mathrm{~nm}$, and on the other. with the conventional mechanical technique. The procedure was observed and analyzed using light and SEM. The SEM images reveal the ability of the femtolaser to produce highprecision cavities in tooth enamel. No signs of collateral damage or cracks were observed, unlike with the conventional mechanical technique.

The light microscopy images point to the irregularity of the cavities made with conventional mechanical instrumentation and the perfect cavity boundary defined in those made with the femtosecond laser.

Figure I shows several rectangular cavities made with the femtosecond laser in enamel. The cavities were ablated using different pulse energies: $0.05 \mathrm{~mJ}$ (row A), $0.03 \mathrm{~mJ}$ (line B), $0.01 \mathrm{~mJ}$ (row C), and finally, $0.007 \mathrm{~mJ}$ (row D). Essentially, the greater the energy of the pulse, the deeper the microstructure. The pitches between the meander lines were $0.02 \mathrm{~mm}$ (column 1) and $0.01 \mathrm{~mm}$ (column 2). Pitch determines the overlapping of the ablated areas. Since the spot size is constant on the enamel surface for the same pulse energy, over-large pitches give rise to inhomogeneous ablation if the spot size is smaller than the pitch. This was the case of the structures in column 1 for both pulse energies, and for case D in column 2, where the pulse energy was very low. In all cases the scanning velocity was $0.05 \mathrm{~mm} / \mathrm{s}$.

Figure 2 shows magnified SEM images corresponding to the lower two energies, both pitches and the same scanning velocity as used in Fig. 1. Focusing on Fig. $2 \mathrm{a}(E=0.007 \mathrm{~mJ}$, $v=0.05 \mathrm{~mm} / \mathrm{s}$ and $s=0.01 \mathrm{~mm}$ ), the processed area is scen to have resulted in a shallow square cavity of approximately 215 um per side, with a homogeneous bottom. There are no signs of heat damage or cracks on the surrounding or bottom

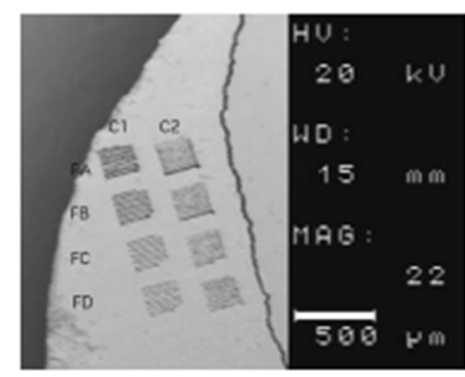

Fig. I SEM micrograph of cavities in enamel performed with the femtosecond laser (original magnification: SEM $\times 374$ )

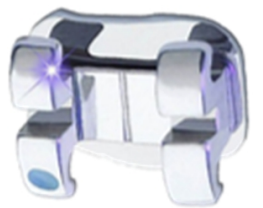


surfaces. In the work described in Fig. 2b, we used the same parameters except for the pitch $(s=0.02 \mathrm{~mm})$. This time the squared cavity was $230 \mu \mathrm{m}$ per side, but the ablated and intact surfaces alternated as a result of the large degree of pitch as compared to the spot size, which was of the order of $0.01 \mathrm{~mm}$. The results obtained upon increasing the pulse energy $(E=0.05 \mathrm{~mJ})$ are shown in Fig. $2 \mathrm{c}$ and $\mathrm{d}$. The square cavity was approximately $225 \mu \mathrm{m}$ per side for the smallest pitch (Fig. 2c), and $215 \mu \mathrm{m}$ for the largest one (Fig. 2d). In comparison with Fig, $2 \mathrm{a}$ and $\mathrm{b}$, the cavities were now much deeper since the ablation rate increased with the pulse energy. The effect of a pitch larger than the spot size is still visible in the case of Fig. 2d, although to a lesser extent since the spot size was now larger (close to $0.02 \mathrm{~mm}$ ).

Figure 3(a, b, c, d) shows the SEM and light microscopy images comparing the results of the two different treatments used in this study: $(\mathrm{a}, \mathrm{c})$ the tooth surface irradiated by a femtosecond laser with SEM; (b, d) abrasion surface with a conventional diamond bur with light microscopy. The abrasion surface with a conventional diamond bur at a $v=450,000 \mathrm{rpm}$ under a water coolant (Fig. 3b) has an irregular surface. The smear layer is present on the surface of the cavity. The enamel rods are completely obliterated by the fusion of material due to the thermal effect.

The cavity prepared with the femtosecond laser (Fiz. 3a) has a diameter of $500 \mu \mathrm{m}$ and the cavity boundary is perfectly defined on both the surface and on the walls. Some of the material is seen to have been redeposited at the bottom of the cavity. The debris is driven towards the previously ablated areas. Therefore, if the sample motion finishes at the boundary - as is the case in Fig. 3a- the debris are driven to the center of the cavity, whereas it is driven towards the boundary if the motion finishes at the center (Fig. 3c). The use of different sets of parameters - including the inwardoutward paths - did not solve this issuc.

Figure $3 \mathrm{~d}$ shows detailed light microscope images of a cavity made with the turbine drill at $v=450,000 \mathrm{~mm}$. Unlike the cavities made with the femtosecond laser. in this image it is possible to observe the presence of microcracks around the cavity. This is a product of the mechanical and thermal effects that occur with conventional mechanical instrumentation. This is not desirable because microorganisms can penetrate through these microcracks, favoring failure of the restoration and the possible start of new caries.

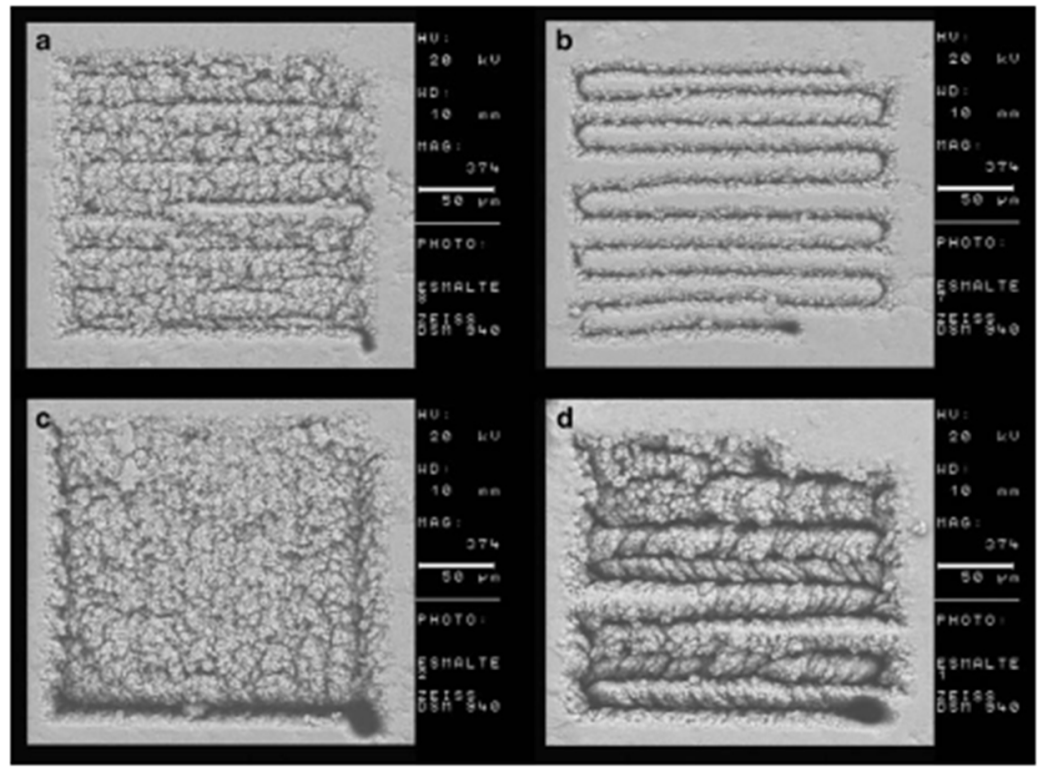

Fig. 2 SEM micrograph of femtosecond laser cavities in enamel with: a $E-0.007 \mathrm{~mJ}, r=0.05 \mathrm{~mm} / \mathrm{s}$ and $s=0.01 \mathrm{~mm}$ (original magnification, SEM $\times 374$ ) : b $E-0.007 \mathrm{~mJ}, v=0.05 \mathrm{~mm} / \mathrm{s}$ and $s=0.02 \mathrm{~mm}$ (original magnification, SEM $\times 374$ ); $\quad E-0.05 \mathrm{~mJ}, v=0.05 \mathrm{~mm} / \mathrm{s}$ and $s=$

$0.01 \mathrm{~mm}$ (original magnification, SEM $\times 374$ ) $\mathrm{d}$ SEM micrograph of femtosecond her cavities in enamel with $E-0.05 \mathrm{~mJ}, \gamma=0.05 \mathrm{~mm} / \mathrm{s}$ and $s=0.02 \mathrm{~mm}$ (original magnification. SEM $\times 374$ )

\section{으springer}


Capítulo 3: Publicaciones Originales

\section{Author's personal copy}

Lasers Med Sci

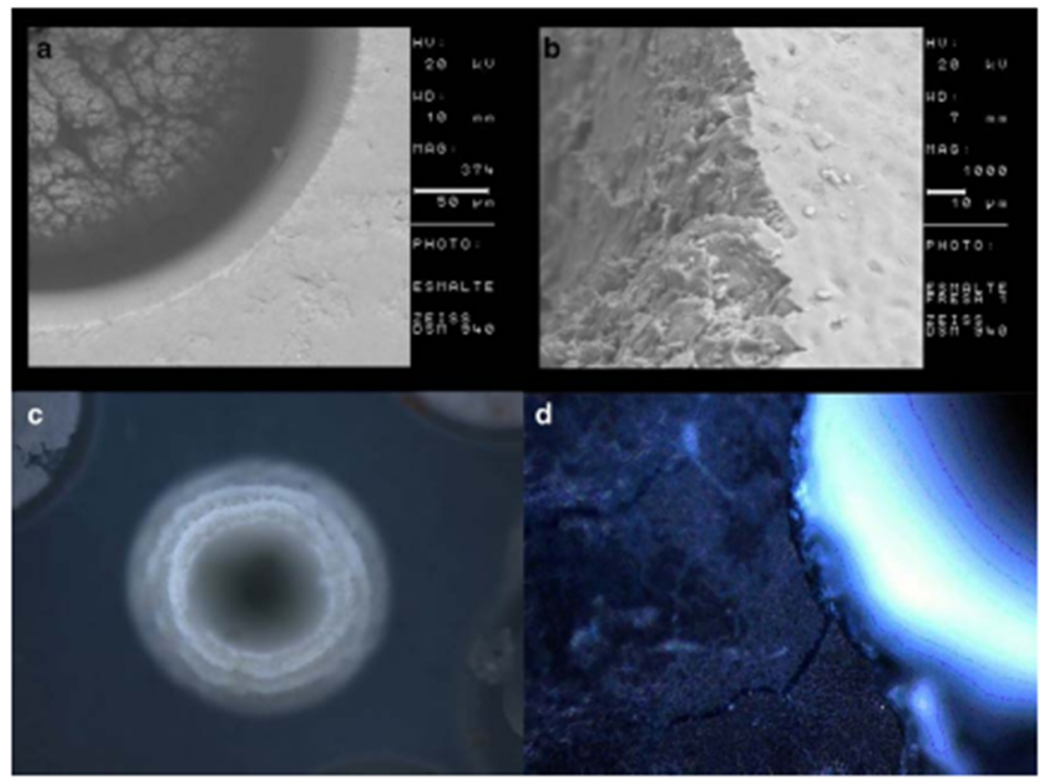

Fig. 3 a SEM micrograph of a circular cavity in enamel induced by femtosecond laser ablation (original magnification, SEM $\times 200$ ). The laser spot was initially located at the periphery and the beam offset was reduced so zero and again increased to its maximum (two passes). The pulse energy was set to $0.4 \mathrm{~mJ}$; b SEM micrograph of mechanical instrumentation cavities in enamel at a speed of 450,000 rpm under abundant water coolant (Boundary of the cavity: original

\section{Discussion}

Many studies have focused on the application of ultrashortpulsed lasers on hard dental tissues [11, 20-22]; however. few of them have addressed their application to the ename. exhaustively [10]. The suppression of microcracks with ultrashort pulses is of great importance in dentistry because these may become the source of new caries. In the present study, we used a femtosecond laser for the ablation of human enamel with the aim of minimizing these microcracks, which systematically appear with conventional mechanical techniques. Conventional techniques for drilling enamel lead to the formation of microfractures on the surface as a result of the high thermal and mechanical loads. In addition. melting and resolidification give rise to a smear layer on the walls of the cavities, such that further treatments are required to provide optimal access of restorative materials to them [23].

The SEM images reveal the ability of the femtolaser to produce high-precision cavities in tooth enamel

magnification, SEM $\times 500)$; $c$ cavity performed by means of femtosec. ond laser ablation. The laser spot was initially located at the center and the beam offset was increased to its maximum and back to zero (two passes). The pulse enengy was set to $0.4 \mathrm{~mJ}$; $\mathrm{d}$ presence of cracks in cavity made with an air-turbine at a speed of $450,000 \mathrm{~mm}$ under abundant water coolant

(Figs. 2a-d, 3a). No signs of collateral damage and cracks were observed, unlike with conventional milling. As described previously in the literature for other biological tissues. the application of subpicosecond pulses almost completely eliminates thermal damage and the appearance of microcracks in adjacent areas $[24,25]$. Rode et al. concluded that the removal of enamel using a subpicosecond laser allows the side effects produced by air turbines to be eliminated. Moreover, this technique permits the painless removal of hard dental tissue, thereby enhancing the efficiency of clinical procedures [26, 27] (Figs. 1, 2a-c, 3a).

We tested different geometries and processing parameters. Our conclusion is that careful selection of the parameters is crucial for achieving precise and high-quality structures on the enamel surfaces. The pulse energy determines the rate of material removal, but very high energies tightly focused on the surface could lead to some damage since phase explosion mechanisms begin to come into play.

The scanning speed determines the number of pulses contributing to ablation in a given region of the surface. The

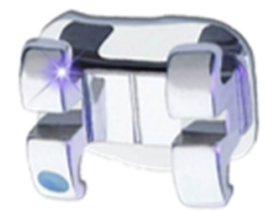


VNIVERSIDAD

BSALAMANCA

faster the scan, the lower number of pulses, and hence lower ablation rates. Both parameters decisively influence the depth of the cavity. The morphology is driven by the sample motion features. The dimensions of the cavities performed were not affected by these parameters, remaining approximately at $200-250 \mu \mathrm{m}$.

We tested two different cavity pattems with rectangular and circular shapes. A meandering and a spiral path were respectively used to produce these geometries. In both cases, the ratio between the pitch and the laser spot size on the surface was very important. A ratio above unity could lead to incomplete ablation of the cavity.

Finally, ablation debris is deposited at the bottom of the cavitics. Its shape is the result of the rapid volume expansion of the evaporating water contained in the tissuc. The location of the debris is determined by the scanning procedure. We checked the possibility of eliminating the debris without using any pressured fluid or gas. Also, we tested some different sample motion strategies, but without success.

According to the results obtained here, it may be stated that human tooth enamel can be successfully removed with femtosecond lasers, in agreement with other investigations addressing the ultrashort-pulsed laser ablation of hard dental tissue [25-27].

This system has many advantages over the mechanical technique and techniques using other types of laser. These are discussed below.

1. When mechanical instrumentation is used, friction generates high temperatures, which cause irreversible damage to the tooth; the tooth surface shows signs of thermal and mechanical damage, together with the presence of a smear layer that is formed after implementation of this technique. In contrast, the femtosecond ( $\mathrm{T}$ i Sapphire) laser causes minimal structural changes to the irradiated enamel. The surfaces show a complete lack of thermal or mechanical damage such as cracks, craters. or charring. The treated surface has a rough and irreg. ular aspect without a smear layer or cracks. These benefits have been also described by several other authors [25].

2. Additionally, the size and shape of burs does not allow complex shapes or minimally invasive treatment [28]. The femtosecond laser affords the possibility of making incisions ten times smaller than that permitted by the smallest bur [29] and allows greater control of the removal of material.

3. Preparations with mechanical instrumentation require the accompanying use of irrigation to prevent pulp involvement after it has undergone the high temperatures generated inside the cavity. In addition, when using lasers of the erbium family on enamel, this requires the joint use of irrigation to reduce possible temperature increases. This irrigation tends to reduce the visibility of the operative field.

4. Ultrashort pulse laser ablation means that irrigation is not required because the process occurs in a shorter time, in which the materials do not have the necessary time to transmit heat (of the order of tens to hundreds of picoseconds), and the generation of a stable particle flux is not possible [22].

5. With the use of the femtosecond laser, patient stress would be theoretically reduced since there is no noise or need for anesthesia on performing the cavity, unlike the case of mechanical ablation.

6. Ultrashort pulse lasers enable the effective ablation of nearly all materials, including metal restorations, which cannot be removed with erbium lasers. This is because when performing femtolaser ablation, the absorption coefficient of the material depends on the intensity of the radiation rather than on the wavelength, as in the case of conventional lasers.

This study was an initial project whose results suggests that the application of ultrashort pulse lasers as contactless drills in dentistry may provide an alternative to classical mechanical techniques, aimed at improving the quality of dental treatment. Further studies will focus on the bonding of dental materials to laser-imadiated enamel.

\section{Conclusions}

In the present study, we demonstrate the ability of femtolasers to produce high-precision cavities in tooth enamel. The femtosecond laser is presented as an optimal tool for the treatment of dental decay and as an altemative to air-turbine drills to reduce the mechanical damage that occurs during the removal of hard dental tissue.

Acknowledgments A.G. and P.M. acknowledge the support of Spanish Ministerio de Ciencia e lnnovecilo throuth the Conot of Program SAUYH (CSD2007.00013) and research projest FIS2009 Program. SAlur (CSD2007.00013) and researtè project FIS2009. 09522, from Jurna de Castill y León through the Program for Groupo of Eucentence (GR27) and of the EC Seventh Framework Progranme (LLSERLAB BUROPE, grant agreencnt no. 228334 ) We also asknowlstpport of the Centro de Laseres Pulsados, C.PU, Sulamanca, Spain

\section{References}

1. Yaman BC, Guray BE, Doner C, Gomex Y, Yazicioglu O, Erdilek D (2011) Effect of the erbium-ytrium-aluminum-garnet laser of

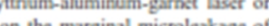
diamond bur cavily propuration on the marginal microleakage of class

2. Anusavise KJ (1997) Efficacy of nonsurgical management of the initial caries kesion. I Dent Edux 6:895-905 
Capítulo 3: Publicaciones Originales

\section{Author's personal copy}

Lasers Mod Sci

3. Peters M, Mclean I (2001) Minimal intervention and concepts for minimally invasive cavity proparations. J Adhes Dent 3:7-16

4. Colucei V, do Amaral FL. Pécora JD, Palma-Dibb RG. Corona SA (2009) Water flow on erbium:ytrium-aluminum. Corona SA (2009) Water flow on erbium:yttrium-aluminumgarnet laser irradiat
Sci $24: 811-818$

5. Fomaini C, Riceputi D, Lupi-Pegurier L, Rocea JP (2012) Patient responses to Er:YAG laser when used for conservative dentistry.

6. Keller U, Hibst R (1989) Experimental studies of the application of the Er.YAG laser on dental hard substances II. Light microscopic and SEM investigations. Lasers Surg Med 9-345-351

7. Parker $\mathrm{S}$ (2007) Surgical lasers and hard dental tissue. Br Dent 202:445-454

8. Lustosa-Pereira AC, Porza DH, Cunha A. Deduvid RA, Duarte-de Morass JF. Gertardt-de Oliveira M (2011) Analysis of the morphology and composition of tooth apices apicectomized using three different ablation technigues. Med Oral Patol Oral Cir Bucal $16: 225-230$

9. Firat E, Gurgan S, Gutknecht N (2012) Microtensile bond strength of an etch-and-rinse adhesive to enamel and dentin affer Er.YAC of an etch-and-rinse adhesive to enamel and dentin affer Er.YAG
laser pretreatment with different pulse durations. Lasers Med Sci 27:15-21

10. Ji L, Li L, Devlin H, Liu Z, Jias J, Whinchead D (2011) Ti:sapphire fembosecond laser ablation of dental enumel, dentins, and cemen. tum. Lasers Med Sci 27(1):197-204

11. Kim BM. Feit MD, Rubenchi AM, Joslin EJ, Celliers PM, Eichler J. Da Silva LB (2001) Influence of pulse duration on ultrasbort laser pulse ablation of biological tissues. J Biomed Opt 6:332-338

12. Niemz MH, Kasenbucher A, Strassl M, Bācker A, Beyerti A, Nickel D et al (2004) Tooth ablation using a CPA-froe thin disk fermosecond laser system. Appl Phys B 79-269-271

13. Zhang N, Wang W. Zhu X, Liu J. Xu X. Huang P. Zhoo J, Li R. Wang M (2011) Investigation of ultrashort pulse laser ablation of solid targets by measuring the ablation-generated momentum using a torsion pendulum. Opt Express 19:8870-8878

14. Pronko PP. Dutta SK. Squier SJ, Rudd JV, Du D. Mourou G (1995) Machining of sub-micron holes using a femtosecond laser at $800 \mathrm{~nm}$. Opt Commun 114:106-110

15. Chichkor BN, Momma C, Nolve S, von Alvensleben F, Tünnemunt A (1996) Femosocond picosecoed and numosecond leser abhation of solids. Appl Phys 63:109-115
16. Varel H. Ashikenasi D, Rosenfeld A, Wahmer M. Campbell EEB (1997) Micromachining of quartz with ultrashort laser pulses. Appl Phys A 65:367-373

17. Nolte S, Momma C, Jacobs H. Tunnermann A. Chichkov BN. Wellegehausen B, Welling H (1997) Ablation of metals by ultrashort laser pulses. J Optic Soc Am B 14:2716-2722

18. Mourou G, Strickland D (1985) Compression of amplified chirped optical pulses. Opt Commun 55:447-449

19. Vizquez de Aldana JR, Méndez C. Roso L. Moreno P (2005) Propagation of ablation channels with multiple femtosecond laser pulses in dielectrics: numerical simulations and experiments. Phys D Appl Phys 38:2764-2768

20. Girard B, Yu D, Armstrong MR, Wilson BC, Clokic CM, Miller RJ (2007) Effects of femtosecond laser irradiation on osseous tissues. Lasers Surg Med 39:273-285

21. Portillo M. Lorenzo MC. Sinchez JM. Peix M. Albaladejo A. Garcia A et al (2012) Morphological alterations in dentine after mechanical treatment and ultrashort pule laser imadiation. Lasers Med Sci 27:53-58

22. Ji L. Li L Devlin H. Liu Z Jiso J, Whitchead D (2012) Tisapphire fembosecond laser ablation of dental enamel, dentinc, and cemen. tum. Lasers Med Sci 27:197-204

23. Elworapoj P. Sditu SK, McCabe JF (2007) Effect of different power paramsters of Er. Cr.YSCGG laser on human dentine. Lasers Med Sci 22:175-182

24. Kohns P. Zhow P. Stormann R (1997) Effective laser ablation of enamel and dentine without thermal side effects. J Laser Appl 9:171-174

25. Pike P, Parizger C, Splinter R, Lockhart P (2007) Temperature distribution in dental tissue after interaction with femtosecond laser pulses. Appl Opt 46:8374-8378

26. Rode AV, Gamaly EG, Luther-Davies B (2002) Subpicosecond laser ablation of dental enumel. J Appl Phys 92:2153-2158

27. Rode AV. Gamaly EG, Luther-Davies B, Taylor B, Graessel TM. Duwes $\mathrm{M}$ et al (2003) Procision ablation of dental enamel using a subpicosecond pulsed laser. Aust Dent J 48:233-239

28. Wieger V. Zoppel S, Wintner E (2007) Ultrashort pulse lasef osteotomy. Laser Phys 17:438-442

29. Girard B, Cloutier M, Wilson DJ, Clokic CMI, Miller RJD, Wilson BC (2007) Microtomographic analysis of healing of femtosecopd laser bone calvaria wounds compared to mechanical instruments in mice with and without application of BMP.7. Lasers Surg Med 39.458-467

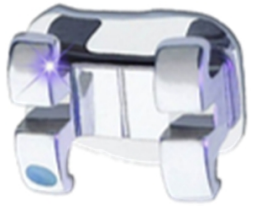




\subsection{ARTÍCULO II}

Lorenzo MC, Portillo M, Moreno P, Montero J, Castillo-Oyagüe R, García A, Albaladejo A. In vitro analysis of femtosecond laser as an alternative to acid etching for achieving suitable bond strength of brackets to human enamel. Lasers Med Sci. 2013 Mar 13. [Epub ahead of print].

ISSN: 0268-8921.

Impact index: 2.402. - JCR Science Edition: 2012.

Category: Surgery.

Position in the category: 45 de 195 (T1/Q1).

\section{RESUMEN}

Este estudio tiene por objeto evaluar el efecto de la irradiación láser y el grabado con ácido ortofosfórico en la resistencia a la cizalla de los brackets de ortodoncia al esmalte.

Tres grupos $(\mathrm{n}=20)$ de premolares extraídos fueron establecidos aleatoriamente en función del tratamiento láser que se realizó en las superficies bucales: (1) no laser (control); (2) láser de Er:YAG (2940 nm, 0.8 W, 100 s/pulse, 10 Hz) y; (3) láser de Ti:Zafiro (795 nm, $1 \mathrm{~W}, 120 \mathrm{fs} /$ pulse, $1 \mathrm{kHz}$ ). Cada grupo fue dividido en dos subgrupos en función de si el grabado con ácido ortofosfórico al 37\% se hizo después de la irradiación con láser o no. Los brackets se cementaron al azar con la resina adhesiva Transbond ${ }^{\mathrm{TM}}$ XT. Después de $72 \mathrm{~h}$, se desarrolló una prueba de resistencia al cizallamiento en una máquina de ensayo universal (velocidad de cruceta 0,5 $\mathrm{mm} / \mathrm{min}$ ). Se examinaron muestras representativas de cada subgrupo experimental 
Capítulo 3: Publicaciones Originales

mediante microscopía electrónica de barrido. Los residuos de resina que quedaron en la superficie de los premolares fueron evaluados utilizando el índice de adhesivo remanente. Se realizó el análisis de los datos utilizando ANOVA, pruebas post-hoc para las comparaciones entre grupos, prueba de chi-cuadrado y de regresión lineal $(\alpha=0.05)$.

Después del grabado ácido, los valores de resistencia a la cizalla no difirieron independientemente del tratamiento láser utilizado. Cuando no se aplicó ácido ortofosfórico, los valores de adhesión para la resistencia al cizallamiento para el grupo láser de pulso ultracorto fueron significativamente mayores que para el resto de grupos.

La aplicación del láser de pulso ultracorto sin ácido parece ser el método más adecuado para mejorar la fuerza de adhesión en la interfase bracket-esmalte, evitando así las desventajas propias del grabado ácido.

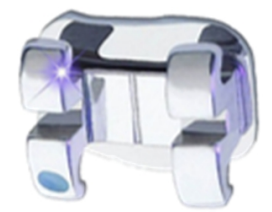


VNIVERSIDAD

BSALAMANCA

Lasers Med Sci

DOI 10.1007/s10103-013-1278-5

ORIGINAL ARTICLE

\section{In vitro analysis of femtosecond laser as an alternative to acid etching for achieving suitable bond strength of brackets to human enamel}

M. C. Lorenzo - M. Portillo - P. Moreno - J. Montero -

R. Castillo-Oyagüe - A. García - A. Albaladejo

Received: 20 November 2012/Accepted: 28 January 2013

O Springer-Verlag London 2013

Abstract This study aims to evaluate the effect of laser urradiation and orthophosphoric acid etching on the shear bond strength (SBS) of orthodontic brackets to enamel. Three groups $(n-20)$ of extracted premolar teeth were randomly established depending on the laser treatment performed on the buccal surfaces: (1) no laser (control); (2) Er.YAG laser $(2,940 \mathrm{~nm}, 0.8 \mathrm{~W}, 100 \mu \mathrm{s} / \mathrm{pulsc}, 10 \mathrm{~Hz})$ and; (3) Ti:Sapphire laser (795 nm, 1 W, $120 \mathrm{fs} /$ pulse, $1 \mathrm{kHz}$ ). Each group was divided into two subgroups according to whether $37 \%$-orthophosphoric acid etching was made after laser irradiation or not. Brackets were randomly luted with Transbond ${ }^{\mathrm{TM}} \mathrm{XT}$ adhesive resin. After $72 \mathrm{~h}$, a SBS test was developed in a universal testing machine (crosshead speed, $0.5 \mathrm{~mm} / \mathrm{min}$ ). Representative specimens from each experimental subgroup were examined by means of scanning electron microscopy. Cement residuals remaining on the premolar surfaces were assessed using the adhesive remnant

M. C. Lorenxo (ㅈ) - M. Portillo - J. Montero - A. Albuladejo Dental Clinic (Faculty of Modicine),

University of Salumanca, Passo Universidad

de Coimbra, s'n, 37007 Salamanca, Spain

c-mail: meruzlorenuora botmail.com

P. Moreno - A. Garcia

Laser Microprocessing Research Group.

University of Salumanca, Plasa de la Mereed.

shin. 37008 Salamanca, Spain

R. Castillo-Oyagüe

Department of Buccofacial Prostheses.

Faculty of Dentistry. Complutense University

of Madrid (U.C.M.). Pra. Ramón y Cajal,

$\sin 28040$ Madrid, Spain

Published coline: 13 March 2013 index. ANOVA, post-hoc tests for intergroup comparisons, chi-square test and linear regression were run for data analyses $(\alpha-0.05)$. After acid etching, SBS values did not differ regardless the laser treatment. When phosphoric acid was not applied, the SBS values of the femtosecond laser group were significantly higher than for the other groups. Femtosecond laser without acid seems to be the most suitable method to improve bond strengths at the bracket/enamel interface, thus avoiding the disadvantages inherent to acid etching.

Keywords Femtosecond laser - Enamel - Adhesion Shear bond strength

\section{Introduction}

The application of $37 \%$-phosphoric acid for $15 \mathrm{~s}$ remains the most common conditioning method for bonding brackets to enamel [1-3]. Despite demonstrating optimal bond strength values [4], the demineralization of the most superficial enamel layer is a potential drawback [5]. As a result, the surface becomes more sensitive to long-term acid attack and caries, mainly in case of incomplete or defective resin impregnation $[2,6]$.

Exposing enamel to laser irradiation seems to provide some degree of protection against demineralization under acid attack [7]. Laser devices have been used for soft tissue surgery, root end sealing and sterilization; and for altering enamel and dentin surfaces to increase resistance to decay or facilitate bonding of composite resins [8-12]. Nonetheless. whereas some studies report significantly lower bond 
Capítulo 3: Publicaciones Originales

Author's personal copy

Lasers Med Sci

strengths for laser-structured than for acid-etched teeth $[2,4$, 13, 14]; others show comparable or even stronger bond strength values for laser treatment [15-17].

The Erbium lasers were specifically introduced in dentistry for cutting enamel and dentin [18, 19]. These lasers emit energy in the wavelength range of $2.6-3 \mu \mathrm{m}$. Such interval coincides with the strongest absorption peak of water, which is an important component of dental hard tissues [20]. In particular, the Er:YAG laser $(2,940 \mathrm{~nm})$ radiation is strongly absorbed by water and hydroxyapatite.

During the last decade, ultrashort pulsed lasers have been tested as a potential and alternative tool for dental surgery and orthodontics. Sapphire crystals doped with titanium ( $\mathrm{T}_{1}$ : Sa) are the main source to produce laser pulses with a duration in the range of the tens and hundreds of femtoseconds. These laser pulses, amplified up to energies of the order of millijoule [21] and conveniently focused on the materials surface, allow the ablation of thin layers with outstanding precision and reproducibility, which may result in much less collateral damage to the adjacent elements than any other thermal, chemical or mechanical process $[22,23]$. These lasers have already been used on dental hard tissues $[24,25]$. The absorption of ultrashort laser radiation is painless and does not involve vibration or heating. Such qualities make them good candidates for use in dental practice [26].

To our knowledge, there is no previous study comparing the performance of ultrashort lasers with regard to other conventional techniques for improving the bond strength of different orthodontic attachments to enamel surfaces.

Accordingly, the aim of the present in vitro study is to evaluate the influence of two different laser treatments (Er: YAG and ultrashort) and orthophosphoric acid etching on the shear bond strength (SBS) of orthodontic brackets to enamel. The null hypothesis tested is that neither laser treatment nor acid etching. nor the combination of both techniques, influences the SBS of brackets to human enamel.

\section{Materials and methods}

Sample preparation and storage

A schematic illustration of the preparation of specimens is shown in Fig. 1. Sixty extracted human premolar teeth were collected and stored in a 0.5 chloramine $T$ solution for a maximum of six months after extraction. Exclusion criteria included previously restored premolars and premolars with enamel defects or cracking and delamination of the enamel.

Premolar teeth were examined with an Axio Ml light microscope (Carl Zeiss, Oberkochen, Germany) operating in the dark-ficld mode. Epiplan $\times 20$ and $\times 50 \mathrm{HD}$ objectives
(Carl Zciss Vision) were attached to a $1300 \times 1030$-pixel digital camera (AxioCam HR, Carl Zciss Vision). Consistent with the exclusion criteria, the selected premolar teeth were mounted in self-cured acrylic blocks. The buccal surfaces were oriented perpendicularly to the bottom of the molds so that the bonded interfaces were parallel to the force applied during the later SBS test.

Before laser irradiation and acid etching, the buecal crown surface of each premolar was polished for $15 \mathrm{~s}$ with fluoride-free pumice slurry, washed for $30 \mathrm{~s}$ and dried for $10 \mathrm{~s}$ with a moisture-free air spray.

Experimental groups

Prior to bonding the metal brackets, the premolar teeth were randomly assigned to three groups $(n-20)$ depending on the laser treatment to be applied on the enamel surfaces: (1) no laser (control); (2) Er:YAG laser (Fidelis Plus III; Fotona, Ljubljana, Slovenia), and (3) ultrashort pulsed laser (Tsunami; Spectra Physics, Mountain View, CA, USA).

\section{Laser irradiation}

\section{Erbium laser processing}

The Er:YAG laser used in the study emits at a wavelength ( $\lambda$ ) of 2,940 $\mathrm{nm}$. The irradiation was performed under the following conditions: $80 \mathrm{~mJ} /$ pulse, VSP $(100 \mu \mathrm{s}), 10 \mathrm{~Hz}$ output power of $0.8 \mathrm{~W}$. focal distance of $10 \mathrm{~mm}$ and beam spot diameter of $0.5 \mathrm{~mm}$ with a non-contact handpiece (R02). The enamel surfaces were previously moistened to avoid cracking and fusion and were cooled with water spray during irradiation. To simulate as closely as possible actual clinical performance, the laser beam was manually directed without the use of any fixed support.

\section{Ultrashort laser processing}

The laser system consists of a commercial Ti:Sapphire oscillator (Tsunami; Spectra Physics) which provides pulses in the near infrared $(\lambda-795 \mathrm{~nm})$ and a regenerative amplifier (Spitfire; Spectra Physics) based on the chirped pulse amplification technique [21] which allows to increase the pulsc energy up to $1 \mathrm{~mJ}$. The system delivers pulses with a duration of approximately $120 \mathrm{fs}$, at a repetition rate of $1 \mathrm{kHz}$ and a maximum output power of $1 \mathrm{~W}$.

The pulse energy is finely controlled by a half-wave plate and a linear polarizer. Neutral density filters were used when further energy reduction was required. The average power of the beam was measured with a thermopile detector (407A; Spectra Physics). The transversal mode is nearly a Gaussian TEM00 with a $9 \mathrm{~mm}$ beam diameter (at $1 / \mathrm{e} 2$ ). The laser pulses were focused by means of achromatic doublet 
VNIVERSIDAD

BSALAMANCA

Author's personal copy

Lasers Med Sci

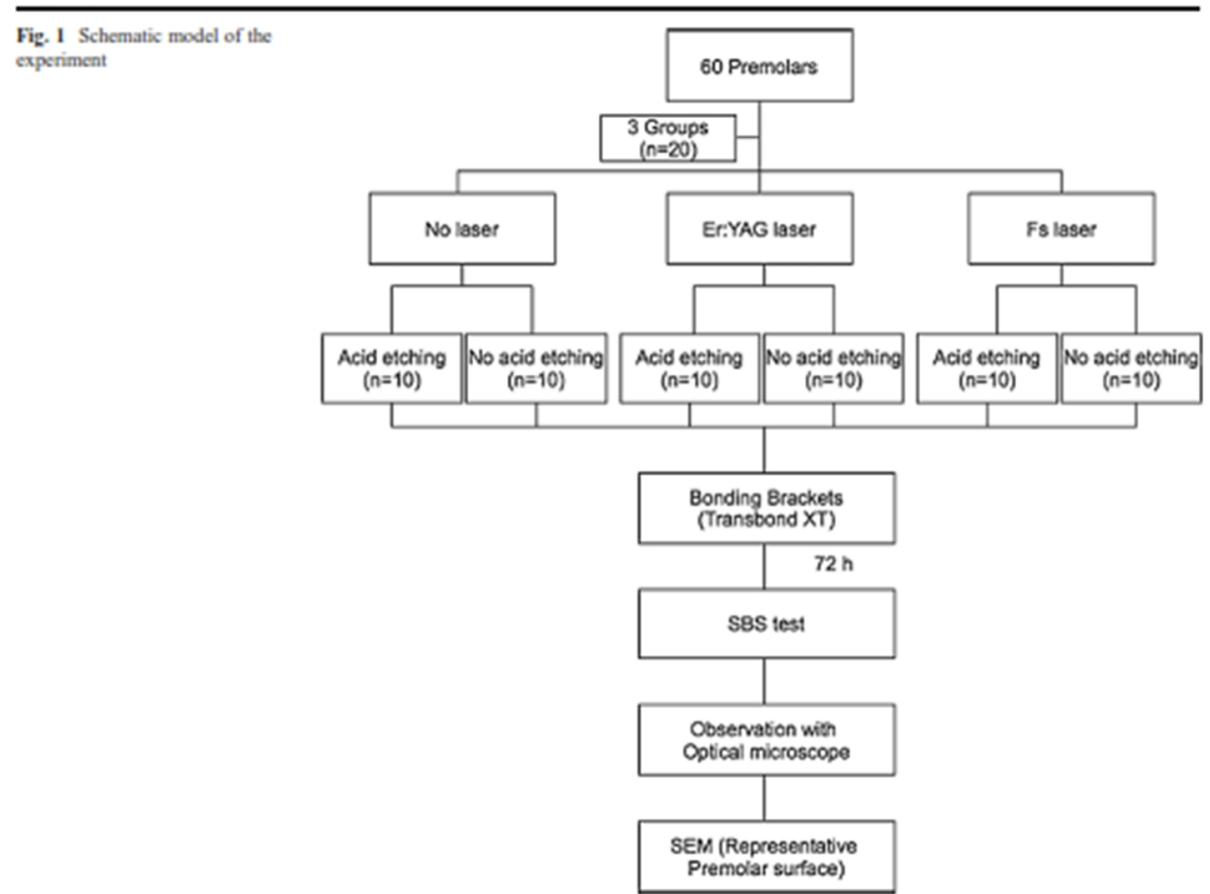

lens $(f-100 \mathrm{~mm})$. With this focusing system the spot size has a diameter of approximately $12 \mu \mathrm{m}$.

The specimens were fixed on a computer-controlled XYZ motorized stage (Micos ES100; Nanotec Electronic GMBH \& Co Munich, Germany). The laser pulses impinged vertically on the enamel surfaces. Therefore, the optimum focalization of the pulses on the teeth surfaces was provided by $Y$ motion and scanning by $X Z$ motion.

For processing the enamel surfaces a computer code was developed driving the three motors in a way that the threedimensional surface of each premolar could be homogeneously scanned across the region of interest (ROI). Such ROI-area is in the range of $15-40 \mathrm{~mm}^{2}$ depending on the tooth morphology. Since the processing setup does not allow beam motion, the angle between the sample surface and the beam axis must be minimized in order to maximize the absorption of the pulse energy. Otherwise, there would be a substantial difference between the structuring at the apex and at the slopes of the surface. So far, the sample is tilted so that the laser pulses face the flatter surface possible. The scanning pattern was bidirectional.

The enamel was processed in tight focusing conditions. The laser parameters were programmed according to previous works on ultrashort laser processing of hard dental tissues $[23,25]$. The focal length of the lens, the pulse energy $(0.03 \mathrm{~mJ})$, the scanning velocity $(0.5 \mathrm{~mm} / \mathrm{s})$ and the pitch between adjacent scans $(0.015 \mathrm{~mm})$ were chosen to generate smoothly overlapping and swallow microstructures.

The teeth samples were laser processed in a saturated vapor atmosphere to preserve the dental tissues from drying. All of the tested specimens were stored in distilled water before and after laser irradiation.

\section{Acid ctching}

For each experimental group, half of the specimens $(n-10)$ were acid-etched for $30 \mathrm{~s}$ by spreading $37 \%$ phosphoric acid gel (3MTM ESPETM Scotchbond ${ }^{\mathrm{M}}$, 3M ESPE, St. Paul, MN, USA) on the enamel surface areas where the brackets were to be located (ROI). Afterwards, the buccal enamel surfaces were rinsed with tap water for $10 \mathrm{~s}$ and dried with oil-free and moisture-free air for $20 \mathrm{~s}$ until the enamel had a faintly white appearance as recommended by the manufacturers. 
Capítulo 3: Publicaciones Originales

Author's personal copy

Lasers Med Sci

\section{Bonding procedure}

Sixty brackets having micro-etched bases (3M Unitek, Monrovia, CA, USA) were randomly bonded to the premolars' buccal surfaces using a total etch adhesive system to enamel consisting of a combination of a primer and an orthodontic adhesive resin (Transbond ${ }^{\mathrm{M}} \mathrm{MT}$; 3M-Unitck, St. Paul, MN, US). The manufacturer's composition and application mode of the materials used in the experiment are detailed in Table 1.

The adhesive resin was applied to each bracket base (area, $9.15 \mathrm{~mm}^{2}$ ) after priming both the tooth and the bracket surfaces [27]. Brackets were then positioned onto the buccal enamel surfaces and pressed firmly with a Hollenback carver to expel the excess adhesive. Each bracket was subjected to a 300 -g compressive foree using a force gauge (Correx. Beme. Switzerland) for $10 \mathrm{~s}$, after which excess bonding resin was removed using a sharp scaler. Then, the composite was lightcured for $20 \mathrm{~s}$ from the occlusal and gingival bracket edges.

The bonding resin was photocured with a LED unit (Bluephase G2; Ivoclar-Vivadent, Schaân, Liechtenstein) emitting in the wavelength range $380-515 \mathrm{~nm}$ and a light intensity of $1,000 \mathrm{~mW} / \mathrm{cm}^{2}$ measured with a built-in radiometer (Bluephase Meter, Ivoclar-Vivadent) which was calibrated every $10 \mathrm{~min}$ to ensure consistent light intensity.

\section{Shear bond strength test}

The bracketed teeth were immersed in sealed containers of deionized water and placed in an incubator at $37^{\circ} \mathrm{C}$ for $72 \mathrm{~h}$ to permit adequate water absorption and equilibration. To conduct the SBS test, the specimens were secured in a jig attached to the base plate of a universal testing machine (Autograph AGS-X $10 \mathrm{KN}$, Shimadru, Tokyo, Japan).
The teeth were set at the base of the machine so that the sharp end of the rod incised in the area between the base and the wings of the bracket, exerting a force parallel to the tooth surface in an occluso-apical direction (crosshead speed. $0.5 \mathrm{~mm} / \mathrm{min}$ ). The force required to debond each bracket was registered in newtons $(\mathrm{N})$ and converted into megapascals (MPa) as a ratio of $\mathrm{N}$ to the bracket's surface area.

Failure mode analysis

After the SBS test, each specimen was examined under an optical microscope (Axio M1: Carl Zeiss) at $\times 50$ magnification to identify the location of the bond failure. The adhesive layers left on the premolar surfaces were assessed by using the adhesive remnant index (ARI), where each specimen was scored according to the amount of material remaining on the enamel surface as follows: 0 -no adhesive remaining: 1-less than $50 \%$ of the adhesive remaining: 2-more than $50 \%$ of the adhesive remaining and 3-all adhesive remaining with a distinct impression of the bracket base.

Scanning electron microscope analysis

Representative premolar surfaces were prepared for scanning electron microscope (SEM) analysis. Samples were dehydrated for $48 \mathrm{~h}$ in a desiccator (Sample Dry Keeper Simulate Corp., Tokyo, Japan) and sputter coated with a 10nm platinum layer in a Polaron E5100 SEM coating unit (Polaron Equipment Ltd., Hertfordshire, England, UK). The morphology of the debonded enamel surfaces was then examined with a variable-pressure SEM (Zeiss EVO MA 25: Carl Zeiss, Jena, Germany).

Table 1 Manufacturer, main composition and application mode of the materials tested

\begin{tabular}{|c|c|c|c|}
\hline Material & Manufacturer & Main components & Modosteps of application \\
\hline $\begin{array}{l}\text { Scotchbond } \mathrm{T}^{\mathrm{MM}} 37 \% \\
\text { phosphoric acid }\end{array}$ & $\begin{array}{l}\text { 3M ESPE, St. Paul, } \\
\text { MN, US }\end{array}$ & $37 \%$ phospboric axid & $\begin{array}{l}\text { The area where the bracket was to be located was } \\
\text { etched with a } 37 \% \text { phosphoric acid gel for } 30 \mathrm{~s} \text {, } \\
\text { rinsed for } 15 \mathrm{~s} \text {, and dried with oil-free and moisture } \\
\text { free air for } 20 \mathrm{~s} \text { until the enamel had a faintly white } \\
\text { appearance }\end{array}$ \\
\hline Transbond $^{\mathrm{TM}} \mathrm{XT}$ & $\begin{array}{l}\text { 3M Unitek: St. Paul, } \\
\text { MN, US }\end{array}$ & $\begin{array}{l}\text { Primer. Bis-GMA (Bisphenol } \\
\text { A-glycidyl methacrylate), } \\
\text { TEGDMA (triethylene glycol } \\
\text { dimethacrylate). Adhesive paste: } \\
\text { Silane-treated quartz, Bis-GMA. } \\
\text { dichlorodimethylsilane reaction } \\
\text { product with silica }\end{array}$ & $\begin{array}{l}\text { Primer. air-dry the tooth surfaces thoroughly. Place a } \\
\text { thin uniform layer of Transbond }{ }^{\mathrm{MM}} \mathrm{XT} \text { primer on } \\
\text { the bracket buse and on the tooth enamel surface to } \\
\text { be bonded. Adhesive: Apply a thin coat of } \\
\text { Transbond }{ }^{\mathrm{TM}} \mathrm{XT} \text { orthodontic adhesive onto the base } \\
\text { of each bracket and seat it firmly in place. A } \\
\text { minimum amount of composite resin must be } \\
\text { utilized to avoid excessive adhesive flash. Scale the } \\
\text { excess resin from around the brackets. Photo-cure } \\
\text { for } 20 \text { s from the oeclusal edge and } 20 \text { s from the } \\
\text { gingival bracket edge }\end{array}$ \\
\hline
\end{tabular}

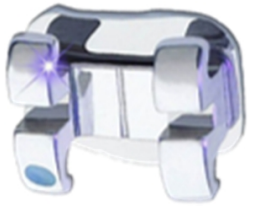


VNIVERSIDAD

BSALAMANCA

Author's personal copy

Lasers Med Sci

Table 2 Mean and standard deviation (SD) of the shear bond strength (SBS) values (MPa) obtained in the experimental groups

\begin{tabular}{llll}
\hline Enamel surface treatments & No laser (control) & Er.YAG laser & Ti-Sapphire laser \\
\hline With acid etching & Mean: $18.6 \mathrm{~b}$ B & Mean: $20.2 \mathrm{~b}$ B & Mean: 22.0 b B \\
& SD: 5.0 & SD: 10.9 & SD: 7.9 \\
Without acid etching & Mean: 6.4 a A & Mean: 7.8 a A & Mean: 22.9 b B \\
& SD: 2.4 & SD: 7.0 & SD: 8.3 \\
\hline
\end{tabular}

ANOVA test: $F-9.698 ; P<0.001$

Similar lowercase letters in rows and equal capital letters in columns indicate the absence of significant differences

Specific areas of the brackets were also explored to identify possible differences among the experimental groups with respect to the surface topography of such brackets.

Statistical analysis

Descriptive statistics including means and standard deviations were calculated for the SBS values. Differences in SBS among the experimental groups were examined using ANOVA and Bonferroni multiple comparisons test.

To assess the influence of acid etching and laser surface treatment on SBS, a step-wise multiple linear regression was run, the SBS being the dependent variable. The predictive variable named "Laser" was divided into two dummy variables considering the absence of laser treatment as "control" reference (i.c., Laser I-Er.YAG against control; Laser 2-ultrashort laser against control). The Determination Coefficient $\left(R^{2}\right)$ was taken as the indicator of the model fit.

The ARI scores were analyzed for percentage and frequency of fracture type, and a chi-square test was used to compare acid-etched and non acid-etched samples within each laser treatment group. The ARI scores were categorized as $\mathrm{ARI}-0-1$ vs. ARI-2-3 for statistical comparisons.

All of the statistical analyses were performed using the SPSS v. 18 software for Windows (Statistical Package for the Social Sciences, Chicago IL., USA). Significance for all statistical tests was predetermined at $P<0.05$. A $P$ value in

Tabk 3 Cross-tabulation of the effect of acid etching within the laser treatment groups according to a dichotomous variable generated from the ARI scores (0-1 score vx. 2-3 scores)

\begin{tabular}{|c|c|c|c|c|c|c|c|c|}
\hline \multirow[t]{3}{*}{ ARI } & \multicolumn{6}{|c|}{ Laser groups } & \multirow{2}{*}{\multicolumn{2}{|c|}{ Total: $n(\%)$}} \\
\hline & \multicolumn{2}{|c|}{ No hser: $n(\%)$} & \multicolumn{2}{|c|}{ Er:YAG laser: $n(\%)$} & \multicolumn{2}{|c|}{ Tt:Sapphire laser: $n(\%)$} & & \\
\hline & $\begin{array}{l}\text { With } \\
\text { etching }\end{array}$ & $\begin{array}{l}\text { Without } \\
\text { etching }\end{array}$ & $\begin{array}{l}\text { With } \\
\text { etching }\end{array}$ & $\begin{array}{l}\text { Without } \\
\text { exhing }\end{array}$ & $\begin{array}{l}\text { With } \\
\text { etching }\end{array}$ & $\begin{array}{l}\text { Without } \\
\text { etching }\end{array}$ & $\begin{array}{l}\text { With } \\
\text { etching }\end{array}$ & $\begin{array}{l}\text { Without } \\
\text { etching }\end{array}$ \\
\hline 0.1 scores & $3(30.0)$ & $10(100.0)$ & $8(80.0)$ & $9(90.0)$ & $2(20.0)$ & $7(70.0)$ & $13(43.3)$ & $26(86.7)$ \\
\hline 2.3 scores & $7(70.0)$ & $0(0.0)$ & $2(20.0)$ & $1(10.0)$ & $8(80.0)$ & $3(30.0)$ & $17(56.7)$ & $4(13.3)$ \\
\hline \multicolumn{3}{|c|}{$\begin{array}{l}\text { Chi-square-10.77 } \\
P<001\end{array}$} & \multicolumn{2}{|c|}{$\begin{array}{l}\text { Chi-square }=0.39 \\
P=053\end{array}$} & \multicolumn{2}{|c|}{$\begin{array}{l}\text { Chi-square- } 5.05 \\
P<005\end{array}$} & \multicolumn{2}{|c|}{$\begin{array}{l}\text { Chi-square-12.38 } \\
P<0001\end{array}$} \\
\hline
\end{tabular}

the $0.05-0.10$ range was regarded as an indicator of a trend towards statistical significance.

\section{Results}

Shear bond strength

列erming the non acid-etched samples, those treated with acer showed statistically higher SBS than those statistically similar to each other (Table 2).

When applying acid etching. the three laser treatment groups performed equally concerning the SBS of brackets human enamel (Table 2).

Acid etching caused no significant effect on SBS in

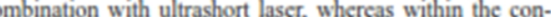
trol and Er:YAG laser groups, acid-etched samples recorded significantly higher SBS values (Table 2).

The Multiple Linear Regression model that attempted to Prer type (MPa) was significant (Chi-square-27.69; gl-3; $P<0.001)$. Acid etching significantly enhanced the SBS tested, the ultrashort laser was the only that significantly mproved the adhesion as compared to the control group $9.93 \mathrm{MPa} ; P<0.001$ ). The ErYYAG laser tended to increase the SBS values at the adhesive interface, but not significanty $(1.46 \mathrm{MPa} ; P=0.55)$. 
Capítulo 3: Publicaciones Originales

\section{Author's personal copy}

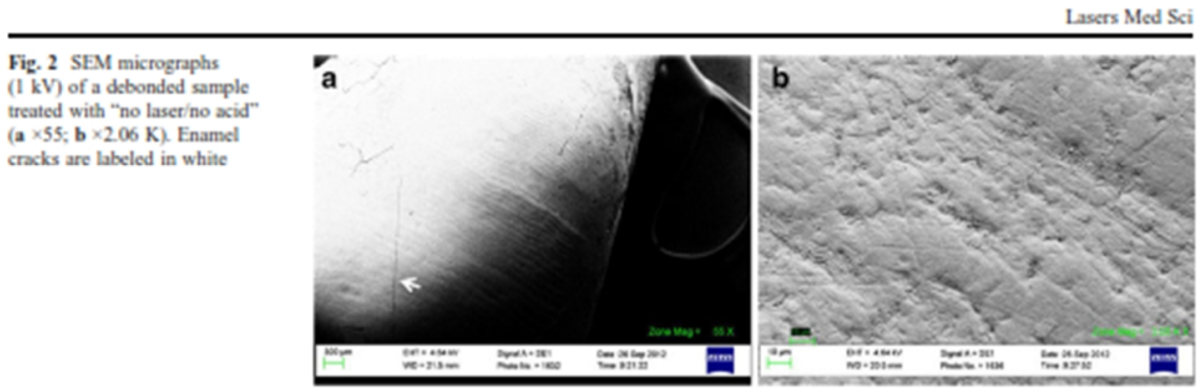

Adhesive remnant index

The ARI scores for the adhesive remaining on the tecth enamel surfaces after debonding are shown in Table 3 . Acid etching significantly increased the proportion of specimens in the category ARI-2-3; except for the Er:YAG laser group, in which acid etching had no significant effect.

The laser treatment yielded no significant differences in the ARI scores among non acid-etched samples (chi-square4.04: $P=0.13$ ). However, when comparing the distribution of ARI scores depending on the laser type in acid-etched specimens, both ultrashort laser and control groups registered a greater proportion of samples in the category ARI $-2-3$ than in the category ARI-0-1. The opposite results were observed for the Er.YAG laser group (chi-square-8.42; $P-0.015$ ).

\section{SEM observations}

Representative SEM images of debonded enamel surfaces after SBS testing are reported in Figs, 2, 3, 4 and 5.

Figure 2 includes micrographs of enamel surfaces treated with "no laser'no acid". All samples of this subgroup scored " 0 " in the ARI index (Table 3), showing no adhesive residuals remaining on the tecth surfaces (Fig. 2b). The cname appears intact, although some microcracks can be observed (Fig. 2a). Such cracks may have occurred due to the metalizing traction or to the SEM vacuum.
Figure 3 shows micrographs of tecth surfaces etched with "Er:YAG laser/no acid". In this subset less than $50 \%$ of the adhesive remained on the enamel surface (ARI-1) (Fig. 3a). Sometimes the teeth surfaces contain remarkable peaks and valleys. Although signs of fusion and solidification may be observed, no superficial cracks were identified (Fig. 3b).

Figure 4 displays micrographs of enamel surfaces treated with "ultrashort laserino acid" after SBS testing. ARI-1 was the most common failure mode. Less than $50 \%$ of the adhesive remained on the teeth surfaces (Fig. 4a). Figure $4 \mathrm{~b}$ shows a resin-free zone in which an undulated surface produced by ultrashort laser irradiation can be noticed.

Figure 5 comprises micrographs of enamel surfaces etched "with ultrashort laser/acid". More than $50 \%$ of the adhesive remained on the teeth surfaces (Fig. 5a). ARI-2 was the predominant failure mode when acid was applied after ultrashort laser. In this case, the phosphoric acid attenuated the pattern left by ultrashort laser processing. although it is still evident (Fig. 5b). Cracks may have occurred due to the metalizing traction or because of the SEM vacuum.

\section{Discussion}

In vitro measurements of the shear debonding forces have been rated as an acceptable methodology to determine future in vivo comparative conditions [14, 27, 28].

Fig. 3 SEM micrographs $(4.64 \mathrm{kV})$ of a debonded specimen trextod with "Er.YAG laser no acid" (a $\times 55 ; \mathbf{b} \times 1.97 \mathrm{~K}$
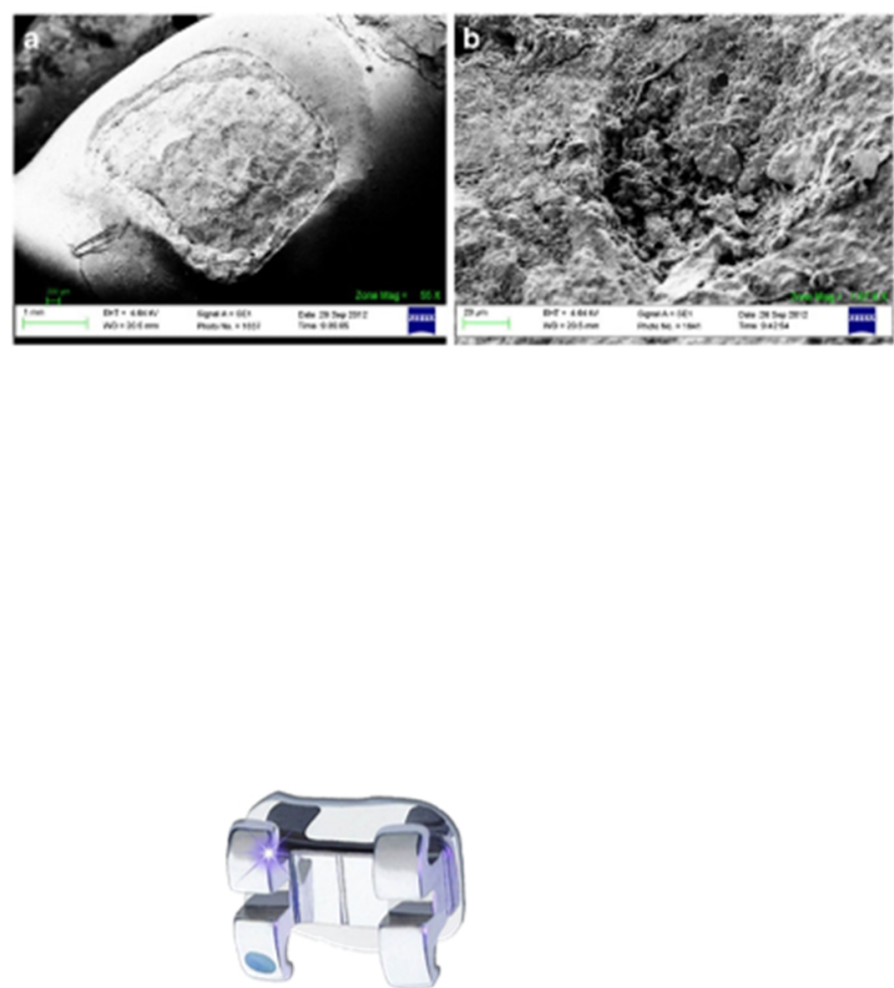
Lasers Med Sci

Fig. 4 SEM images $(4.64 \mathrm{kV})$ of a debonded sample treated with "Ti:Sapphire no acid" (a $\times 55$; b $\times 1.97 \mathrm{~K}$ )
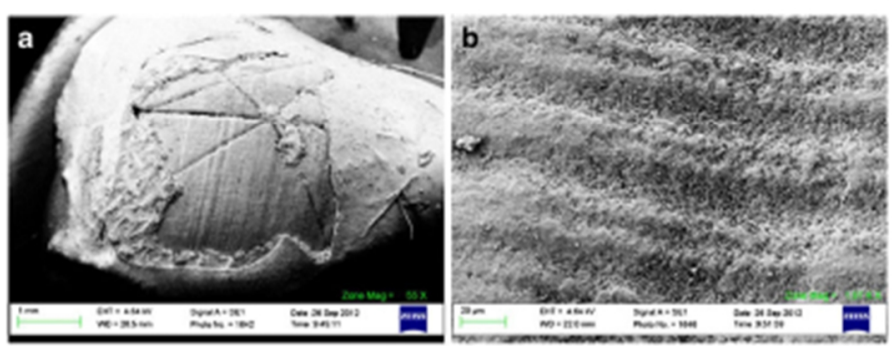

The results of the current experiment require the rejection of the null hypothesis, as differences among the experimental subgroups were confirmed.

When the teeth enamel surfaces were acid-etched, no significant differences were found for different laser treatments (Table 2). Nevertheless, the bond strength at the bracket/enamel interface significantly decreased in the case of teeth surfaces treated with "no laser'no acid" and "Er: YAG laser'no acid" (Table 2). Findings concerning the SBS values before and after acid application in the "no laser" group were consistent with other studies [15, 28-31]. Acid etching generates microporosities on the enamel surfaces through which the luting resin can penetrate [32]. After polymerizing, the micromechanical interlocking of resin tags within the acid-etched enamel surfaces provides the best achievable adhesion [33]. However, the decalcification of the enamel surface caused by acid etching, facilitates the caries attack [4].

The results of this investigation demonstrate that bonding to Er:YAG laser-treated enamel surfaces provide significantly weaker SBS values than bonding to simply acid-etched surfaces. Nonetheless, the combination of Er:YAG laser plus acid etching produced statistically similar SBS to that of acid-etched surfaces non treated with laser. Such results are in good agreement with former studies $[2,13,16]$. Hibst et al. and Altundasar et al, discovered microcracks on teeth enamel surfaces treated with Er:YAG laser that could be interpreted as a sign of thermal damage [20,34]. Authors reporting lower bond strengths in related research argued

Fig. 5 SEM images $(4.64 \mathrm{kV})$ of a debonded specimen treated TiSapphire acid" (a $\times 55$ : b $\times 1.97 \mathrm{~K}$ ) that microcracks constituted weak regions on the teeth surfaces that give rise to fractures and contaminant filtrations to the tissues [35, 36]. In contrast, some studies find similar or even greater bracket-to-enamel bond strengths when the Er: YAG laser is applied than when the enamel surfaces are just acid-etched [17, 37-39]. Such contradictory results may be attributed to differences among the study protocols. Previous investigations have demonstrated the influence of water flow rate [40], air pressure [41]. pulse duration [42], and laser irradiation distances [14] on the ablation rate, efficiency, surface morphology and SBS values. Hence, with the parameters programmed in our experiment it has been evidenced that Er.YAG laser irradiation of human enamel surfaces is not a good alternative to phosphoric acid etching for bonding brackets.

Therefore, either if samples were not laser processed or Er:YAG laser was used, greater SBS values were recorded when the enamel surfaces were acid-etched afterwards. Conversely, the ultrashort laser performed equally in terms of SBS regardless of the use of acid etching (Table 2). The ultrashort laser ability to provide high SBS values without applying phosphoric acid may be due to the micro and nanoroughness produced by laser ablation, which determines an undulated enamel surface texture (Fig. 4b).

To our knowledge, this is the first study on the adhesion of brackets to enamel that uses an ultrashort pulsed laser as a conditioner. In the current experiment, this type of laser has proved to be an appropriate substitute for orthophosphoric acid or Er:YAG laser. With the ultrashort laser, the practical
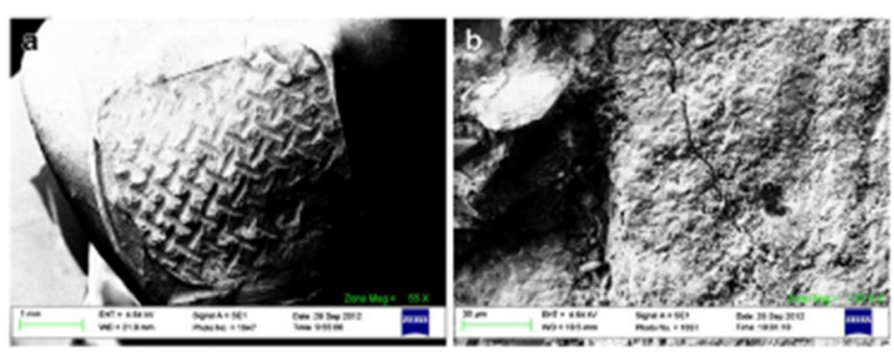
Capítulo 3: Publicaciones Originales

Author's personal copy

Lasers Med Sci

absence of thermal load on the remaining dental tissues prevents the formation of microcracks [23] that could impair the adhesion of brackets to enamel. According to our results, the ultrashort laser might replace the phosphoric acid, equaling the SBS and avoiding the adverse effects of acid etching. With this laser. the induction of microstructural changes on the irradiated enamel is minimal; it does not require irrigation and the acoustic disturbance is minimized [23]. Ultrashort pulses could induce thermal fatigue and mechanical damage of dehydrated enamel and dentin [43]. However, as the ultrashort laser generates a plasma-induced ablation, the thermal damage is always lower than that produced with erbium-based laser systems, which emit longer pulses. In our study. the premolar teeth were always hydrated; thereby the adverse effects that may cause the ultrashort laser on dehydrated enamel surfaces were avoided. Although Fig. 5 b shows a crack on the enamel surface, which could seem contradictory with the above discussion, this fissure may be due to electron collisions, to the traction generated during metallization or even to the SEM vacuum.

Microscopic observations of the failure sites provided some useful information (Figs, 2, 3, 4, 5). When no acid was applied after the tested laser treatments, more ARI-0 values were recorded (Table 3 and Figs. 2, 3, 4) probably because the adhesive does not have enough retention into the enamel causing the bracket debonding. In the surfaces treated with "no laser/acid"; and on enamel surfaces treated with "ultrashort laserlacid" (Fig. 5), most samples recorded ARI scores-2-3 (Table 3). These results are consistent with the literature [14, 15, 28]. Dunn et al. [32] attributed such effect to a blending of the typical pattem of the acid-etched enamel that might prevent the penetration of resin into the enamel surfaces. This can be advantageous for removing the residues after debonding. because less adhesive is expected to be left on the enamel surfaces. However, there is an increased risk of enamel fracture at the time of debonding [28]. When using ultrashort laser, although no differences in SBS were observed between acid-etched and non acidetched samples, the subsequent application of phosphoric acid might possibly increase the depth of the microretentions. This would make the resin tags deeper and more retentive, leaving more adhesive resin layering on the cnamel surfaces.

Clinical trials are necessary to support these conclusions, as ideal laboratory conditions are not common in daily practice [44]. Furthermore, the type of adhesive resin and the strict following of the manufacturers' instructions are also key factors for clinical success [45]. Despite the results obtained with ultrashort lasers in these and other in vitro tests, some drawbacks still preclude their implementation for the clinical practice. Among them, the time to etch the enamel surfaces still remains very long as a result of the small etching rate per pulse and the low repetition rates available. However some ultrashort laser systems for microstructuring purposes are being developed and even already commercialized reaching repetition rates in the megahertz range what should overcome the lack of competitivity of this technique. The same can be said with regard to the equipment costs and the dimensions of the laser processing system. In the last years, remarkable steps towards the miniaturization and therefore, the reduction of the investment costs, have been done which foresees a promising future for some applications in the field of odonthology.

\section{Conclusions}

Within the limitations of this study, ultrashort pulsed laser seems to be an optimal alternative for bonding orthodontic brackets to enamel. As the adhesion provided by ultrashort laser irradiation and acid etching is comparable, the adverse effects of phosphoric acid can be avoided by using this laser system.

\section{References}

1. Proffit WR (1986) Contemporary orthodontics. Mosby, Toronto

2. Martinez-Insuia A, Da Silva DL, Rivera FG, Santana-Penin U. (2000) Differences in bonding to acid-etched or ErYAG-lasertreated enamel and dentin surfaces. J Prosthet Dent 84:280-288

3. Bishara SE, Oonsombat C, Soliman MM, Warren JJ, Laffoon JE, Ajlouni R (2005) Comparison of bonding time and shear boed strength betwen a marentional and a new integrated bonding system. Angle Orthod 75:237-242

4. Lasmar MF, Reher VG, Lalloo R, Reher P (2012) Enamel demineralization and bracket bond strength when etching with axid and or ErYAG liser. Aust Dent J 57:190-195 5. Boyd RL. (1994) Comparison of three self-applied topical fluoride preparations for control of decalcification Angle Orthod 64:86

6. Ogaard B, Rolla G, Arends J (1985) Orthodontic appliances and enamel demineralization. Part 1. Lesion development. Am Orthod Dentofacial Onthop 94:68-73

7. Sogenaes RF, Stern RH (1965) Laser effest on resistance of humun dental enamel to demineralization in vitro. IS Calif Dent Assoe 33:328-329

8. Hidks MJ, Flaiz CM, Westermin GH, Berg JH. Blarkensu R1. Powell Gi. (1993) Caries-like lesion initiation and progression in sound enamel following argon laser irradiation: an in vitro study. ASDC J Dent Child 60:201-206

9. Westerman GH, Hicks MJ, Flaitz CM, Blankenue RJ, Powell GL. Berg JH (1994) Argon laser irradiation in roo surface caries: in vitro study examines laser's effects. J Am Dent Assoc 125:401. 407

10. Stratmunn U, Schaurshmidt K, Schurenberg M, Ehmer U (1995) The effect of Arf-excimer laser irradiation of the human enamel surface on the boed strength of orthodontic applances. Scanning Microse 9:469-476

11. Moritz A. Sperr W, Schoop U, Goharkhay K. Gutknecht N. Doertbudak O (1997) Nd:YAG laser irradiation of infected root canals in combination with microbiological examinations. Am Dent Assoc 128:1525-1530

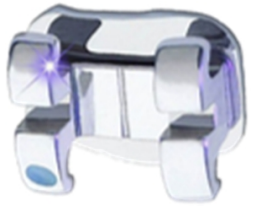


VNiVERSIDAD

BSALAMANCA

Author's personal copy

Lasers Med Sci

12. Hamamci N, Akkurt A, Basaran G (2010) In vitro evaluation of microleakage under orthodontic brackets using two different laser etching, self etching and acid etching methods. Lasers Med Sci 25:811-816

13. Von Fraunhofer JA. Allen DJ. Orbell GM (1993) Laser etching of enamel for direct bonding. Angle Orthod 63:73-76

14. Basaran G, Hamamei N, Akkur A (2011) Shear bond strength of bonding to enamel with different laser irradiation distances. Lasers

Med Sci 26:149-156
15. Lee BS, Hsich TI, Lee YL, Lan WH, Hsu Y1, Wen PH, Lin CP (2003) Bond strengths of orthodontic bracket after acid-etched. Er. YAG laser-irradiated and combined treatment on enamel surface. Angle Otthod 73:565-570

16. Kim JH, Kwon OW, Kim HI, Kwon YH (2005) Effectiveness of an Er.YAG laser in etching the enamel surface for orthodontic bracket retention. Dent Mater J 24:596-602

17. Hosseini MH, Namvar F, Chalipa J, Saber K, Chiniforush N, Sarmad S. Mirhashemi AH (2012) Comparison of shear bond strength of onthodortic brackets bonded to enumel prepared by ErYAG luser and conventional acid-etching, J Dent (Tehran) 9:20-26

18. Li ZZ Reinisch L Van de Merwe WP (1992) Bone ablation with Er:YAG and $\mathrm{CO}_{2}$ laser study of thermal and acoustic effocts. lasers Surg Med 12:79-85

19. Hibst R (2004) Laser for caries removal and cavity preparation: state of the art and future directions. J Oral Laser Appl 2:203-212 20. Hibs R. Keller U (1989) Experimental studies of the application of Hibst R, Kellicr U (1989) Expenimental studies of the application of the Er.YAG liser on dental hard substances: 1

21. Strickland D. Mourcu G (1985) Compression of amplified chirped optical pulses. Ont Commun 56:219-221

22. Chichkov BN, Momma C, Nolse S, von Alvensleben F, Tünnermann A (1996) Femtosecond, picosecond and nanosecond laser ablation of solidk. Appl Phys A 63:109-115

23. Luengo MC, Portillo M. Sinchez JM, Peix M, Moreno P, Garcia A. Montero J, Albaladejo A (2013) Evaluation of micromorpbo. logical changes in tooth enamel atfer mathinical and ultrafast laser preparation of surface cavities. Lasers Med Sci 28:267-273

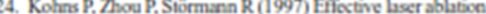
and dentine without thermal side effacts. J Laser Appl 9:171-174

25. Portillo Muñoz M. Losenzo Luengo MC, Sảnchez Lborente JM. Peix Sinchez M, Albaludejo A. Garcia A. Moreno Pedraz P (2012) Morphological alterations in dentine affer mechanical tratment and ulrashort pulse laser irradiation. Lasers Med Sci 27:53-58

26. Serbin J, Bauer T, Fallnich C, Kasenbucher A, Arnold WH (2002) Femtosecond lasers as novel tool in dental surgery. Appl Surf Sci 197-198:737-740

27. Goracci C. Margvelashvili M. Giovannetti A. Vichi A. Ferrari M (2012) Shear bond strength of orthodantic brackets bonded with a new self-adhering flowable resin composite. Clin Oral Investig. new seli-sdhering thowable resin
doi-10.1007/:500784-012-0729.x

28. Gokcelik A, Orel Y Orel E, Artun N, Autar N, Firatli S, Firatli E (2007) The influence of Er.YAG haser condtioning versus self. (2007) The influence of Er.YAG laser conditioning versus self.
etching adhesives with acid etching on the shear bond strength of etching adhesives with acid etching on the shear bond st

orthodontic brackets. Photomed Laser Surg 25:508-512

Attrill DC, Farrar SR, King TA, Dickinson MR, Davies RM $(2000)$
Er.YAG $(\lambda-2.94 u m)$ laser etching of dental enamel as an alter. native to acid etching. Lasers Med Sci 15:154-161
30. Obeidi A, Liu PR, Ramp LC, Beck P. Gutknocht N (2010) Acidetch interval and shear bond strength of Er. Cr.YSGG laserprepard enamel and dentin. Lasers Med Sci 25.263-169

31. Lima AF, d Silva VB, Soures GP. Marchi GM. Baggio Aguiar FH. Lovadino JR (2012) Influence of previces acid etching on interface morphology and boed strength of self-etching adhesive to cavosurmorphology and boed strength of selt

32. Dunn WJ, Davis JT, Bush AC (2005) Shear bond strength and SEM evaluation of composite bonded to Er.YAG laser-prepared

33. Van Meaboek B, De Munck J, Mattrx D. Van Landuyt K, Lambrochts $\mathrm{P}(2003)$ Microtensike bond strengths of an exhlerinse and self-exth adhesive so cnamel and dentin as a function of surface treatmant. Oper Dent 28:647-660

4. Altundasar E, Ozcelik B, Cehreli ZC, Matsumoto K (2006) Ultramorpbological and histochemical changes after ER, CR:YSGG laser irradiation and two different imigation regimes. J Endod 32:465-468

35. De Murck J, van Moerbeek B, Yudhira R, Lambrechts P. Vanherle G (2002) Micro-tensile boed strength of two adhesives to Erbium: YAG-lased vx bur-sut enamcl and dentin. Eur J Oral Sci llo:-322329

36. Obeidi A, McCrocken MS, Liu PR, Litaker MS, Beck P, Rahemtulla $F(2009)$ Enhancement of bonding to mamel and dentin prepared by Fr. Cr.YSGG laser. Lasers Surg Med 41:454-462

37. Liberman R, Segal TH, Nordenberg D, Serebro L (1984) Adhesion of composite materials to enamel: comparison between the use of acid and lasing as pretreatment. Lasers Surg Med 4:323use 327

38. Baparan G, Oner T, Berk N, Hamamci O (2007) Etching enamel for orthodontics with an erbium, chromium:yttrium-scandium gallium-garnet laser system. Angk Orthod 77:117-123

9. Orer T, Bayaran G, Berk N (2008) Laser etching of enamel for orthodontic bonding. Am J Orthod Dentofacial Orthop 134:193197

40. Mir M, Meister J, Franxen R, Sabounchi SS, Lampert F, Gutknecht N (2008) Influence of water-layer thickness on Er:YAG laser ablation of enamel of bovine anterior teeth. Lasers Med Sci 23:451-457

4. Rizsalla N, Bader C, Bortolotto T, Krejci I (2012) Improving the efficiency of an Er.YAG laser on enamel and dentin. Quintessence Int 43:153-160

42. Li ZZ Code JE, Van De Merwe WP (1992) Er.YAG laser ablation of enamel and dentin of human teeth: determination of ablation rates at various fluences and pulse repetition rates. Lasers Surg Med 12:625-630

43. Rego-Fillbo FD, Datra-Corréa M, Nicolodelli $G$, Bagnato VS, de Araujo MT (2013) Influense of the hydration state on the ultrashort Araser ablation of dental hard tissues. Lasers Mod Sci 28:215-222

44. Oyague RC, Monticelli F, Toledano M. Osorio E, Ferrari M. Oyorio R (2009) Effect of water aging on microtensile bonds Osonio R (2009) Etract of water aging on mictotensile bonds strength of dual-cured resin cements to pre-tre

45. Gomes AL., Castillo-Oyagüe R, Lynch CD, Montero J, Albaladejo A (2013) Influence of sandblasting granulometry and resin cement composition on microtensile bond strength to zircenia ceramic for dental prosthetic frameworks. I Dent 41(1):31-41 
Capítulo 3: Publicaciones Originales

\subsection{ARTÍCULO III}

Lorenzo MC, Portillo M, Moreno P, Montero J , García A, Santos-del Riego SE, Albaladejo A. Ultrashort pulsed laser conditioning of human enamel: In vitro study of the influence of geometrical processing parameters on shear bond strength of orthodontic brackets.

ISSN: 0268-8921.

Impact index: 2.402. - JCR Science Edition: 2012.

Category: Surgery.

Position in the category: 45 de 195 (T1/Q1).

\section{RESUMEN}

El presente estudio tiene por objeto identificar la mejor elección de parámetros a la hora de acondicionar el esmalte utilizando el láser de pulso ultracorto.

Las superficies de sesenta y tres premolares extraídos fueron procesadas con láser de pulso ultracorto $(\lambda=795 \mathrm{~nm}$, duración de pulso de 120 fs; frecuencia de repetición de $1 \mathrm{kHz}$ ) para producir patrones con diferentes pasos (s) en el rango micrométrico con el fin de evaluar la influencia de tales microestructuras en las fuerzas de resistencia a la cizalla de los brackets de ortodoncia al esmalte. Las muestras fueron clasificadas en nueve grupos correspondientes al grupo control (muestras no tratadas) y ocho grupos diferentes procesados con láser (patrones con s de 15 a 180 $\mu \mathrm{m}$, aumentando progresivamente). Se cementaron brackets en todas las muestras con resina adhesiva Transbond ${ }^{\mathrm{TM}} \mathrm{XT}$ y tras 72 horas, fueron sometidas a pruebas de resistencia en una máquina universal de ensayos. Además, un tercio de las

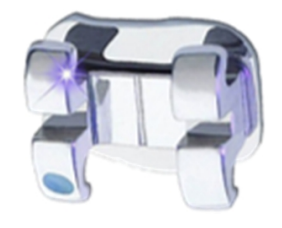


muestras se sometió al análisis morfológico de la superficie por medio de microscopía electrónica de barrido y al análisis del tipo de fallo basado en el índice de adhesivo remanente (ARI).

Los resultados mostraron que el microestructurado del esmalte con el láser de pulso ultracorto aumenta notablemente la fuerza de adhesión de los brackets. Los patrones densos $(\mathrm{s}<90 \mu \mathrm{m})$ producen el mayor incremento en la fuerza de adhesión en comparación con el grupo control, mientras que los menos densos (s>90 $\mu \mathrm{m}$ ) dan lugar a pequeñas mejoras de la fuerza de adhesión. Se encontró gran correlación de este comportamiento con el tipo de fallo predominante en ambos escenarios.

Hasta ahora, el mejor compromiso entre la adecuada eficiencia adhesiva, la disminución del tiempo de procesado y la conservación de la superficie del esmalte sugiere la realización de patrones de procesado con pasos del orden de $90 \mu \mathrm{m}$. 
Lasers Med Sci

DOt 10.1007/s10103-013-1491-2

ORIGINAL ARTICLE

Ultrashort pulsed laser conditioning of human enamel: in vitro

5 study of the influence of geometrical processing parameters

6 on shear bond strength of orthodontic brackets

30 M. C. Lorenzo - M. Portillo - P. Moreno - J. Montero -

9 A. Garcia - S. E. Santos-del Riego - A. Albaladejo

2 Reseived: 11 July 2013 /Accepted 5 Nowember 2013

13 Springer-Verhag London 2013

14 Abstract The surfaces of 63 extracted premolar teeth were processed with intense ultrashort laser pulses $(\lambda-795 \mathrm{~nm}$; pulse duration, $120 \mathrm{fs}$; repetition rate, $1 \mathrm{kHz}$ ) to produce cross patterns with different pitches $(s)$ in the micrometer range in order to evaluate the influence of such microstructures on the shear bond strengths of orthodontic brackets to enamel. The samples were classified in nine groups corresponding to the control group (raw samples) and eight different laserprocessed groups (cross pattems with $s$ increasing from 15 to $180 \mu \mathrm{m})$. Brackets were luted with Transbond ${ }^{\mathrm{TM}} \mathrm{XT}$ adhesive resin to all the samples; after $72 \mathrm{~h}$, they all were submitted to strength test in a universal testing machinc. Additionally, a third of the samples underwent morphological analysis of the debonded surface by means of scanning electron microscope microscopy and an analysis of the failure mode based on the adhesive remnant index. The results showed that enamel microstructuring with ultrashort laser pulses remarkably increase the bond strength of brackets. Dense cross patterns ( $s<$ $90 \mu \mathrm{m})$ produce the highest increase of bond strengths as compared to control group whereas light ones $(s>90 \mu \mathrm{m})$

M. C. Lerenno - M. Portillo - J. Montero - A. Albaladejo Dental Clinic (Faculty of Medicine), University of Salumanca, Passo Universidad de Coimbra, s/n. 37007 Salamanca, Spaip

P. Moreno - A. Garcia

Grupo de Mictoprocesado de Materiales con Liscr, University of Salamanca, Plaza de ha Mereed, sn. 37008 S dumunca, Spuin

S. E. Santos-del Riego

Department of Modicinc, University of A Corunis, Edeficio Universitario de la Facultad de Ciencias de la Salud, Ona SN. 15005 A Corunis, Spain

\section{C. Lerenso ()}

Clinica Odantológica, Universidad de Salmanca (USAL), Prolongación del Paseo de la Universidad de Coimbra SN. 37007 Salamanca, Spain

give rise to smaller improvements of the bond strength. A 34 strong correlation of this behavior with the predominant fail- 35 ure mode in both scenarios was found. So far, the best com- 36 promise between suitable adhesive efficiency, processing time 37 minimization, and enamel surface preservation suggests the 3 performance of cross pattems with pitches in the order of $90 \mu \mathrm{m}$.

Keywords Femtosecond laser - Enamel - Adhesion - Shear bond strength

Introduction

The brackets are the basis of contemporary orthodontics on which treatments are built to treat all types of malocclusions [1-5]. A proper bracket-cnamel adhesion is essential to successfully complete these treatments. However the enamelbracket interface still needs to be improved and requires further research and looking for new materials and techniques. Despite some currently available adhesive systems can dissolve the smear layer, the most common technique used for orthodontic brackets to enamel is still the total etch adhesive using orthophosphoric acid [5, 6]. This adhesive system generates a rough area on the surface and microporosities for micromechanical retention which allows the incorporation of small resin "tags" within the enamel surface, thereby creating microscopic mechanical interlocks between the enamel and resin $[7,8]$. The process provides good bond strengths but may cause decalcifications, exposing the enamel to caries attack and loss of enamel [9-12]. Because of these drawbacks, rescarchers look for a surface conditioner which could match the adhesive effectiveness in bracket bonding but without producing these collateral effects.

Ultrashort pulsed laser sources have attracted increasing interest for processing all kind of materials [13]. These laser

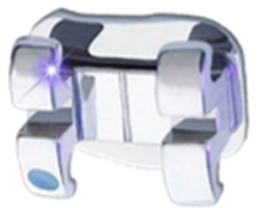




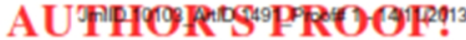

pulses, amplified up to energies of the order of millijoule [14] and focused on the surface of materials, allow the ablation of thin layers with extreme precision and reproducibility, causing much less collateral damage to the adjacent material than any other thermal, chemical or mechanical process as it has been already demonstrated for dental tissues [15-22]. These outstanding features are a consequence of the nature of the interaction of such laser pulses with matter, which is based on nonlinear processes of light absorption and ionization of the material which depend mostly on the peak intensity of the pulses followed by fast ejection due to phase explosion processes without remarkable thermal coupling with the surrounding material. This is far different from the conventional thermal ablation provided by continuous and pulsed laser sources above hundreds of picoseconds, which is based on linear absorption of the radiation, subsequent conversion of the laser energy into heat and increase of the temperature up to the vaporization point of water in the material causing explosive removal of enamel.

The total time spent in the bracket bonding is an importan factor for the orthodontist in the choice of the materials and procedure for conditioning the enamel surface and the subsequent bracket adhesion. Notwithstanding the remarkable properties of ultrashort laser processing of dental tissues, processing time is probably the main bottleneck to open the orthodontic treatment to the technique. Full conditioning of one of the surfaces of a dental piece may take hours, what is unacceptable from the point of view of the clinical practice. Ultrashort laser sources with repetition rates up to tens of megahertz are available (commonly known as oscillators) but the pulses are short of energy to induce ablation of dental tissues. However, sources providing pulses with energies high enough to induce ablation at repetition rates of some hundred kilohertz have recently broken into the market. These new systems will allow reduction of the processing time in orders of magnitude, although some problems associated to heat should be studied. Regardless of the current and future development of laser sources with higher repetition rates, other factors affect directly the processing time and have a great influence on the adhesion properties. Namely, the geometrical features of the microstructured patterns, particularly the "density" (which accounts for the fraction of the surface that is effectively modified by laser irradiation) and the scanning speed which is at the same time limited by the pulse energy and the number of pulses needed to achieve the optimal geometry for improving the adhesion properties and to respect the integrity and mechanical properties of the original surface Since the latter is constricted by the ablation requirements and the minimization of the collateral effects of the laser imadia tion, it is the density of the microstructured pattem and its influence on the adhesion properties which is susceptible to be investigated in order to shorten the processing time. To our accumulation as a result of the repetition rate may arise and knowledge, there is no research focused on this issue and these studies are needed to optimize the use of this tool as an alternative to traditional conditioners in order to (1) improve bracket-enamel adhesive effectiveness, (2) minimize the problems associated to current conditioners, and (3) match or even reduce the conditioning time of the existing adhesive systems

So far, a study of the influence of the density of ultrashort pulsed laser microstructured pattems on the shear bond strengths (SBS) of orthodontic brackets to enamel was carried out. Cross patterns with different pitches were written by ultrafast laser ablation on the surfaces of premolars that were later submitted to SBS tests, scanning electron microscope (SEM) observations, and failure mode analysis. A discussion based on the results of such analysis allows us to identify the best choice of parameters for enamel conditioning with ultrashort pulsed lasers.

\section{Materials and methods}

Sixty-three extracted human premolar teeth were collected and stored in a 0.5 chloramine T solution for a maximum of 6 months after extraction. Exclusion criteria included previously restored premolars and premolars with defects or cracking and delamination of the enamel.

Premolar teeth were examined with an Axio Ml ligh microscope (Carl Zeiss, Oberkochen, Germany) operating in

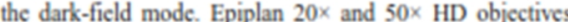
(Carl Zeiss Vision) were attached to a 1,300 $\times 1,030$ pixel digital camera (AxioCam HR, Carl Zeiss Vision). Consistent with the exclusion criteria, the selected premolar teeth were mounted in self-cured acrylic blocks. The buccal surfaces were oriented perpendicularly to the bottom of the molds so that the bonded interfaces were parallel to the force applied during SBS tests.

Before laser irradiation, the buccal crown surface of cach premolar was polished for $15 \mathrm{~s}$ with fluoride-free pumice slumy, washed for $30 \mathrm{~s}$, and dried for $10 \mathrm{~s}$ with a moisturefree air spray.

Experimental groups

Prior to bonding the metal brackets, the premolar teeth were 158 randomly assigned to nine groups, consisting of seven premo- 100 lars per group, depending on the density of the laser 160 microstructured pattem determined by the pitch (s): (1) no 161 laser (control), (2) $s-15 \mu \mathrm{m},(3) s-30 \mu \mathrm{m}$, (4) $s-45 \mu \mathrm{m}$, (5) 162 $s=60 \mu \mathrm{m},(6) s=90 \mu \mathrm{m},(7) s-120 \mu \mathrm{m},(8) s-150 \mu \mathrm{m}$, and 163 (9) $s-180 \mu \mathrm{m}$. 
Capítulo 3: Publicaciones Originales

AUTHOR'S PROOF!

Lasers Med Sci

\section{Ultrashort laser processing}

The laser system consists of a commercial Ti:Sapphire oscillator (Tsunami; Spectra Physics, Mountain View, CA, USA) which provides pulses in the near infrared $(\lambda-795 \mathrm{~nm})$ and a regenerative amplifier (Spitfire: Spectra Physics) based on the chirped pulse amplification tochnique [14] which allows to increase the pulse energy up to $1 \mathrm{~m}$. The system delivers pulses with a duration of approximately $120 \mathrm{fs}\left(1 \mathrm{fs}-10^{-15} \mathrm{~s}\right)$ at a repetition rate of $1 \mathrm{kHz}$ and a maximum mean output power of $1 \mathrm{~W}$.

The pulse energy is fincly controlled by a half-wave plate and a linear polarizer. Neutral density filters were used when further energy reduction was required. The transversal mode is nearly a Gaussian TEM00 with a $9 \mathrm{~mm}$ beam diameter $\left(1 / \mathrm{c}^{2}\right)$. The laser pulses were focused by means of an achromatic doublet lens $(f-100 \mathrm{~mm})$.

The specimens were fixed on a computer-controlled XYZ motorized stage (Micos ES100; Nanotoc Electronic GMBH \& Co Munich, Germany). The laser pulses impinged always perpendicular to the enamel surfaces. Therefore, the optimum focalization of the pulses on the teeth surfaces was provided by $\mathrm{Y}$ motion and scanning by $\mathrm{XZ}$ motion.

For processing the enamel surfaces, a computer code was developed driving the three motors in a way that the threedimensional surface of each premolar could be homogeneously scanned across the region of interest (ROI). Such an ROI area is in the range of $15-40 \mathrm{~mm}^{2}$ depending on the tooth morphology. Whenever possible, we processod a larger area than bracket bases in order to ensure that adhesive deposition and bracket bonding was entirely performed within the laserprocessed surface of the tooth. We have to bear in mind that the processed area in excess does not have any detrimental effect on the bonding strengths. Since the processing setup does not allow beam motion. the angle between the sample surface and the beam axis must be minimized in order to maximize the absorption of the pulse energy. Otherwisc, there would be a substantial difference between the structuring at the apex and at the slopes of the surface. So far, the sample is tilted so that the laser pulses face the flatter surface possible.
The enamel was processed in tight-focusing conditions. 20 The laser parameters were programmed according to previous 200 works on ultrashort laser processing of hard dental tissues [15, 200 16]. The focal length of the lens, the pulse energy $(0.03 \mathrm{~mJ}), \quad 207$ and the scanning velocity $(0.5 \mathrm{~mm} / \mathrm{s})$ were chosen to generate 200 smoothly overlapping and swallow ablated microstructures. 200 These parameters give a peak fluence of approximately $30 \mathrm{~J} / 210$ $\mathrm{cm}^{2}$ (the ablation threshold fluence for enamel being $0.58 \mathrm{~J} / 21$. $\mathrm{cm}^{2}$ [19]. With the focusing configuration used, the spot size 212 has a diameter of approximately $12 \mu \mathrm{m}\left(1 / \mathrm{c}^{2}\right)$, whereas the 21 : grooves generated on the surfaces are approximately $40 \mu \mathrm{m} \quad 21$. provided the ablation threshold fluence for enamel is well 21 s below $1 / c^{2}$ times the peak fluence in our experiments.

All these parameters remain constant for all the processed 217 specimens. The pitch between adjacent scans was gradually 218 increased from 15 up to 180 um generating the eight groups 219 for further analysis as it was stated before.

The tecth samples were laser processed in a saturated vapor 221 atmosphere to preserve the dental tissues from drying. All of 222 the tested specimens were stored in distilled water before and 223 after laser imadiation.

Bonding procedure

Sixty-three brackets having micro-etched bases (3M Unitek, 2210 Monrovia, CA, USA) were randomly bonded to the premo- 227 lars' buccal surfaces using a total etch adhesive system to 228 enamel consisting of a combination of a primer and an ortho- 220 dontic adhesive resin (Transbond TM XT; 3M-Unitek, St. 230 Paul, MN, US). The manufacturer's composition and applica- 23. tion mode of the materials used in the experiment are detailed 232 in Table 1 .

The adhesive resin was applied to each bracket base (area, 23. $9.15 \mathrm{~mm}^{2}$ ) after priming both the tooth and the bracket sur- 23 \% faces [23]. Brackets were then positioned onto the buceal 230 enamel surfaces and pressed firmly with a Hollenback carver 237 to expel the excess adhesive. Each bracket was subjected to a $23 \%$ 300-g compressive force using a force gauge (Correx. Beme, 230 Switzerland) for $10 \mathrm{~s}$, after which excess bonding resin was

Table 1 Mode of application, composition, and manufacturer of the maserials

\begin{tabular}{|c|c|c|c|}
\hline Matcrial & Manufaxtured & Composition & Modesteps of application \\
\hline & & Primer: BisGMA, TEGDMA & $\begin{array}{l}\text { Primer. Air dry tooch thoroughly. Place small amount } \\
\text { of Transbond XT primer in well. Apply thin uniform } \\
\text { coat of primer on each tooth surface to be bonded. }\end{array}$ \\
\hline Transbond XT & 3M ESPE, St. Paal, MN, USA & $\begin{array}{l}\text { Adhesive paste: Silane-treated quartz, } \\
\text { Bis-GMA. dichlorodimethylsilane } \\
\text { reaction product with silica. }\end{array}$ & $\begin{array}{l}\text { Adhesive: Aply a small bead of Transbend XT in the } \\
\text { transfer tray. Seat the tray holding firmly in place. } \\
\text { Cure the mesial and oeclusal sides of each tube for } \\
10 \mathrm{~s} \text {. Scale the excess resin from around the tubes. }\end{array}$ \\
\hline
\end{tabular}

TEGDMA triethylene glycol-dimcthacrylats, Bis-GM.1 bysphenyl glycidyl methacrylate

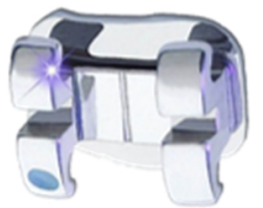




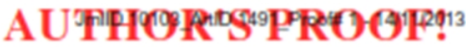

removed using a sham scaler. Then, the composite was light cured for $20 \mathrm{~s}$ from the occlusal and gingival bracket edges.

The bonding resin was photocured with a LED uni (Bluephase G2; Ivoclar-Vivadent, Schaän, Liechtenstein) emitting in the wavelength range $380-515 \mathrm{~nm}$ and a light intensity of $1,000 \mathrm{~mW} / \mathrm{cm}^{2}$ measured with a built-in radiometer (Bluephase Meter, Ivoclar-Vivadent) which was calibrated every $10 \mathrm{~min}$ to ensure consistent light intensity.

\section{Shear bond strength test}

The bracketed teeth were immersed in sealed containers of deionized water and placed in an incubator at $37^{\circ} \mathrm{C}$ for $72 \mathrm{~h}$ to permit adequate water absorption and equilibration. To conduct the SBS test, the specimens were secured in a jig attached to the base plate of a universal testing machine (Autograph AGS-X $10 \mathrm{KN}$, Shimadru, Tokyo, Japan).

The teeth were set at the base of the machine so that the sharp end of the rod incised in the area between the base and the wings of the bracket, exerting a force parallel to the tooth surface in an occluso-apical direction (crosshead speed, $0.5 \mathrm{~mm} / \mathrm{min}$ ). The force required to debond each bracket was registered in Newtons and converted into megapascals as a ratio of $\mathrm{N}$ to the bracket's surface area.

\section{Failure mode analysis}

After the SBS test, each specimen was examined with an optical microscope (Axio MI; Carl-Zciss) at $50 \times$ magnification to identify the location of the bond failure. The adhesive layers left on the premolar surfaces were assessed by using the adhesive remnant index (ARI), where each specimen was electron microscope in order to examine the morphology 287 of the debonded interfaces.

Statistical analysis

Descriptive statistics including means and standard deviations were calculated for the SBS values. Differences in SBS among the experimental groups were examined using analysis of variance (ANOVA) and Bonferroni multiple comparisons test.

To assess the influence of the laser surface treatment on SBS, a step-wise multiple linear regression was run, the SBS being the dependent variable. The determination coefficien $\left(R^{2}\right)$ was taken as the indicator of the model fit. The visualization of the relationship between SBS and pitch was performed by crossing data in a scatter plot and a quadratic regression fit plot.

The ARI scores were analyzed for pereentage and frequency of fracture typc, and a Chi-square test was used to match up the laser-processed groups with the control group. The AR scores were categorized as ARI-0-1 vs. ARI-2-3 for statistical comparisons.

All of the statistical analyses were performed using the SPSS v.20 software for Windows (Statistical Package for the Social Sciences, Chicago, IL, USA). Significance for all statistical tests was predetermined at $p<0.05$. Graphics were obtained by the Stata/SE v11.1 (StataCorp LP, Lakeway Drive, TX, USA)

Results scored according to the amount of material remaining on the enamel surface as follows: 0 -no adhesive remaining. 1-less than $50 \%$ of the adhesive remaining. $2-$ more than $50 \%$ of the adhesive remaining, and 3-all adhesive remaining with a distinct impression of the bracket base.

\section{Scanning electron microscope analysis}

Three specimens per group underwent surface morphological analysis with a variable pressure SEM (Zeiss EVO MA25; Carl Zeiss, Germany). Specific regions across the surface were explored to obtain a paramount view of the effect of laser processing.

In addition, representative fractured specimens from each group were dehydrated for $48 \mathrm{~h}$ in a desiccator (Sample Dry Keeper Simulate Corp., Japan) and then mounted on aluminum stubs with carbon cement. They were sputter coated with 10-nm platinum layer by means of a sputter-coating Unit E500 (Polaron Equipment Ltd. Watford, UK) and then observed with the same scanning

Shear bond strength

Mean values and standard deviations of SBS for the different groups are presented in Table 2. Whereas control group provides values close to those obtained in the literature, approximately $8 \mathrm{MPa}$, the laser-processed groups present much higher values. The results obtained are in the order of two and three times those of the control group, respectively, if we gather the laser-processed specimens in two families. The first one, the specimens where a cross pattern with $\mathbf{}>90$ um was performed and a second one including those processed with $s$ $\leq 90 \mu \mathrm{m}$.

The ANOVA test showed that the variance of SBS within the groups was significantly discrepant $(F-7.149$; $p<0.001)$. The Bonferroni post hoc intergroups comparisons indicated that all laser-processed groups obtained significantly higher SBS than the control group. However, $s=120 \mu \mathrm{m}, s=150 \mu \mathrm{m}$, and $s=180 \mu \mathrm{m}$ were not significantly discrepant with regard to all the subgroups. The best adhesive performance was shown between the range 15-90 $\mu \mathrm{m}$.

314 
Capítulo 3: Publicaciones Originales

AUTHOR'S PROOF!

Lasers Med Sci

12.1 Table 2 Mean and standard deviation (SD) of the shear boed strength (SBS) values (MPa) obtained among the experimental groups. ANOVA with Bonferroni correction

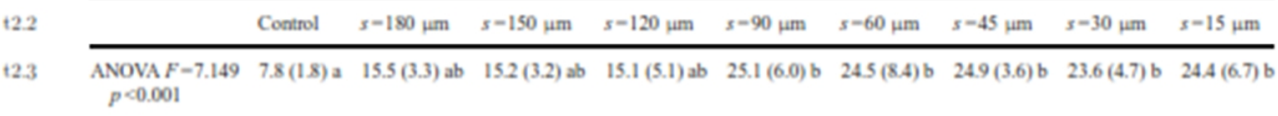

Similar letters in rows indicate the absence of significant differences afta Bonfaroni post boc intergeups comparisons

The multiple linear regression model that attempted to predict the SBS values according to the laser treatment (yes/no) and the quantitative variable "pitch" was highly significant $(F-20.952 ; d f-2 ; p<0.001)$ and highly predictive $\left(R^{2}-0.50\right)$. From this model, we observed that the intersection (representing the control group, since it is coded as laser -0 and density- 0 ) has on average a SBS of 7.79 ( $95 \% \mathrm{Cl}-2.9-12.7 \mathrm{MPa})$, but the laser treatment significantly enhanced the SBS values $(95 \% \mathrm{Cl}-12.8$ $24.4 \mathrm{MPa} ; p<0.001)$. Based on the standarized coefficients, the predictor "Laser" is stronger than density of the cross pattem $(\beta-0.79$ vs. $\beta--0.42$, respectively), but this could be attributed to the fact that the relationship is not linear but quadratic, as it is depicted in Fig. 1, thus its influence is underestimated using a linear approach. But we have chosen the linear model for parsimonious interpretation of the relationship and because the effect of the dichotomous vaniable laser treatment performs better in a lincar model.

\section{SEM observations}

Representative SEM images of the cnamel surface for specimens of the different groups before bonding brackets and of the debonded enamel surfaces after SBS testing are reported in Figs. 2 and 3.

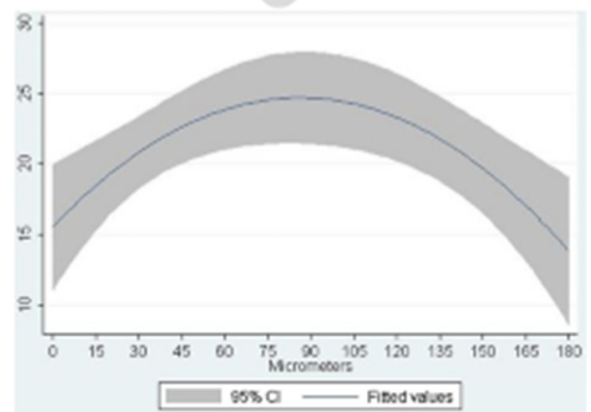

Fig. 1 Fit plot with $95 \%$ confidence interval of the fitted values of SBS according to a cuadratic regression based only on the cross pattern pinch (s)
Morphological analysis of laser-processed surfaces

Figure $2 b-i$ correspond to SEM micrographs of laserprocessed surfaces. Cross pattems with the desired pitches are achieved by ultrafast ablation and the ablation grooves exhibit clean and sharp edges without a recasting layer and no apparent damage to the original enamel surface beyond the limits of the microstructure. The absence of melted and scattered debris and cracks demonstrates the negligible thermal coupling of the laser pulses with the bulk material and the small influence of the propagation of shockwaves on the integrity of the cnamel surface.

Since the laser parameters were not changed for the different groups, the grooves should be identical from one specimen to the others. They are approximately $40 \mu \mathrm{m}$ wide. This can be confirmed looking at the images corresponding to the less dense pattems (Fig. 2b-f) where most of the original enamel surface was preserved. However, the smaller the pitch value the more surface is removed by laser ablation so that for a certain value of the pitch, most of the original surface has been removed (Fig. $2 \mathrm{~g}-\mathrm{i}$ ). The shape of the processed area changes drastically, becoming a homogencous surface some tens of microns below the raw surface of enamel and remarkably with a roughness in the micrometer range which has nothing to do with the smoothness of the original enamel surface (see Fig. $2 \mathrm{i}$ which corresponds to the extremal case with $s-15 \mathrm{~m}$ ). Obviously, the different features of the processed surfaces for the different groups should have a relevant role on the adhesion propertics.

ARI analysis

SEM micrographs of the enamel surface after debonding are shown in Fig. 3a-i. Following the criteria of Artun y Bergland [24], we assigned an ARI value to each one of the specimens after SEM observation of the adhesion area. Table 3 shows the result of these observations grouping ARI $-0-1$ and 2-3, respectively, and splitting the different laser-processed groups. In addition, Fig. $3 \mathrm{a}-\mathrm{i}$ shows a micrograph of the debonded area for a representative specimen out of each group.

ARI -0 is the failure mode associated to brackets bonded directly to the raw enamel surface (Fig. 3a). The debonded surfaces do not show any residual of adhesive. The failure mode of the laser-processed specimens exhibits a behavior 388 389 390 391 392 393 394 395 396 397 398 
VNiVERSIDDAD

BSALAMANCA

CAMPUS DE EXCELENCIA INTERNACIONAL

\section{AUTHOR'S5PROOF!'13}

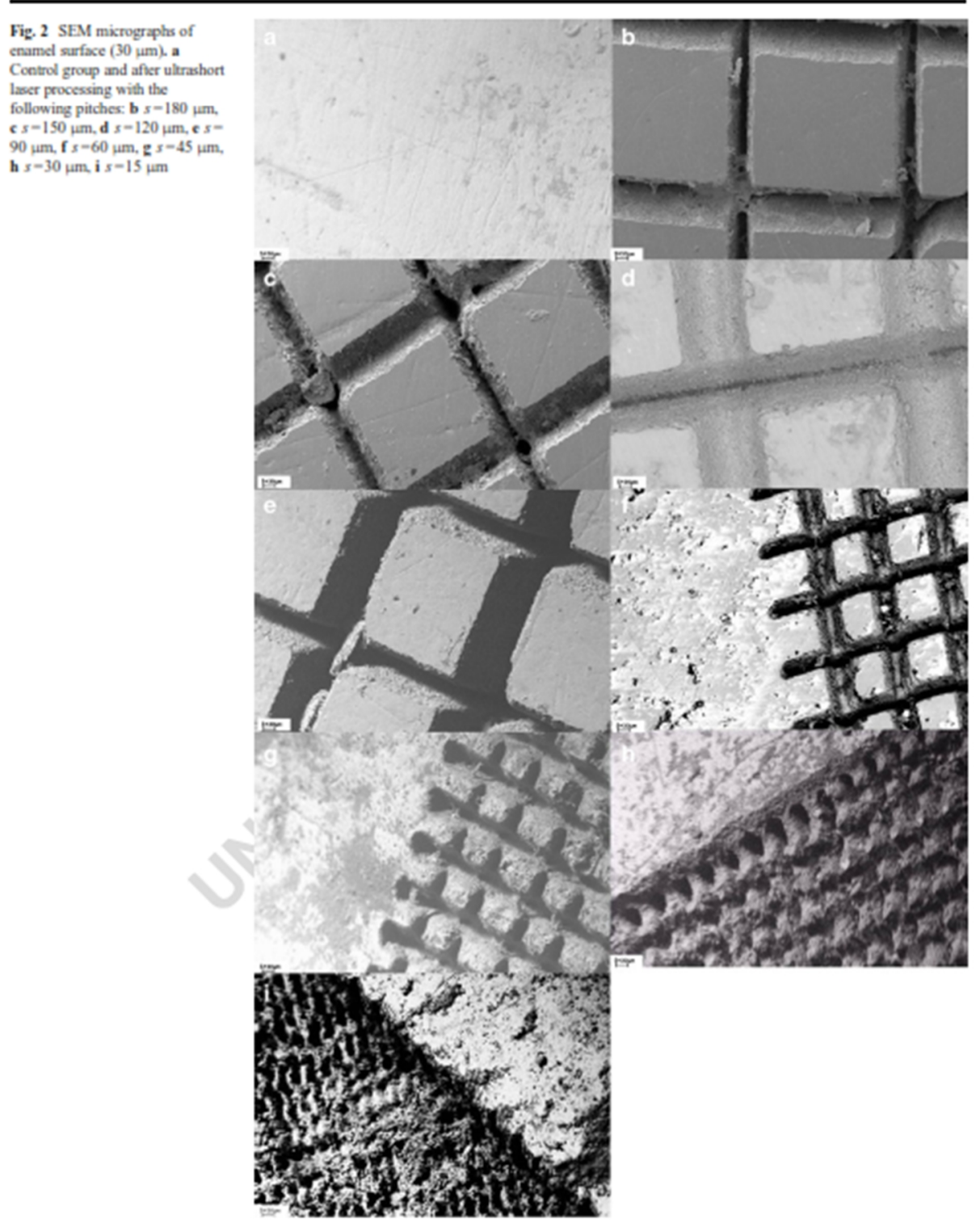

390 which is correlated to the density of the pattern. The lower the

to that of the control group (Fig, 3b, c) what is consistent with 401 
Capítulo 3: Publicaciones Originales

AUTHOR'S PROOF!

JmllD 10103 Artid 1491_Proot: 1 - 14/11/2013 Lasers Med Sci

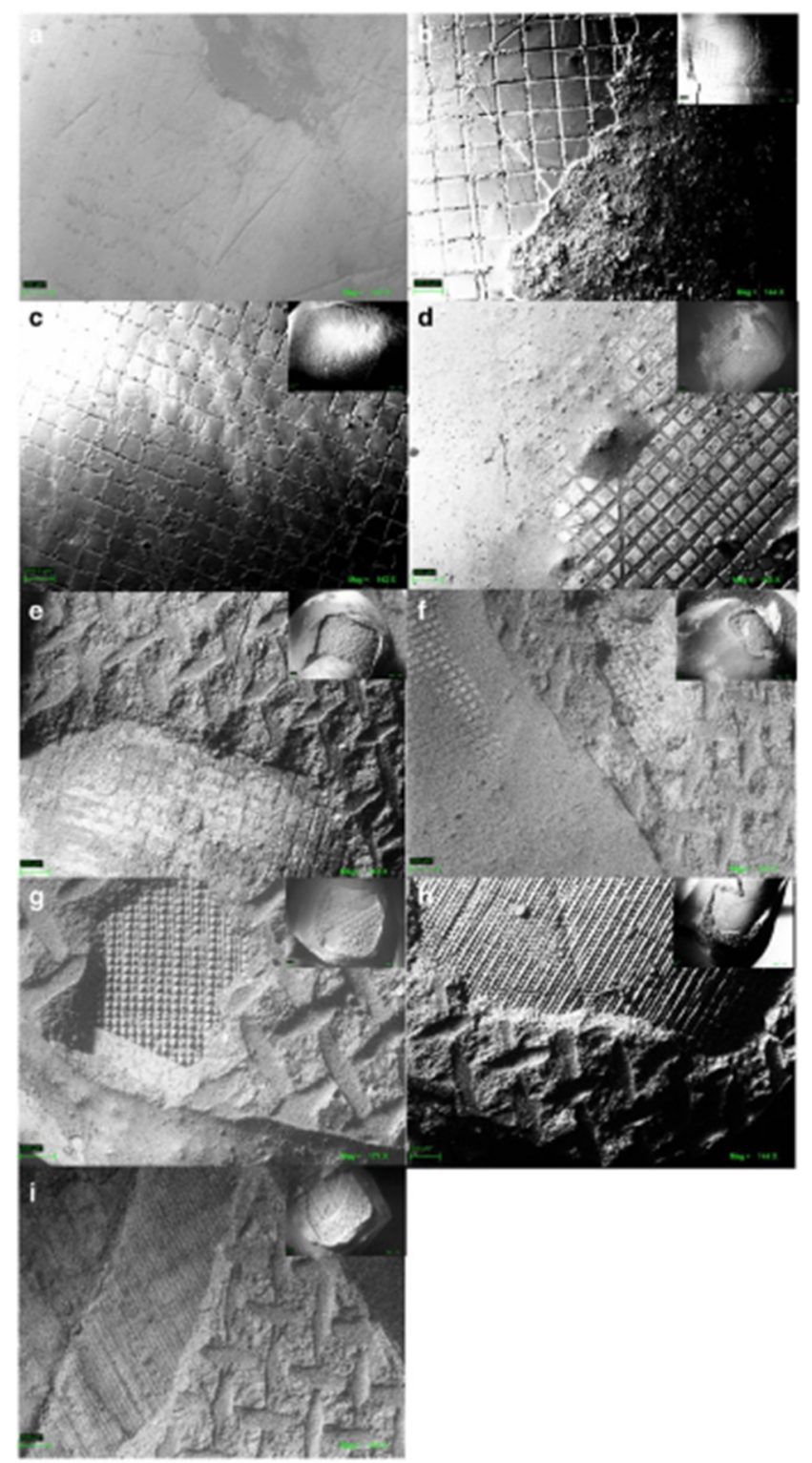

Fig. 3 SEM images of debonded specimens $(200 \mu \mathrm{m})$, a Control group and laser processed b $s=180 \mu \mathrm{m}, \boldsymbol{c} s=150 \mu \mathrm{m}, \mathrm{d} s=120 \mu \mathrm{m}$, e $s=90 \mu \mathrm{m}, \mathrm{f} s-$ $60 \mu \mathrm{m}, \mathrm{g} s-45 \mu \mathrm{m}, \mathrm{h} s=30 \mu \mathrm{m}, \mathrm{i} s-15 \mu \mathrm{m}$

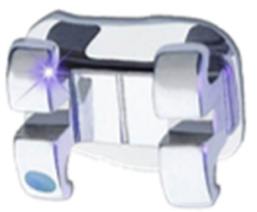




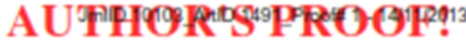

Table 3 Cross-tabulation of the effect of surface treatment groups sccording to a dichotomous varible generted from the ARI scores (0-1 score vx 2-3 scores). No laser subgroup was used as reference for the two-by-two comparisons

132

Laser groups

\begin{tabular}{llllllllll} 
ARI & $\begin{array}{l}\text { Control } \\
(\%)\end{array}$ & $\begin{array}{l}s-180 \mu \mathrm{m} \\
(\%)\end{array}$ & $\begin{array}{l}s-150 \mu \mathrm{m} \\
(\%)\end{array}$ & $\begin{array}{l}s-120 \mu \mathrm{m} \\
(\%)\end{array}$ & $\begin{array}{l}s-90 \mu \mathrm{m} \\
(\%)\end{array}$ & $\begin{array}{l}s=60 \mu \mathrm{m} \\
(\%)\end{array}$ & $\begin{array}{l}s=45 \mu \mathrm{m} \\
(\%)\end{array}$ & $\begin{array}{l}s-30 \mu \mathrm{m} \\
(\%)\end{array}$ & $\begin{array}{l}s-15 \mu \mathrm{m} \\
(\%)\end{array}$ \\
\hline $0-1$ scores & 100 & 100 & 100 & 100 & 40 & 0 & 20 & 0 & 80 \\
2-3 scores & 0 & 0 & 0 & 0 & 60 & 100 & 80 & 100 & 20 \\
Two-by-two comparisons & $\mathrm{a}$ & $\mathrm{a}$ & $\mathrm{a}$ & $\mathrm{a}$ & $\mathrm{B}$ & $\mathrm{B}$ & $\mathrm{B}$ & $\mathrm{B}$ & $\mathrm{a}$
\end{tabular}

(no laser as re ference)

Chi-square: 33.333 (df: 8 ); $p<0.001$

403 it is not discriminated in Table 3 , the failure mode evolves to ARI- 1 as we increase the density of the pattem $(s-120 \mu \mathrm{m}$ Fig. 3d) where some of the adhesive remained on the enamel surface (but covering less than $50 \%$ of the total surface). In the resin-free areas, the footprint of the cross pattem can be clearly observed although the grooves appear less remarkable since the adhesive has filled them.

Increasing the density of the pattem leads to failure modes which correspond mainly to ARI-2 (s-60 and $90 \mu \mathrm{m}$; Fig. $3 c, f)$ and finally ARI-3 (s-30, $45 \mu \mathrm{m}$; Fig. $3 \mathrm{c}, \mathrm{d})$. In such cases, more than $50 \%$ of the surface (ARI-2) or the full surface (ARI-3) shows the residuals of adhesive. However, further increase of the pattern density seems to break the debonding trend. For $s-15 \mu \mathrm{m}$ (Fig. 3i), the index come back to values $0-1$, indicating that, conceming failure mode, the behavior of an almost fully microstructured surface resembles the enamel raw surface.

\section{Discussion}

Acid etching is routincly used in orthodontics as conditioner of the enamel surface to obtain a high bracket-enamel adhesive efficiency. However, this procedure results in chemical changes that may produce modification of the organic matter and decalcification of the inorganic component of enamel [10]. By the way, acid etching lacks selectivity and therefore the enamel surface is completely modified. In a previous study [17], it was demonstrated that ultrashort pulsed laser microstructuring of enamel surfaces could substitute acid etching as conditioning procedure as far as the SBS values obtained were comparable. As it is now well known, this laser microstructuring is very respectful with the chemical and physical properties of the original material that surrounds the processed area, specially as compared to other laser sources, avoiding almost all of the collateral effects derived from the thermal load to the material as microcracks, charring, chemical modifications, and so on [15-21, 25-27].

Nevertheless, ultrashort pulsed laser processing has a clear disadvantage as compared to acid etching as a conditioning technique. For the experiments reported in the aforementioned previous work [17], the processing took a remarkably longer time than the acid conditioning. So far, our goal in the present work was to explore how the processing parameters (in this case, the pitch of a cross pattem which was as small as $15 \mu \mathrm{m}$ in Lorenzo et al. [17]) could affect the adhesion efficiency whereas the processing time was reduced and the largest portion of enamel surface was preserved. In Table 4, we report the average laser processing time for a complete premolar surface for the different cross patterns carried out on enamel. Since the processed surface was different for each specimen. we have estimated the time to process the minimum area $\left(\sim 15 \mathrm{~mm}^{2}\right)$. Obviously, the denser the pattem, the longer it takes to be realized.

For the new tests, the pitch was increased from $15 \mu \mathrm{m}$ (what we have called a very dense cross pattem) to $180 \mu \mathrm{m}$. We did not process with larger pitches because in those cases. the effect of the pattern on the enamel surface was almost negligible. For the specimens processed. SBS tests and SEM observations were carried out. From the SBS tests, we have observed that dense cross pattems ( $s \leq 90 \mu \mathrm{m})$ give rise to values three times $(\sim 25 \mathrm{MPa})$ higher than for the control group, which corresponds to raw enamel surfaces. As we increased the pitch, we found a different behavior ( $s>$ $90 \mu \mathrm{m})$; the values obtained in SBS tests decreasing to just twice ( 15 MPa) those of the control group. For the latter, the portion of original enamel surface is still very large and the adhesion takes place due to the infiltration of the adhesive within the laser-processed grooves (Fig 2b-d), which present rough walls and bottom that favor adhesion. The larger the pitch, the less original surface remains unaltered and is substituted by the laser-processed grooves (Fig. 2e-i). These

Table 4 Average laser processing time for a complete premolar safface for the different cross pattems carriod out an enamel. These times wers estimated for the minimum area processed $\left(15 \mathrm{~mm}^{2}\right)$

\begin{tabular}{llllllllll}
\hline$S$ (microns) & 15 & 30 & 45 & 60 & 90 & 120 & 150 & 180 & $t 4.2$
\end{tabular}

$\begin{array}{llllllllll}\mathrm{T} \text { (minutes) } & 120 & 90 & 60 & 45 & 30 & 25 & 20 & 15 & 14.3\end{array}$

Q1 Springer 
Capítulo 3: Publicaciones Originales

AUTHOR'S PROOF!

Lasers Med Sci

472 surfaces foster adhesive penetration and therefore stronger 473 bracket-cnamel adhesion.

Anyway, the analysis of shear bond strengths indicates that all the specimens exhibit values beyond the elinically acceptable values $(6-8 \mathrm{MPa})$ suggested by Reynolds and von Fraunhofer [28] regardless of the density of the pattem and these values are similar to those obtained with acid etching $[29,30]$.

In vitro studies on adhesion tests of direct bonding demonstrated that the fracture site in debonding metallic orthodontic brackets is usually located in the resin-bracket interface [31]. The ARI index provides information that has notable clinical implications for clean-up following debonding of brackets. A low ARI score implies that there is a minimal risk of iatrogenic damage to the enamel surface when residual resin composite is removed following debonding and clean-up procedures [32].

In our study, SEM observations of the failure region provide useful information (Fig. 3). We have found a clear correlation between the density of the cross pattern and the failure mode. For slightly modified surfaces, the failure mode resembles raw enamel surface behavior as expected. As we increased the density of the pattern, the ARI index evolved first to I (Fig. 3d) indicating that some resin is still adhered to the tooth after debonding and to 2 and 3 for $s \leq 90 \mu \mathrm{m}$, when a remarkable amount of adhesive remains adhered to the specimen after debonding or the fracture takes place in the interface between resin and bracket. Finally, for extremely dense cross patterns $(s-15 \mu \mathrm{m})$, ARI values come back to $0-1$. These results are consistent and compatible with the discussion conceming SBS tests. In the case of the less dense cross patterns, the surface behaves mostly as the unaltered enamel surface. As soon as we increase the density of the cross pattern. stronger adhesion induces the appearance of higher ARI scores. Finally, for the densest pattem, the bracket adheres to a surface that is no longer the original surface but an altemative surface some microns below the original one. homogeneous and much rougher than the polished enamel surface. So far, the adhesion is very strong but conceming failure, the debonding takes place uniformly all across the new surface and the result is that the remnant adhesive is scaree.

\section{Conclusions}

The introduction of an ultrashort pulsed laser cross pattem on the enamel surfaces improves bonding strengths of brackets whatever the pitch and the more the denser the pattern. Concerning the iatrogenic damage of the enamel surfaces, dense pattems lead to surfaces exhibiting large amounts of resin after debonding whereas large pitches give rise to surfaces almost free of adhesive residuals and obviously, the proportion of unaltered enamel surface is larger. With regard to time processing, since it mainly depends on scanning velocity (that was a fixed parameter in the study in order to ensure suitable ablation of enamel) and the total length of 52 scanning for a fixed area of the specimen, it increases with $52:$ the density of the pattem.

So far, although some relevant improvements in ultrashort 525 laser technology should be expected in the near future that will 520 shorten the time to condition the enamel surfaces for bracket $\quad 527$ bonding, up to date, the best compromise is to achieve high 523 bond strengths, avoid excessive iatrogenic damage, and pre- 520 serve a large portion of the original enamel surface is to 53.30 perform cross patterns with pitches in the order of $90 \mu \mathrm{m}$. If the requirements concerning bond strengths are not so de- 532 manding. less dense pattems provide shorter processing times, $\quad 033$ less risk of iatrogenic damage, and an outstanding preservation of the original enamel surface.

Acknowledgments The aubors acknowledge the financial support from the Ministerio de Economia y Competitivided (projects Censolider from the Ministeno de Economin y Competitividad (projects Consolider
SAUUL CSD2007.00013 and FIS2009-09522) and Junta de Castilla y León (project SAOS6A12-2). We are grateful to the Centro de Liseres Pulsados (CLPU, Spain) for allowing free SEM observation of the specimens

\section{References}

1. Angle EH (1928) The lasest and best in orthodontic mochanism. Dert Cosmos 70:1143-1158

2. Bishura SE, Solimun MM, Ovnsombat C, Laffoon JF, Ajlouri R (2004) The effect of variation in mesh-base design on the shear boed strength of orthodontic brackets. Angle Orthod 74:-400-404

3. Lugato IC, Pignatta LM, Arantes Fde M. Sintos EC (2009) Comparison of the shear bond strength of onventional mesh buse and sundblasted orthodectic bracket bases. Bra Oral Res 23.407 414

4. Kang DY. Choi SH, Cha JY, Hwang CJ (2013) Quantitative analysis Kang DY, Choi SH, Cha $J Y$, Hwang CJ (2013) Quantitative analysis of mechanically retentive ceramic bracket buse surfaces with a the

5. Türkỉz C. Ulusyy C (2012) Evaluxicen of diffarent enamel condi. tioning techniques for orthodontic bonding. Korean J Orthod 42:32tioning lachnimues for orthodontic bonding. Korean J Orthod 42:32-

6. Schnebel B, Mateer S, Maganrini AL, Freeman K (2012) Clinical acceptability of two self-etch adhesive resins for the bonding of orthodontic brackets to enamel. J Orthod 39-256-261

7. Gwinnett A, Matsui A (1967) A stady of enamel adhesive. The physical relabionship betwoen enumel and adhesive. Arch Oral Bio 12:1615-1620

8. Buobocore MG, Matsui A. Gwinsett A (1968) Penstration of resin dertal materials into enamel surfaces with reference to bonding Anch Oral Biol 13.61-70

9. Buonocuore MG (1955) A simple method of increasing the adhesion of acrylic filling materials to enamel surfaces. J Dent Res 34:849-853

10. Pashley DH (1992) The effects of acid etching on the pulpodentin complex. Oper Dent 17:229-242

11. Lehman R. Davidson CL (1981) Loss of surface ensmel after acid ething procedures and its relation to flowride content. Am J Orthed $80-73-82$

12. Shey Z. Brandt S (1982) Enamel loss dee to axid treatment for bonding. J Clin Othod 16:338-340

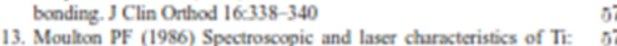
3. Moulion PF (1986) Spectrosoopic and laser characteristics of Ti:
Al203. J Opt Soc Am B 3:125-133
578

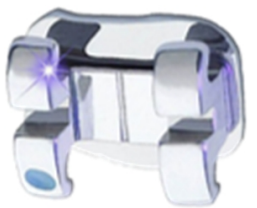


VNIVERSIDAD

BSALAMANCA

\section{AUTHOR'PS:PROOF!'}

14. Strickland D. Mourou G (1985) Compression of amplified chirpet optical pulses. Opt Commun 56:219-221

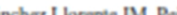

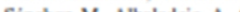
Sinchez M, Albaladejo A. Gartia A, Moreno Pedrzz P (2012) Morpbologeal alterabions in dentine after mochankal treatment and

16. Leengo MC, Portillo M. Sínchez JM. Peix M. Moreno P, Garcin A. Montero J, Albaladijo A (2013) Evaluation of micromoophological changes in tooth enamel affer mochanical and ultrafast laser prepura. tion of surfice cavities. Lasers Mad Sci 28:267-273

17. Lorenno MC, Portillo M, Moreno P, Monicto J, Castillo-Oyagüe R. Garcia A, Albaladejo A (2013) In vitro analysis of femtosecond leser as an alternative to acid etching for achieving suitable bond strength of brackets to human enamd. Lasers Mad Sci (in press)

18. Portillo M, Lorenro MC, Moreno P. Gurcia A, Montero J, Cebullos L Fuentes MV, Albaladejo A (2013) Influence of Er:YAG and Ti sapphire laser imadiation on the microtensile bond strength of severed adhesives to dentin. Lasers Med Sci (in press)

19. Ji L, Li L, Devlin H, Liu Z Jino J, Whinchead D (2012) Tissapphire fentoeccond laser ablation of dental enamel, dentine, and cementum Lasers Med Sa 27:197-204

20. Rego Filho Fde A, Dutra-Corra M, Nixobdelli G, Bagnato VS, de Arajo MT (2013) Influence of the hydration state on the ultrashoet hare ablation of dental hard tissues. Lasers Med Sci 28(1) 215-222 21. Screlle F, Poks, Halcei H, Braun A, Dehn C, Frenten M, Meister (2013) Ultrashort pulsed laser (USPL) application in dentistry: basic investigations of ablation rates and thresholds on cral hard tissue and restorative materials L asers Med Sci (in press) restorative matenals Lisers Med Sci (in pressi)

22. Braun A, Krilike Rf, Frantsen M, Bourauel C, Stark H, Schelle 2013) Heat generation caused by ablation of dental hard tissues with an ultrasbort pulse laser (USPL) system. Lasers Mod Sci (in press)
23. Goracci C, Margvelashvin M, Giovannetti A. Vichi A. Ferrari M (2013) Shear bond strength of orthodontic brackets bonded with a new self-sdhering flowable resin composite. Clin Oral lnvestig 17 new self-sdh $609-617$

24. Artun J, Bergland S (1984) Clinical trials with cristal growth conditioning as an alternative to acid-etch enamel pretreatment. Am

25. Hibst R, Keler U (1989) Experimental studies of the application of the Er.YAG laser on dental hard substances: L. Measurement of the ablation ratc. Lasess Surg Mad 9.335-344:

26. Wakh L, Patham S (1991) Enamel fusion ueing a carban doxide heser a tachnique for sealing pits and fisseres. Cin Prev Dent 13:16-20

27. Altundasar E, Ozcelnk B, Cehreli ZC, Matsumoto K (2006) Ultramorphological and histochemical changes after ER, CR: YSGG laser irradiation and two different irrigation regimes. Endod 32:-465-468

28. Reynolds IR, van Fraunhofer JA (1976) Direst bonding of orthodon. tic atuchments to texth: the relstion of achesive bond strength to gauge mesh size. Br J Onthod 3-9)-95

29. Bayron C. Himama N, Akkun A (2010) Shear bond stength of bonding to enamel with different lase irradiation distances. lasers Med Sci 26:149-156

30. Scougall Vilchis RI, Yamamoto S, Kitai N, Yamamoto $K$ (2009) Shear bond strength of orthodontic brackets bonded with different self-erching adhesives. Am J Orthod Dentofacial Orthop 136:425-430

31. Keirer S. Ten Carc JM, Arends J (1976) Direct bonding of orthodoptic brackets. Am J Orthod 69:318-327

Zarinsia K. Eid NM, Kence MU (1995) debonding techniques on the enumel surface an in vitro qublitative 630 study. Am J Orthed Dentofac Orthop 108:284-293 
Capítulo 3: Publicaciones Originales

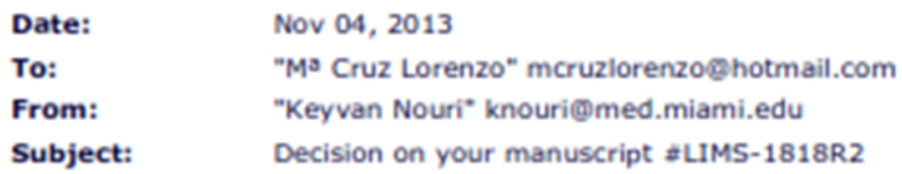

\section{Dear MRS M Cruz Lorenzo:}

We are pleased to inform you that your manuscript, "Ultrashort pulsed laser conditioning of human enamel: In vitro study of the influence of geometrical processing parameters on shear bond strength of orthodontic brackets." has been accepted for publication in Lasers in Medical Science.

For queries regarding your accepted paper, please click the following link http://www.springer.com/10103; then click on "Contacts", and then "Production Editor", complete the query form and click "Submit".

Please remember to always include your manuscript number, \#LIMS-1818R2, whenever inquiring about your manuscript. Thank you.

Best regards,

Keyvan Nouri

Lasers in Medical Soience

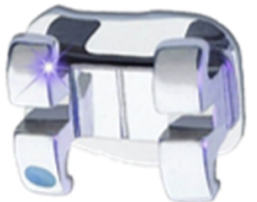



Capítulo 4: Discusión

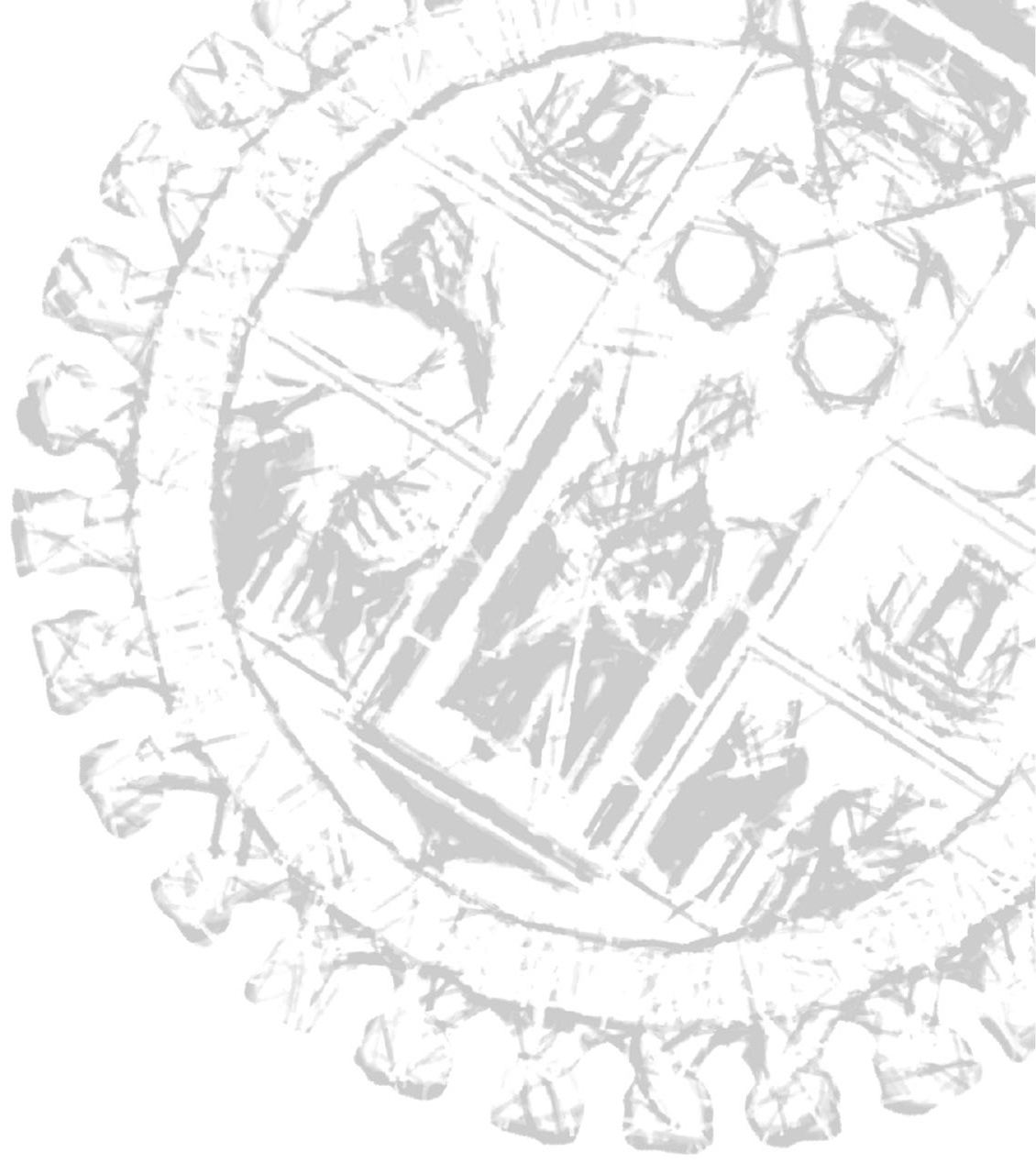

CAPítVLO4

DíSCVSí@N

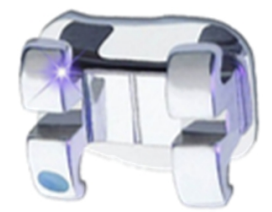



a instrumentación mecánica con turbina y fresa es el sistema más utilizado para la preparación cavitaria, si bien es conocido que produce fisuras y cracks en la superficie del esmalte debido a los efectos nocivos térmicos y mecánicos que genera, así como molestias derivadas del ruido y la necesidad de anestesia que hacen que no sea un tratamiento con el que el paciente se sienta cómodo (Anusavice, 1997). Para prevenir los efectos térmicos y preservar la pulpa en buenas condiciones, se utiliza irrigación conjunta que suele reducir la visibilidad del campo operatorio. Además el tamaño y la forma de las fresas no permite realizar formas geométricas complicadas ni un tratamiento mínimamente invasivo (Wieger y cols., 2007). Es por ello que se hace necesario buscar una alternativa a dicha técnica que minimice o anule estos inconvenientes.

En el campo de la Ortodoncia, conseguir una óptima eficacia adhesiva en la interfase bracket-resina $\mathrm{y}$, sobre todo en la interfase esmalte-resina, es un factor crucial para el éxito de los tratamientos. La interfase bracket-resina está muy mejorada debido a que los sistemas de retención en la base de estos aditamentos son aceptables y puede incrementarse de distintas formas (McColl y cols., 1998). Los principales fracasos de adhesión tienen lugar en la interfase esmalte-resina, motivo por el cual centramos nuestro interés en este punto.

A la hora de poder elegir el sistema más adecuado para mejorar esta adhesión se necesita un conocimiento extenso de los diferentes métodos de acondicionamiento, así como de los cementos y sistemas adhesivos.

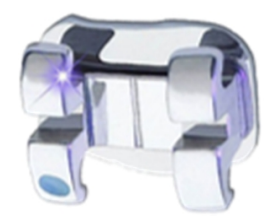


Una mala preparación del esmalte conlleva una insuficiente adhesión. El grabado con ácido ortofosfórico al 37\% es el método más utilizado en el acondicionamiento previo para el cementado de brackets porque alcanza un equilibrio entre eficacia adhesiva -al disolver selectivamente ciertas formaciones de hidroxiapatita que permiten que la resina penetre de un modo más eficiente (Silverstone y cols, 1975)-, tiempo de sillón y coste; pero a su vez, presenta numerosos inconvenientes principalmente derivados de la desmineralización del esmalte (Gorelick y cols., 1982; Ogaard y cols., 1988; Martínez-Insúa y cols., 2000; O'Reilly y cols., 2013) que hacen que no sea un sistema ideal. Es por ello que muchos investigadores basan sus estudios en buscar alternativas a esta técnica que igualen los valores de adhesión y, a su vez, mejoren los efectos negativos que produce. Principalmente, van enfocadas tanto a variación de tiempo y concentraciones ácidas, como al empleo de otros ácidos y/o sistemas de acondicionamiento de la superficie, que intentan solventar dichos problemas siendo más conservadores y menos nocivos para la superficie del esmalte.

Entre esas líneas de investigación se encuentra la ablación con láser, de tal manera que, por un lado, los láseres de Erbio han sido ampliamente estudiados con el objetivo de postularse como una alternativa adecuada al grabado ácido, existiendo mucha controversia al respecto hasta el momento actual. Por otro lado, el láser de pulsos ultracortos surge como una opción de aplicación en los tejidos duros dentarios, principalmente para la preparación cavitaria (Kim y cols., 2001; Girard y cols., 2007b; Portillo y cols., 2012; Ji y cols., 2012; Schelle y cols., 2013; Braun y cols., 2013; BelloSilva y cols., 2013), ya que pocos estudios han centrado su investigación en el campo de la adhesión. Así, aparece un reducido número de éstos relacionados con adhesión a dentina (Ji y cols., 2012; Rego Filho y cols., 2013; Braun y cols., 2013) y recientemente, tan sólo uno que trata de adhesión a esmalte (Kabas y cols., 2013). 
Esta tesis pretende establecer unas directrices preliminares para la utilización de láseres de pulsos ultracortos con el objetivo de mejorar la adhesión de brackets en la interfase esmalte-resina y minimizar los inconvenientes derivados del acondicionamiento con ácido ortofosfórico al $37 \%$ o con láser de Er:YAG, especialmente los que conciernen a la conservación del esmalte.

Dicho esto, y observando las numerosas ventajas que se derivan del empleo de este láser para producir la ablación de diferentes materiales, lo primero que nos planteamos fue saber si esas mismas ventajas se observarían al procesar esmalte (capítulo III.1). Se realizó una comparación cualitativa entre la preparación cavitaria con técnica mecánica convencional y con láser de femtosegundos a $795 \mathrm{~nm}$. Para ello se utilizaron terceros molares totalmente incluidos con el fin de minimizar, e incluso anular, los efectos que produce cualquier fisura que pueda aparecer en un molar erupcionado como consecuencia de la masticación y así, asegurar que la superficie dental de dichos dientes esté íntegra. Las imágenes al MEB revelaron la capacidad de dichos láseres para producir cavidades de gran precisión en el esmalte (Figs. III.1. 2a-d, 3a). A diferencia de lo que ocurre con el fresado convencional, no se observaron signos de daño colateral ni fisuras. Nuestros resultados concuerdan con lo descrito previamente en la literatura para otros tejidos biológicos, que afirman que la aplicación de pulsos ultracortos elimina casi por completo el daño térmico y la aparición de microcracks en las áreas adyacentes (kohns y cols., 1997; Pike y cols., 2007). Además esta técnica permite la remoción indolora del tejido duro dental, mejorando así la eficiencia de los procedimientos clínicos (Rode y cols., 2002; Rode y cols., 2003) (Figs. III.1. 1, 2a-c, 3a). Para la realización de las cavidades se probaron distintas geometrías y variables de procesado, teniendo en cuenta que la selección cuidadosa de los parámetros es crucial para lograr estructuras precisas y de alta calidad en la superficie del esmalte. La energía por pulso determina la tasa

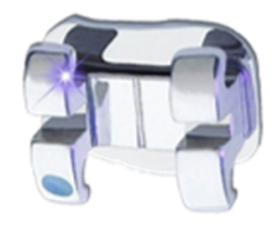


de material eliminado, pero energías muy altas fuertemente focalizadas en la superficie podrían generar algún daño debido a que los mecanismos de explosión de fase comienzan a entrar en juego. La velocidad de escaneado determina el número de pulsos que contribuyen a la ablación en una región determinada. Cuanto más rápido es el escaneado, menor número de pulsos $\mathrm{y}$, por lo tanto menor tasa de ablación. Ambos parámetros influyen decisivamente en la profundidad de la cavidad. La morfología y dimensiones de las cavidades están determinadas por las características de movimiento de las muestras y la propia energía de los pulsos. En el caso de las cavidades preparadas se eligieron parámetros que producían dimensiones muy similares a 200-250 $\mu \mathrm{m}$, cualquiera que haya sido el patrón geométrico elegido.

Se testaron dos patrones cavitarios diferentes: con forma rectangular y con forma circular. Se utilizó una trayectoria serpenteante y una trayectoria en espiral respectivamente para producir estas geometrías (Figura 28). En ambos casos la relación entre el paso y el tamaño del foco láser en la superficie fue muy importante. Una proporción superior a la unidad podría conducir a la ablación incompleta de la cavidad. En los dos trabajos posteriores (cap. III.2 y III.3) se optó por un patrón de procesado en forma de cuadrícula, ya que es el que se ajusta a las necesidades de adhesión a brackets.

Se observó que parte de los productos de ablación se depositaron en la parte inferior de las cavidades. Su forma es el resultado de la rápida expansión del volumen del agua evaporada contenida en el tejido. Se exploró la ubicación de ese debris y se comprobó la posibilidad de eliminarlo utilizando líquido o gas a presión. También, se probaron diferentes estrategias de movimiento de la muestra, pero en ningún caso se obtuvo éxito. 
De acuerdo con los resultados de este primer estudio, se puede afirmar que el esmalte dental puede ser removido con éxito por el láser de pulsos ultracortos, hecho que coincide con otras investigaciones enfocadas a la ablación con este sistema en el tejido duro dental (Rode y cols., 2002; Rode y cols., 2003; Pike y cols., 2007).

Basándonos en este experimento, se establecieron las ventajas de este láser con respecto a la técnica mecánica convencional y a otros tipos de láseres consultados en la bibliografía y concordantes con diferentes estudios. Así, el láser de pulso ultracorto:

- $\quad$ Produce mínimos cambios estructurales en el esmalte irradiado que aparece sin signos de fisuras, grietas o carbonización.

- $\quad$ Ofrece la posibilidad de hacer cavidades mucho menores que las que se pueden hacer con una fresa del diámetro más pequeño (Girard y cols., 2007a), pudiendo llegar incluso a cavidades de pocas micras si fuera necesario.

- $\quad$ No se requiere irrigación porque el proceso de ablación ocurre en un espacio de tiempo muy corto en el que no hay posibilidad de transmisión del calor, a diferencia de la instrumentación mecánica y los láseres de Erbium, que precisan la utilización conjunta de irrigación para disminuir el posible aumento de temperatura (Ji y cols., 2012).

- $\quad$ Al no haber ruido ni necesidad de anestesia para realizar la cavidad con el láser de pulso ultracorto, se reduce el estrés del paciente.

- $\quad$ Puede ablacionar casi todo tipo de material, incluidas las restauraciones de metal, que no pueden ser removidas por los láseres de Erbium. Esto es así porque cuando se realiza la ablación con láser de pulso ultracorto, el coeficiente de absorción

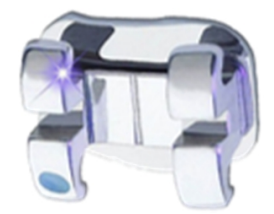


del material depende de la intensidad de la radiación en vez de depender de la longitud de onda, como ocurre en el caso de los láseres convencionales.

Los resultados de este estudio ofrecen una alternativa a la técnica mecánica convencional e intentan centrarse en optimizar la calidad del tratamiento dentario. En este momento, observando las ventajas mecánicas de los pulsos ultracortos, nuestra atención se dirige a estudiar su comportamiento para comprobar cómo actúa en la adhesión de brackets a esmalte (capítulo III.2) y a establecer los parámetros de procesado adecuados (capítulo III.3).

Para la realización de ambas pesquisas para estudiar la eficacia adhesiva esmaltebracket (capítulos III.2 y III.3) se utilizó el análisis de resistencia a la fuerza de la cizalla debido a que la medición in vitro con este sistema ha sido establecida como un método aceptable para poder extrapolar los resultados a lo que ocurre in vivo bajo condiciones comparables (Gokcelik y cols., 2007; Başaran y cols., 2011; Goracci y cols., 2013). Para realizar estudios de adhesión a esmalte están aceptadas tanto el método de resistencia al cizallamiento como el de microtensión (Rasmussen, 1996). El primero fue desarrollado por Shimada y su equipo como una alternativa al test de microtensión (Shimada y cols., 2002). Este método consiste en la aplicación de una fuerza de cizalla utilizando un alambre fino de acero inoxidable. Resulta útil para probar materiales que fallan ante valores comprendidos entre $18-20 \mathrm{MPa}$, o menos (Chappell y cols., 1997), mientras que con la técnica de microtensión, introducido por Sano y su equipo, podemos medir grandes fuerzas de adhesión (Sano y cols., 1994). El test de microtensión no es fácil de usar en el esmalte y existe una alta probabilidad de que éste se separe de la dentina cuando se aplica una fuerza de tracción a los especímenes (Foong y cols., 2006), por lo que el test de resistencia a la cizalla se considera más útil en la medición de la eficacia adhesiva en ortodoncia. 
Además, este método es menos exigente en términos de producción de muestras y las áreas de evaluación de la adhesión pueden ser controladas mucho mejor usando tubos capilares de diámetro conocido. Este test utiliza áreas de adhesión de aproximadamente $4 \mathrm{~mm}$ de diámetro, mientras que las que utiliza el test de microtensión están en el orden de 1 mm de diámetro (Foong y cols., 2006).

En la primera investigación de adhesión en Ortodoncia (capítulo III.2), se utilizó el láser de pulsos ultracortos para comprobar la eficacia adhesiva de los brackets al esmalte en comparación con la que se obtiene con el ácido ortofosfórcio al 37\% o el láser de Er:YAG. Los resultados derivados de este estudio confirmaron diferencias entre los grupos.

Cuando la superficie del diente fue grabada sólo con ácido ortofosfórico, no se encontraron diferencias significativas con respecto a los resultados obtenidos mediante el acondicionamiento combinado con los láseres testados (tabla III.2.2). Sin embargo, la fuerza de adhesión disminuyó significativamente en el caso de las superficies tratadas sin láser y sin ácido y en las tratadas sin ácido/con láser de Er:YAG (Tabla III.2.2). Los resultados de los valores de adhesión que se obtuvieron tras las aplicación convencional con ácido ortofosfórico fueron consistentes con los resultados de otros estudios (Attrill y cols., 2000; Lee y cols., 2003; Gokcelik y cols., 2007; Obeidi y cols., 2010; Lima y cols., 2012). En todos ellos se reflejaron valores de adhesión adecuados. Esto es así porque el grabado con este ácido genera microporosidades en la superficie del esmalte a través de las cuales la resina puede penetrar (Dunn y cols., 2005). Tras la polimerización, el entrelazado micromecánico de los tags de resina logra esa buena adhesión (Van Meerbeek y cols., 2003) pero como ya se sabe, la descalcificación del esmalte causada por el ácido facilita el ataque de la caries.

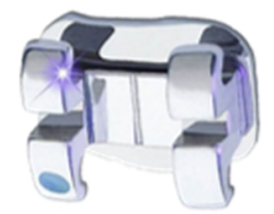


Los resultados de resistencia al cizallamiento que se obtienen con el acondicionamiento con láser de Er:YAG son controvertidos ya que hay estudios que reflejan valores de adhesión similares o incluso mayores que con el grabado ácido (Liberman y cols., 1984; Başaran y cols., 2007; Özer y cols., 2008; Hosseini y cols., 2012; Sağıı y cols., 2013), mientras que otros obtienen valores menores (Von Fraunhofer y cols., 1993; Martínez-Insúa y cols., 2000; Kim y cols., 2005; Dunn y cols., 2005; Lasmar y cols., 2012), argumentado que los cracks que se observan en la superficie del esmalte son consecuencia del daño térmico generado por este láser (Hibst y cols., 1989; Altundasar y cols., 2006) y que esos cracks constituyen regiones débiles que dan lugar a fracturas y filtraciones que contaminan el tejido (De Munck y cols., 2002; Obeidi y cols., 2009) con lo cual, pierden adherencia. Nosotros creemos que estos resultados tan contradictorios pueden ser atribuidos a las diferencias encontradas en los protocolos de estudio. Investigaciones previas han demostrado la influencia del caudal de agua (Mir y cols., 2008), la presión del aire (Rizcalla y cols., 2012), la duración del pulso (Li y cols., 1992) y la distancia de irradiación láser (Başaran y cols., 2011) en la tasa de ablación, la eficiencia, la morfología superficial y los valores de resistencia a la cizalla. Teniendo en cuenta esto, con los parámetros programados en nuestro experimento, se comprueba que la irradiación con láser de Er:YAG en la superficie del esmalte para la adhesión de brackets no es una buena alternativa al grabado con ácido ortofosfórico. Por lo tanto, ya sea si las muestras no fueron procesadas con láser o si se utilizó el láser de Er:YAG, los mayores valores de adhesión en la resistencia a la cizalla se registraron cuando el esmalte fue posteriormente grabado con ácido.

Por el contrario, con el láser de pulsos ultracortos los valores de adhesión se mantienen similares, independientemente del empleo posterior del grabado ácido (tabla III.2.2). La capacidad de este láser para obtener altos valores de adhesión sin 
la aplicación de ácido ortofosfórico puede ser debida a las micro y nanorrugosidades producidas por la ablación láser (Fig. III.2.4b). Al usar pulsos ultracortos, la práctica ausencia de carga térmica en el tejido dental remanente previene la formación de microcracks, que pueden afectar a la adhesión de los brackets al esmalte. Según nuestros resultados, este láser podría sustituir al ácido ortofosfórico, igualando los valores de adhesión y evitando los efectos adversos derivados del mismo, de tal forma que genera mínimos cambios microestructurales en el esmalte irradiado, no requiere irrigación y la perturbación acústica es inapreciable. Cierto es que algún estudio pone de manifiesto que este láser puede inducir fatiga térmica y daño mecánico en esmalte y dentina deshidratada (Rego-Filho y cols., 2013), pero como contrapunto hemos de decir que por un lado, el daño térmico siempre será menor que el producido por los láseres de Erbium, que emiten pulsos largos. Por otra parte, los premolares utilizados en el presente estudio se mantuvieron continuamente hidratados, así dichos efectos adversos fueron evitados.

El índice ARI proporciona una información con notables implicaciones clínicas para la limpieza del esmalte posterior al descementado de los brackets. Al medir este índice se observó que, cuando no se aplicó ácido tras el procesado con láser, se registraron más valores de ARI=0-1 (tabla III.2.3; Figs. III.2.2-4), problablemente porque el adhesivo no tuvo retención suficiente al esmalte causando el descementado del bracket en ese punto. En las superficies tratadas con ácido y sin láser, y con láser de pulso ultracorto más ácido (Fig. III.2.5), la mayoría de las muestras registraron valores de ARI=2-3 (Tabla III.2.3). Estos resultados son consistentes con la literatura (Lee y cols., 2003; Gokcelik y cols., 2007; Başaran y cols., 2011). Dunn y cols., (Dunn y cols., 2005) atribuyeron este efecto a una mezcla del patrón típico de grabado ácido que podría dificultar la penetración de la resina en la superficie del esmalte. Con el láser de pulsos ultracortos, aunque no hay diferencias significativas

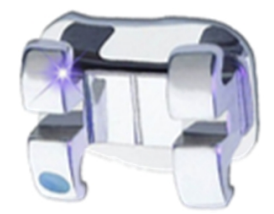


en los valores de resistencia a la cizalla entre grabar la superficie con ácido y no grabarla, su posterior aplicación posiblemente podría aumentar la profundidad de las microrretenciones. Esto originaría tags de resina más profundos y retentivos, dejando mayor capa de resina en la superficie del esmalte.

$\mathrm{Al}$ comprobar que este láser podría sustituir al grabado ácido como acondicionamiento del esmalte, ya que los valores de resistencia al cizallamiento que se obtuvieron fueron comparables, en la siguiente investigación (cap. III.3), se decidió no aplicar ácido y estudiar cómo los parámetros de procesado (en este caso, la densidad del patrón microestructurado en el esmalte, que en el estudio anterior (cap.III.2) se realizó con distancias entre líneas de barrido de $15 \mu \mathrm{m}$ ) pueden afectar a la eficiencia en la adhesión. Se eligió este parámetro porque determina la fracción de superficie que es procesada y porque la principal desventaja observada fue el tiempo que tardaba en tratarse completamente la superficie. Cuanto menos denso es el patrón de procesado, menos tiempo se tarda en realizarlo y mayor superficie de esmalte queda preservada.

Teniendo en cuenta esto, el paso se fue aumentando desde $15 \mu \mathrm{m}$ (patrón muy denso) hasta 180 um. No se aumentó más porque, para valores superiores, la porción de superficie que es procesada es muy baja y no se observan diferencias con la superficie no tratada con láser. Al realizar el test de resistencia a la cizalla se observó que los patrones más densos ( $\mathrm{s} \leq 90 \mu \mathrm{m})$ dan lugar a valores de adhesión tres veces $(\approx 25 \mathrm{MPa})$ mayores que los del grupo control, que se corresponde con la superficie de esmalte sin tratar. Al aumentar el paso, se observa un comportamiento diferente ( $\mathrm{s}>90 \mu \mathrm{m})$, ya que los valores de resistencia a la cizalla disminuyeron a sólo dos veces $(\approx 15 \mathrm{MPa})$ mayores que los del grupo control. Para el patrón menos denso, la porción preservada de esmalte intacto es muy grande y la adhesión se produce 
por la infiltración del adhesivo en los surcos procesados por el láser (Figs. III.3.2 bd), que presentan las paredes y el fondo rugosos y favorecen la adhesión. Cuanto más denso es el patrón de procesado, menos superficie de esmalte aparece intacta, siendo sustituida por los surcos que realiza el láser (Figs. III.3.2 e-i). Esta superficie fomenta la penetración del adhesivo y, por lo tanto, se genera una adhesión bracketesmalte más fuerte.

De cualquier modo, en este estudio el análisis de resistencia al cizallamiento indica que todos los especímenes tratados muestran valores por encima de los clínicamente aceptables (6-8 MPa) sugeridos por Reynolds y von Fraunhofer (Reynolds y cols., 1976), independientemente de la densidad del patrón. Estos valores son similares a los obtenidos con el grabado ácido (Scougall Vilchis y cols., 2009; Başaran y cols., 2010).

Con respecto al índice ARI, en este estudio (cap.III.3) se encontró una clara correlación entre la densidad del patrón y el tipo de fallo (Fig. III.3.3). Así, para las superficies levemente modificadas, el tipo de fallo recuerda al comportamiento de la superficie de esmalte limpias, sin tratar, lo que era de esperar. Al aumentar la densidad del patrón, el índice ARI evoluciona primero a 1 (Fig. III.3. 3d) indicando que parte de resina permanece adherida al diente tras el descementado, y a 2 y 3 para $\mathrm{s} \leq 90 \mu \mathrm{m}$, donde una importante cantidad de adhesivo queda adherida al esmalte tras el descementado, o el fallo se ha producido en la interfase bracketresina. Finalmente para patrones muy densos $(\mathrm{s}=15 \mu \mathrm{m})$, el valor de ARI regresa a 0-1. Estos resultados son consistentes y compatibles con la discusión referente al test de resistencia a la cizalla. En el caso de los patrones menos densos, la superficie del esmalte se comporta prácticamente como la superficie de esmalte sin tratar. Al aumentar la densidad del patrón, se genera una adhesión más fuerte que induce la

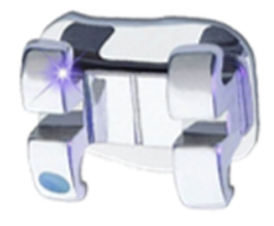


aparición de valores ARI mayores. Finalmente, para el patrón más denso, el bracket se adhiere a una superficie que ya no es la inicial, sino una superficie alternativa a la original del esmalte pero unas micras por debajo de ésta, homogénea y mucho más rugosa que la superficie de esmalte pulida. La adhesión en esta superficie es mayor pero, en relación al fallo, el descementado se lleva a cabo uniformemente en toda la nueva superficie y el resultado es que el adhesivo remanente es escaso.

Con la presente tesis, no se pretende establecer una guía clínica en base a las primeras experiencias reflejadas, ya que a pesar de los exitosos resultados obtenidos, en el campo de la adhesión, hoy en día el láser de pulsos ultracortos presenta inconvenientes que impiden su aplicación en la práctica clínica. Entre ellos, el tiempo de microestructurado para acondicionar la superficie del esmalte que es muy largo debido a la pequeña tasa de procesado por pulso y las bajas tasas de repetición disponibles. Sin embargo, hay algunos sistemas láser de pulsos ultracortos para propósitos de microestructurado que ya han sido desarrollados e incluso comercializados, alcanzando tasas de repetición del orden del megahertzio lo que debería superar la falta de competitividad de esta técnica. Lo mismo podemos decir en relación a los costos y a las dimensiones del sistema. En los últimos años, se han producido importantes avances encaminados hacia la miniaturización y por tanto, a la reducción de los costes de inversión que hace que se augure un futuro prometedor para algunas aplicaciones en el campo de la odontología.

Futuras investigaciones deberían centrarse en el estudio sistemático de la influencia en las propiedades de adhesión de la modificación de los demás parámetros de procesado del láser, tanto los relacionados con las propiedades físicas de los propios pulsos láser como de los parámetros geométricos del procesado. 


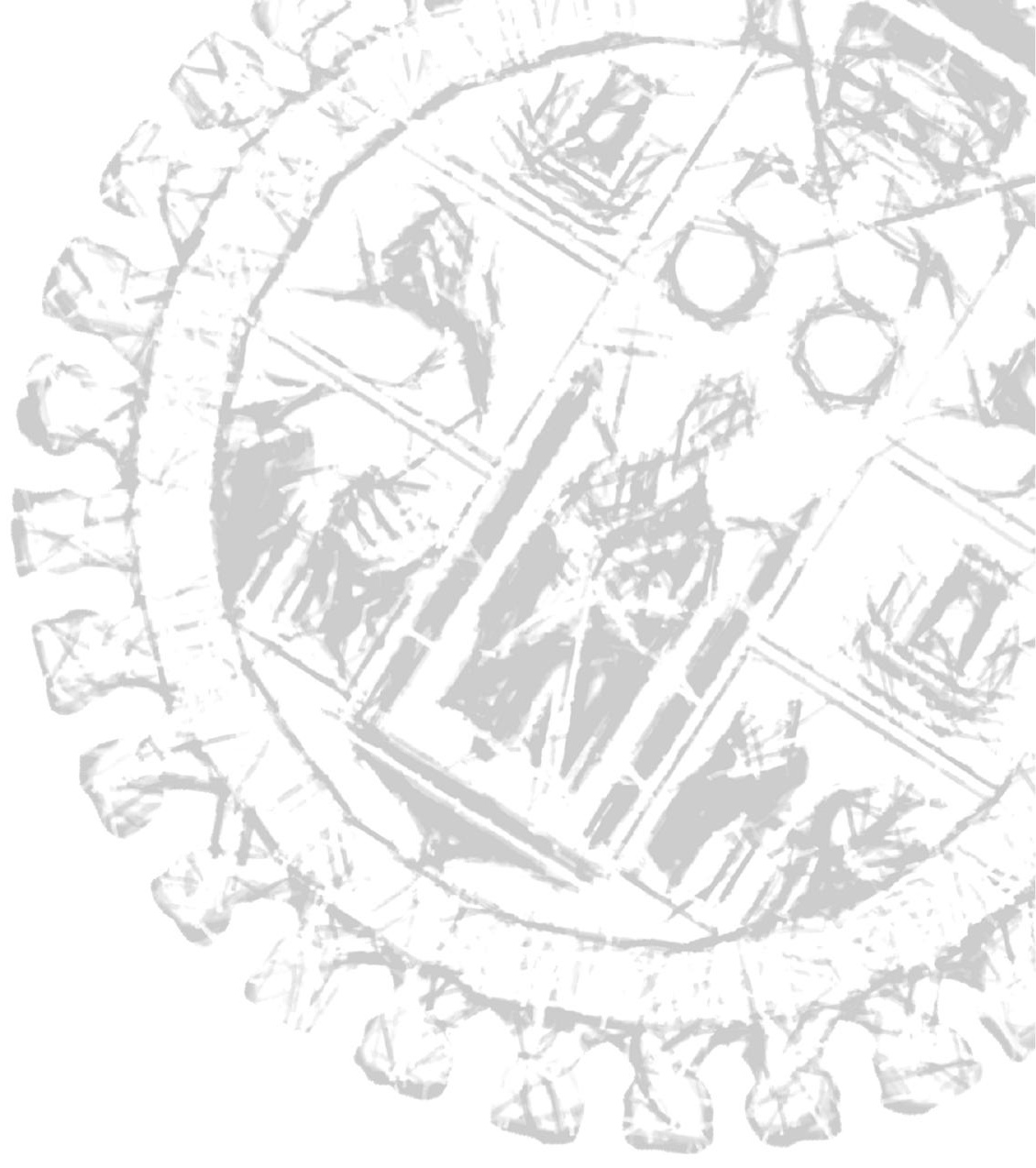

CAPítVLO 5

\section{CONCLVSIONES}

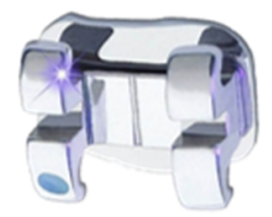



1. El láser de pulso ultracorto tiene la capacidad de producir cavidades de alta precisión en el esmalte, con minimización y/o ausencia de efectos térmicos y mecánicos en los tejidos adyacentes, a diferencia de la turbina, que lleva a la formación de microfracturas en la superficie del esmalte. Se presenta como una herramienta óptima para el tratamiento de la caries dental y como alternativa a la técnica mecánica convencional con turbina para disminuir el daño que se produce durante la remoción del tejido duro dentario.

2. El láser de pulso ultracorto sin el empleo de un acondicionamiento ácido previo permite obtener eficacias adhesivas similares a las obtenidas con el grabado con ácido ortofosfórico eliminando, a su vez, los efectos adversos provocados por éste, con lo cual se plantea como una buena alternativa para el cementado de brackets de ortodoncia en el esmalte. El tratamiento con láser de Er:YAG obtiene unas fuerzas de adhesión esmalte-brackets inferiores a las generadas por el tradicional acondicionamiento ácido a no ser que previamente se acompañe de éste.

3. Para obtener una eficacia adhesiva adecuada en el cementado de brackets sobre el esmalte con el láser de pulsos ultracortos, se deben obtener densidades en el patrón de microestructurado elevadas con barridos separados de 15 a $90 \mu \mathrm{m}$. Sin embargo, para obtener una correcta eficacia adhesiva esmalte-bracket, evitar el daño iatrogénico excesivo, realizar un procesado más rápido de la superficie dentaria y preservar gran cantidad de esmalte intacto, los patrones

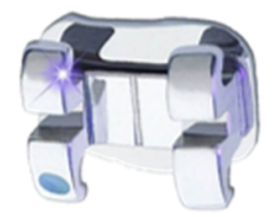




\section{VNIVERSIDAD \\ BSALAMANCA}

excesivamente densos no son adecuados, siendo preferibles densidades más bajas. Si los requisitos relativos a las fuerzas de adhesión no son tan exigentes, los patrones muy poco densos $(\mathrm{s}>>90 \mu \mathrm{m})$ proporcionan tiempos de procesado más cortos, menor riesgo de daño iatrogénico y una mejor conservación de la superficie original del esmalte. 

Capítulo 6: Bibliografía

Ahrari F, Basafa M, Fekrazad R, Mokarram M, Akbari M. The efficacy of Er, Cr:YSGG laser in reconditioning of metallic orthodontic brackets. Photomed Laser Surg. 2012; 30(1): 41-6.

Ahrari F, Fekrazad R, Kalhori KA, Ramtin M. Reconditioning of ceramic orthodontic brackets with an Er, Cr:YSGG laser. Lasers Med Sci. 2013; 28(1): 2238.

Altundasar E, Ozçelik B, Cehreli ZC, Matsumoto K. Ultramorphological and histochemical changes after Er, Cr:YSGG laser irradiation and two different irrigation regimes. J Endod. 2006; 32: 465-8.

Amaral FL, Colucci V, Souza-Gabriel AE, Chinelatti MA, Palma-Dibb RG, Corona SA. Bond durability in erbium:yttrium-aluminum-garnet laser-irradiated enamel. Lasers Med Sci. 2010; 25(2): 155-63.

Angle H. The latest and best in orthodontic mechanism. Dent Cosmos. 1928; 70: $1143-58$

Anic I, Vidovic D, Luic M, Tudja M. Laser induced molar tooth pulp chamber temperature changes. Caries Res. 1992; 26: 165-9.

Anusavice KJ. Efficacy of nonsurgical management of the initial caries lesion. J Dent Educ. 1997; 61(11): 895-905.

Arisu HD, Bala O, Alimzhanova G, Turkoz E. Assessment of morphological changes and permeability of apical dentin surfaces induced by Nd:YAG laser irradiation through retrograde cavity surfaces. J Contemp Dent Pract. 2004; 5: 102-13.

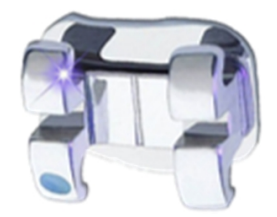


Artés-Ribas M, Arnabat-Dominguez J, Puigdollers A. Analgesic effect of a low-level laser therapy $(830 \mathrm{~nm})$ in early orthodontic treatment. Lasers Med Sci. 2013; 28(1): $335-41$.

Arnabat-Domínguez J, España-Tost AJ, Berini Aytes L, GayEscoda C. Erbium:YAG application in the second phase of implant surgery: a pilot study in 20 patients. Int J Oral Maxillofac Implants. 2003; 18: 104-12.

Artun J, Bergland S. Clinical trials with crystal growth conditioning as an alternative to acid-etch enamel pretreatment. Am J Orthod. 1984; 85(4): 333-40.

Attrill DC, Davies RM, King TA, Dickinson MR, Blinkhorn AS. Thermal effects of the Er:YAG laser on a simulated dental pulp: a quantitative evaluation of the effects of a water spray. J Dent. 2004; 32: 35-40.

Attrill DC, Farrar SR, King TA, Dickinson MR, Davies RM. Er:YAG $(\lambda=2.94 \mu \mathrm{m})$ laser etching of dental enamel as an alternative to acid etching. Lasers Med Sci. 2000; 15: 154-61.

Bach G, Neckel C, Mall C, Krekeler G. Conventional versus laser-assisted therapy of periimplantitis: a five-year comparative study. Implant Dent. 2000; 9(3): 247-51.

Başaran G, Hamamcı N, Akkurt A. Shear bond strength of bonding to enamel with different laser irradiation distances. Lasers Med Sci. 2011; 26(2): 149-56.

Başaran G, Ozer T, Berk N, Hamamci O. Etching enamel for orthodontics with an erbium, chromium:yttrium-scandium-gallium-garnet laser system. Angle Orthod. 2007; 77: 117-23. 
Capítulo 6: Bibliografía

Başaran G, Hamamcı N, Akkurt A. Shear bond strength of bonding to enamel with different laser irradiation distances. Lasers Med Sci. 2010; 26: 149-56.

Bhaskar SN. Orban's Oral Histology and Embriology. St. Louis: CV Mosby; 1986.

Bello-Silva MS, Wehner M, Eduardo Cde P, Lampert F, Poprawe R, Hermans M, Esteves-Oliveira M. Precise ablation of dental hard tissues with ultra-short pulsed lasers. Preliminary exploratory investigation on adequate laser parameters. Lasers Med Sci. 2013; 28(1): 171-84.

Benderli Y, Gökçe K, Büyükgökçesu S. In vitro shear bond strength of adhesive to normal and fluoridated enamel under various contaminated conditions. Quintessence Int. 1999; 30(8): 570-5.

Berk N, Başaran G, Ozer T. Comparison of sandblasting, laser irradiation, and conventional acid etching for orthodontic bonding of molar tubes. Eur J Orthod. 2008; 30(2): 183-9.

Berkovitz BKB, Holland GR, Moxham BJ. Oral anatomy, histology and embryology. $3^{\text {a }}$ Ed. Edinburgh; New York: Mosby; 2002.

Berry TG, Barghi N, Knight GT, Conn LJ Jr. Effectiveness of nitric-NPG as a conditioning agent for enamel. Am J Dent. 1990; 3(2): 59-62.

Bishara SE, Soliman MM, Oonsombat C, Laffoon JF, Ajlouni R. The effect of variation in mesh-base design on the shear bond strength of orthodontic brackets. Angle Orthod. 2004; 74: 400-4.

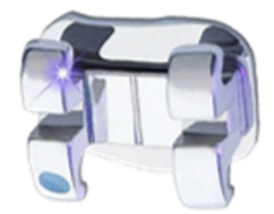


Bishara SE, Oonsombat C, Soliman MM, Warren JJ, Laffoon JF, Ajlouni R. Comparison of bonding time and shear bond strength between a conventional and a new integrated bonding system. Angle Orthod. 2005; 75: 237-42.

Bishara SE, Ostby AW, Ajlouni R, Laffoon JF, Warren JJ. Early shear bond strength of a one-step self-adhesive on orthodontic brackets. Angle Orthod. 2006; 76(4): 689-93.

Bloembergen N. Laser-induced electric breakdown in solids. IEEE J Quant Electron. 1974; 10(3): 375-86.

Blosser RL. Time dependence of 2.5\% nitric acid solution as an etchant on human dentin and enamel. Dent Mater. 1990; 6(2): 83-7.

Blum JY, Abadie JM. Effects du laser Nd:YAP sur les materiaux endocanalaires. Endo. 1996; 15: 37-45.

Blum JY, Michailesco P, Abadie JM. An evaluation of the bactericidal effect of the Nd:YAP laser. J Endod. 1997; 23: 583-5.

Blum R. Restorative dentistry with the Er:YAG laser. J Oral Laser Applic. 2001; 1: $55-8$.

Boehm R, Rich J, Webster J, Janke S. Thermal stress effects and surface cracking associated with laser use on human teeth. J Biomech Eng. 1977; 77: 189-94.

Bourgeois F, Ben-Yakar A. Femtosecond laser nanoaxotomy properties and their effect on axonal recovery in C. elegans. Opt Express. 2008; 16(8): 5963. 
Capítulo 6: Bibliografía

Bowen RL. Dental filling material comprising vynil silane treated fused silica and a binder consisting of the reaction product of bisfhenol and glycidel methacrylate. US Patent 3,066,112. 27-11-1962.

Bowes JH, Murray MM. The chemical composition of teeth: The composition of human enamel and dentine. Biochem J. 1935; 29(12): 2721-7.

Boyd RL. Comparison of three self-applied topical fluoride preparations for control of decalcification. Angle Orthod. 1994; 64: 86.

Bradley PF. A review of the use of the Neodymium:YAG laser in oral and maxillofacial surgery. Br J Oral Maxillofac Surg. 1997; 35: 26-35.

Braun A, Krillke RF, Frentzen M, Bourauel C, Stark H, Schelle F. Heat generation caused by ablation of dental hard tissues with an ultrashort pulse laser (USPL) system. Lasers Med Sci. 2013. In press.

Buonocuore MG. A simple method of increasing the adhesion of acrylic fillings materials to enamel surfaces. J Dent Res. 1955; 34: 849-53.

Buonocore MG, Matsui A, Gwinnett AJ. Penetration of resin dental materials into enamel surfaces with reference to bonding. Arch Oral Biol. 1968; 13: 61-70.

Calderón J. Descripción de las resinas compuestas. En: García J, editor. Patología y terapéutica dental. Madrid: Síntesis; 1997. p. 424-33.

Carneiro FC, Nadanovsky P. Dentistica Ultraconservative. São Paulo: Livaria Santos; 2003.

Cavalcanti BN, Lage-Marques JL, Rode SM. Pulpal temperature increases with Er:YAG laser and high-speed handpieces. J Prosthet Dent. 2003; 90: 447-51.

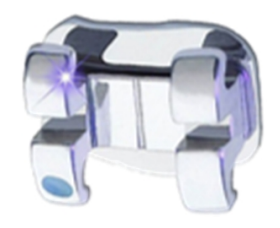


Cehreli ZC, Altay N. Effects of a nonrinse conditioner and $17 \%$ ethylenediaminetetraacetic acid on the etch pattern of intact human permanent enamel. Angle Orthod. 2000; 70(1): 22-7.

Chappell RP, Cobb CM, Spencer P, Eick JD. Dentinal tubule anastomosis: a potencial factor in adhesive bonding?. J Prosthet Dent. 1997; 72: 183-8.

Chen X, Liu X. Short pulsed laser machining: How short is short enough?. J Laser Appl. 1999; 11: 268-72.

Chen WH. Laser root canal therapy. J Indiana Dent Assoc. 2002; 81: 20-3.

Chen H, Liu J, Ge WQ, Sun YC, Wang Y, Lü PJ. Effects of fluence and scanning velocity on the ablation efficiency of dentin and enamel by femtosecond laser. Zhonghua Kou Qiang Yi Xue Za Zhi. 2013; 48(5): 299-302.

Chichkov BN, Momma C, Nolte S, von Alvensleben F, Tünnermann A. Femtosecond, picosecond and nanosecond laser ablation of solids. Appl Phys. 1996; 63: 109-15.

Clokie C, Bentley KC, Head TW. The effects of the helium-neon laser on postsurgical discomfort: a pilot study. J Can Dent Assoc. 1991; 57(7): 584-6.

Colucci V, do Amaral FL, Pécora JD, Palma-Dibb RG, Corona SA. Water flow on erbium:yttrium-aluminum-garnet laser irradiation: effects on dental tissues. Lasers Med Sci. 2009; 24(5): 811-8.

Coluzzi D. Er:YAG Laser caries and composites removal and enamel preparation. Wavelenghts. 2002; 10(3): 11-31. 
Capítulo 6: Bibliografía

Cox CJ, Pearson GJ, Palmer G. Preliminary in vitro investigation of the effects of pulsed Nd:YAG laser radiation on enamel and dentin. Biomaterials. 1994; 15: 114551.

Delgado-Ruíz RA, Calvo-Guirado JL, Moreno P, Guardia J, Gomez-Moreno G, Mate-Sánchez JE, Ramirez-Fernández P, Chiva F. Femtosecond laser microstructuring of zirconia dental implants. J Biomed Mater Res B Appl Biomater. 2011; 96(1): 91-100.

De Munck J, Van Meerbeek B, Yudhira R, Lambrechts P, Vanherle G. Microtensile bond strength of two adhesives to Erbium:YAG lased vs. bur-cut enamel and dentin. Eur J Oral Sci. 2002; 110: 322-9.

De Munck J, Van Landuyt K, Peumans M, Poitevin A, Lambrechts P, Braem M, Van Meerbeek B. A critical review of the durability of adhesion to tooth tissue: methods and results. J Dent Res. 2005; 84(2): 118-32.

Domínguez A, Velásquez SA. Effect of low-level laser therapy on pain following activation of orthodontic final archwires: a randomized controlled clinical trial. Photomed Laser Surg. 2013; 31(1): 36-40.

Dostalova T, Jelinkova H, Krejsa O, Hamal H. Evaluation of the surface changes in enamel and dentin due to possibility of thermal overheating induced by Erbium:YAG laser radiation. Scanning Microsc. 1996; 10: 285-90.

Dunn WJ, Davis JT, Bush AC. Shear bond strength and SEM evaluation of composite bonded to Er:YAG laser-prepared dentin and enamel. Dent Mater. 2005; 21(7): 616-24.

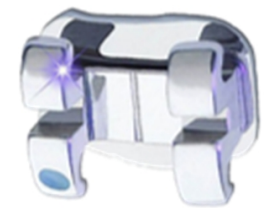


Ekworapoj P, Sdihu SK, McCabe JF. Effect of different power parameters of Er, Cr:YSGG laser on human dentine. Lasers Med Sci. 2007; 22: 175-82.

Eliades T. Orthodontic materials research and applications: part 1. Current status and projected future developments in bonding and adhesives. Am J Orthod Dentofacial Orthop. 2006; 130(4): 445-51.

El Yazami H, Azehoui N, Ahariz M, Rey G, Sauvetre E. Periodontal evaluation of an Nd:YAP laser combined with scaling and root planning for nonsurgical periodontal treatment. J Oral Laser Applications. 2004; 4: 97-102.

Erickson RL. Surface interactions of dentin adhesive materials. Operat Dent. 1992; 5: 81-94.

España A, Velasco V, Gay Escoda C, Berini L, Arnabat J. Aplicaciones del láser de $\mathrm{CO}_{2}$ en odontología. Madrid: Ergon; 1995.

Eversole LR, Rizoiu IM. Preliminary investigations on the utility of an erbium, chromium:YSGG laser. J Calif Dent Assoc. 1995; 23: 41-7.

Firat E, Gurgan S, Gutknecht N. Microtensile bond strength of an etch-and-rinse adhesive to enamel and dentin after Er:YAG laser pretreatment with different pulse durations. Lasers Med Sci. 2012; 27(1): 15-21.

Foong J, Lee K, Nguyen C, Tang G, Austin D, Ch'ng C, Burrow MF, Thomas DL. Comparison of microshear bond strengths of four self-etching bonding systems to enamel using two test methods. Aust Dent J. 2006; 51(3): 252-7.

Fornaini C, Riceputi D, Lupi-Pegurier L, Rocca JP. Patient responses to Er:YAG laser when used for conservative dentistry. Lasers Med Sci. 2012; 27(6): 1143-9. 
Capítulo 6: Bibliografía

Fosse G. A quantitative analysis of the numerical density and the distributional pattern of prisms and ameloblasts in dental enamel and tooth germs. VI. The vertical compression of the prism pattern on the outer enamel surface of human permanent teeth. Acta Odontol Scand. 1968; 26(6): 545-72.

Frederickson KS, White WE, Wheeland RG, Slaughter DR. Precise ablation of skin with reduced collateral damage using the femtosecond-pulsed, terawatt titaniumsapphire laser. Arch Dermatol. 1993; 129(8): 989-93.

Freitas PM, Navarro RS, Barros JA, de Paula EC. The use of Er:YAG laser cavity preparation: a SEM evaluation. Microsc Res Tech. 2007; 70(9): 803-8.

Frentzch M, Koort HJ. Lasers in dentistry new possibilities with advancing laser technology?. Int Dent J. 1990; 40: 323-32.

Gabel CV, Antonie F, Chuang CF, Samuel ADT, Chang C. Distinct cellular and molecular mechanisms mediate initial axon development and adult-stage axon regeneration in C. elegans. Development. 2008; 135: 1129-36.

Gamaly EG, Rode AV, Luther-Davies B, Tikhonchuk VT. Ablation of solids by femtosecond lasers: ablation mechanism and ablation thresholds for metalsand dielectrics. Phys Plas. 2002; 9: 949-57.

García Barbero J. Patología y Terapéutica dental. Madrid: Síntesis; 1997.

Gardner A, Hobson R. Variations in acid-etch patterns with different acids and etch times. Am J Orthod Dentofacial Orthop. 2001; 120(1): 64-7.

Gassoni A, Rodrigues JA. Argon laser: a ligth source alternative for photopolimerization and in-office tooth bleaching. Gen Dent. 2007; 55(5): 416-9.

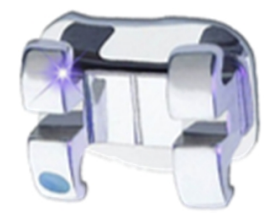


Gerard N, Hendler BH. Laser arthroscopy of the temporomandibular joint. Compend Contin Educ Dent. 1995; 16(4): 350-4.

Gerhardt-Szep S, Werelius K, de Weerth F, Heidemann D, Weigl P. Influence of femtosecond laser treatment on shear bond strength of composite resin bonding to human dentin under simulated pulpal pressure. J Biomed Mater Res B Appl Biomater. 2012; 100(1): 177-84.

Girard B, Cloutier M, Wilson DJ, Clokie CMI, Miller RJD, Wilson BC. Microtomographic analysis of healing of femtosecond laser bone calvaria wounds compared to mechanical instruments in mice with and without application of BMP7. Lasers Surg Med. 2007a; 39(5): 458-67.

Girard B, Yu D, Armstrong MR, Wilson BC, Clokie CM, Miller RJ. Effects of femtosecond laser irradiation on osseous tissues. Lasers Surg Med. 2007b; 39(3): $273-85$.

Gokcelik A, Ozel Y, Ozel E, Arhun N, Attar N, Firatli S, Firatli E. The influence of Er:YAG laser conditioning versus self-etching adhesives with acid etching on the shear bond strength of orthodontic brackets. Photomed Laser Surg. 2007; 25(6): $508-12$.

Goharkay K. Moritz A, Wilder-Smith P, Schoop U, Kluger W, Jakolitsch S, et al. Effects on oral soft tissue produced by a diode laser in vitro. Lasers Surg Med. 1999; 25: 401-6.

Goldman L, Gray JA, Goldman J, Goldman B, Meyer R. Effect of laser beam impacts on teeth. J Am Dent Assoc. 1965; 70: 601-6. 
Capítulo 6: Bibliografía

Gomes AL, Castillo-Oyagüe R, Lynch CD, Montero J, Albaladejo A. Influence of sandblasting granulometry and resin cement composition on microtensile bond strength to zirconia ceramic for dental prosthetic frameworks. J Dent. 2013; 41(1): $31-41$.

Gómez de Ferraris ME, Campos Muñoz A. Histologia y Embriologia bucodental. $2^{\mathrm{a}}$ Ed. Madrid: Médica Panamericana; 2002.

Goodman BD, Kaufman HW. Effects of an Argon laser on crystalline properties and rate of dissolution in acid of tooth enamel in the presence of sodium fluoride. J Dent Res. 1977; 56: 1201-7.

Goracci C, Margvelashvili M, Giovannetti A, Vichi A, Ferrari M. Shear bond strength of orthodontic brackets bonded with a new self-adhering flowable resin composite. Clin Oral Investig. 2013; 17(2): 609-17.

Gorelick L, Geiger AM, Gwinnett AJ. Incidence of white spot formation after bonding and banding. Am J Orthod. 1982; 81 :93-8.

Goswami M, Singh A. Comparative evaluation of shear bond strength of composite resin bonded to acid etched or Nd: Yag lased enamel. J Indian Soc Pedod Prev Dent. 2011; 29: 140-3.

Graber TM, Vanarsdall RL, Vig KW. Ortodoncia. Principios y técnicas actuales. $4^{\mathrm{a}}$ Ed. Madrid: Elsevier Mosby; 2006.

Grassi RF, Pappalardo S, Frateiacci A, Scortechini A, De Benedittis M, Petruzzi M. Antibacterial effect of Nd:YAG laser in periodontal pockets decontamination: a in vivo study. Minerva Stomatol. 2004; 53: 355-9.

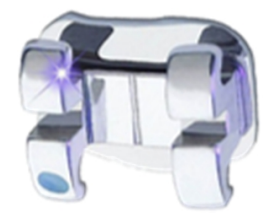


Groth EB, Mercer CE, Anderson P. Microtomographic analysis of subsurface enamel and dentine following Er:YAG laser and acid etching. Eur J Prosthodont Restor Dent. 2001; 9: 73-9.

Guo SX, Bourgeois F, Chokshi T, Durr NJ, Hilliard MA, Chronis N, Ben-Yakar A. Femtosecond laser nanoaxotomy lab-on-a chip for in vivo nerve regeneration studies. Nature Methods. 2008; 5: 531-3.

Gutknecht N, Moritz A, Conrads G, Slevert T, Lampfert F. Bactericidal effect of the Nd:YAG laser in in vitro root canals. J Clin Laser Med Surg. 1996; 14: 77-80.

Gutknecht N, Neubler-Moritz M, Fallot S, Lampert F. The efficiency of root canal disinfection using a holmium: ytrium-aluminium-garnet laser in vitro. J Clin Laser Med Surg. 1997; 15: 75-8.

Gutknecht N, van Gogswaardt D, Conrads G, Apel C, Schubert C, Lampert F. Diode laser radiation and its bactericidal effect in root canal wall dentin. J Clin Laser Med Surg. 2000; 18(2): 57-60.

Gutknecht N, van Gogswaardt D, Conrads G, Apel C, Schubert C, Lampert F. Diode laser radiation and its bactericidal effect in root canal wall dentin. J Clin Laser Med Surg. 2000; 18(2): 57-60.

Gwinnett AJ, Matsui A. A study of enamel adhesives. The physical relationship between enamel and adhesive. Arch Oral Biol. 1967; 12: 1615-20.

Gwinnett AJ. Histologic changes in human enamel following treatment with acidic adhesive conditioning agents. Arch Oral Biol. 1971; 16: 731-8. 
Capítulo 6: Bibliografía

Gwinnett AJ. A comparison of shear bond strengths of metal and ceramic brackets. Am J Orthod Dentofac Orthop. 1988; 93: 346-8.

Gwinnett AJ, Garcia-Godoy F. Effect of etching time and acid concentration on resin shear bond strength to primary tooth enamel. Am J Dent. 1992; 5(5): 237-9.

Habelitz S, Marshall SJ, Marshall G, Balooch M. Mechanical properties of human dental enamel on the nanometer scale. Arch Oral Biol. 2001; 46: 173-83.

Hafez MI, Coombs RR, Zhou S, McCarthy ID. Ablation of bone, cartilage and facet joint capsule using Ho:YAG laser. J Clin Laser Med Surg. 2002; 20: 251-5.

Hamamci N, Akkurt A, Başaran G. In vitro evaluation of microleakage under orthodontic brackets using two different laser etching, self etching and acid etching methods. Lasers Med Sci. 2010; 25(6): 811-6.

Harashima T, Takeda FH, Zhang C, Kimura Y, Matsumoto K. Effect of argon laser irradiation on instrumented root canal walls. Endod Dent Traumatol. 1998; 14: 2630.

Heiroth S, Lippert T, Wokaun A, Koch J, Günther D, Garrelie F, Guillermin M. Laser ablation characteristics of yttria-doped zirconia in the nanosecond and femtosecond regime. J Appl Phys. 2010; 107: 014908-10.

Heisterkamp A, Mamom T, Kermani O, Drommer W, Welling H, Ertmer W, Lubatschowski H. Intrastromal refractive surgery with ultrashort laser pulses: in vivo study on the rabbit eye. Graefes Arch Clin Exp Ophthalmol. 2003; 241(6): 5117. 
Hendler BH, Gateno J, Mooar P, Sherk HH. Holmium:YAG laser arthroscopy of the temporomandibular joint. J Oral Maxillofac Surg. 1992; 50(9): 931-4.

Henning T, Nieswand E, Rechmann P. A new picosecond laser emitting blue light for use in periodontology. En: Rechmann P, Fried D, Henning T. Lasers in dentistry VII. Proc SPIE. 2001; 4249: 36-43.

Henostroza G. Adhesión en Odontología Restauradora. 2a Ed. Madrid: Ripano; 2010.

Hertel IV, Stoian R, Ashkenasi D, Rosenfeld A, Campbell EB. On the physics of material processing with femtosecond lasers. En: Midorikawa K, Sugioka K. Laser Precision Microfabrication. LPM 2000. RIKEN Rev. 2001; 32: 23-30.

Hibst R, Keller U. Experimental studies of the application of Er:YAG laser on dental hard substances.I. Measurement of the ablation rate. Lasers Surg Med. 1989; 9: $338-44$.

Hibst R, Stock K, Gall R, Keller U. Er:YAG laser for endodontics: efficiency and safety. Proc SPIE. 1997; 3192: 19-27.

Hibst R, Keller U. Measurement and modelling of temperature distribution for Er:YAG laser root canal sterilisation. Proc SPIE. 1998; 3564: 204-9.

Hibst R. Laser for caries removal and cavity preparation: state of the art and future directions. J Oral Laser Appl. 2004; 2: 203-12.

Hicks MJ, Flaitz CM, Westerman GH, Berg JH, Blankenau RL, Powell GL. Carieslike lesion initiation and progression in sound enamel following argon laser irradiation: an in vitro study. ASDC J Dent Child. 1993; 60: 201-6. 
Capítulo 6: Bibliografía

Hildebrand NK, Raboud DW, Heo G, Nelson AE, Major PW. Argon laser vs conventional visible light-cured orthodontic bracket bonding: an in-vivo and in-vitro study. Am J Orthod Dentofacial Orthop. 2007; 131(4): 530-6.

Hossain M, Nakamura Y, Yamada Y, Kimura Y, Matsumoto N, Matsumoto K. Effects of Er, Cr:YSGG laser irradiation in human enamel and dentin: ablation and morphological studies. J Clin Laser Med Surg. 1999; 17(4): 155-9.

Hossain M, Nakamura Y, Yamada Y, Kimura Y, Nakamura G, Matsumoto K. Ablation depths and morphological changes in human enamel and dentin after Er:YAG laser irradiation with or without water mist. J Clin Laser Med Surg. 1999; 17: 105-9.

Hossain M, Nakamura Y, Yamada Y, Murakami Y, Matsumoto K. Compositional and structural changes of human dentin following caries removal by Er, Cr:YSGG laser irradiation in primary teeth. J Clin Pediatr Dent. 2002; 26: 377-82.

Hossain M, Yamada Y, Nakamura Y, Murakami Y, Tamaki Y, Matsumoto K. A study on surface roughness and microleakage test in cavities prepared by Er:YAG laser irradiation and etched bur cavities. Lasers Med Sci. 2003; 18(1): 25-31.

Hosseini MH, Namvar F, Chalipa J, Saber K, Chiniforush N, Sarmadi S, Mirhashemi AH. Comparison of shear bond strength of orthodontic brackets bonded to enamel prepared by Er:YAG laser and conventional acid-etching. J Dent (Tehran). 2012; 9:20-6.

Hoy CL, Durr NJ, Chen P, Piyawattanametha W, Ra H, Solgaard O, Ben-Yakar A. Miniaturized probe for femtosecond laser microsurgery and two-photon imaging. Optics Express. 2008; 16: 9996-10005.

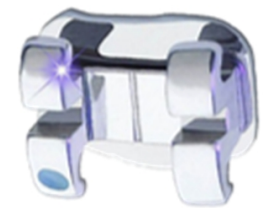


Jacobo C, Torrella F, Bravo-González LA, Ortiz AJ, Vicente A. In vitro study of the antibacterial properties and microbial colonization susceptibility of four selfetching adhesives used in orthodontics. Eur J Orthod. 2013. [Epub ahead of print]. Ji L, Li L, Devlin H, Liu Z, Jiao J, Whitehead D. Ti:sapphire femtosecond laser ablation of dental enamel, dentine, and cementum. Lasers Med Sci. 2012; 27(1): 197-204.

Joubert Hued R. Odontología adhesiva y estética. Madrid: Ripano-Editorial Médica; 2010.

Juhasz T, Loesel HL, Kurtz RM, Horvath C, Bille JF, Mourou G. Corneal refractive surgery with femtosecond lasers. IEEE J Sel Top Quant Electron. 1999; 5: 902-10.

Kabas As, Ersoy T, Gülsoy M, Akturk S. Femtosecond laser etching of dental enamel for bracket bonding. J Biomed Opt. 2013; 18(9): 98003.

Kang DY, Choi SH, Cha JY, Hwang CJ. Quantitative analysis of mechanically retentive ceramic bracket base surfaces with a three-dimensional imaging system. Angle Orthod. 2013; 83(4): 705-11.

Kautek W, Mitterer S, Krüger J, Husinsky W, Grabner G. Femtosecond pulse laser ablation of human corneas. Appl Phys A. 1994; 58(5): 513-8.

Keim RG, Gottlieg EL, Nelson AH, et al. 2002 JCO study of orthodontic diagnosis and treatment procedures.1. Results and trends. J Clin Orthod. 2002; 36: 553-68.

Keizer S, ten Cate JM, Arends J. Direct bonding of orthodontic brackets. Am J Orthod. 1976; 69(3): 318-27. 
Capítulo 6: Bibliografía

Keller U, Hibst R. Experimental studies of the application of the Er:YAG laser on dental hard substances II. Light microscopic and SEM investigations. Lasers Surg Med. 1989; 9: 345-51.

Keller D, Hibst R. Lasers in oral surgery. Medical applications of lasers II. Proc SPIE. 1994; 2327: 146-54.

Kermani O, Lubatschowski H, Asshauer T, Ertmer W, Lukin A, Ermakov B, Krieglstein GK. Q-switched CTE:YAG (2.69 microns) laser ablation: basic investigations on soft (corneal) and hard (dental) tissues. Laser Surg Med. 1993; 13: $537-42$.

Kim BM, Feit MD, Rubenchik AM, Joslin EJ, Celliers PM, Eichler J, Da Silva LB. Influence of pulse duration on ultrashort laser pulse ablation of biological tissues. J Biomed Opt. 2001; 6(3): 332-8.

Kim JH, Kwon OW, Kim HI, Kwon YH. Effectiveness of an Er:YAG laser in etching the enamel surface for orthodontic bracket retention. Dent Mater J. 2005; 24: 596602.

Kim JH, Kwon OW, Kim HI, Kwon YH. Acid resistance of erbium-doped yttrium aluminum garnet laser-treated and phosphoric acid-etched enamels. Angle Orthod. 2006; 76(6): 1052-6.

Kimura Y, Yonoga K, Yokoyama K, Kinoshita J, Ogata Y, Matsumoto K. Root surface temperature increase during Er:YAG laser irradiation of root canals. J Endod. 2002; 28: 76-8.

Kinloch AJ. Adhesion and Adhesives. Science and Technology. London: Chapman and Hall; 1987.

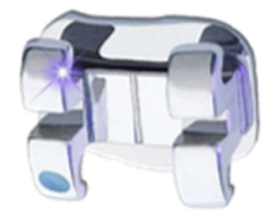


Kohns P, Zhou P, Stormann R. Effective laser ablation of enamel and dentine without thermal side effects. J Laser Appl. 1997; 9(3): 171-4.

Kreisler M, Al Haj H, Gotz H, Duschner H, d'Hoedt B. Effect of simulated $\mathrm{CO}_{2}$ and GaAlAs laser surface decontamination on temperature changes in Ti-plasma sprayed dental implants. Lasers Surg Med. 2002; 30: 233-9.

Kreisler M, Kohen W, Beck M, Al Haj H, Christoffers A, Gotz H. Efficacy of $\mathrm{NaOCl} / \mathrm{H}_{2} \mathrm{O}_{2}$ irrigation and GaAlAs laser in decontamination of root canals in vitro. Lasers Surg Med. 2003; 32: 189-96.

Krüger J, Kautek W, Newesely H. Femtosecond-pulsed laser ablation of dental hydroxyapatite and single-crystalline fluoroapatite. Appl Phys. 1999; 69: 403-7.

Kuper S, Stuke M. Femtosecond uv excimer laser ablation. Appl Phys B. 1987; 44(4): 199-204.

Kutsch VK. Dental caries illumination with the argon laser. J Clin Laser Med Surg. 1993; 11: 558-9.

Lasmar MF, Reher VG, Lalloo R, Reher P. Enamel demineralization and bracket bond strength when etching with acid and /or Er:YAG laser. Aust Dent J. 2012; 57(2): 190-5.

Lee BS, Hsieh TT, Lee YL, Lan WH, Hsu YJ, Wen PH, Lin CP. Bond strengths of orthodontic bracket after acid-etched, Er:YAG laser-irradiated and combined treatment on enamel surface. Angle Orthod. 2003; 73: 565-70.

Lehman R, Davidson CL. Loss of surface enamel after acid etching procedures and its relation to fluoride content. Am J Orthod. 1981; 80: 73-82. 
Capítulo 6: Bibliografía

Li ZZ, Reinisch L, Van de Merwe WP. Bone ablation with Er:YAG and $\mathrm{CO}_{2}$ laser: study of thermal and acoustic effects. Lasers Surg Med. 1992; 12: 79-85.

Li ZZ, Code JE, Van De Merwe WP. Er:YAG laser ablation of enamel and dentin of human teeth: determination of ablation rates at various fluences and pulse repetition rates. Lasers Surg Med. 1992; 12: 625-30.

Liberman R, Segal TH, Nordenberg D, Serebro LI. Adhesion of composite materials to enamel: comparison between the use of acid and lasing as pretreatment. Lasers Surg Med. 1984; 4: 323-7.

Lima AF, da Silva VB, Soares GP, Marchi GM, Baggio Aguiar FH, Lovadino JR. Influence of previous acid etching on interface morphology and bond strength of self-etching adhesive to cavosurface enamel. Eur J Dent. 2012; 6: 56-62.

Lizarelli RFZ, Kurachi C, Misoguti L, Bagnato VS. A comparative study of nanosecond and picosecond laser ablation in enamel: Morphological aspects. J Clin Laser Med Surg. 2000; 18: 151-8.

Lizarelli RFZ, Kurachi C, Misoguti L, Bagnato VS. Characterization of enamel and dentin response to Nd:YAG picosecond laser ablation. J Clin Laser Med Surg. 1999; 17: $127-31$.

Loesel FH, Fischer JP, Gotz MH, Horvath C, Juhasz T, Noack F, Suhm N, Bille JF. Non-thermal ablation of neural tissue with femtosecond laser pulses. Applied Physics B. 1998; 66: 121-8.

Lorenzo MC, Portillo M, Moreno P, Montero J, Castillo-Oyagüe R, García A, Albaladejo A. In vitro analysis of femtosecond laser as an alternative to acid etching

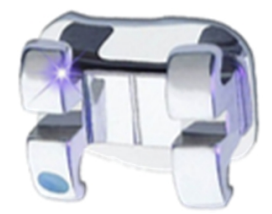


for achieving suitable bond strength of brackets to human enamel. Lasers Med Sci. 2013 [In press].

Lubatschowski H, Maatz G, Heisterkamp A, Hetzel U, Drommer W, Welling H, Ertmer W. Application of ultrashort laser pulses for intrastromal refractive surgery. Graefes Arch Clin Exp Ophthamol. 2000; 238: 33-9.

Luengo MC, Portillo M, Sánchez JM, Peix M, Moreno P, García A, Montero J, Albaladejo A. Evaluation of micromorphological changes in tooth enamel after mechanical and ultrafast laser preparation of surface cavities. Lasers Med Sci. 2013; 28(1): 267-73.

Lugato IC, Pignatta LM, Arantes Fde M, Santos EC. Comparison of the shear bond strengths of conventional mesh bases and sandblasted orthodontic bracket bases. Braz Oral Res. 2009; 23: 407-14.

Lustosa-Pereira AC, Pozza DH, Cunha A, Dedavid BA, Duarte-de Moraes JF, Gerhardt-de Oliveira M. Analysis of the morphology and composition of tooth apices apicectomized using three different ablation techniques. Med Oral Patol Oral Cir Bucal. 2011; 16: 225-30.

Luk K, Tam L, Hubert M. Effect of light energy on peroxide tooth bleaching. J Am Dent Assoc. 2004; 135: 194-201.

Maatz G, Heisterkamp A, Lubatschowski H, Barcikowski S, Fallnich C, Welling H, Ertmer W. Chemical and physical side effects at application of ultrashort laser pulses for intrastromal refractive surgery. J Opt A. 2000; 2: 59-64.

MacColl GA, Rossouw PE, Titley KC, Yamin C. The relationship between bond strength and orthodontic bracket base surface area with conventional and 
Capítulo 6: Bibliografía

microetched foil-mesh bases. Am J Orthod Dentofacial Orthop. 1998; 113(3): 27681.

Maijer R, Smith DC. Crystal growth on the outer enamel surface-an alternative to acid etching. Am J Orthod. 1986; 89(3): 183-93.

Maiman T. Stimulated optical radiation in ruby. Nature 1960; 187: 493-4.

Mann AB, Dickinson ME. Nanomechanics, chemistry and structure at the enamel surface. Monogr Oral Sci. 2006; 19: 105-31.

Marion JE, Kin BM. Medical applications of ultra-short pulse lasers. Proc SPIE. 1999; 3910: 42-50.

Martínez-Insúa A, Da Silva Domínguez L, Rivera FG, Santana-Penín UA. Differences in bonding to acid-etched or Er:YAG-laser-treated enamel and dentin surfaces. J Prosthet Dent. 2000; 84(3): 280-8.

Martins GR, Cavalcanti BN, Rode SM. Increases in intrapulpar temperature during polymerization of composite resin. J Prosthet Dent. 2006; 96(5): 328-31.

Meckel AH, Grebstein WJ, Neal RJ. Structure of mature human enamel as observed by electron microscopy. Arch Oral Biol. 1965; 10: 775.

Mehl A, Folwaczny M, Haffner C, Hickel R. Bactericidal effects of 2.94 microns Er:YAG laser radiation in dental root canals. J Endod. 1999; 25(7): 490-3.

Meléndez JL, Varela R, Cueto G, Mondragón J, Carrillo L, Coronado E et al. Evaluación del grabado del esmalte en piezas con ápice inmaduro y maduro utilizando ácido ortofosfórico al 37\% por medio de microscopia electrónica de barrido. Acta odontol venez. 2002; 40(1): 26-30.

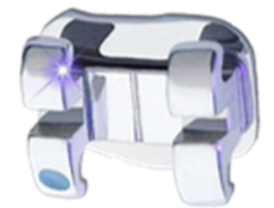


Miller RJ. Treatment of the contaminated implant surface using the Er, Cr:YSGG laser. Implant Dent. 2004; 13: 165-70.

Mir M, Meister J, Franzen R, Sabounchi SS, Lampert F, Gutknecht N. Influence of water-layer thickness on Er:YAG laser ablation of enamel of bovine anterior teeth. Lasers Med Sci. 2008; 23: 451-7.

Miserendino LJ, Pick RM. Lasers in dentistry. Singapor: Quintessence; 1995.

Mjor IA, Pindborg JJ. Histología del diente humano. Barcelona: Labor, Barcelona; 1974.

Momma C, Chichkov B, Nolte S, von Alvensleben F, Tünnermann A, Welling H. Short-pulse laser ablation of solid targets. Opt Commun. 1996; 129: 134-42.

Momma C, Nolte S, Welling H, Kasenbacher A, Niemz MH. Laser in Medicine. Berlin Heidelberg: Springer-Verlag; 1997.

Moritz A, Sperr W, Schoop U, Goharkhay K, Gutknecht N, Doertbudak O. Nd:YAG laser irradiation of infected root canals in combination with microbiological examinations. J Am Dent Assoc. 1997; 128: 1525-30.

Moritz A, Jakolisch S, Goharkhay K, Schoop U, Kluger W, Mallinger R. Morphologic changes correlating to different sensitivities of Escherichia coli and Enterococcus faecalis to Nd:YAG laser irradiation through dentin. Laser Surg Med. 2000; 26: 250-61.

Moritz A, Schoop U, Goharkhay K, Jakolisch S, Kluger W, Wernisch J. The bactericidal effect of Nd:YAG, Ho:YAG and Er:YAG laser irradiation in the root canal: an in vitro comparision. J Clin Laser Med Surg. 1999; 17: 161-4. 
Capítulo 6: Bibliografía

Moritz A, Gutknecht N, Doertbudak K, Schoop U, Schauer P. Bacterial reduction in periodontal pockets through irradiation with a diode laser: a pilot study. J Clin Laser Med Surg. 1997; 15: 33-7.

Moriyama EH, Zangaro RA, Villaverde AB, Lobo PD, Munin E, Watanabe IS. Dentin evaluation after Nd:YAG laser irradiation using short and long pulses. J Clin laser Med Surg. 2004; 22: 43-50.

Moshonov J, Sion A, Kasirer J, Rotstein I, Stabholz A. Efficacy of argon laser irradiation in removing intracanal debris. Oral Surg Oral Med Oral Pathol Oral Radio Endod. 1995; 79: 221-5.

Moshonov J, Peretz B, Brown T, Rotstein I. Cleaning of the root canal using Nd:YAP laser and its effect on the mineral content of the dentin. J Clin laser Med Surg. 2004; 22: 87-9.

Moulton PF. Spectroscopic and laser characteristics of Ti: $\mathrm{Al}_{2} \mathrm{O}_{3}$. J Opt Soc Am. 1986; 3(1): 125-33.

Mourou G, Strickland D. Compression of amplified chirped optical pulses. Opt Commun. 1985; 55: 447-9.

Nakabayashi N, Pashley D. Hybridazation of dental hard tissues. Tokyo: Quintessence Publ Co. Ltd; 1998: 37-56.

Neev J, Carrasco WA, Armstrong WB, Da Silva LB, Feit MD, Matthews DL, Perry MD, Rubenchik AM, Stuart BC. Applications of ultrashort pulse lasers for hard tissue surgery. IEEE Journal of Selected Topics in Quantum Electronics. 1996; 2: 790-800. 
Nicolás Silvente AI. Estudio in vitro del efecto de diferentes métodos de acondicionamiento del esmalte en el recementado de brackets [Tesis doctoral]. Murcia: Universidad de Murcia; 2010.

Nicolodelli G, Kurachi C, Bagnato VS. Femtosecond laser ablation profile near an interface: Analysis based on the correlation with superficial properties of individual materials. Appl Surf Sci. 2011; 257: 419-22.

Nicolodelli G, Kurachi C, Rego RF, Omairi T, Bagnato VS. Evidence of 5aminolevulinic acid (ALA) penetration increase due to microdrilling in soft tissue using femtosecond laser ablation. Lasers Med Sci. 2012; 27(5): 1067-71.

Niemz MH. Laser-Tissue Interactions: Fundamentals and Applications. $3^{\mathrm{a}} \mathrm{Ed}$. Berlín: Springer-Verlag. 1998.

Niemz MH. Cavity preparation with Nd:YLF picosecond laser. J Dent Res. 1995; 74: 1194-9.

Niemz MH, Kasenbacher A, Strassl M, Bäcker A, Beyerti A, Nickel D, Giesen A. Tooth ablation using a CPA- free thin disk femtosecond laser system. Appl Phys. 2004; 79: 269-71.

Nishimura N, Schaffer CB, Friedman B, Tsai PS, Lyden PD, Kleinfeld D. Targeted insult to individual subsurface cortical blood vessels using ultrashort laser pulses: Three models of stroke. Nature Methods. 2006; 3: 99-108.

Nolte S, Momma C, Jacobs H, Tunnermann A, Chichkov BN, Wellegehausen B, Welling H. Ablation of metals by ultrashort laser pulses. J Optical Soc Am BOptical Phys. 1997; 14(10): 2716-22. 
Capítulo 6: Bibliografía

Obata A, Tsumura T, Niwa K, Ashizawa Y, Deguchi T, Ito M. Super pulse $\mathrm{CO}_{2}$ laser for bracket bonding and debonding. Eur J Orthod. 1999; 21(2): 193-8.

Obeidi A, Liu PR, Ramp LC, Beck P, Gutknecht N. Acid-etch interval and shear bond strength of Er, Cr:YSGG laser-prepared enamel and dentin. Lasers Med Sci. $2010 ; 25(3): 363-9$.

Obeidi A, McCracken MS, Liu PR, Litaker MS, Beck P, Rahemtulla F. Enhancement of bonding to enamel and dentin prepared by Er, Cr:YSGG laser. Lasers Surg Med. 2009; 41: 454-62.

Odegaard J, Segner D. Shear bond strength of metal brackets compared with a new ceramic bracket. Am J Orthod Dentofac Orthop. 1988; 94: 201-6.

Ogaard B, Rølla G, Arends J. Orthodontic appliances and enamel demineralization. Part 1. Lesion development. Am JOrthod Dentofacial Orthop. 1988; 94: 68-73.

Oh KT, Choo SU, Kim KM, Kim KN. A stainless steel bracket for orthodontic application. Eur J Orthod. 2005; 27(3): 237-44.

Oho T, Morioka T. A possible mechanism of acquired acid resistance of human dental enamel by laser irradiation. Caries Res. 1990; 24: 86-92.

Oraevsky A, Da Silva L, Rubenchik A, Feit M, Glinsky M, Perry M, Mammini B, Small W, Stuart B. Plasma mediated ablation of biological tissues with nanosecondto-femtosecond laser pulses: Relative role of linear and nonlinear absorption. IEEE J Sel Top Quantum Electron. 1996; 2: 801-9.

O'Reilly MT, De Jesús Viñas J, Hatch JP. Effectiveness of a sealant compared with no sealant in preventing enamel demineralization in patients with fixed orthodontic

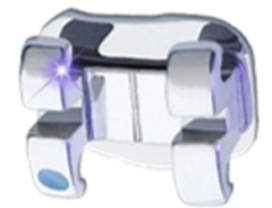


appliances: a prospective clinical trial. Am J Orthod Dentofacial Orthop. 2013; 143(6): 837-44.

Orza Segada JM. Láseres y sus aplicaciones. Madrid: Nuevas Tendencias (Consejo Superior de Investigaciones Científicas); 1986.

Oyagüe RC, Monticelli F, Toledano M, Osorio E, Ferrari M, Osorio R. Effect of water aging on microtensile bonds strength of dual-cured resin cements to pretreated sintered zirconium-oxide ceramics. Dent Mater. 2009; 25: 392-9.

Ozel E, Korkmaz Y, Attar N, Bicer CO, Firatli E. Leakage pathway of different nano-restorative materials in class V cavities prepared by Er:YAG laser and bur preparation. Photomed Laser Surg. 2009; 27(5): 783-9.

Özer T, Başaran G, Berk N. Laser etching of enamel for orthodontic bonding. Am J Orthod Dentofacial Orthop. 2008; 134: 193-7.

Oztoprak MO, Nalbantgil D, Erdem AS, Tozlu M, Arun T. Debonding of ceramic brackets by a new scanning laser method. Am J Orthod Dentofacial Orthop. 2010; 138(2): 195-200.

Packham DE. Adhesion. En: Packman DE, editor. Handbook of adhesion. England: Longman Scientific \& Technical; 1992. p. 18-20.

Padday JF. Contact angle measurement. En Packham DE, editor. Handbook of adhesion. England: Longman; 1992.

Park S, Quinn JB, Romberg E, Arola D. On the brittleness of Enamel and Selected Dental Materials. Dent Mater. 2008; 24: 1477-85.

Parker S. Surgical lasers and hard dental tissue. Br Dent J. 2007; 202: 445-54. 
Capítulo 6: Bibliografía

Pashley DH. The effects of acid etching on the pulpodentin complex. Oper Dent. 1992; 17: 229-42

Pearson GJ, Schuckert KH. The role of lasers in dentistry: present and future. Dent Update. 2003; 30: 70-6.

Pecaro BC, Garehime WJ. The $\mathrm{CO}_{2}$ laser in oral and maxillofacial surgery. J Oral Maxillofac Surg. 1983; 41: 725-8.

Perdigao J, Ritter AV. Adesao aos tecidos dentários. En: Livaria santos, editora. Odontologia Restauradora-Fundamentos e posibilidades. Sao Paulo: Baratieri LN; 2001.

Perry MD, Stuart BC, Banks PS, Feit MD, Yanovsky V, Rubenchik AM. Ultrashort-pulsed laser machinig of dielectric materials. J Appl Phys. 1999; 85(9): $6803-10$

Peters M, Mclean I. Minimal intervention and concepts for minimally invasive cavity preparations. J Adhes Dent. 2001; 3: 7-16.

Pike P, Parigger C, Splinter R, Lockhart P. Temperature distribution in dental tissue after interaction with femtosecond laser pulses. Appl Opt. 2007; 46(34): 83748.

Pithon MM, Dos Santos RL, de Oliveira MV, Ruellas AC, Romano FL. Metallic brackets bonded with resin-reinforced glass ionomer cements under different enamel conditions. Angle Orthod. 2006; 76(4): 700-4.

Plasencia E. Algunos aspectos teórico-prácticos de la odontología adhesiva. Bol Inf III Región 26. 1977: 127-48.

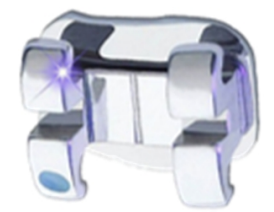


Portillo Muñoz M, Lorenzo Luengo MC, Sánchez Llorente JM, Peix Sánchez M, Albaladejo A, García A, Moreno Pedraz P. Morphological alterations in dentine after mechanical treatment and ultrashort pulse laser irradiation. Lasers Med Sci. 2012; 27(1): 53-8.

Portillo M, Lorenzo MC, Moreno P, García A, Montero J, Ceballos L, Fuentes MV, Albaladejo A. Influence of Er:YAG and Ti:sapphire laser irradiation on the microtensile bond strength of several adhesives to dentin. Lasers Med Sci. 2013. In press.

Potts TV, Petrou A. Argon laser initiated resin photopolymerization for the filling of root canals in human teeth. Laser Surg Med. 1991; 11: 257-62.

Powell GL, Ellis R, Blankenau RJ, Schouten JR. Evaluation of argon laser and conventional light-cured composites. J Clin laser Med Surg. 1995; 13: 315-7.

Powers J, Kim HB, Turner D. Orthodontic adhesives and bond strength testing. Semin Orthod. 1997; 3: 147-56.

Proffit WR. Contemporary orthodontics. Toronto: Elsevier Mosby; 1986.

Pronko PP, Dutta SK, Squier SJ, Rudd JV, Du D, Mourou G. Machining of submicron holes using a femtosecond laser at 800 nm. Opt Commun. 1995; 114: 10610.

Rasmussen ST. Analysis of dental shear bond strength tests, shear or tensile?. Int J Adhesion and Adhesives. 1996; 16: 147-54. 
Capítulo 6: Bibliografía

Ratkay-Traub I, Ferincz IE, Juhasz T, Kurtz RM, Krueger RR. First clinical results with the femtosecond neodynium-glass laser in refractive surgery. J Refract Surg. 2003; 19(2): 94-103.

Rego Filho F de A, Dutra-Corrêa M, Nicolodelli G, Bagnato VS, de Araujo MT. Influence of the hydration state on the ultrashort laser ablation of dental hard tissues. Lasers Med Sci. 2013; 28(1): 215-22.

Reynolds IR, von Fraunhofer JA. Direct bonding of orthodontic attachments to teeth: the relation of adhesive bond strength to gauge mesh size. Br J Orthod. 1976; 3: $91-5$.

Rizcalla N, Bader C, Bortolotto T, Krejci I. Improving the efficiency of an Er:YAG laser on enamel and dentin. Quintessence Int. 2012; 43(2): 153-60.

Rizoiu IM, Eversole LR, Kimmel AI. Effects of an erbium, chromium: yttrium, scandium, gallium, garnet laser on mucocutaneous soft tissues. Oral Surg med Oral Pathol Oral Radiol Endod. 1996; 82: 386-95.

Rizoiu I, Kohanghadosh F, Kimmel AI, Eversole LR. Pulpal thermal responses to an erbium, chromium:YSGG pulsed laser hydrokinetic system. Oral Surg Oral Med Oral Pathol Oral Radiol Endod. 1998; 86: 220-3.

Rode AV, Gamaly EG, Luther-Davies B. Subpicosecond laser ablation of dental enamel. J Appl Phys. 2002; 92(4): 2153-8.

Rode AV, Gamaly EG, Luther-Davies B, Taylor BT, Graessel M, Dawes JM, Chan A, Lowe RM, Hannaford P. Precision ablation of dental enamel using a subpicosecond pulsed laser. Aust Dent J. 2003; 48(4): 233-9.

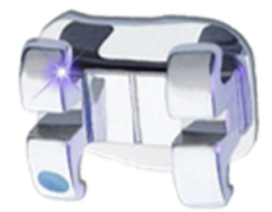


Rosenberg SP. The use of the erbium, chromium:YSGG laser in microdentistry. Dent Today. 2003; 22: 70-3.

Rubahn HG. Laser Applications in Surface Science and Technology. Chichester: John Wiley \&Sons; 1999.

Rupprecht S, Tangermann K, Kessler P, Neukam FW, Wiltfang J. Er:YAG laser osteotomy directed by sensor controlled systems. J Craniomaxillofac Surg. 2003; 31: $337-42$.

Sağır S, Usumez A, Ademci E, Usumez S. Effect of enamel laser irradiation at different pulse settings on shear bond strength of orthodontic brackets. Angle Orthod. 2013 (In press).

Sakae T, Sato Y, Numata Y, Suwa T, Hayakawa T, Suzuki K, Kuwada T, Hayakawa K, Hayakawa Y, Tanaka T, Sato I. Thermal ablation of FEL irradiation using gypsum as an indicator. Lasers Med Sci. 2007; 22(1): 15-20.

Sandford MA, Walsh LJ. Differential thermal effects of pulsed vs continuous $\mathrm{CO}_{2}$ laser radiation on human molar teeth. J Clin Laser Med Sur. 1994; 12: 139-42.

Sano H, Shono T, Sonoda H, et al. Relationship between surface area for adhesion and tensile bond strength - evaluation of a micro-tensile bond test. Dent Mater. 1994; 10: 236-40.

Saralegui A, González C. Histología dental. En: García J, editor. Patología y terapeútica dental. Madrid: Síntesis; 1997. p. 42-59.

Schawlow AL, Townes H. Infrared and optical masers. Phys. Rev. 1958; 112: 19409. 
Capítulo 6: Bibliografía

Schelle F, Polz S, Haloui H, Braun A, Dehn C, Frentzen M, Meister J. Ultrashort pulsed laser (USPL) application in dentistry: basic investigations of ablation rates and thresholds on oral hard tissue and restorative materials. Lasers Med Sci. 2013. In press.

Schnebel B, Mateer S, Maganzini AL, Freeman K. Clinical acceptability of two selfetch adhesive resins for the bonding of orthodontic brackets to enamel. J Orthod. 2012; 39: 256-61.

Schwarz F, Sculean A, Berakdar M, Georg T, Reich E, Becker J. Periodontal treatment with an Er:YAG laser or scaling and root planing. A 2 year follow up split mouth study. J Periodontol 2003; 74: 590-6.

Scougall Vilchis RJ, Yamamoto S, Kitai N, Yamamoto K. Shear bond strength of orthodontic brackets bonded with different self-etching adhesives. Am J Orthod Dentofacial Orthop. 2009; 136: 425-30.

Serbin J, Bauer T, Fallnich C, Kasenbacher A, Arnold WH. Femtosecond lasers as novel tool in dental surgery. Appl Surf Sci. 2002; 197-198: 737-40.

Sexton J, O’Hare D. Simplified treatment of vascular lesions using de Argon laser. J oral Maxillofac Surg. 1993; 51: 12-6.

Shey Z, Brandt S. Enamel loss due to acid treatment for bonding. J Clin Orthod. 1982; 16: 338-40

Shimada Y, Kikushima D, Tagami J. Microshear bond strength of resin-bonding systems to cervical enamel. Am J Dent 2002; 15: 373-7.

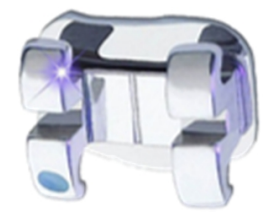


Shirk MD, Molian PA. A review of ultrashort pulsed laser ablation of materials. J Laser Appl. 1998; 10(1): 18-28.

Silverstone LM, Saxton CA, Dogon IL, Fejerskov O. Variation in the pattern of acid etching of human dental enamel examined by scanning electron microscopy. Caries Res. 1975; 9(5): 373-87.

Sognnaes RF, Stern RH. Laser effect on resistance of human dental enamel to demineralization in vitro. JS Calif Dent Assoc. 1965; 33: 328-9.

Srinivasan R, Sutcliffe E, Braren B. Ablation and etching of polymethylmethacrylate by very short (160 fs) ultraviolet (308 nm) laser pulses. Appl Phys Lett. 1987; 51: 1285.

Steen WM. Laser material processing. 2a Ed. London: Springer; 1998.

Stern D, Schoenlein RW, Puliafito CA, Dobi ET, Birngruber R, Fujimoto JG. Corneal ablation by nanosecond, picosecond, and femtosecond lasers at 532 and 625 nm. Arch Ophthalmol. 1989; 107(4): 587-92.

Stern RH, Vahl J, Sognnaes RF. Laser enamel: ultra-structural observations of pulsed carbon dioxide laser effects. J Dent Res. 1972; 51(2): 455-60.

Strassl M, Wiegwr V, Winter E. Novel approach for dental hard tissue ablation by ultrashort laser pulses. Trends Optics Photonics. 2005; 98: 819-25.

Stratmann U, Schaarschmidt K, Schurenberg M, Ehmer U. The effect of ArFexcimer laser irradiation of the human enamel surface on the bond strength of orthodontic appliances. Scanning Microsc. 1995; 9: 469-76. 
Capítulo 6: Bibliografía

Strickland D, Mourou, G. Compression of amplified chirped optical pulses. Opt Commun. 1985; 55: 447-9.

Stuart BC, Feit MD, Rubenchik AM, Shore BW, Perry MD. Laser-induced damage in dielectrics with nanosecond to subpicosecond pulses. Phys Rev Lett. 1995; 74(12): 2248-51.

Stuart BC, Feit MD, Herman S, Rubenchik AM, Shore BW, Perry M. Optical ablation by high-power short-pulse lasers. J Opt Soc Am B. 1996; 13(2): 459-68.

Suhm N, Gotz MH, Fischer JP, Loesel F, Schlegel W, Sturm V, Bille JF, Schroder R. Ablation of neural tissue by short-pulsed lasers-A technical report. Acta Neurochir (Wien). 1996; 138(3): 346-9.

Sun YC, Vorobyev A, Li H, Guo CL, Wang Y. Influence of intra-pulpal temperature when using femtosecond laser in specific parameters to prepare cavities in tooth enamel: an in vitro study. Beijing Da Xue Xue Bao. 2013; 18; 45(2): 286-90.

Takeda FH, Harashima T, Kimura Y, Matsumoto K. Effect of Er:YAG laser on the root canal walls of human teeth: an SEM study. Endod Dent Traumatol. 1998a; 14: $270-3$.

Takeda FH, Harashima T, Kimura Y, Matsumoto K. Efficacy of Er:YAG laser irradiation in removing debris and smear layer on root canal walls. J Endod. 1998b; 24(8): 548-51.

Talbot TQ, Blankenau RJ, Zobitz ME, Weaver AL, Lohse CM, Rebellato J. Effect of argon laser irradiation on shear bond strength of orthodontic brackets: an in vitro study. Am J Orthod Dentofacial Orthop. 2000; 118(3): 274-9.

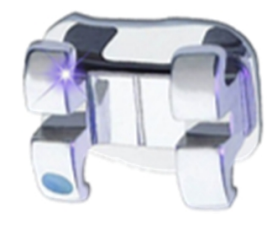


Tirlapur UK, Konig K. Targeted transfection by femtosecond laser light. Nature. 2002; 418: 290-1.

Toledano M, Osorio R, Leonardi de G, Rosales-Leal JI, Ceballos L, CabrerizoVilchez MA. Influence of self-etching primer on the resin adhesion to enamel and dentin. Am J Dent. 2001; 14: 205-10.

Toledano M, Osorio R, Sánchez F, Osorio E. Arte y Ciencia de los Materiales Dentales. Madrid: Ediciones Avances Médico-Dentales, S.L.; 2003.

Trelles MA, Verkruysse W, Segui JM, Udaeta A. Treatment of melanotic spots in the gingiva by argon láser. J Oral Maxillofac Surg. 1993; 51: 759-61.

Triolo PT Jr, Swift EJ Jr, Mudgil A, Levine A. Effects of etching time on enamel bond strengths. Am J Dent. 1993; 6(6): 302-4.

Tsai PS, Friedman B, Ifarraguerri AI, Thompson BD, Lev-Ram V, Schaffer CB, Xiong Q, Tsien RY, Squier JA, Kleinfeld D. All-optical histology using ultrashort laser pulses. Neuron. 2003; 39: 27-41.

Tsai PS, Friedman B, Squier JA, Kleinfeld D. Ultrashort pulsed laser light: A cool tool for ultraprecise cutting of tissue and cells. Opt Photonic News. 2004; 14: 24-29.

Türköz C, Ulusoy C. Evaluation of different enamel conditioning techniques for orthodontic bonding. Korean J Orthod. 2012; 42(1): 32-8.

Usumez A, Aykent F. Bond strengths of porcelain laminate veneers to tooth surfaces prepared with acid and Er, Cr:YSGG laser etching. J Prosthet Dent. 2003; 90: 2430. 
Capítulo 6: Bibliografía

Usumez S, Orhan M, Usumez A. Laser etching of enamel for direct bonding with an Er, Cr:YSGG hydrokinetic laser system. Am J Orthod Dentofacial Orthop. 2002; 122: 649-56.

Valletta R, Prisco D, De Santis R, Ambrosio L, Martina R. Evaluation of the debonding strength of orthodontic brackets using three different bonding systems. Eur J Orthod. 2007; 29: 571-7.

Van Meerbeek B, Inokoshi S, Braem M, Lambrechts P, Vanherle G. Morphological aspects of the resin-dentin interdiffusion zone with different dentin adhesive systems. J Dent Res. 1992; 71(8): 1530-40.

Van Meerbeek B, Braem M, Vanherle G. Morphological characterization of the interface between resin and sclerotic dentin. J Dent. 1994; 22(3): 141-6.

Van Meerbeek B, Perdigao J, vanherle G. Enamel and dentin adhesión. En: Fundamentals of operative dentistry. A contemporary approach. 2a Ed. Chicago: Quintessence Publishing; 2002.

Van Meerbeek B, DeMunck J,Mattar D, Van Landuyt K, Lambrechts P. Microtensile bond strengths of an etch \& rinse and self-etch adhesive to enamel and dentin as a function of surface treatment. Oper Dent. 2003; 28: 647-60.

Varel H, Ashkenasi D, Rosenfeld A, Wähmer M, Campbell EEB. Micromachining of quartz with ultrashort laser pulses. Appl Phys A. 1997; 65: 367-73.

Vázquez de Aldana JR, Méndez C, Roso L, Moreno P. Propagation of ablation channels with multiple femtosecond laser pulses in dielectrics: numerical simulations and experiments. J Phys D Appl Phys. 2005; 38: 2764-8.

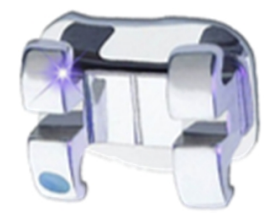


Vicente A, Bravo LA. Influence of an etchant and a desensitizer containing benzalkonium chloride on shear bond strength of brackets. J Adhes Dent. 2008; 10(3): 205-9.

Von Fraunhofer JA, Allen DJ, Orbell GM. Laser etching of enamel for direct bonding. Angle Orthod. 1993; 63: 73-6.

Walsh LJ, Perham SJ. Enamel fusion using a carbon dioxide laser: a technique for sealing pits and fissures. Clin Prev Dent. 1991; 13(3): 16-20.

Wang X, Ishizaki NT, Suzuki N, Kimura Y, Matsumoto K. Morphological changes of bovine mandibular bone irradiated by Er, Cr:YSGG laser: an in vitro study. J Clin Laser Med Surg. 2002; 20: 245-50.

Warembourg P, Rocca J, Bertrand Ma. Efficacy of an Er:YAG laser to remove endodontic pastes: An in vitro study. J Oral Laser Appl. 2001; 1: 43-7.

Watanabe W, Arakawa N, Matsunaga S, Higashi T, Fukui K, Isobe K, Itoh K. Femtosecond laser disruption of subcellular organelles in a living cell. Opt Express. 2004; 12: 4203-13.

Westerman GH, Hicks MJ, Flaitz CM, Blankenau RJ, Powell GL, Berg JH. Argon laser irradiation in root surface caries: in vitro study examines laser's effects. J Am Dent Assoc. 1994; 125: 401-7.

Wetter NU, Barroso MC, Pelino JE. Dental bleaching efficacy with diode laser and LED irradiation: an in vitro study. Lasers Surg Med. 2004; 35: 254-8. 
Capítulo 6: Bibliografía

White JM, Goodis HE, Marshall GW, Marshall SJ. Identification of the physical modification threshold of dentin induced by Neodymium and Holmium YAG lasers using scanning electron microscopy. Scanning Microsc. 1993; 7: 239-46.

Wieger V, Zoppel S, Wintner E. Ultrashort pulse laser osteotomy. Laser Phys. 2007; 17(4): 438-42.

Wilkerson MK, Hill SD, Arcoria CJ. Effects of the argon laser on primary tooth pulpotomies in swine. J Clin Laser Med Surg. 1996; 14: 137-42.

Willms L, Herschel A, Niemz MH, Pioch T. Preparation of dental hard tissue with picosecond laser pulses. Lasers Med Sci. 1996; 11(1): 45-51.

Wyman A, Duffy S, Sweetland HS, Sharp F, Rogers K. Preliminary evaluation of a new high power diode laser. Lasers Surg Med. 1992; 12: 528-36.

Xu HHK, Smith DT, Jahanmir S., et al. Indentation damageand mechanical properties of human enamel and dentine. J Dental Research. 1998; 77: 472-80.

Yaman BC, Guray BE, Dorter C, Gomeç Y, Yazıcıoglu O, Erdilek D. Effect of the erbium:yttrium-aluminum-garnet laser or diamond bur cavity preparation on the marginal microleakage of class $\mathrm{V}$ cavities restored with different adhesives and composite systems. Lasers Med Sci. 2012; 27(4): 785-94.

Yanik MF, Cinar H, Cinar HN, Chisholm AD, Jin Y, Ben-Yakar A. Functional regeneration after laser axotomy. Nature. 2004; 432: 822.

Yoshida Y, Nagakane K, Fukuda R, Nakayama Y, Okazaki M, Shintani H, Inoue S, Tagawa Y, Suzuki K, De Munck J, Van Meerbeek B. Comparative study on adhesive performance of functional monomers. J Dent Res. 2004; 83(6): 454-8.

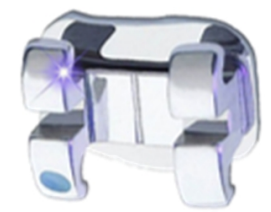


Zarrinnia K, Eid NM, Kehoe MJ. The effect of different debonding techniques on the enamel surface: an in vitro qualitative study. Am J Orthod Dentofacial Orthop. 1995; 108(3): 284-93.

Zelander T. El esmalte. En: Pindborg JJ, Mjör IA, editores. Histología del diente. Barcelona: Labor S.A.; 1974. p. 72-92.

Zhang N, Wang W, Zhu X, Liu J, Xu K, Huang P, Zhao J, Li R, Wang M. Investigation of ultrashort pulse laser ablation of solid targets by measuring the ablation-generated momentum usinga torsion pendulum. Opt Express. 2011; 19: $8870-8$. 

Anexos

\title{
7.1. REGLAMENTACIÓN TESIS EN
}

\section{BASE A ARTíCULOS}

\author{
VNIVERSiDAD \\ BSALAMANCA \\ CAMPUS DE EXCELENCIA INTERNACIONAL
}
PROCEDIMIENTO PARA LA PRESENTACIÓN DE LA TESIS DOCTORAL EN LA UNIVERSIDAD DE SALAMANCA EN EL FORMATO DE COMPENDIO DE ARTÍCULOS/PUBLICACIONES

(Comisión de Doctorado y Posgrado, 15 de febrero de 2013)

\section{1.- Justificación}

El capítulo II del Reglamento de Doctorado de la Universidad de Salamanca, sobre la elaboración y defensa de La Tesis Doctoral, en su artículo 14.1. establece que "los estudios de doctorado concluyen con la elaboración y defensa de una tesis doctoral, que consistirá en un trabajo original de investigación, elaborado por el doctorando, en cualquier campo del conocimiento, siguiendo el formato determinado por la Comisión Académica del Programa de Doctorado, entre los posibles formatos establecidos por la Comisión de Doctorado."

Asimismo, el artículo 14.3 determina que "La redacción de la tesis doctoral se hara en castellano o en una de las lenguas habituales para la comunicación cientifica en su campo de conocimiento. Si la tesis doctoral está redactada en un idiomo diferente al castellano, se acompañará de un documento, avalado por el Director de la misma, en el que consten el título, el indice, la introducción, un resumen significativo y las conclusiones de la tesis doctoral en castellano."

Las publicaciones científicas en revistas especializadas, del trabajo original e inédito realizado en una Tesis Doctoral, garantizan que el autor de la Tesis, personal investigador en formación de un programa de doctorado haya adquirido una de las competencias básicas definidas en el RD 99/2011, de 28 de enero, por el que se regulan las enseñanzas oficiales de doctorado, en concreto la capacidad de comunicación con la comunidad académica y científica y con la sociedad en general acerca de sus ámbitos de conocimiento en los modos e idiomas de uso habitual en su rama de conocimiento en la comunidad cientifica internacional.

De acuerdo con ello, la Comisión de Doctorado y Posgrado establece como posible formato de presentación de Tesis Doctoral, la modalidad de Tesis por Compendio de Artículos/Publicaciones, publicados 0 aceptados en revistas especializadas y de prestigio, siempre que sean resultado de la actividad investigadora desarrollada por el doctorando.

A tal efecto, con el objetivo de garantizar la calidad y validez de dichas tesis, se establece a continuación el procedimiento a seguir, que comienza con las recomendaciones y requisitos mínimos de la estructura de este formato de tesis.

2.- Tramitación, número y tipo de publicaciones, autoría:

2.1. Dentro del Plan de Investigación del doctorando, bien en su origen o bien en su revisión anual, podrá indicar su intención de realizar su tesis en el formato de compendio de articulos/publicaciones. El informe correspondiente que el tutor y director del doctorando realizan anualmente sobre dicho Plan, así como la evaluación del mismo que realiza la Comisión Académica del Programa de Doctorado, se pronunciará sobre la autorización de dicho formato.

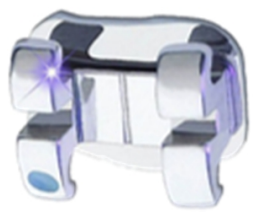


2.2.- En el momento de la solicitud de depósito de la Tesis por compendio de artículos/publicaciones los artículos/publicaciones aportadas por el doctorando deberán cumplir los supuestos siguientes:

a. Un mínimo de tres artículos o capítulos publicados o aceptados para su publicación, con posterioridad al inicio de los estudios de doctorado, en revistas científicas del ámbito de la especialidad del trabajo desarrollado en la tesis e indexadas en el Science Citation Reports (o equivalente según la CNEAI en los campos científicos en los que dicho criterio no sea aplicable) Excepcionalmente se podrá admitir un número inferior de publicaciones a las tres mencionadas cuando su relevancia y excelencia esté bien documentada.

b. El doctorando deberá ser primer autor de al menos dos de las aportaciones presentadas. En el caso de que no sea primer autor, el doctorando especificará cuál ha sido su aportación científica a la publicación lo que deberá estar certificado por el director de la tesis doctoral.

No se aceptarán como aportaciones válidas publicaciones de trabajos no relacionados con el proyecto de tesis doctoral, ni trabajos en forma de abstract, los recogidos en proceedings o en suplementos de revistas, los trabajos de revisión, las cartas, artículos de opinión, comentarios, introducciones, etc.

En el caso de que el doctorando no sea primer autor de al menos dos de las aportaciones presentadas o el número de aportaciones sea inferior a tres, se requiere un informe de valoración de la calidad de las aportaciones por parte de la Comisión Académica del Programa de Doctorado para aprobar la continuación de los trámites de la tesis doctoral.

3.- Documentación a aportar junto con la solicitud de depósito de Tesis Doctoral por Compendio de Artículos/Publicaciones:

Además de la documentación prevista en el artículo 17 del Reglamento de Doctorado de la Universidad de Salamanca en el caso de tesis doctoral por compendio de artículos, la solicitud de depósito deberá ir acompañada por los siguientes documentos

3.1.- Aceptación por escrito y con firma original de los coautores, a que el doctorando presente el trabajo y, declaración de que el doctorando es el autor principal de la investigación recogida en los artículos. No más de dos coautores que sean doctores, podrán formar parte de la propuesta de miembros para constituir el tribunal que juzgue la tesis.

3.2.- Renuncia expresa de los coautores no doctores a presentar los trabajos como parte de otra Tesis Doctoral

\section{4.- Formato y estilo de la Tesis por Compendio de Publicaciones:}

Las tesis que se presenten en la modalidad de Tesis Doctoral como compendio de publicaciones en la Universidad de Salamanca, deberán al menos incluir los siguientes apartados: 
Anexos

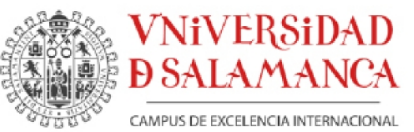

4.1.- Una página inicial especificando que la tesis corresponde a un compendio de trabajos previamente publicados 0 aceptados para publicación, el nombre y afiliación de los autores, la referencia completa de la revista o editorial, la carta de aceptación si no han sido publicados y el DOI si existiera de los artículos, libros o capítulos de libro que se incorporan a la tesis.

4.2.- A continuación se incluirá la autorización del director a codirectores para la presentación de la tesis en esta modalidad, el informe de la Comisión Académica del Programa de Doctorado y la autorización de la Comisión de Doctorado y Posgrado de la Universidad para su tramitación en dicha modalidad.

4.3.- Un apartado en castellano que refleje la coherencia y relación directa entre los articulos/publicaciones presentados. Dicho apartado incluirá al menos una introducción con los antecedentes del tema objeto de estudio, la hipótesis de trabajo y los objetivos así como las principales conclusiones. Cuando se considere oportuno podrá incluirse un anexo metodológico que complete descripción de la metodología indicada en los artículos

4.4.- Seguidamente, se incluirá una copia completa de las publicaciones originales que conformarán la Tesis Doctoral (artículos, capítulos de libro, libro o libros aceptados o publicados)

4.5.- En el supuesto de que los artículos que integran la tesis estén redactados en una lengua distinta al castellano, se incluirá para cada uno un resumen en castellano en el cual se especificarán: los objetivos de la investigación, la metodología utilizada, los resultados alcanzados, y las conclusiones finales.

4.6. - Si la Comisión Académica lo considera, la tesis contendrá un apéndice en el que se incluyan los principales índices de calidad de las publicaciones aportadas y cualquier otra documentación necesaria que permita acreditar los requisitos exigidos.

5.- Regulaciones particulares de los Programas de Doctorado:

La Comisión Académica de cada Programa de Doctorado podrá indicar requisitos adicionales para el formato de tesis por artículos/publicaciones presentadas en el programa en cuestión, estableciendo una regulación particular compatible con el presente procedimiento.

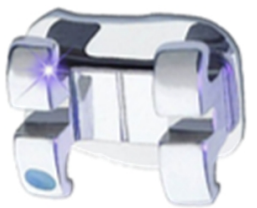



Índice Temático

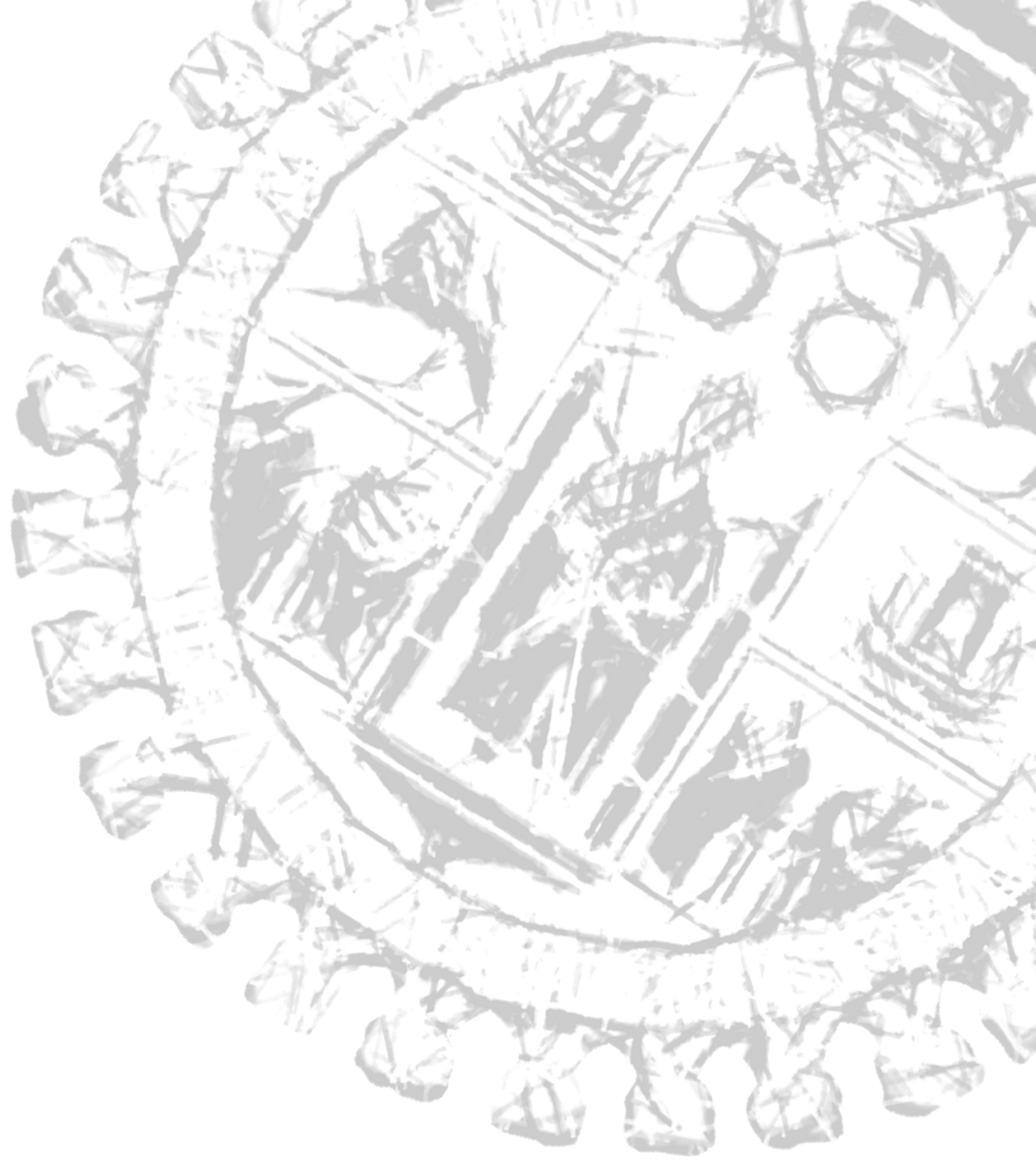

ÍNDÍCE TEMÁTİCO

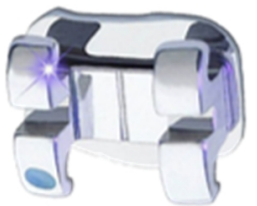



Índice Temático

\section{A}

Ablación, 16, 40, 63, 64, 65, 69, 70, 72, 77, 80, 83, 84,

$87,88,89,90,92,93,95,96,98,99,103,104,144$, $145,146,147,150,151$

Ablación ultrarrápida, 84, 90, 96

Ácido ortofosfórico, 16, 17, 19, 44, 51, 53, 55, 66, 69,

$71,103,104,116,117,144,145,149,150,151$,

157,181

Acondicionamiento, 16, 17, 19, 61, 65, 69, 70, 71, 103, $143,144,145,149,150,152,157,184$

Acondicionamiento ácido, 19, 103, 157

Adherente, 41, 42, 49

Adhesión, xv, 16, 17, 18, 19, 20, 41, 42, 43, 44, 45, 47, $48,49,50,52,53,54,55,68,69,70,71,93,94,97$, $103,104,117,128,143,144,145,146,148,149$,

$150,152,153,154,157,158,195$

Adhesión a esmalte, xv, 44, 50, 93, 97, 144, 148

Adhesivo, 41, 42, 44, 46, 47, 49, 53, 54, 69, 117, 128,

151,153

Aditamentos, xv, 143

alternativa, xv, 16, 17, 19, 39, 40, 70, 71, 97, 103, 108,

$143,144,148,150,154,157$

Amelogeninas, 35

Amplificación regenerativa, 72, 73

Análisis morfológico, v, 128

Aplicación del adhesivo, 49

ARI, 29, 128, 151, 153

\section{C}

Capa de hidratación, 35

Capilaridad, 42, 43, 46

Caries dental, 19, 108, 157

Cirugía, 66

Coeficiente de absorción, 62, 63, 64, 72, 147
Composición química, 33, 98

Conservadora, 103

CPA, 29, 72, 73, 184

Cracks, 16, 65, 97, 103, 143, 150

\section{D}

Densidad del patrón de microestructurado, 18

Dentina, 33, 34, 35, 37, 41, 44, 50, 58, 64, 66, 96, 97, $98,144,148,151$

Deshidratación, 17, 98

Desmineralización, 16, 51, 52, 53, 55, 103, 144

Desventajas, 16, 117

Dientes permanentes, 37

Dientes primarios, 37

Duración del/los pulso/s, 57, 61, 150

\section{E}

Efectos mecánicos, $x V$

Efectos térmicos, 16, 19, 40, 89, 97, 98, 103, 143, 157

Eficacia adhesiva, v, 16, 19, 54, 55, 103, 104, 143, 144, $148,149,157$

Electrón, 62, 84, 87

Emisión pulsada, 56, 61

Enamelinas, 35

Energía, 43, 50, 56, 58, 61, 62, 63, 64, 66, 67, 72, 73, $76,77,80,81,84,87,88,89,90,91,92,93,95,97$, 145

Esmalte, v, 16, 17, 18, 19, 20, 33, 34, 35, 36, 37, 38, 40, $41,42,43,44,46,50,51,52,53,54,55,57,58,61$, $64,65,66,68,69,70,71,85,92,93,94,96,97,98$ $99,103,104,107,108,116,117,127,128,143$ $144,145,147,148,149,150,151,152,153,154$ $157,181,184,198$

Esmalte aprismático, 35, 37 
Esmalte prismático, 35, 37, 38

Especímenes, 18, 148, 153

Estructura histológica, 33

$\mathbf{F}$

FDA, 29, 40

Fibra óptica, 61, 78

Filtros neutros, 77, 78

Fisuras, 16, 18, 38, 68, 70, 103, 143, 145, 147

Fresas, xv, 143

Fusión, 63, 65, 89, 108

G

Grabado total, 17, 45, 46, 47, 69

Grupo, 17, 116, 117, 127, 128, 152

\section{H}

Hidratados, 151

Hidroxiapatita, 35, 36, 42, 64, 144

Humectancia, 43

\section{I}

Inconvenientes, 16, 39, 52, 65, 103, 143, 144, 145, 154

Infrarrojo, 56, 61, 74, 107

Instrumental rotatoiro, 39, 69

Intensidad, 49, 62, 78, 84, 86, 88, 90, 95, 103, 148

lonómeros de vidrio, 48

Irradiación, 16, 69, 71, 104, 107, 116, 150

Irregularidades, 44, 50, 53

\section{$\mathbf{L}$}

Láser de Er:YAG., 61

Láser de pulsos ultracortos, 16, 20, 94, 95, 104, 144,

$147,149,150,151,154,157$

Láser de pulsos ultracortos., 72
Láser femtosegundo (características, interacción con la materia), v, 95, 98, 145

Líneas de barrido, 92, 93, 152

Longitud de onda, 56, 57, 58, 61, 62, 63, 64, 78, 80, 84, 95, 148

\section{M}

Material, 35, 41, 44, 48, 49, 62, 63, 64, 65, 77, 84, 85, $86,87,88,89,90,91,92,95,146,147,165,174$, 192

Matriz inorgánica, 34, 51

Matriz orgánica, 34, 47

Medio activo, 56, 61, 72

Microestructurado, 16, 19, 20, 94, 96, 104, 128, 152, 154,157

Microestructuras, 81, 92, 93, 95, 127

Microscopía electrónica, 108, 117, 128

Microscopía óptica, 16, 18, 104, 107, 108

Molares, 17, 107, 145

Muestras, 17, 18, 80, 94, 116, 127, 146, 149, 150, 151

Ojo de cerradura, 36

Oscilador de $\mathrm{Ti}$

Zafiro, 73, 74

Pieza de mano, 61

Polimerización, 48

Premolares, 17, 18, 116, 127, 151

Preparación cavitaria, xv, 17, 18, 39, 65, 69, 82, 94, 96, $97,98,103,143,144,145$

Procesado, 20, 57, 58, 65, 75, 78, 86, 94, 128, 145, $146,148,151,152,153,154,157$ 
Índice Temático

Pulsos, xv, 16, 20, 56, 58, 59, 61, 65, 72, 73, 74, 75, 77, $78,80,81,82,83,84,85,86,88,90,92,93,96,97$, $103,104,107,145,148,151,154$

\section{$\mathbf{R}$}

Radiación, 56, 61, 62, 65, 84, 89, 148

Resina, 42, 44, 49, 50, 52, 54, 68, 116, 127, 143, 144, $145,149,151,153$

Resina compuesta, 49

Resinas de composite, 49

Rubí, 58

\section{S}

Sistema adhesivo, 17, 18, 44

Sistema de focalización, 78

Step, 164

Subgrupo, 116

Suero salino fisiológico, 17

Superficie, $x v, 16,17,18,19,20,33,34,35,37,41,42$, $43,44,46,49,50,51,52,53,55,58,62,65,66,68$, $70,71,79,80,81,82,83,84,86,88,89,90,91,92$, $93,94,95,98,104,117,128,143,144,145,146$ $149,150,151,152,153,154,157$

\section{$\mathbf{T}$}

Tejidos adyacentes, 19, 103, 157

Tejidos duros dentales, 40, 63, 70, 98

Tensión superficial, 42, 43, 46

Test de microtensión, 148

Test de resistencia a la cizalla/al cizallamiento, 18, 152, 153

$\mathrm{Ti}$

zafiro, 56, 72, 116

Tipo de fallo, 18, 128, 153

Tratamiento Içaser, 17, 116, 117

Trepanado, 82, 83

Turbina, xv, 17, 19, 39, 69, 103, 108, 143, 157

\section{$\mathbf{U}$}

Umbral, 84, 88, 91, 98

V

Vaporización, 64, 89

Velocidad de barrido, 92, 93

Vestibular, 17, 18

Tags de resina, 46, 149, 152 
